\title{
EL COSTO SOCIAL DEL ACOSO LABORAL EN MUJERES.
}

Análisis del costo social originado por demandas judiciales promovidas por maltrato impetradas a empleadas administrativa en la provincia de Mendoza, según el modelo ecológico de Bronfrenbrenner.

Director: Dr. Juan B. Farrés Cavagnaro

PADT (tutora): Lic. María del Carmen Tamargo

Alumno: Lic. Mario Manuel Ernesto Lamagrande Coria

\section{1}


A todas las obreras A Cande y Sara, su amor guía mi vida A mis viejos obreros de manos quebradas A Juan el arquitecto de la tesis, mendocino ilustre y amigo A María del Carmen que me ayudo a construir el proyecto A Silvina y Carlos que a capa y espada defienden a los desprotegidos A la Escuela de Economía que me abrió un mundo de oportunidades $Y$ todos los que han creído 


\section{1. ÍNDICE DE CONTENIDOS}

A. PORTADA 1

B. AGRADECIMIENTOS $\mathbf{2}$

1.0.0.INDICE DE CONTENIDOS

2.0.0.PROLOGO $\mathbf{5}$

3.0.0.INTRODUCCIÓN $\quad 6$

4.0.0.CARACTERIZACIÓN DEL PROBLEMA $\mathbf{7}$

5.0.0.MARCO TEÓRICO 9

5.1.0. El por qué del acoso laboral en las mujeres que trabajan 9

5.2.0. El acoso laboral en las mujeres y la salud 10

5.3.0. El acoso según el modelo sistémico de Urie Bronfenbrenner 13

$\begin{array}{ll}\text { 5.3.1. Microsistema } & 17\end{array}$

5.3.2. Mesosistema 18

5.3.3. Exosistema 19

5.3.4. Macrosistema 22

5.4.0. ¿Cómo enferma la mujer psicológicamente por acoso laboral? 24

5.4.1. Cómo se enferma psíquicamente por el acoso la mujer 24

5.5.0. Conceptualización de la agresión en el ámbito laboral. 31 Formas.

5.5.1. Psicología del acosador

32

5.5.2. ¿Por qué el grupo omite el acoso? 33

5.5.2.1.Desesperanza y compañeros de empleo 34

6.0.0. PROPÓSITO Y OBJETIVOS ESPECÍFICOS $\quad 39$

7.0.0. PROCESOS METODOLOGICOS

9.3.0. En lo económico 45

9.3.1. El costo económico para las organizaciones que lo 45 implementan como una práctica de despido

9.4.0. En lo jurídico 46

9.5.0. En la salud $\quad 48$

9.6.0. En la política $\quad 48$

10.0.0.BIBLIOGRAFÍA $\quad \mathbf{4 9}$

11.0.0.ANEXOS $\mathbf{5 7}$

8.1. 0. Presentación de los casos 57

8.1.1. CASO 1

8.1.2. CASO 2

8.1.3. CASO 3

8.1.4. CASO $4 \quad 80$

8.1.5. CASO 5

8.1.6. CASO $6 \quad 106$

8.1.7. CASO $7 \quad 114$

8.1.8. CASO 8 
Reglamentaciones provinciales y proyectos de ley en la República 145 Argentina

11.1.1. LEGISLATURA DE LA CIUDAD AUTONOMA DE LA CIUDAD 145 DE BUENOS AIRES

11.1 11.1.2. PROYECTO DE LEY DE VIOLENCIA LABORAL DE LA PROVINCIA DE MENDOZA 


\section{PROLOGO}

El trabajo de Mario Lamagrande reúne tres requisitos esenciales de cualquier tesis. En primer lugar es original, esto significa que aunque no lo sea la problemática planteada teniendo en cuenta que, la agresión laboral se ha constituido en una práctica corriente en este ámbito de la actividad económica del cual se ocupa la legislación, el abordaje y la investigación que realiza el autor, empleando un enfoque sistémico, pone al descubierto situaciones de suma gravedad que afectan a la condición humana de las afectadas en materia de salud y de allí deduce múltiples consecuencias sociales. De la utilización del enfoque sistémico, surge con claridad que el tratamiento de un tema de esta naturaleza no debe ser tratado unidimensionalmente, sino integralmente, de lo cual se plantean aspectos que deben ser tenidos en cuenta confiriéndoles mayor importancia. En segundo término, es necesaria, en el sentido que el problema planteado requiere que sea investigado con mayor profundidad y amplitud que, como puede deducirse de esta investigación, requiere una revisión del marco axiológico y jurídico que regula situaciones de esta naturaleza. Por último, es transferible, dado que puede constituirse en un significativo aporte para reformular el tratamiento de estos casos y ser una fuente doctrinaria del derecho y de decisiones políticas que al respecto deben adoptarse.

Espero que el autor prosiga ahondando una problemática como la expuesta, cuyas consecuencias sociales en materia del deterioro de la salud de la mujer empleada y el costo social ello implica, aun no se perciben en su verdadera magnitud. 


\section{INTRODUCCIÓN}

El tratamiento del tema referido al acoso laboral de la mujer en las organizaciones económicas parte de considerar demandas judiciales laborales, en la provincia de Mendoza atendiendo a que se ha convertido en una práctica frecuente sobre la cual la legislación aun no ha precisado en forma satisfactoria su accionar.

El caso en examen se articula con una intencionalidad definida consistente en una forma tendiente a lograr por parte del empleador la desvinculación sin causa del trabajador, específicamente en la mujer, a fin de evitar la indemnización consecuente si optara por un despido con justa causa.

Esto ha dado lugar a definir esta situación como mobbing ${ }^{1}$ o "Acoso moral en el empleo", que consiste en un proceso de desgaste ejercido por personas que tienen a su cargo la dirección de la organización y que actúan en forma directa o indirecta sobre un empleado.

La determinación de un problema como el señalado, implica considerar los aspectos siguientes:

a) El costo tangible para las organizaciones (económico) derivado del costo judicial (ver fallos);

b) El costo tangible para el empleado (económico) por pérdida del empleo, servicios jurídicos y servicios médicos;

c) El costo intangible para la organización por deterioro del clima organizacional;

\footnotetext{
1 Las definiciones más usuales se refieren a modo de ampliación a que es "... un proceso de destrucción sistemático y continuado" (Abajo Olivares, 2004); "Una situación de violencia recurrente y sostenida en el tiempo. Su establecimiento es posible mediante la utilización de la violencia (generalmente sin marcas) y el ejercicio de poder en forma abusiva; donde en la cadena -víctima vs. (victimario/ entorno/ organización) - es siempre la víctima quien está en inferioridad de condiciones, al menos respecto a la organización". (Martin, 2006); "El mobbing o terror psicológico en el ámbito laboral consiste en comunicación hostil y sin ética, dirigida de manera sistemática por uno o varios individuos contra otro, que es así arrastrado a una posición de indefensión y desvalimiento, y activamente mantenido en ella. Estas actividades tienen lugar de manera frecuente (como criterio estadístico, por lo menos una vez a la semana) y durante largo tiempo (criterio estadístico: por lo menos seis meses). A causa de la elevada frecuencia y la duración de la conducta hostil, este maltrato acaba por resultar en considerable miseria mental, psicosomática y social." (González de Rivera Revuelta \& Rodriguez Abuín, 2005)
} 
d) El costo intangible para la empleada producida por daño psíquico no cuantificable; y

e) El costo social intangible (familiar y relacional)

\section{CARACTERIZACIÓN DEL PROBLEMA}

En el tema en análisis, deben tenerse en cuenta las perspectivas que se exponen a continuación.

En primer término, el acoso conceptualizado como la acción de acosar ${ }^{2}$ es una forma de agresión que deviene, dada la magnitud alcanzada en la sociedad moderna, en un tipo o variedad de conflicto social, entendido como la oposición de intereses y contrario al de cooperación o integración social. Ambos procesos deben ser considerados, según el contexto en que la problemática se instale, como funcional o disfuncional. En este caso, implica disfunciones sociales diversas.

En segundo término, este tipo de fenómeno, no tiene un impacto sólo económico, ni psicológico, ni jurídico aun afectando en principio a organizaciones económicas y a las personas que las componen, sino social. Por lo tanto una errónea forma de tratamiento de este problema radica en circunscribirlo a un campo disciplinar determinado, de allí que se proponga la aplicación del enfoque sistémico.

En un sentido un tanto similar, (Torrico Linares, Santín Vilariño, Andrés Villas, Menéndez Álvarez-Dardet, \& López López, 2002) sostienen, "/os economistas tienden a ocuparse del modo en que las organizaciones distribuyen recursos y toman decisiones en situaciones de incertidumbre. Los ingenieros industriales se interesan por las condiciones tecnológicas. Los sociólogos se han dirigido al estudio de la estructura de la organización y a su relación con el ambiente exterior. Mientras que los psicólogos se han centrado en el estudio del comportamiento de los individuos y grupos. Asimismo, dada la complejidad y variedad de este fenómeno es virtualmente imposible dar una definición exhaustiva del mismo. Incluso algunos autores han sugerido que el concepto de

2 "Perseguir, sin darle tregua ni reposo, a un animal o a una persona - Perseguir, apremiar, importunar a alguien con molestias o requerimientos" (Real Academia Española, 2001) 
organización está cambiando, ya que las formas de concebirlas deben adecuarse a cada época". En realidad lo que plantean estos autores es una crítica al en el quehacer científico cuando el análisis se realiza desde una perspectiva unidisciplinar o multidisciplinar como puntos de vista diferente sobre un mismo fenómeno.

Consecuentemente la revisión del problema desde varias perspectivas profesionales, la violencia en la organización resulta disímil para cada género y es una emergencia que es validada desde un macrosistema ${ }^{3}$ (Palací Descals, y otros, 2005).

$\mathrm{Si}$ bien en principio, la interrelación se presenta inicialmente, en una dimensión unidimensional, el conflicto laboral desde la perspectiva económica y psicológica, incide y de allí su naturaleza social, en múltiples consecuencias, planteando un problema de decisión política en el sentido que importa revertir la legislación haciéndola acorde a los problemas propios de este tipo de conflicto.

En tercer término, su tratamiento, importa efectuar consideraciones de carácter epistemológico y metodológico, además del efectuado que implicaría una de carácter ontológico, teniendo en cuenta que según se ha señalado, implica considerar este fenómeno social, en el marco del conflicto.

El tratamiento epistemológico y especialmente metodológico, conduce sin lugar a dudas, a efectuar una consideración sistémica, como se expondrá en el curso de este trabajo, dando lugar a un enfoque que deriva de su articulación con disciplinas diversas. En otros términos, a una convergencia y emergencia interdisciplinaria (Bunge). Por ello, "no hay emergencia en sí misma o separada de las cosas que emergen: sea lo que fuere lo que emerge, su surgimiento tiene lugar en un objeto (complejo) [...] y no hay emergencia ex nihilo: todo emerge a partir de algo, como las interacciones o bien entre componentes de un sistema o bien entre algunos de ellos y elementos del

3 "se refiere a los marcos culturales o ideológicos que afectan o pueden afectar transversalmente a los sistemas de menor orden (micro-, meso y exo-) y que les confiere a estos una cierta uniformidad, en forma y contenido, y a la vez una cierta diferencia con respecto a otros entornos influidos por otros marcos culturales o ideológicos diferentes." (Sánchez, 2001) 
entorno" (Bunge, Emergencia y convergencia. Novedad cualitativa y unidad de conocimiento, 2004)

Se explica así que la complejidad del acoso, es más que la suma de las partes lo cual no puede implicar que su tratamiento se efectúe desde una perspectiva holísitica que dejaría de lado aspectos particulares que merecen una consideración adecuada Sintetizar el maltrato como la acción de un sujeto o sujetos que sobre una víctima, es un recorte técnico. El psicoterror (Ovejero, 2006) ejercido en el ámbito laboral es el emergente que nace de la interacción de diferentes sistemas (laboral, comunicacional, económico, legal y social) y la forma de pesquisarla es a partir del acoso.

\section{MARCO TEÓRICO}

\subsection{El por qué del acoso laboral en las mujeres que trabajan}

Una de las poblaciones más acosadas y maltratadas por estas prácticas son las mujeres (Hirigoyen, 2001), de ahí la preocupación y el enfoque adoptado. La situación de deterioro por estrés laboral "burnout" puede conducir a la muerte a la mujer que lo padece (Gil-Monte, 1997). La explicación de este asunto es que su ingreso en el sistema laboral implicó una sobrecarga del rol que ejercía en la sociedad tradicional, porque además de trabajar también ha tenido que seguir haciéndose cargo de los hijos y las tareas domésticas (Lamagrande, 2000).

A ello se agrega que, en Latinoamérica, hay mayor cantidad de mujeres que de hombres en situación de pobreza (Valenzuela, 2003) y que la diferencia de género condiciona situaciones de violencia (Francisca, 2011), evidentemente por la subordinación de las mujeres ante los varones

En toda la República Argentina, La asociación civil "La Casa del Encuentro", un espacio feminista y social, realizó una investigación sobre asesinatos de mujeres en el año 2008, registrando 207 casos. El informe abarca las muertes producidas desde el $1^{\circ}$ de enero al 31 de diciembre de 2008. La información se obtuvo a través de una recopilación realizada en diarios nacionales y agencias de noticias DYN y Telam (Zula, 2009) agregando que asimismo la violencia contra la mujer constituye una violación de los derechos 
humanos y las libertades fundamentales e impide total o parcialmente a la mujer gozar de dichos derechos y libertades, y preocupada por el descuido de larga data de la protección y fomento de esos derechos y libertades en casos de violencia contra la mujer (Naciones Unidas. Asamblea General, 1993)

El problema vulnera la posibilidad del logro de los objetivos previstos en el paradigma del Desarrollo Humano Sustentable dentro del cual no puede dejarse de lado la defensa de los derechos de la mujer; por lo cual se siguen incorporando en este paradigma problemáticas como las consideradas en este trabajo.

\subsection{El acoso laboral en las mujeres y la salud}

La vinculación de este tema referido a la agresión impacta sin duda en un problema de salud como un emergente social, que no ha sido hasta el momento receptado debidamente por el Estado a través de una legislación adecuada que es propia de su función.

En el análisis del problema constituido por la agresión de la mujer en el ámbito laboral se impone necesariamente, que previo al juzgamiento del proceso, en la primera instancia de la recepción de la queja en la consulta debe producirse la validación de las percepciones de la víctima. Ello considerando a que este acto reúne las características de un proceso salutógeno, por eso, en atención primaria, el diagnóstico a tiempo de patologías de corte psicosocial evita múltiples efectos, de allí la importancia de la prevención jurídica que surge como un reclamo en este ámbito. La noción de salud paulatinamente está mudando de su versión negativa de patologías que centra su percepción en el "enfermar" que es algo temido y evitado, a considerarla como un bien valioso que por todos los medios debe ser conservado.

Por ello se infiere que las enfermedades derivadas a causa del acoso es un proceso psicosocial donde se cruzan individuos e instituciones y además aspectos jurídicos, económicos y relacionales lo cual representa una emergencia, un emergente difícil de probar legalmente, y sus consecuencias económicas y sociales parecen difíciles de reconocer. No obstante, debe tenerse en cuenta que, en la Constitución de la Organización Mundial de la Salud se expresa, "Los Estados parte en esta Constitución declaran, en conformidad con 
la Carta de las Naciones Unidas, que los siguientes principios son básicos para la felicidad, las relaciones armoniosas y la seguridad de todos los pueblos. Concluyendo, "la salud es un estado de completo bienestar físico, mental y social, y no solamente la ausencia de afecciones o enfermedades". Este ideal de la generación de posguerra es una visión de ventura que va más allá de la nulidad de los síntomas (visibles) y se agrega, "La salud de todos los pueblos es una condición fundamental para lograr la paz y la seguridad, y depende de la más amplia cooperación de las personas y de los Estados" (Organización Mundial de la Salud-OMS, 1947)

Esta apreciación holística, "de todos", incluye la dimensión material: la gente, el territorio y el intangible Estado donde los resultados alcanzados por cada Estado en el fomento y protección de la salud son valiosos para todos (Organización Mundial de la Salud-OMS, 1947). Es oportuno aquí señalar que esto no puede desglosarse a partir de una apreciación cartesiana de mentecuerpo.

Es fácil descubrir las filosofías mezquinas en aquellos que consideran la formulación de la OMS como un loable objetivo, que se formula con altas probabilidades de ser excusado por la tríada interna que configura su esencia. La complejidad que guarda este asunto se entrama con una pregunta ontológica que conduce a si la Salud, ¿es sólo lo que vemos y palpamos?

Promover estados de salud tiene que ir de la mano de la promoción del bienestar, que emana de la visión de entes que trascienden los países como estructura real para adentrarse en sus valores universales.

El bienestar se gesta en cada ámbito, y sus beneficios convergen en la sociedad.

Reconocido así que el acoso laboral importa un problema de salud en el marco conceptual expuesto respecto a que, en general, el acoso o psicoterror ${ }^{4}$, se traduce en acciones que se dan sistemáticamente en el tiempo y tienen como objetivo que la empleada se desgaste psíquica y corporalmente para verse obligada a renunciar. Este tipo de comportamiento al igual que la finalidad que lo inspira conduce a que incluso pueda ser considerado como una

4 Clasificación usada por los teóricos españoles entre ellos el citado Iñaki-Piñuel 
psicopatía. Se identifica así con la violencia que se ejerce en el ámbito laboral que implica invariablemente un deterioro integral de la persona. Esto es un remedo de la sociedad capitalista fundada en los valores propios del liberalismo individualista, propio del siglo XIX y principios del XX, que en una concepción atomista imponía el principio del homus economicus. Recuérdese la denominada ley de hierro de los salarios de David Ricardo.

Si bien esta concepción de la economía se fue revirtiendo paulatinamente, aun subsiste en algunas formas del quehacer social, entre ellas la expuesta en este trabajo.

Específicamente, la ley de ART en Argentina omite patologías de corte psicosocial (ley 24.557, actualizada por decreto 1,278/2000). Al no ser reconocidas estas patologías, la "actora" depende del grado de amplitud e idoneidad de la cámara laboral y la de la penal, si también considera que estuvo en riesgo la vida, sobre todo en casos de acoso sexual.

Las organizaciones estatales o privadas, se constituyen ámbitos donde se ejerce el acoso laboral y aunque son conceptualmente distintos, la esencia del acoso es la misma, como asimismo, sus efectos con relación a la víctima y no obstante, la diferencia entre las causas determinantes.

La necesidad de modificar un obrar social tan negativo como el del acoso laboral, se constituye en una misión educativa que debe ser entendido en sentido amplio, propio de las instituciones propios de este quehacer como creadoras y divulgadoras de una concepción destinada a estudiar y formar acerca de la agresión como una problemática social. Esto se constituye en una dimensión importante, ya que el sistema educativo reproduce estereotipos de género y de subordinación. Este sistema reproduce estereotipos de género y de subordinación. Igualmente, en lo que concierne a las personas, objeto esencial del tema en análisis, ello importa el reconocimiento de una concepción humana en constante evolución, enmarcada en una valoración que ha dado lugar a un interminable proceso en el cual aun existen áreas no exploradas o admitidas. 
Es precisamente el acoso o agresión en el ámbito laboral, una de las áreas que aun no resultan conocidas y reconocidas oficialmente, aunque la legislación está avanzando en este terreno, aun resulta insuficiente.

Evidentemente un tema de esta naturaleza también se enmarca en el largo proceso de las reivindicaciones obreras de origen incierto.

No es novedad que el acoso en el ámbito laboral es una práctica frecuente denunciada por la Organización Internacional del Trabajo (OIT) que, en numerosos artículos intenta generar una verdadera conciencia acerca de sus consecuencias. Por tanto, es útil la referencia de que resulta imprescindible la colaboración o permisividad del resto del personal de la organización. La persecución psicológica se desarrolla en medio de un sorprendente silencio e inhibición de los observadores, que antes de nada procuran 'ser de los nuestros'. El factor catalítico clave en el inicio y desarrollo del acoso es el resto de la organización [Buendía, 2003; citado por (Ovejero, 2006), pág. 110]

La dificultad de apreciar el maltrato radica en que se está dentro de ese sistema y resulta difícil tener una perspectiva sobre prácticas que llegan a considerarse normales de igual modo que se daba en el marco filosófico racionalista imperante desde el siglo XVIII6 que aun influye en ésta. En sentido similar el concepto de salud partía de una disociación entre cuerpo y mente, observable en los baremos jurídicos que tienden a atomizar al hombre en partes, en el cual cada idóneo pone un porcentaje.

\subsection{El acoso según el modelo sistémico de Urie Bronfenbrenner}

Como se ha sostenido precedentemente, el acoso, en este caso el laboral en mujeres, debe ser considerado siguiendo el enfoque sistémico, dejando de lado los enfoques atomista y holístico. El atomismo, es reduccionista al sostener que la sumatoria de las partes no agrega nada al todo a la inversa en el holístico, el todo no es reductible a las partes. En otros términos, el todo implica características que no existen en las partes.

Finalmente, el sistémico que parte de considerar que todo es un sistema de sistemas y termina neutralizando los otros dos.

6 (Wikipedia, 2010) 
Consecuentemente, la idea del enfoque sistémico parte de la idea de sistema, como un conjunto de partes que se articulan entre si y se orientan al alcance de uno o varios objetivos. (Farrés Cavagnaro, 1981)

De este modo la idea de sistema, según Bunge, consta de cuatro elementos de análisis. El primero, se refiere a la configuración del sistema, esto es la determinación del objeto de estudio, en este caso el acoso laboral en mujeres; el segundo, la estructura, o sea la descripción de los elementos que configuran este fenómeno en sí; el tercero, la función o dinámica, en otros términos la forma en que se desenvuelve $y$, el cuarto, el entorno, ambiente o extrasistema que actúa como un marco condicionante.

La idea de sistema se instala en la de enfoque considerado como la orientación más amplia que se confiere al análisis de un problema y por tanto, la teoría de los sistemas, "se orienta al estudio de la realidad siguiendo como principio el de su captación como una totalidad única [...] que entraña la idea de sistematicidad del conocimiento, como la más amplia composición recurrente de lo que se sabe o se supone acerca de un conjunto de fenómenos" (Farrés Cavagnaro, 1981).

Así expuesto el problema en examen, deviene una consideración metodológica consistente en lo que Bunge ha denominado "convergencia y emergencia" referida a la coincidencia de distintas disciplinas para el abordaje de determinado tipo de fenómenos.

El territorio surgido entre la economía, la psicología y la justicia se convierte en una zona gris que se caracteriza por un modo particular de observar y tratar los datos obtenidos, es decir, se trata de un enfoque sobre el problema del maltrato a la mujer en relación a su empleo.

Siguiendo este razonamiento se concluye que, la violencia no puede descontextualizarse, porque las cosas se comprenden en relación. Si una mujer pierde su empleo, puede no significar mucho para una labor estadística, pero los efectos sobre su persona son significativos ya que se deprimió por el maltrato verbal y físico de su jefe y esto la condujo al despido; su familia perdió la cobertura social a pesar de que aumentaron sus gastos médicos, solicitó ayuda a un abogado para gestionar su demanda laboral, etc. Pero, para 
el contexto significó la recarga en un juzgado y el aumento de demanda de atención de su salud afectada y de allí otras derivaciones. En esta apreciación queda en claro la naturaleza del mundo y del conocimiento, que requiere la adopción del enfoque sistémico.

Por eso, enfermar resulta una convergencia de síntomas que dan como resultado ese padecer, pero también es la emergencia de diferentes sistemas (personal, familiar, social, laboral, etc.). Para entender el costo del enfermar es necesario integrar ese todo en partes coherentes que resultan más que la suma de sus partes, además una interrelación de efectos subsecuentes.

La solución al problema del acoso también llega en relación al enfoque con el que elegimos observar las cosas. Al propiciar un abordaje armónico de la psicología en relación con el sistema sanitario, la economía tangible e intangible y la justicia como un modulador, el modelo ecológico de Bronfenbrenner (ver gráfico 1) sirve para ligar supuestos específicos, graficar y representar la interacción de los diferentes componentes en el caso particular del acoso.

Tiene la particularidad de facilitar la convergencia ${ }^{7}$ de lo psíquico, los componentes axiológicos y las normas respecto de las distorsiones que se generan en el ambiente cuando existen situaciones de acoso. Este modelo fue utilizado inicialmente para entender el desarrollo infantil a tal punto que la teoría de los sistemas ecológicos de Bronfenbrenner, proporciona un análisis detallado de las influencias ambientales. Además, por aceptar que las características biológicas que influyen sobre una persona interactúan con las fuerzas ambientales (Shaffer, Psicología del desarrollo. Infancia y adolescencia. Quinta edición, 2000). Es utilizado como modelo de abordaje para otros temas de salud, tales como la intervención para pacientes oncológicos (Torrico Linares, Santín Vilariño, Andrés Villas, Menéndez Álvarez-Dardet, \& López López, 2002), para intervenciones respecto a niños con discapacidad (García

\footnotetext{
7 "Cuando dos disciplinas convergen, emerge una interdisciplina enteramente nueva. Y cuando emerge un nuevo punto de vista general (enfoque), es probable que converjan algunos campos de investigación previamente desconectados. Por consiguiente, la difundida creencia acerca de que el concepto de emergencia excluye el de convergencia y debe ser desechado porque obstaculiza la unidad del conocimiento es errónea" (Bunge, Emergencia y convergencia. Novedad cualitativa y unidad de conocimiento, 2004).
} 
Sánchez, 2001) y abordaje de conflictos de valores en personas mayores (Cortés, 2001), entre otros.

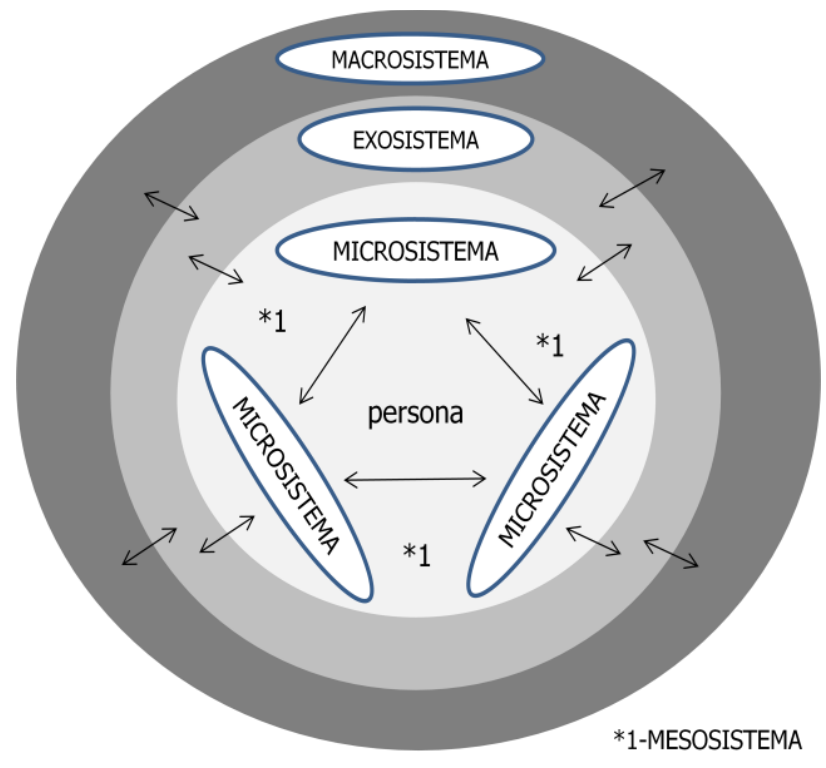

Gráfico 1: El modelo ecológico de Bronfenbrenner (Torrico Linares, Santín Vilariño, Andrés Villas, Menéndez Álvarez-Dardet, \& López López, 2002).

La importancia del ambiente en la noción de salud se debe a que aquel ambiente representa la fuente de estímulo para la persona desde múltiples dimensiones (afectiva, conductual, del pensamiento). Como lo planteara Gendlin ${ }^{8}$, "el cuerpo y el entorno juntos constituyen un proceso interaccional". El cuerpo está "hecho de materiales del entorno" (Alemany, 1997). En esta interacción se debe agregar los estímulos que condicionan los pensamientos y las tramas neurales. En otros términos la interacción, internalización y socialización que conduce a la formación de la personalidad.

La referencia de los sistemas está al servicio de mostrar el nexo causal entre la relación del acosador con la víctima y cómo esta última se soporta en el ambiente. Según el postulado de Bronfenbrenner, "los ambientes naturales son la principal fuente de influencia sobre la conducta humana, con lo cual la observación en ambientes de laboratorio o situaciones clínicas nos ofrecen poco de la realidad humana" (Torrico Linares, Santín Vilariño, Andrés Villas, Menéndez Álvarez-Dardet, \& López López, 2002)

8 Eugene T. Gendlin, filósofo americano y psicoterapeuta que desarrolló un procedimiento para pensar y trabajar con lo implícito. 
En general, los teóricos jurídicos y psicológicos del mobbing coinciden en que los acosadores, germinan en ambientes o escenarios propicios para estas situaciones caracterizados por falta de organización [(Abajo Olivares, 2004); (Martin, 2006); (Chavez, 2009), de apoyo social (Gil-Monte, 1997), culturas organizacionales de corte machista (Toselli, Grassis, \& Ferrer, 2007) u organizaciones pequeñas (Ovejero, 2006)]

La pérdida de bienestar se traduce en la productividad de la persona y su contexto. Al enfermar, la afectación directa se da en tardanzas y ausentismo, además del costo en tratamiento clínico, psiquiátrico y/o psicológico para sí misma y su contexto familiar (nuclear y extenso).

Al tratarse el acoso como un proceso psicosocial, la relación entre los diferentes sistemas y sus componentes varía de acuerdo al grado de malestar de la persona.

\subsubsection{Microsistema}

En este modelo el microsistema se define como un patrón de actividades, roles y relaciones interpersonales que la persona en desarrollo experimenta en un entorno determinado, con características físicas y materiales particulares. Las mujeres en este nivel se emplean para dar soporte material a su cotidianeidad, que es su familia (nuclear y extensa), en actividades sociales. La empleada recibe ingresos (flujo nominal: dinero) por ofrecer la utilización de su "factor productivo trabajo" que les permite formar parte de la población económicamente activa y de diferentes sistemas en que participa dando lugar a un proceso transaccional donde el sujeto cumple con lo solicitado y por lo cual es remunerado.

En el libro póstumo de Michel Focault El poder psiquiátrico, el filósofo explica, que el cuerpo de las personas puede entenderse en más de una dimensión. Esta clasificación sirve para comprender el porqué de la complejidad de la inserción de la mujer en el mercado laboral. Se refiere al del cuerpo jurídico de las personas sometido a la trama escrita, es decir, la que es propia de las normas que rigen una disciplina particular y ajustada a cada época. En la

9 Es la capacidad física e intelectual con la que cuenta el ser humano para transformar elementos de la naturaleza en bienes aprovechables para satisfacer sus necesidades (De Santis, 2001). 
psicología dinámica se considera que el varón está en relación a la disciplina militar, que es capaz de dar la vida por una causa, y la mujer da vida. Esta particular metáfora entrama una idea que se va gestando en los pasajes anteriores: el sistema disciplinar que mana de las leyes ha caducado. Implícitamente, las organizaciones en sus relaciones mantienen, a pesar de los intentos de aplanar los organigramas, estilos que guardan analogía con la disciplina militar, por eso muchas personas "dejan la vida en su empleo". En el maltrato a la mujer se observa claramente un cambio de enfoque en el sentido que el empleo está al servicio de la vida.

\subsubsection{Mesosistema}

El concepto de mesosistema comprende "las interrelaciones de dos o más entornos en los que la persona en desarrollo participa activamente" (Bronfenbrenner, 2002). En este nivel se da el intercambio económico de la empleada con el exterior; puede ahorrar su dinero a través del sistema bancario y financiero o bien comprar en el mercado de bienes y servicios, por eso es considerado un "sistema de microsistemas" (Torrico Linares, Santín Vilariño, Andrés Villas, Menéndez Álvarez-Dardet, \& López López, 2002).

Una mujer con empleo mantiene reciprocidad con su entorno y sus intercambios se dan sin problemas, como puede ser trabajar para brindar una educación privada a sus hijos u obtener mayor confort contando poder económico para sostener sus decisiones.

Sobre el tema en análisis podrían reconocerse criterios disimiles. Uno de ellos está referido a sostener que las interacciones femeninas salen del imaginario social en el que la mujer cuando toma decisiones, resoluciones y confrontaciones, estableciendo así nuevas pautas disciplinares que no se corresponden con las ideas masculinas entramadas en la subordinación y la obediencia. $Y$ otro sustentado en el enfoque de género que sostiene que la mujer se inserta en el mundo socio-productivo pero esto no redefine, ni transforma las relaciones de subordinación a las que está sometida. La discriminación se mantiene en su perjuicio en cuanto a igual posición, menor salario o que aun sigue siendo la responsable del cuidado y reproducción de la familia. 
Tal como se explicó anteriormente, el cambio introducido por la mujer está germinando y esto genera grupos de resistencia, de ahí que muchas mujeres con poder de decisión se masculinizan lo que implica retornar a un paradigma basado en una supremacía de género, perdiendo de esta forma la oportunidad de acceder a ese espacio. En este punto es necesario hacer referencia al rol de género, que es lo que se espera desde lo social del macho y la hembra, como en el caso del recién nacido varón, al cual se viste de celeste, mientras que las mujeres usan aros. Estas características impostadas por la cultura se ven diluidas en el entorno laboral, en el uniforme, por ejemplo, que borra las diferencias.

Entre estos microsistemas encontramos el lugar donde la mujer establece vínculos con otras organizaciones, como las propias del sistema educativo, religioso, recreativo o cultural, donde, al ganar espacios de decisión, influye y condiciona de modo directo.

Este análisis del progreso en el rol de la mujer no puede ser coartado por formas estereotipadas de discriminación como aquellas a las que se hace referencia en este trabajo.

\subsubsection{Exosistema}

En el tratamiento del mobbing jurídico casi no se aborda esta temática y problemática. Su valor reside en que es el lugar donde muchas veces se toman las decisiones que condicionan su vida. Tal es el caso de un ajuste, y "se refiere a uno o más entornos que no incluyen a la persona en desarrollo como participante activo pero en los cuales se producen hechos que afectan a lo que ocurre en el entorno que comprende a la persona en desarrollo, o que se ven afectadas por lo que ocurre en ese entorno" (Bronfenbrenner, 2002), como en el caso de otros grupos de relación, como los amigos de su pareja, los padres de los compañeros de sus hijos, las personas de su grupo religioso o de ambitos de esparcimiento.

Al entrar al sistema laboral, la mujer al igual que el varón incorpora una serie de vivencias ajenas a ella que provienen de personas allegadas, por ejemplo, el temor a dejar el empleo por la dificultad de volver a encontrar otra oportunidad laboral. También entran en consideración las características de su 
red de contención, como si cuentan con información suficiente respecto de los derechos de estar en relación con un empleo o el modo en que han resuelto sus problemas de trabajo, el índice de desempleo de la zona en la que habita o la accesibilidad a organismos que puedan asesorarla, entre otros.

Para entender el valor del contexto en el condicionamiento de la salud, se citan dos ejemplos. El primero, se refiere a una serie de experimentos llevados a cabo por John Christian en 1957 en la isla James $^{10}$ con ciervos (ceruur nippon), los cuales mostraron que la presión ambiental llevó a la mortandad de esa especie quizás como se ha sostenido que "La mortalidad, sin duda, se debió al shock producido a consecuencia de un grave trastorno metabólico, probablemente por una prolongada hiperactividad adrenoconical, a juzgar por el material histológico. No había muestras de infección, hambre ni ninguna otra causa clara que explicara la masiva mortalidad" (Hall, 2003)

Otro estudio que tiene en cuenta el factor ambiental a nivel humano es el realizado por Durkehim ${ }^{11}$ sobre el suicidio, el cual refiere: "Resulta que el suicidio debe depender necesariamente de causas sociales y constituir por esto un fenómeno colectivo. Ciertos hechos examinados, especialmente las variaciones geográficas y por estaciones del suicidio, nos habían llevado de un modo expreso a esta conclusión": la tasa anual de suicidios que existe en varios países europeos desde la sexta década del siglo XIX se mantiene constante 0 con cambios muy leves a lo largo de prolongados períodos. Igualmente, los picos o los valles acusados en las gráficas se corresponden con acontecimientos como guerras o depresiones económicas. También se percató de que la tasa de suicidios es diferente de unos países a otros y de unas comunidades a otras. Por ejemplo, en las sociedades católicas había menos suicidios que en las protestantes.

En los dos ejemplos anteriores se observa que el ambiente condiciona la vida. En un caso llevó a la mortandad de una especie, mientras que, en el otro,

10 Es una isla a veintidós y medio kilómetros al oeste de la población de Cambridge, en Maryland. Su superficie aproximada es de 113 hectáreas.

11 Émile Durkheim (Épinal, Francia, 15 de abril 1858 - París, 15 de noviembre 1917). Uno de los creadores de la sociología moderna, junto a Max Weber y Karl Marx. Fundador de la primera revista dedicada a la sociología, el Année Sociologique, con el cual también se identifica al grupo de estudiosos que desarrolló su programa de investigación sociológica (Wikipedia, 2011). 
las personas quedaron a merced de los vaivenes sociales. Esta dermis que va cubriendo las interacciones cotidianas de las empleadas condiciona su realidad y su destino psicofísico.

En este nivel, aparecen otras realidades cercanas a la mujer que van condicionando su realidad, al reforzar en ocasiones lo forzado por el acosador.

Es claro que las consecuencias del maltrato de mujeres empleadas se manifiesta en la salud de la acosada y en el estilo de interacción acosadoracosada. Aunque es una terrible simplificación no atender a los factores sociales, y volviendo sobre los ejemplos citados en este punto, si un grupo de animales muere de estrés, si las personas se quitan la vida en un vaivén social, se puede especular que el mobbing tal vez sea la primer manifestación de una anomalía de naturaleza psicosocial, un estilo de aprendizaje desarrollado en este espacio histórico-económico-social, que necesita ser paliado en el contexto y no sólo en las consecuencias individuales.

Cuando Heyns Leymann ${ }^{12}$ explicó que el maltrato crónico es una forma de hacer enfermar a una persona por acumulación de estrés, a fin de obtener evidencia que le ayudase a explicar lo que les acontecía a las personas expuestas a esa situación de violencia silenciosa, se valió de los aportes del biólogo Konrad Lorenz, que racionalizó un proceder del reino animal que pone en evidencia las acciones de algunos miembros de la especie al atacar en conjunto a uno de los suyos, explicando así lo que sufrían esas personas que llegaban incluso a perder la vida en el empleo. La psicología no le alcanzó para explicar la complejidad del mobbing, por ello necesitó de la justicia y de la biología.

El entramado de interacción de gente e instituciones obliga incluir un nivel más amplio que pueda generar reglamentaciones sociales (leyes) que

12 El profesor Heinz Leymann (Wolfenbüttel, Alemania, 17 de julio de 1932 - Estocolmo, 1999), se nacionalizó como ciudadano sueco en 1955. Vivió en Suecia largos años. Era doctor en psicología pedagógica y también obtuvo el grado de doctor en la ciencia médica de la psiquiatría. En los años 60, un médico sueco detectó un especial tipo de comportamiento hostil en la escuela, el cual se mantenía durante un largo período. Este comportamiento fue denominado bulling. A principios de los 80, el profesor Leymann encontró el mismo tipo de comportamiento hostil a largo plazo en empleados y en sus lugares de trabajo. Desde entonces, Heinz Leymann es el experto internacional más reconocido en el campo del mobbing en los lugares de trabajo (Wikipedia, 2010). 
sean facilitadas por los representantes del pueblo (políticos), y eso se da a nivel del macrosistema.

\subsubsection{Macrosistema}

Este nivel se refiere "a las correspondencias, en forma y contenido, de los sistemas de menor orden que existen o podrían existir, al nivel de la subcultura o de la cultura en su totalidad, junto con cualquier sistema de creencias o ideología que sustente estas correspondencias" (Bronfenbrenner, 2002), las nociones de politica, justicia y salud se tienen que aunar en el marco social.

Se incluyen aquí aspectos observados en niveles más interpersonales (microsistema), donde el acoso es una cuestión de individuos. Los acontecimientos a nivel de macrosistema tienen el carácter de decisiones, de reglamentaciones, de la visión del grupo que se aleja de los sujetos en relación. Por eso, en aproximaciones psicosociales quedan excluidas. Aunque resultan en su conjunto condicionantes de lo explicado en los subsistemas anteriores.

El nacimiento de la economía como ciencia y también de la psicología, como se explicó, en ese momento histórico en que en Europa empezó a aumentar la "presuntuosa congratulación propia, y en los siglos XVIII y XIX, el dogma del progreso inevitable se convirtió en indiscutible artículo de fe popular" (Huxley, 1947)

Esa creencia de "todo por nada" se adentra en las estructuras económicas y da lugar a la aparición de ideologías que condicionan la vida de la sociedad y la del individuo.

Al enunciar un sistema de creencias implícito, se hace referencia a que existe un órgano que nutre al mesosistema, al exosistema y al microsistema, porque de ese orden emana una ley, un orden que implica juicios de valor implícitos en las racionalizaciones. Estos son sostenidos por las organizaciones que dictan las leyes traducidas en teorías que justifican esos valores de poder específico, que son inexistentes, pero perduran en sus ideas. El factor en cuestión implícito es una psicología particular que circula por los diferentes niveles, dando un significado a las relaciones tanto de las organizaciones como de la persona. 
Técnicamente la interacción de los agentes de producción está representada por el factor productivo, que es la "capacidad física e intelectual con la que cuenta el ser humano para transformar elementos de la naturaleza en bienes aprovechables para satisfacer sus necesidades" (De Santis, 2001). Esa relación de producción en el macrosistema es "la forma en que se organiza la actividad económica de una sociedad, la producción de bienes y servicios y su distribución entre sus miembros" y tiene un "ordenamiento jurídico que específica el régimen de propiedad y las condiciones de contratación entre particulares. El Estado elabora e impone ese ordenamiento jurídico y se reserva para sí ciertos ámbitos y formas de actuación. Este encuadre sirve por tanto para determinar qué agentes como en qué condiciones podrán adoptar decisiones económicas.

En resumen, el abordaje sistémico permite dar un enfoque que integre distintos niveles que expliquen y den solución al problema del acoso. Los sistemas enumerados en el modelo ecológico de Urie Bronfenbrenner interactúan desde el macrosistema al microsistema. El nivel mayor está condicionado por creencias implícitas que determinan un orden determinado en emergencia por la interacción de factores.

El enfoque de Bronfenbrenner es válido atendiendo que adhiere al enfoque sistémico y pondera la importancia del entorno, ambiente o contexto social en la problemática del acoso. Sin embargo, es criticable por su apego al modelo ecologista o biologista, cuestión esta que se debe superar, confiriéndole a las dos dimensiones de análisis la interna (el análisis del problema en sí) y la externa, (el contexto o entorno) su entidad de naturaleza socio cultural.

Las prácticas del acoso, en cualquier ámbito en que se las analice, no dejan de ser una pauta de conducta social, originada por el sostenimiento de ciertos valores derivados de situaciones determinadas.

La mujer acosada es un emergente que se corresponde a la interacción de varios sistemas como el laboral, social, comunicacional, económico, sanitario (Macrosistema). Cada persona siente sobre si las condiciones de estos sistemas, es decir, su cuerpo (cuerpos) responde a cada una de estas dimensiones y por ende su psiquismo (un intangible económico) afecta su microsistema. En este 
proyecto se reparara en el costo del acoso sobre la salud de las mujeres como víctimas (plano individual) de la violencia ejercida por medios económicos, sociales, comunicacionales usados por la organización laboral. El malestar se traslada a su grupo primario (familia, amigos, etc.) y a la larga es una trampa que también contamina a la organización en costos tangibles por ejemplo, absentismo (que es el resultado de ausencias y tardanzas), demandas legales.

El aporte de Bronfenbrenner es útil, con la observación apuntada, al tratamiento de este problema.

\section{4. ¿Cómo enferma la mujer psicológicamente por acoso laboral?}

Los efectos del acoso surgen de las principales definiciones acerca del acoso moral o mobbing que muestran coincidencia en señalar al ámbito laboral como un facilitador del enfermar en el empleo.

En este sentido, "El acoso moral en el lugar de trabajo es un comportamiento irracional ${ }^{13}$ repetido con respecto a un empleado o a un grupo de empleados, que constituye un riesgo para la salud y la seguridad. Un sistema de trabajo puede utilizarse como medio para discriminar, humillar, debilitar o amenazar poniendo en riesgo la salud mental o física del empleado. El acoso moral suele constituir un mal uso o un abuso de autoridad, cuyas víctimas pueden tener dificultades para defenderse". (FACTS, 2007)

Se replica aquí nuevamente que el ambiente condiciona la salud de las personas, lo cual surge del análisis del modelo de Bronfenbrenner que parte de un microsistema a un macrosistema, el mobbing y así mismo, se explicó el modelo biológico propuesto el biólogo Konrad Lorenz (ver 5.3.4) y se complementa con la perspectiva cognitiva del psicólogo Americano Albert Ellis.

\subsubsection{Cómo se enferma psíquicamente por el acoso la mujer}

Uno de los modelos terapéuticos más exitosos contemporáneos es el de la Terapia Racional Emotiva Cognitiva ${ }^{14}$ o TREC, este procedimiento está al servicio de modificar el modo en que las personas crean sus problemas

13 Se entiende como el comportamiento que una persona razonable, teniendo en cuenta todas las circunstancias, consideraría que discrimina, humilla, debilita o amenaza.

14 Terapeuta cognitivo conductual estadounidense que en 1955 desarrolló la terapia racional emotiva conductual. Es considerado por muchos como el padre de las terapias cognitivas conductuales y basado en una encuesta de 1982 entre profesionales de la psicología de EE. UU. y Canadá, uno de los psicoterapeutas más influentes de la historia. 
emocionales (Lega, Vicente, \& Ellis, 1997). Para este cometido se analizan cinco factores; el primero es el ambiente, los otros cuatro consideran al sujeto en función de sus pensamientos o cogniciones, reacciones físicas, emociones y conductas. Todos estos componentes interactúan simultáneamente y un cambio en un nivel afecta a los demás.

a) El ambiente según el modelo de Bronfenbrenner se comprende como estructuras anidadas, cada una dentro de la siguiente, como un conjunto de muñecas rusas (Shaffer, Psicología del desarrollo. Infancia y adolescencia. Quinta edición, 2000)

El lugar aporta aspectos físicos y también psíquicos. De allí que las ideas se nutren de estímulos ambientales, por citar el estudio de agresión de Bandura ${ }^{15}$ donde los un grupo de niños eran expuestos a una película donde un adulto golpeaba un muñeco y otro no. Posteriormente, se hacía pasar a los niños a un salón de juegos donde estaba el mismo juguete. Los menores que vieron la agresión filmada del adulto golpeador agredieron igual o más al muñeco versus los niños que no vieron la proyección.

La agresión tiene un componente gregario o imitativo, y el entorno es el lugar donde se gesta esta respuesta.

b) El pensamiento forma parte del modo o forma de conocer (cognición) y se nutre de las percepciones, de la memoria dando lugar al procesamiento mental de la información (Coon, 1999). Ese análisis de una situación particular da por resultado el modo en que se comporta el sujeto; por ejemplo un jefe que recibe en su primer día a un nuevo empleado y mientras le habla este mira por encima de su hombro sin fijar la mirada, pudiendo pensar: "es un mal educado al no mirarme"y sentirse enojado o por el contrario pensar "soy una persona aburrida nadie quiere escucharme" $\mathrm{y}$ entristecerse o que, "es tímido vamos ayudarle" y sentirse enternecido así una misma situación puede generar pensamientos y emociones diferentes.

15 Albert Bandura ( $n$. en Mundare, Canadá, 4 de diciembre de 1925) es un psicólogo ucraniano-canadiense de tendencia conductual-cognitiva, profesor de la Universidad Stanford,1 reconocido por su trabajo sobre la teoría del aprendizaje social y su evolución al Sociocognitivismo, así como por haber postulado la categoría de autoeficacia. (Wikipedia, 2011) 
c) Las reacciones físicas son los síntomas corporales, es decir, lo que el cuerpo percibe. En situaciones donde una empleada reacciona con pánico experimenta palpitaciones, sudoración, nauseas, opresión en el pecho, falta de aire, mareo, hormigueo, ahogo entre otros síntomas (Cia, 1999). Estas sensaciones se correlacionan con el sistema nervioso autónomo, por ejemplo en la percepción del dolor en estados de ansiedad y el cerebro abre la espina bifida amplificando la sensación de malestar (Baron, 1996)

d) Las emociones son un estado particular que en general se describe con expresiones como triste, alegre, ansioso/a, feliz, etc. Técnicamente es un proceso desencadenado por la valoración cognitiva de una situación que produce una alteración en la activación del organismo (Fernández-Abascal Enrique G., 1997). Estas pueden graduarse, como en el caso de la tristeza que es mayor cuando se esta frente a la perdida de un ser querido, al de extraviar los documentos o en casos situaciones similares

e) Las conductas humanas pueden observarse y cuantificarse por ejemplo, una empleada que experimenta una fobia ${ }^{16}$ específica a su ámbito laboral evitara ese aspecto temido ya sea de forma imaginaria o real.

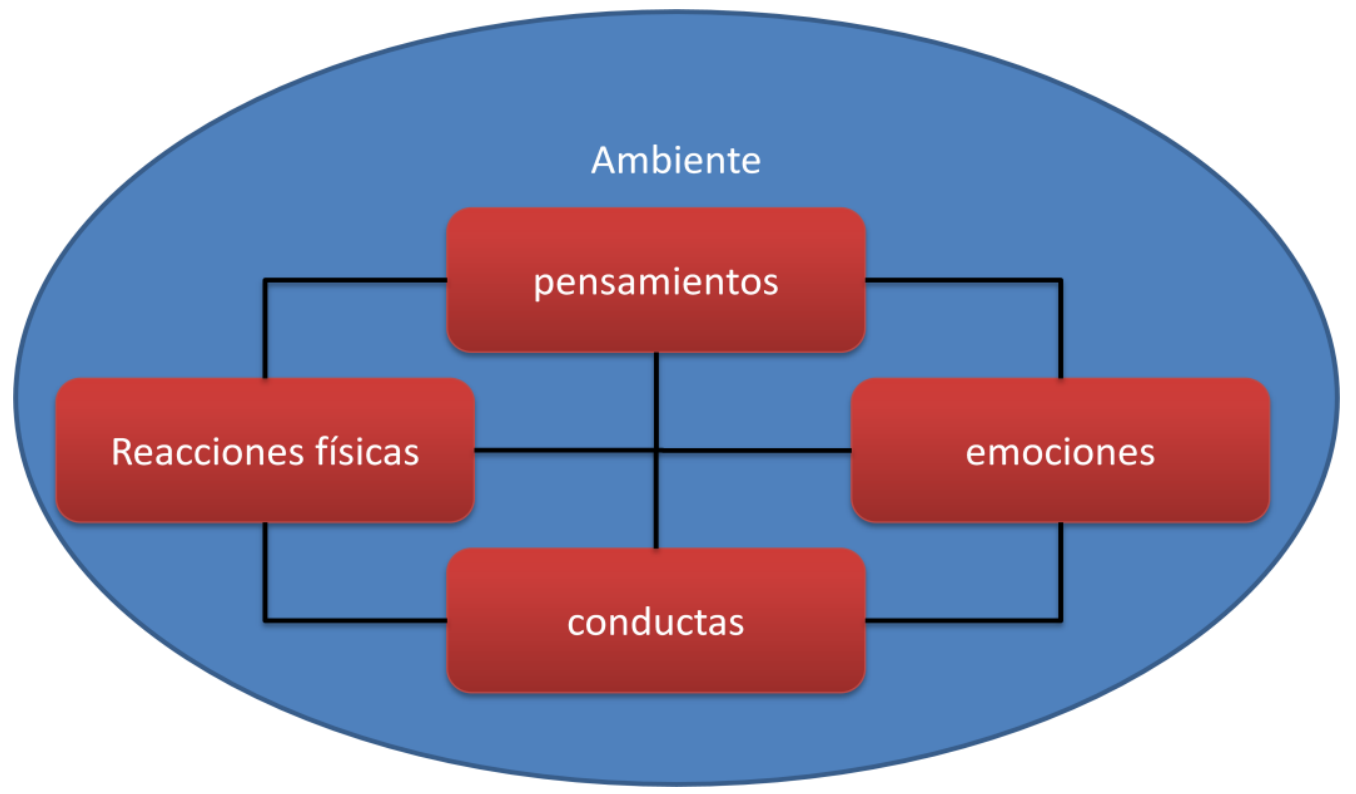

Gráfico 1: Los cinco factores de nuestras experiencias de la vida. Centro de terapia cognitiva, 1986, Newport Beach, CA (citado sin fines comerciales)

16 "La fobia es un miedo persistente, excesivo, irracional y desproporcionado a determinados objetos o situaciones, que se acompaña, con una marcada tendencia a evitarlos. Genera gran malestar o sufrimiento y produce restricciones importantes en la vida cotidiana, ya sea en las relaciones interpersonales, laborales o sociales, necesita ser tratada". (Cia, 1999) 
El ambiente repercute de un modo directo en el individuo. Su estilo para procesar los eventos del ambiente, su herencia genética, su educación, su historia previa entendida como un sistema de creencias afectará más o menos rápido al individuo con relación a situaciones que pueden ser aversivas para su salud.

En el microsistema de la mujer trabajadora tiene contacto con una serie de realidades sociales concretas su familia, empleo, amigos y otras organizaciones de tal modo que en el proceso laboral la mujer realiza su labor por lo cual recibe su salario como un sujeto económico para su sustento, compra de bienes o para el ahorro. El proceso de transacción es correcto.

Al atender al modelo del TREC una mujer sin problemas en su empleo la situación con su ambiente laboral opera de esta forma:

- Situación: Cobrar el salario;

- Pensamiento: Pagar la cuota de la escuela de los hijos;

- Emoción: Alegría, satisfacción;

- Reacción física: Relajarse; y

- Conducta: Dirigirse al colegio de su hijo.

En este ejemplo se puede observar que en esa relación transaccional no hay distorsión y ello implica que, cuando una persona es contratada debe cumplir con requisitos imprescindibles como estar en condiciones psíquicas y físicas (psicofísico) lo cual forma parte de un proceso de selección que permite evitar riesgos futuros para el empleador. A partir de ello la mujer al ser empleada, queda en relación de dependencia con su empleador y se establece así una situación de beneficio mutuo de producción y remuneración por ese trabajo. Sin embargo, en la dinámica de los grupos cada sujeto en sí aporta su microcosmos al ámbito laboral. Estas situaciones al igual que en las familias su resolución significa un crecimiento para el individuo y el grupo lo cual no excluye la aparición de distorsiones que comienzan cuando existen agendas ocultas, como el caso de una reestructuración de la organización en la cual se hace necesario despedir empleados. Surge así una situación donde el elevado costo de la indemnización cambia la relación entre empleador y empleado al 
ponerse en evidencia una intención oculta que distorsiona el vínculo y en ese proceso se producen múltiples consecuencias para la empleada.

Una de las tantas situaciones de una empleada en uno de los casos traído a colación en los anexos se observa la siguiente secuencia comportamental:

- Situación: Levantar bolsas de tierra de $20 \mathrm{~kg}$ de un lado a otro.

- Pensamiento: "Por qué tengo que hacer esto si soy cajera"; "debo ser un monstruo nadie me ayuda"; "siento que me voy a morir".

- Emoción: angustia, miedo, frustración.

- Reacción física: dolor, palpitaciones, sudoración, nauseas.

- Conducta: actuar sin consciencia como un autómata.

Atendiendo a ello se analizará que sucede en ese vínculo enfermizo que establece el empleador.

El biólogo Gregory Bateson ${ }^{17}$ en su trabajo con pacientes esquizofrénicos descubrió en la interacción familiar lo que denominó el "doble vínculo" situación en la cual una persona, haga lo que haga, no puede ganar.

Esta particular relación se configura en el mobbing donde:

a) La situación de maltrato se da entre dos o más personas una a los fines del mobbing, se constituye en "víctima" a ella cabe agregar por lo general el acoso no se vale sólo del acosador sino del grupo que se involucra en esta situación.

b) Las experiencias del psicotrauma son repetidas, el acoso se da en el tiempo. Al acosador puede tomarle semanas, meses y hasta años en algunos casos destruir a su víctima. Lo coincidente en esas experiencias es que los eventos traumáticos son reiterados y el maltrato se convierte en algo cotidiano.

c) La comunicación del acosador parte de un mandato primario negativo. Que puede presentarse en dos formas "No hagas eso, o te echare del

17 Gregory Bateson (Nace el Reino Unido, el 9 de mayo de 1904 y muere en San Francisco, Estados Unidos, el 4 de julio de 1980) sus principales actividades fueron la antropología, la lingüística y la cibernética cuyo trabajo interesa con muchos otros campos intelectuales. (Wikipedia, 2011) 
empleo", o "Si no haces eso, te echaré del empleo". En ambas situaciones lo importante para la víctima es evitar ser castigado.

d) Lo que hace difícil caer en este modelo es que hay un mandato secundario que está en conflicto con el primero en un nivel más abstracto, y que, al igual que el primero, está reforzado por castigos o señales que anuncian un peligro para la supervivencia. Este mandato secundario es más difícil de describir que el primario, por dos razones. Primero, el mandato secundario se trasmite por lo común, mediante medios no verbales como la postura, el gesto, el tono de voz, la acción significativa y las implicaciones ocultas. En el comentario verbal pueden usarse todas para transmitir el mensaje más abstracto (Bateson, 1991). Segundo, el mandato secundario puede chocar con cualquier elemento de la prohibición primaria (Bateson, 1991). Las formas posibles son: "Esto no es un castigo"; "No soy yo quien manda hacer esto"; "No estás preso puedes irte cuando quieras"; "No dudes que te aprecio"; y así sucesivamente.

e) Por último existe un mandato negativo terciario que prohíbe a la víctima escapar del campo. En este nivel el acosador refuerza los dos niveles anteriores porque existe una amenaza a la supervivencia, como son del tipo "no hay trabajo"; "No podés trabajar en ningún lugar"; "Somos los únicos que podemos recibirte".

Se entiende que es una comunicación que llega a tal nivel de distorsión que y en el intento de interpretarlo, la victima cada vez enferma más.

Las escalas de valoración de acoso centran su atención en las conductas de acoso pero también en la comunicación verbal y no verbal.

La mujer en relación a un empleo mantiene diferentes niveles de contacto, y en algunas ni siquiera tiene conciencia de que está siendo afectada. En un sistema económico simple es el trabajo el primer elemento del factor productivo, por ende una distorsión en un nivel menos complejo repercute en todo el sistema.

De todo ello se infiere que la situación de enfermar se da por la repetición y por un estilo particular de maltrato denominado a veces "crimen limpio" por no manifestarse externamente. 
En el ámbito laboral hay situaciones que se caracterizan porque el acosador no le presta atención a la víctima omitiéndola o haciendo como sino existiera. Ella piensa "algo estoy haciendo mal, ¿será mi aspecto?, ¿estaré haciendo lo suficiente, realmente será así o tal vez está muy ocupado", subsecuentemente cae en estados de ansiedad y angustia. Tiene palpitaciones, mareos, nauseas y vómitos. Finalmente, se retira del empleo por estar descompuesta.

La situación es reiterada, el acosador lleva a cabo de este modo un proceso paulatino de desgaste el que omitirla o ignorarla se convierte en una de las tantas acciones emprendidas simultáneamente. En general, el acosador implanta ante el acosado un comportamiento donde reiteradamente resalta sólo lo negativo por ejemplo, llegar tarde, cometer un error y en contraste, no reconoce o valora sus logros

En los ocho casos estudiados un factor común relevado en las entrevistas se constata que lo bien hecho se considera como una obligación aunque fuera extraordinario; la diferencia se aprecia cuando aparecía un problema derivado por esa situación da lugar a descalificar, omitir o denigrar.

En circunstancias como éstas el acosador ponía en práctica acciones a través de ciertas actitudes tales retirar la mirada, hacer como que no está presente, quitarle su puesto de trabajo y con frases que remarcan esta situación como :"no hay trabajo afuera, quien va a mantener a sus hijos".

Igualmente, aquellos que no son acosados colaboran con el acosador a fin de no ser víctimas del maltrato, autojustificando su proceder con expresiones como :"algo habrá hecho".

Conscientemente el sistema laboral en el que se contrató a una persona saludable le entrega a la sociedad y a su grupo familiar otro sujeto alienado. Este estilo de conducción hace reflexionar sobre la frase de Erich Fromm ${ }^{18}$ "¿Necesitamos de personas enfermas para tener una economía sana?".

Enfermar en el ámbito laboral es un proceso que conduce a la perdida de motivación y expectativas positivas en el sujeto.

18 Psicoanalista, sociólogo perteneció a la escuela de Frankfurt y sus aportes teóricos han influido la psicología contemporánea. 


\subsection{Conceptualización de la agresión en el ámbito laboral. Formas.}

La agresión siempre es intencional. Este estilo particular de relación encuadra en la cognición social: "A la luz del modelo clásico E (estímulo) - O (organismo) - $R$ (respuesta), la cognición social podría representarse en 0 , como los procesos y estructuras que median entre la situación social y la conducta social del individuo" (Enesco). Hay un saber social que hace referencia al estilo que aprende el acosado, ser víctima y lo cual se constituye en un objetivo del acosador: remover a la empleada.

Las acciones impartidas por el acosador violan las normas de higiene y seguridad por implementar acciones que, como se expuso en 5.4, afectan la comunicación y tienden a desmotivar a la empleada que es víctima del acoso. Un acosador debe tratarse como un agente nocivo para la salud del empleado.

Cuando una persona es segura de sí misma, enérgica, expresiva de sus emociones es asertiva pero aquel que hiere, daña o destruye es agresivo.

Por eso la agresión puede tener dos formas: la hostil que surge del enojo con el objetivo de dañar y la instrumenta/ que se dirige a hacer daño, pero sólo como un medio para lograr sus cometidos (Myers, 1997).

Esta conducta destructiva del acoso se implementa de acuerdo a las siguientes formas:

a) Individual o colectiva. Cuando está a cargo de una persona quién ha adoptado o no la decisión de despido o de varios integrantes de un mismo nivel de decisión.

b) Directa $o$ indirecta. Según la ejercite quien toma la decisión de despedir a la empleada o la disponga a través de subalternos que actúan en el marco de la denominada "obediencia debida" de dudosa legitimidad.

De esta clasificación surgen combinaciones tales como:

a) Individual - directa;

b) Colectiva- directa;

c) Individual-indirecta; $y$

d) Colectiva-indirecta.

Cada forma es susceptible de análisis particulares, especialmente, no sólo referidas a la responsabilidad del o los acosadores sino incluso, respecto de 
sus perfiles psicológicos, al igual que sucede con quienes intermedian en la ejecución, respecto a lo cual se hace referencia en el punto siguiente.

\subsubsection{La psicología del acosador}

Además de lo expuesto respecto al acoso o agresión laboral particularizada en mujeres y sus implicancias económicas, político-jurídicas y en materia de salud, cabe también hacer referencia al tratamiento de este fenómeno polifacético considerando la conducta y perfil psicológico del acosador más allá de los valores morales que le son propios.

En general el acosador es un sujeto con baja autoestima [ (Ovejero, 2006); (Martin, 2006); (Hirigoyen, 2001)] que busca remover a quien se le presenta como competencia argumentando fallas en su desempeño. No está descartado además la existencia de un tipo de conducta sádica (Fromm, 2004). El maltratador puede pensarse en dos direcciones, una disfrutando de la agresión que propicia y la otra cumplir con la tarea encomendada. De una forma y otra el resultado es el mismo desvincular a la empleada por medio de artilugios ilegales y encubiertos que son nocivos para su salud psíquica.

Concretamente, el acosador lleva la relación a los bordes de lo punible, y, al mismo tiempo, lo hace la organización al responder solidariamente con la situación.

Queda claro que existe una primera relación, entre la víctima y el acosador y es la más ampliamente estudiada por los teóricos jurídicos. Dando lugar a un tipo de enfermedad que se organiza con el objetivo de evitar los costos del despido.

El consentimiento de actos de esta naturaleza conduce a mantener una actitud colectiva de silencio, sin reconocer la existencia de una patología de corte social no incluida en la legislación de riesgo de trabajo (Ley 24557 y su actualización mediante el decreto 1278/2000)

En general, se considera indeseable la violencia, pero aun es una práctica que algunos padres usan con sus hijos, en lo que se conoce como 
disciplina basada en afirmar el poder ${ }^{19}$ (Shaffer, Psicología del desarrollo. Infancia y adolescencia. Quinta edición, 2000), estrategia usada por docentes que padecen del síndrome de burnout ${ }^{20}$ (Gil-Monte, 1997) para moldear el comportamiento de sus estudiantes; igualmente la acción de algunos sujetos para resolver sus conflictos de pareja (Súñer, 2002), o la puesta en práctica por algunos países para resolver problemas (Myers, 1997). Igualmente, es una herramienta utilizada por acosadores en el ámbito laboral [(Abajo Olivares, 2004); (Martin, 2006); (Toselli, Grassis, \& Ferrer, 2007); (Diaz, 2007)]. Se entiende entonces que la violencia es un flujo, una corriente, que en el ámbito interpersonal se produce a través de un proceso interactivo. Estas interacciones se producen a través de la comunicación verbal y no verbal, por ejemplo un expediente que circula entre diferentes sistemas ${ }^{21}$ (laboral, social, sanitario, comunicacional, etc.), etc. En este movimiento hay una repetición, y esa es la forma en que se aprende: observando y actuando.

\subsection{2. ¿Por qué el grupo omite el acoso?}

El pensamiento de los individuos en grupo está condicionado por lo que se conoce como error fundamental de la atribución $^{22}$, que consiste en la tendencia de los observadores a subestimar las influencias situacionales y a sobreestimar las influencias disposicionales sobre la conducta de los demás. Por ejemplo, si alguien trata de evitar una la espera de un trámite se piensa que esa persona es desconsiderada o mal educada (disposición interna), sin

19 Tipo de disciplina en la que un adulto se apoya en su poder superior (por ejemplo, dando bófetas o suspendiendo privilegios) para modificar o controlar la conducta de un niño. (Shaffer, Desarrollo Social y de la Personalidad, 2002)

20 Psicosocial: Síndrome de agotamiento emocional, despersonalización y falta de realización personal en el trabajo, que puede desarrollarse en aquellas personas cuyo objeto de trabajo son personas en cualquier actividad. (Gil-Monte, 1997)

21 "... sistema como objeto estructurado... modelo CESM... Postula que cualquier sistema $\mathrm{s}$ puede ser modelado, en cualquier instante dado, como la cuaterna: $\mu(\mathrm{s})=\square \mathrm{C}(\mathrm{s}), E(\mathrm{~s}), \mathrm{S}(\mathrm{s})$, $\mathrm{M}(\mathrm{s}) \square$ donde $\mathrm{C}(\mathrm{s})=$ Composición: la colección de todas las partes de $\mathrm{s} ; \mathrm{E}(\mathrm{s})=$ Entorno: la colección de elementos no pertenecientes a $s$ que actúan sobre los componentes de $s$, o sobre los que algunos o todos los componentes de $\mathrm{s}$ actúan $\mathrm{S}(\mathrm{s})=$ Estructura: la colección de relaciones, en particular vínculos, entre componentes de o entre estos y elementos del entorno $\mathrm{E}(\mathrm{s}) ; \mathrm{M}(\mathrm{s})=$ Mecanismo: la colección de procesos de $\mathrm{s}$ que lo hacen comportarse del peculiar modo en que lo hace." (Houdé, Kayser, Koenig, Proust, \& Francois, 2003)

22 Teoría de la atribución: Es la manera en que las personas explican la conducta de los demás -por ejemplo, atribuyéndola ya sea a disposiciones internas (rasgos, motivos y actitudes perdurables) o a situaciones externas (Myers, 1997) 
embargo, podría justificarlo por una urgencia personal como una atribución situacional. Las organizaciones que acosan tienden a magnificar lo situacional: "Tuvimos que actuar de este modo porque la situación económica no permite tener este tipo de personas", "Otros lo hacen y peor", "Desde arriba me dijeron que tenía que hacerlo", etc. Nunca harían una valoración disposicional del tipo: "Lo hago porque soy cruel", "Porque creo que es la única forma de hacer esto", etc.

Por último, cabe traer a colación como un factor motivacional del maltrato la presencia de otros que en lugar de inhibir ese comportamiento, tienden a mantenerlo y propiciarlo.

Dos aspectos estudiados al respecto son el efecto de la coacción ${ }^{23}$ y el efecto de audiencia ${ }^{24}$ que tienen un poderoso influjo en la individualidad y conducta ética. Sus manifestaciones son la condescendencia, la conformidad y la obediencia.

Lo expresado, tiende a dar cuenta que el acoso y el maltrato necesita de actores y de público.

\subsubsection{Desesperanza y compañeros de empleo}

La desmotivación que provoca el acosador en la victima y que es apañada por sus compañeros se explica por medio del modelo de desesperanza aprendida ${ }^{25}$ : ... los individuos (personas o animales) pueden aprender que no tienen control sobre lo que les sucede en algunas situaciones. Debido a que esto significa asumir la ineficacia de las propias acciones para modificar las circunstancias adversas en las que se encuentra inmerso el individuo, la indefensión aprendida comporta consecuencias tales como la aceptación resignada de una situación negativa... este síndrome aparece a partir del aprendizaje de que las consecuencias son incontrolables y esto se atribuye a

23 La presencia de otros contribuye a que los participantes pongan su máximo esfuerzo, fenómeno bien comprobado no sólo en seres humanos sino también en animales. (Petri \& Govern, 2006)

24 Al coaccionar a individuos ocurren si un miembro hace algo y el resto funge como audiencia. (Petri \& Govern, 2006)

25 "... estado psicológico en la motivación, los procesos cognoscitivo la emotividad se trastornan porque un organismo pasó por experiencias de falta de control" (Petri \& Govern, 2006) 
una inadecuación personal, general y crónica. La desesperanza, el aumento de sintomatología depresiva, la frustración, los sentimientos de fracaso y la pérdida de autoestima se encuentran entre los efectos más frecuentes de la desocupación y han sido ampliamente estudiadas... los sujetos con trabajos precarios, que perciben que se encuentran sometidos a una enorme desprotección socio-laboral y registran que la modificación de tales condiciones laborales no depende de ellos, experimenten sentimientos de desesperanza... el trabajo inseguro es aquel en el que el trabajador no controla las condiciones de su trabajo, ya sea individual o colectivamente. Esta percepción es, tal vez, un factor que hace que los esfuerzos en modificar tales condiciones se perciban como infructuosos o inútiles (Leibovich de Figueroa, 2006)

Las fases del mobbing muestran como la persona se desesperanza que se entiende la forma en que una persona se desmotiva para lo cual deben tenerse en cuenta:

Fase 0: La seducción: en esta parte el acosador arma su trama con otros que serán quienes lo secundaran en su accionar. Aun en este nivel no muestra sus aspectos más agresivos (Martin, 2006)

Fase 1: El conflicto: cuando se produce el maltrato en sí. La persona queda a merced del acosador que cuenta con un grupo, un respaldo que en general, está ajustado a la dinámica de la cultura de la organización.

En este nivel se produce el primer síntoma del desamparo que es la pasividad porque la empleada tiene una deficiencia motivacional ocasionada por la incontrolabilidad de los eventos (Petri \& Govern, 2006), es decir, no sabe cómo responder por estar en un contexto de doble vínculo.

Fase 2: Acoso moral en el trabajo. Como se expuso en las definiciones previas son conductas que se dan en un lapso durante el que se espera que la persona abandone el lugar de trabajo. Estas acciones son repetidas y avaladas por el grupo.

La mujer víctima de las acciones de acoso genera un retraso del aprendizaje o retraso asociativo (Petri \& Govern, 2006) que se manifiesta en una deficiencia de aprendizaje, porque se condicionó en el sentido de que las consecuencias de una situación determinada no pueden modificarse con sus 
respuestas. Esto es lo que manifiesta un doble vínculo donde la víctima no puede responder.

Fase 3: El entorno. Este es el aspecto más desarrollado entendiéndolo desde las relaciones básicas hasta las familiares.

La respuesta del entorno laboral será la que determinará la resolución rápida del acoso o bien su implantación permanente, con el consiguiente daño en la salud del acosado. Por tanto, el entorno es un elemento básico en el desarrollo o en la resolución del acoso laboral. (Martin, 2006)

De esta manera en el maltrato de la mujer también se deja el terreno listo para agredir a otros. Sólo es cuestión de tiempo. De ello queda claro que el grupo es condicionado y hay factores particulares en acción.

Fase 4: La actuación de la empresa: En general se dice que cualquier empresa puede contener esta acción aunque algunas, pueden reparar la con mayor celeridad. El acoso funciona bien en la ignorancia o amparándose en aspectos sociales como el "machismo". Por eso puede facilitar o detener esta acción. En el modelo ecológico de Bronfenbrenner se observa que la empresa al estar conectada con niveles superiores puede perder de vista que sus empleados dan vida a la organización.

Fase 5: La marginación: Es el momento en que la persona sale del empleo enferma psíquica y físicamente. Esta condición personal es la confirmación de porqué se lo quería desvincular. Lo que da lugar a que la exclusión del acosado del mundo laboral, deje abierta la posibilidad de despidos, jubilaciones anticipadas, invalidez, pérdida de la razón y a veces, incluso, la pérdida de la vida (suicidio, accidentes laborales mortales). La marginación es potenciada por 'compañeros' deseosos de obtener beneficios o prebendas a expensas de los derechos usurpados al acosado y que son incapaces de conseguir por los cauces ordinarios. Además, en esta fase el personal subalternos (administrativos, becarios, residentes, personal en prácticas) aprovechan para hacer todo tipo de humillaciones, faltar el respeto al acosado, crear rumores malignos y comentarios vejatorios, falsedades y calumnias: todos quieren hacer 'méritos' ante al acosador, al que temen con 
pavor y es quien reparte favores y consiente las conductas más miserables (Martin, 2006)

La fase 4 y la 5 conduce a los efectos somáticos (Petri \& Govern, 2006) donde las personas en este nivel se vuelven menos agresivas y competitivas que otros individuos en situaciones parecidas, lo cual siempre conduce a perder, incluso su vida.

La persona abatida es alguien que deja de responder porque actúa de forma automática y eso lo hace menos interactivo. De ahí que el grupo pierda la noción de lo "humano" o "inhumano". La victima solicita ayuda y se le es negada en tal situación porque el acosado asume que no importa lo que haga no hay forma de evitar el castigo. Esta es la clave de la manera en que las instituciones - sean malévolas, como los campos de concentración, o benévolas, como los hospitales - pueden deshumanizar a las personas ${ }^{26}$ (Myers, 1997)

Cómo es posible que tantas personas educadas y entrenadas no sepan discernir entre lo bueno y malo. Freud ya había dado cuenta de ello al sostener que no somos totalmente conscientes de nuestros impulsos y deseos.

La multitud es impulsiva, versátil e irritable y se deja guiar casi exclusivamente por lo inconsciente. Los impulsos a los que obedece pueden ser, según las circunstancias, nobles o crueles, heroicos o cobardes, pero son siempre tan imperiosos, que la personalidad e incluso el instinto de conservación, desaparecen ante ellos. Nada en ella es premeditado. Aun cuando desea apasionadamente algo, nunca lo desea mucho tiempo, pues es incapaz de una voluntad perseverante. No tolera aplazamiento alguno entre el deseo y la realización. Abriga un sentimiento de omnipotencia. La noción de lo imposible no existe para el individuo que forma parte de una multitud. La multitud es extraordinariamente influenciable y crédula. Carece de sentido crítico y lo inverosímil no existe para ella. Piensa en imágenes que se enlazan unas a otras asociativamente, como en aquellos estados en los que el individuo da libre curso a su imaginación sin que ninguna instancia racional intervenga para juzgar hasta qué punto se adaptan a la realidad sus fantasías. Los

26 La cursiva y negrita son personales. 
sentimientos de la multitud son siempre simples y exaltados. De este modo, no conoce dudas ni incertidumbres (Freud, (1920 [reimpreso, 1997]))

El grupo configurado por compañeros de empleo se ajusta a los principios de la presencia de otros, ha quedado expreso que al aceptarse el empleo se paga por la obediencia a las normas de la organización, sean estas explícitas o implícitas.

La mayoría de los efectos observados al coaccionar a individuos ocurren si un miembro hace algo y el resto actúa como audiencia. La forma en que se manifiesta el efecto es la denominación que se ajusta al paradigma siguiente:

1. Puede ocurrir en forma implícita esto se conoce como conformidad.

"Lo admitamos o no, todos somos conformistas. Desde luego no todos nos apegamos a las mismas reglas, pero en situaciones de grupo tendemos a coincidir al momento de tomar una decisión. La conformidad es entonces un cambio en nuestras creencias o comportamiento como resultado de presiones reales o imaginarias provenientes de un grupo o individuo ${ }^{127}$ (Petri \& Govern, 2006)

2. El apego en forma explícita frente a una petición se conoce como condescendencia y es el cambio de conducta en respuesta a una petición directa. Tal como versa el dicho "el camino al mal se da de a pasos pequeños". Casi sin darse cuenta marchan el acosador y sus adherentes convencidos de su acción.

3. Por último, la obediencia se convierte en acatar una orden directa de una figura de autoridad. Los experimentos de Milgran $^{28}$ (1963, 1965, 1975) indican que las personas no importa su condición social, nivel educativo alcanzado puede someterse a aceptar realizar órdenes que les resultaban desagradables e injustificables desde el punto de vista ético.

Las personas obedecen órdenes que incluso son disonantes con sus creencias o moral, de ahí que el acosador no tenga sentimientos de malestar

27 La cursiva es personal y la negrita pertenece al autor.

28 Stanley Milgram (15 De agosto de 1933 al 20 de diciembre de 1984) fue psicólogo social en la Universidad de Yale, Harvard University y la Universidad de ciudad de Nueva York. Mientras que en Harvard, dirigió el experimento de small-world (el origen de la noción de seis grados de separación), y mientras que en Yale, llevó a cabo el experimento de Milgram en obediencia a la autoridad. También introduce el concepto de extraños familiares. 
pues se justifican en que "sólo obedecían órdenes directas". Recuérdese la justificación por las fuerzas nazis en el exterminio que justificaban su accionar en la eficiencia del cumplimiento del mandato del Estado.

Hallar personas maltratadas en su empleo no es un hecho aislado sino una tarea validada por la dirección. De ahí que la evaluación de este tipo de problemas se realice en función de factores ambientales (estresores externos) más que en función de la personalidad (estresores internos). Aquí aparece una bifurcación entre los expertos de la salud mental de la empresa y los que acompañan a quien ha sido víctima del hostigamiento. Los primeros tratan por todos los medios técnicos de mostrar a un enfermo usando para ello, una mirada introspectiva o clínica olvidando el factor externo o social que ha facilitado el desgaste personal a consecuencia del hostigamiento psicológico.

El evaluador de parte de la empresa cae en una trampa porque olvida una premisa importante: la empresa contrató a ese sujeto por estar saludable. Esto es garantizado por el proceso de selección de personal

El grupo es condicionado por sus miembros y generan autojustificaciones tanto personales como de todos. De ahí el efecto de la "rana hervida" (Miralles, 2007) no te das cuenta hasta que te quemas. Estos elementos sirven para explicar la condición psicosocial de los eventos que llevan a enfermar.

\section{PROPÓSITO Y OBJETIVOS ESPECÍFICOS}

Las mujeres dentro del ámbito laboral tienen más posibilidades de estar expuestas a la violencia, lo que se convierte en un factor de riesgo psicosocial para quienes son víctimas del mismo.

A la luz de los aportes interdisciplinarios expuestos queda en evidencia, que el padecimiento de una víctima genera un efecto en cadena que se proyecta a la sociedad en su conjunto porque en muchos casos queda un grado de discapacidad y la imposibilidad de reinserción laboral por las consecuencias acarreadas.

La perspectiva dada desde el modelo ecológico de Bronfenbrenner y enfoque sistémico, da una visión panorámica de que los costos resultantes de este tipo de acciones son tangibles e intangibles. 
En definitiva este trabajo es una apertura para una investigación sistemática en la provincia de Mendoza.

El objetivo principal del trabajo se centro en analizar el costo de enfermar por maltrato laboral en mujeres de 25 a 40 años en atención directa al público o cargos administrativos en empresas privadas en la provincia de Mendoza.

Los objetivos específicos se redefinieron en el trabajo y son:

- Describir ocho casos de acoso comprobado en mujeres con funciones administrativas.

- Describir las consecuencias psicofísicas en grado de incapacidad y los costos de las mismas.

- Proponer una valoración sistémica para entender el acoso.

\section{PROCESOS METODOLOGICOS}

\subsection{Metodología cualitativa}

\subsubsection{Análisis documental. (Ver 11. 1. Anexo Presentación de casos)}

a. Expedientes judiciales. Información proveniente de hechos de casos y las conclusiones diagnósticas aportadas por los peritos de la Suprema Corte de la provincia de Mendoza.

b. Historia clínica. Información proveniente de hechos y conclusiones diagnósticas obtenidas de la aplicación de los siguientes test psicológicos: MBI: evaluación del síndrome de quemarse en el trabajo o burnout, LIPT: evaluación del acoso laboral, HTP: prueba proyectiva para evaluación de los mecanismos de defensa, PRIME-MD: evaluación de trastornos clínicos del eje I según las normas del DSM IV, TQ: Detección de sintomatología psicotraumática, MIPS: evaluación de rasgos de personalidad, presencia de indicadores de agradabilidad) y datos cualitativos de las entrevistas semiestructuradas (método interrogativo) tomadas a mujeres con empleos administrativos y de atención al público sin personal a cargo de 25 a 40 años que presentaban un padecer psíquico - somático a consecuencia del mobbing y el porcentaje de incapacidad dad por el perito de parte. 
7.1.2. Evaluación psicopatológica posterior al proceso judicial por medio de la técnica SDL-90 $R$ y de reinserción laboral. (Ver 11. 1. Anexo Presentación de casos)

\subsection{Variables de incidencia identificadas}

Se utilizaron las normas del Manual Psiquiátrico Americano en su cuarta edición (DSM IV) organizado en un sistema multiaxial ${ }^{32}$.

Se estudiaron los trastornos clínicos surgidos del acoso, descartando que las empleadas presentaron trastornos de personalidad, problemas médicos que pueden ser considerado como factor pre mórbido a las consecuencias psicológicas y somáticas del acoso. En el análisis ambiental se hizo hincapié en las consecuencias surgidas de los micro y macro contextos de actuación laboral (ver marco teórico 5.3). La evaluación en esta parte incluyó los costos directos de la enfermedad (tratamiento, inactividad laboral, comunicaciones, traslados, indemnización) y los costos indirectos intangibles (condición vincular ${ }^{33}$, daño psíquico ${ }^{34}$ ).

Por último, se aplicó una escala estructurada y entrevista semiestructurada a cada ex empleada para determinar el estado psíquico y determinar si se reinsertarón laboralmente después del proceso judicial a causa de la situación de acoso.

\section{ANÁLISIS DE LA INFORMACIÓN}

Se analizaron casos de acoso laboral judicializados ocurridos a mujeres de entre 25 y 40 años, que se desempeñaban en puestos administrativos y/o de atención al público y que no tenían personal a cargo.

\footnotetext{
32 Eje I Trastornos clínicos. Otros problemas que pueden ser objeto de atención clínica. Eje II Trastornos de la personalidad. Retraso mental. Eje III Enfermedades médicas. Eje IV Problemas psicosociales y ambientales. Eje V Escala de evaluación global. El uso del sistema multiaxial facilita una evaluación completa y sistemática de los distintos trastornos mentales y enfermedades médicas, así como de los problemas psicosociales y ambientales, y del nivel de actividad, que podrían pasar desapercibidos si el objetivo de la evaluación se centrara en el simple problema objeto de la consulta. Un sistema multiaxial proporciona un formato adecuado para organizar y comunicar información clínica, para captar la complejidad de las situaciones clínicas y para describir la heterogeneidad de los individuos que presenten el mismo diagnóstico.

33 En muchas ocasiones el estrés asociado arrastra a la persona a romper con su pareja.

34 Relacionado al umbral perceptivo de la empleada evaluada.
} 
En una primera instancia se compararon las conclusiones provenientes los peritajes producidos en las causas iniciadas por las empleadas víctimas de acoso ante la Suprema Corte de Justicia de la Provincia de Mendoza con el psicodiagnóstico de parte. En segundo término, se tuvieron en cuenta las demandas de parte y las resoluciones jurídicas contrastándolas con la realidad concreta de la vida de las mujeres víctimas de acoso, grado de recuperación y de inserción laboral posterior.

Durante el proceso se analizó la diferencia entre trabajo y empleo, los perfiles institucionales que favorecen la aparición de acosadores, también sobre la particular comunicación de actos, dichos y alianzas validados en el macrosistema.

\subsection{Valoración cualitativa}

En los casos 1, 2, 3 y 4 analizados (ver anexo I), hay coincidencia de las cámaras del trabajo que ratifican los montos reclamados. A pesar de haber transcurrido al menos tres años desde el inicio de la demanda, el padecimiento psíquico y somático de las ex empleadas se sostiene en el tiempo. La imposibilidad de reinserción laboral constituye una consecuencia no tenida en cuenta en los procesos judiciales.

En el quinto caso, la empresa por temor a la exposición mediática decidió cancelar el total de lo demandado y la ex empleada no obstante contar con recursos económicos obtenidos a consecuencia de la demanda, no logra aún reinsertarse laboralmente y está sometida a la actualidad ha tratamiento psiquiátrico.

En los casos 6,7 y 8 a pesar de que no hay sentencia de las cámaras de trabajo, las valoraciones periciales ratifican el malestar evaluado como consecuencia del acoso.

Como se aprecia en esta aproximación cualitativa, las consecuencias del malestar transcienden el mero padecer psicopatológico, al igual que se lo expreso en el marco teórico se adentra en un proceso social por transformar a una empleada saludable en una incapacitada. 
Este padecer crónico no es más que una regla sostenida como puede verse en estos casos exploratorios pero que pueden definir una línea de investigación, para pensar si la dificultad tiene que ver con la patología surgida del asunto demandado, por el estigma de la demanda laboral o un cruce de ambas.

Es posible concluir que en las primeras evaluaciones de estos casos ocurridos en el 2006, reevaluados en el 2010 hay evidencia que, en varios transcurrieron hasta cuatro años desde el suceso que llevó a demandar al empleador.

Tal como se planteo en el marco teórico, es imperativo evitar pensar a estar personas como un diagnóstico aislado. En todos los casos la vida de relación fue perturbada como por ejemplo en el caso 1 donde por la situación vivida termino separándose de su pareja; o la degradación de condición física degradada como se presenta en el caso cuatro que el juzgado reconoce el deterioro físico de la actora por las características del acoso.

El dato más valioso recogido en general, es que en todos los casos, las consecuencias se han mantenido en la actualidad sobre todo lo que respecta a la reinserción laboral, que se vio truncada por el miedo a padecer nuevamente de la violencia que condujo a retirarse del mercado laboral. Este retiro prematuro de las estas mujeres jóvenes representa socialmente un sobrecarga para el estado a largo plazo con consecuencias aún no valoradas.

En total estos ocho casos acarrearon un costo directo de $\$ 880.110$ más impuestos, es decir, en promedio el costo de la desvinculación por acoso de $110.013,75$ representa una demanda superior a un acuerdo entre las partes por desvinculación del empleo, sin contar las consecuencias a nivel de la imagen pública que resulta también un tema digno de investigar.

\section{CONCLUSIONES EMERGENTES Y DESAFÍOS PENDIENTES}

A grandes rasgos la violencia en el ámbito laboral es un ejercicio sistemático y contagioso $^{37}$. El maltrato se puede relevar en intensidad, en

37 Por ser un proceso que ya dijimos circula entre los diferentes sistemas y se sustenta en el aprendizaje vicario u observacional. 
frecuencia y en la forma. Se expuso que la violencia es una corriente como tal, hay ámbitos que son menos propensos a conducir estas acciones, es decir, son resistentes, otras en cambio son facilitadores o buenas conductoras. Que haya personas maltratadas en su entorno laboral no es un hecho aislado sino validado por la dirección. (Lamagrande M. , El intangible salud mental, 2004) por lo cual se analizaron características de las instituciones facilitadoras de la violencia.

Se considero deseable y necesario aportar herramientas que validen el proceder de quienes buscan amparar una población para la cual estas situaciones de acoso pueden derivar en algunos casos en empobrecimiento económico [(Valenzuela, 2003); (Gil Rodriguez \& Irma, 2007)] y un incremento de sus posibilidad de enfermar (física, psíquica y socialmente) (Hirigoyen, 2001)

\subsection{El costo social tangible e intangible}

El costo social tiene dos tramas la tangible que se traduce en la empleada en términos económicos directos de asistencia sanitaria, legal y social y los costos intangibles que son las repercusiones en la vida de relación de estas mujeres como se explico en el apartado 5 del marco teórico.

En el caso 1 (ver anexo págs. 57-63) es notorio el asunto cuando se expresa el costo del tratamiento psicofarmacológico, de atención psicológica y psiquiátrica, demorada por quedar desempleada entrando en un círculo vicioso que se tradujo en su vida al ser excluida de su seno familiar y separarse de su pareja.

En el aspecto intangible cabe considerar los diferentes costos intangibles enunciados en la introducción que impactan en la organización que son el costo del juicio, el desgaste psicosocial que se plantea en la organización que impacta en la cultura y el clima. En definitiva, hay un empañamiento de la imagen de la empresa que es vista por sus empleados como un monstruo y esa vivencia no verbal es traducida en un desmedro de compra por parte del consumidor.

Serían aplicables los conceptos modernos de cultura organizacional corporativa, clima organizacional e imagen empresaria que se ven afectados por situaciones como las descriptas.

\subsection{Consecuencias sociales del acoso laboral en mujeres}


El concepto de lo social es un concepto amplio, contrariamente a lo que se emplea erróneamente en muchas ocasiones.

Lo social se diferencia del mundo físico de los fenómenos, caracterizados por la ausencia de vida, e igualmente, del biológico caracterizado por la presencia de fenómenos en los cuales existe presencia de vida y, por último, el de lo social en el cual se instalan los fenómenos que son el resultado de la interacción humana. En otros términos de la conducta humana. Por consiguiente, la economía, el derecho, la sociología, la psicología social, la politología, la antropología cultural, entre otros son disciplinas sociales.

Teniendo en cuenta lo expuesto el fenómeno del acoso en sus diferentes formas, es un fenómeno social, sus causas y efectos son sociales y se traducen, en diferente medida, en todos o en la mayoría de los ámbitos sociales indicados.

\subsection{En lo económico}

El costo económico valorado en el trabajo tiene dos dimensiones de análisis, una intrasistémica (microsistema) estos es, para la organización económica donde se genera el problema y otra para el empleado afectado. Además y otra extrasistema o contextual, que se vincula con el macrosistema o exosistema constituido por la sociedad en la cual operan el Estado, por una parte, y los diversos sistemas sociales constituidos por las organizaciones de salud, sean estatales, no estatales que de alguna manera tienen injerencia en el tratamiento de las afectaciones en la salud de la empleada.

El fenómeno en si del acoso en este caso, genera un costo en cadena no sólo para el microsistema sino para el macrosistema. Todo ello por la derivación de daños subsecuentes.

\subsubsection{El costo económico para las organizaciones que lo implementan como una práctica de despido}

Las empresas que nacen con la mera intención de acumulación de capital emprenden rutinas agresivas para el medio ambiente y las personas. Este tipo de organizaciones olvida el capital humano, y a pesar de que no son instituciones malévolas como un campo de concentración, se sirven de interacciones deshumanizadas. 
Estas estructuras de negocio nacen y perecen rápidamente dejando secuelas nefastas como es el aprendizaje asimilado por aquellos que formaron parte de las mismas.

La visión cortoplacista y el éxito efímero de las mismas encandila a otros emprendimientos llevándolos a emular su estilo, de ese modo a largo plazo empiezan acarrear consecuencias materiales graves como son las demandas por acoso que suelen ser más costosas porque se demandan rubros que la encarecen y el más caro de todos su imagen.

Un dicho común entre algunos empresarios locales es "se aprende perdiendo" y es así que para sobrevivir las empresas deben pensar como se proyectan en el tiempo. En la creencia superficial de que "no hay nada seguro" las instituciones se embarcan en situaciones absurdas como los de contratar a "duros" para enderezar el rumbo. Esto es una idea mágica. El aprendizaje es un cambio relativamente permanente consecuencia de la repetición que se logra en un desarrollo saludable y empático. En la actualidad a nadie le queda duda que el desarrollo de un niño saludable, requiere de afecto, límites y un ámbito donde pueda manifestarse y expresarse. De ese mismo modo, crecen las empresas sanas, miran el hoy para un porvenir mejor, es decir, su enfoque es amplio.

De ahí que un ideal donde deben desarrollarse estos ideales sean los organismos públicos, que deben prevenir y legislar para crear políticas maduras de gestión y administración.

En definitiva, el costo de estos despidos en términos económicos son caros y prolongados sometiendo la imagen organizacional a valoraciones negativas y de largo plazo.

\subsection{En lo jurídico}

Además de los costos derivados en lo psicológico y en lo económico existe un costo tangible e intangible en lo jurídico que afecta tanto al microsistema como al macrosistema. El intangible es el producido por el desgaste y tiempo que se invierte en la resolución judicial de estos litigios, amén de una organización y funcionamiento judicial sumamente lento (véase la duración de los juicios en los casos expuestos en el anexo I); e igualmente, el costo 
económico derivado para el microsistema y el Estado en las áreas intervinientes.

Para obrar del mismo modo, resultar necesario componer un marco axiológico y normativo que importe legislar sobre la base de una concepción que derive en una legislación ajustada a la realidad, entendiendo que el Estado en su condición de persona jurídica o ideal distinta de las personas de sus habitantes y de quienes las gobiernan es el encargado de velar con carácter soberano por el bienestar de todas las personas. Para ello le cabe la función de regulación de las conductas orientándolas a fines (función de política), cumpliendo así una función consecuente y esencial: la integración de la sociedad para que impere el bienestar general.

En forma particular la reglamentación surgida a través del derecho, ajusta esa función en materia laboral, a la de regular la convivencia entre el empleador y empleado en relación a un sistema social acorde con valores insertos en el mismo concepto de desarrollo humano.

El tratamiento del tema de referencia conduce a sostener que no hay reglamentación o regulación jurídica que no se sustente en un marco axiológico.

La sistema jurídico, nace de esa psicología que se entrama en el valor de relación, que pertenece a los intangibles y es de carácter emocional, por eso la dificultad de cuantificarla. De ahí el conflicto, porque el sistema de reglas que nace de las sucesivas capas de artículo sobre artículo vienen a destiempo de las razones del hombre. Así, el tiempo como valor y modo de cuantificar la eficacia saca a relucir que la letra en su traducción de bit de factor electrónico necesita un nuevo carácter que sustituya y monitoree el antiguo orden que, al entrar en conflicto, no hace más que traducirse como un trastorno psicosocial.

El sistema jurídico, responde a una estructura piramidal (CN.art. 108). En el régimen judicial argentino, la administración de justicia es un poder concurrente de la Nación y de las provincias. En tal sentido, los artículos 5 y 123 de la Constitución Nacional establecen que cada provincia dictará para sí una constitución de acuerdo con los principios, declaraciones y garantías de la ley suprema, "que asegure su administración de justicia". De no quedar 
suficientemente explicitado en la CN son las provincias las que, en las reformas que se avecinan deberán abrir la posibilidad de leyes de protección laboral.

Las provincias deberían legislar a través de normas que contemplen mecanismos de prevención de violencia laboral y garanticen un ejercicio digno y saludable del trabajo y de esta forma, se sustraería al poder judicial de casos sobre maltrato que en definitiva, la sentencia sólo beneficia a la víctima.

Las personas empiezan a segregar su propio orden y entran en conflicto con las viejas reglas, como se puntualizó en el microsistema, que es ese poder disciplinar militarizado que se traduce en normas y reglas estructuradas deben dar a un sistema lógico. De ahí que los sistemas de salud estén perturbados por escapar en su orden administrativo y profesional hacia pautas que se corresponden a otro enfoque histórico de las personas pero, sobre todo, a la psicología que se entrama en las relaciones de poder.

\subsection{En la salud}

Como ha sido tratado en este trabajo, el problema de la agresión laboral que se ha centrado en la mujer empleada, constituye un factor determinante en el deterioro de su salud mental y física.

En esta tesis los aspectos que se señalan, tanto en sus causas como en sus efectos - económicos-jurídicos e incluso políticos- se subordinan al de la salud y no podría ser de otra manera, porque la preservación de esta debe ser y lo es, el objeto central del Estado.

Se resaltan aquí los efectos de la agresión en lo psíquico por entender que ello no está suficientemente considerado en el tratamiento jurídico de este problema.

Es más se deja planteado se deja planteado en el franco proceso en formación que se ha dado en llamar "desarrollo humano"

\subsection{En la política}

Finalmente las conclusiones concluyen en el rol que debe jugar el rol del Estado moderno en una problemática como la planteada.

No cabe duda que a través de la formulación de políticas de Estado en materia laboral, la conexión del derecho y de la salud deben materializarse en el dictado de leyes más específicas que contemplen y preserven no sólo a la 
mujer empleada, sino que con ello se eviten los perjuicios asociados a la sociedad.

Se están produciendo avances en esta materia con el dictado de ley de la CABA y como el proyecto de ley de la provincia de Mendoza que aún no ha prosperado (ver anexo 11.2.1)

Esto se constituye en definitiva en un reclamo universal de justicia

\section{BIBLIOGRAFÍA}

Abajo Olivares, F. J. (2004). Mobbing. Acoso psicológico en ámbito laboral. Buenos Aires : Ediciones De Palma.

Agulló Tomás, M. S., Rodríguez Suárez, J., \& Agulló Tomás, E. (2005). Métodos de la investigación psicosocial. En F. Palací Descals, Psicología de la Organización (págs. 35-71). Madrid: Pearson Educación, S.A.

Alcántara, S. M., \& Hernández Sánchez, A. (2005). NECESIDAD DE ESTUDIOS Y LEGISLACIÓN SOBRE FACTORES PSICOSOCIALES. Rev Cubana Salud Pública , 31(4):338-44.

Alemany, C. (1997). Psicoterapia experiencial y focusing. Bilbao: Desclée De Brouwer.

Álvarez Chávez, V. H. (2009). Mobbin, estrés y acoso en el ámbito del trabajo. 1a. ed. Buenos Aires: García Alonso .

AMERICAN PSYCHIATRIC ASSOCIATION. (1995). DSM IV, "Manual Diagnóstico y Estadistico de los Trastornos Mentales. Cuarta edición". Barcelona: Editorial Masson. Barcelona.

Ardila, R. (1979). Psicología del aprendizaje. México: Siglo veintiuno editores, S.A.

Bandura, A. (1982). Teoría del aprendizaje social. Madrid: Espasa Calpe S.A.

Baron, R. A. (1996). Psicología. México: Prentice-Hall Hispanoamérica, S.A.

Bateson, G. (1991). Pasos hacia una ecología de la mente. Buenos Aires: LUMEN.

Bermejo, F., Rivera, J., Trincado, R., Javier, O., \& José, M. (1998). Aspectos sociales y familiares del paciente con demencia. Madrid: Diaz de Santos. 
Bronfenbrenner, U. (2002). La ecología del desarrollo humano: experimentos en entornos naturales y diseñados. Barcelona: Paidos.

Bunge, M. (2005). Diccionario de filosofia. México. Tercera edición en español: Siglo XXI Editores.

Bunge, M. (2004). Emergencia y convergencia. Novedad cualitativa y unidad de conocimiento. Barcelona: Gedisa, S.A.

Bustelo, G. (16 de 11 de 2008). Crecieron $112 \%$ los juicios por enfermedades laborales en un año. Recuperado el 16 de 11 de 2008, de Diario "Los Andes": http://www.losandes.com.ar/notas/2008/11/16/sociedad-392772.asp

Cabrera Salceda, M. E. (10 de 2008). Infomed Red de Salud de Cuba. Recuperado el 2011 de 08 de 05, de Discapacidad visual: http://www.sld.cu/galerias/pdf/sitios/rehabilitacion-arte/discapacidad_visual.pdf

Castro Solano, A. (2004). Aplicaciones del MIPS en los ámbitos laboral, educativo y médico. Buenos Aires: Editorial Paidos.

Chavez, Á. (2009). Mobbing, estrés y acoso en el ámbito del trabajo. Buenos Aires: García Alonso.

Chistine, G. D. (1998). El control de tu estado de ánimo. España: Ediciones Paidos.

Cia, A. (1999). Estrategias para superar el Pánico y la Agarofobia. Manual práctico de recursos terapéuticos. Buenos Aires: El Ateneo.

Coon, D. (1999). Psicología. Exploración y aplicación. México: Editores Thomson Internacional.

Cortés, A. (2001). Los conflictos éticos de las personas mayores a través de la teoría cultural-ecológica. Revista Multidisciplinar de Gerontología , 109-115.

Costa Lieste, E. (1988). El estado explotador. Cultura política y cultura económica: el caso argentino. Buenos Aires: Libreria Editorial Tesis.

De Santis, G. (2001). Introducción a la economía. Estructura y problemas de la economía Argentina. La Plata: Instituto de Estudios Fiscales y Económicos (I.E.F.E).

Del Popolo, J. H. (1996). Psicología Judicial. Mendoza: Ediciones Juridicas Cuyo.

Denegri, M. (2007). Introducción a la psicología económica. Bogota: PSICOM Editores. 
Dessors, D., \& Marie-Pierre, G.-B. (1998). Organización del trabajo y salud. De la psicopatología a la psicodinámica del trabajo. Buenos Aires: LUMEN.

Diaz, V. L. (2007). Acoso laboral: ¿un flagelo negociable? Buenos Aires: Editorial Quorum.

Durkheim, E. (2008). El Suicidio.6ta. Edición. Madrid: Akal.

Enesco, I. (s.f.). Diccionario critico de las ciencias sociales. Recuperado el 2010 de 05 de 25, de Cognición social: http://www.ucm.es/info/eurotheo/diccionario/C/cognicion_social.pdf

Exposito, F. (2011). Violencia de Género. Mente y Cerebro , 20-25.

FACTS. (2007). Agencia Europea para la Seguridad y la Salud en el Trabajo. Recuperado el 2007 de Octubre de 20, de Prevención de la violencia contra el personal del sector de la enseñanza: http://agency.osha.eu.int

Farrés Cavagnaro, J. (1981). La teoría general de los sistemas. Universidad del Aconcagua , 5-12.

Fernández-Abascal Enrique G., V. A. (1997). Psicología General: Motivación y emocion. España: Editorial Ramon Areces.

Flores, F. (1999). Manual de Costos. Buenos Aires: Aplicación tributaria S.A.

Focault, M. (2003). El poder psiquiátrico. Buenos Aires: Fondo de cultura económica Argentina.

Freud, S. ((1920 [reimpreso, 1997])). Psicología de las masas y análisis del yo. Buenos Aires: Paidos.

Fromm, E. (2004). Anatomía de la destructividad humana. México: Editores Siglo XXI de España. Decimo novena edición en español.

Fromm, E. (1997). EL MIEDO A LA LIBERTAD. Buenos Aires: PAIDOS.

Fromm, E. (1987). La revolución de la esperanza. Argentina: Biblioteca Actual.

Garbie, A. (2002). Economía para prinicipiantes. Buenos Aires: Era Naciente S.R.L.

García Sánchez, F. A. (2001). Conceptualización del desarrollo y la Atención Temprana desde las diferentes escuelas psicológicas. Conceptualización del desarrollo y la Atención (págs. 29-30). Madrid: http://www.sld.cu/galerias/pdf/sitios/rehabilitaciontemprana/modelo_ecologico_y_modelo_integral_de_intervencion.pdf. 
Ghersi, C. A. (2006). Cuantificación económica. Daño moral y psicológico. Buenos Aires: Editorial Astrea.

Gil Rodriguez, E. P., \& Irma, L. A. (2007). La violencia de género. Feminismo. Barcelona: UOC.

Gil-Monte, P. y. (1997). Desgaste psíquico en el trabajo: el sindrome de quemarse. Madrid: Editorial Síntesis.

González de Rivera Revuelta, J. L., \& Rodriguez Abuín, M. J. (2005). Cuestionario de estrategias de acoso en el trabajo. El LIPT-60. Madrid: Editorial EOS.

Hall, E. (2003). La dimensión oculta. Vigesimoprimera edición. México: Siglo XXI. Editores.

Hernández Sampieri, R., Collado, C. F., \& Baptista Lucio, P. (1997). METODOLOGÍA DELA INVESTIGACIÓN. México : MCGRAW-HILL.

Hernandez, M. (s.f.). MOBBING Y DERECHOS HUMANOS. Recuperado el 13 de Octubre de 2008, de EL KAROSHI: http://usuarios.lycos.es/mobbinglat/Karoshi.htm

Hirigoyen, M.-F. (2001). El acoso moral en el trabajo: distinguir lo verdadero de lo falso. Barcelona: Paidos Contextos.

Houdé, O., Kayser, D., Koenig, O., Proust, J., \& Francois, R. (2003). Diccionario de Ciencias Cognitivas. Neurociencias, psicología, inteligencia artificial, lingüistica y filosofía. Buenos Aires: Amorrortu.

Huxley, A. (1947). Ciencia, libertad y paz. Buenos Aires: Editorial Sudamericana.

Katon, W., \& Schulberg, H. (1992). Epidemiology of depression in primare care. Gen Hosp Psychiatry , 14: 237-47.

Lamagrande, M. (2004). El intangible salud mental. Mendoza: Consejo profesional de Ciencias Económicas.

Lamagrande, M. (2000). El Síndrome de Burnout en el personal municipal. Mendoza, Argenti: Tesis - Universidad del Aconcagua.

Lamagrande, M. M. (Mayo del 2006). El acoso laboral (mobbing) y el perjuicio institucional. Revista del Consejo Profesional de Ciencias Económicas, 30.

Lega, L., Vicente, C., \& Ellis, A. (1997). Teoría y práctica de la terapia racional emotivo - conductual. México: Siglo XXI editores S.A. 
Leibovich de Figueroa, N. y. (2006). Evaluación psicológica del estrés por inestabilidad laboral. Buenos Aires. Argentina: Paidos.

Mac Donald, A. F. (2008). Mobbing. Acoso moral en el derecho del trabajo. Buenos Aires: Editorial Cathedra Jurídica.

Marianetti, J. E., Mejia, O., \& Moles, P. (2001). La pericia psicológica. Mendoza: Ediciones Juridicas de Cuyo.

Martin, A. (2006). Moobing. Acoso Moral y psicológico en las relaciones laborales. Buenos Aires: Induvio Editora.

Millon, T. (1995). MIPS (INVENTARIO MILLON DE ESTILOS DE PERSONALIDAD). Buenos Aires: PAIDOS.

Miralles, J. (18 de 07 de 2007). El síndrome de la rana hervida. Recuperado el 05 de 10 de 2009, de Espacio de libertad: http://www.espaciodelibertad.net/index2.php?option=com_content\&do_pdf $=1 \&$ id $=44$

Myers, D. G. (1997). Psicología social. México: McGraw-Hill.

Naciones Unidas. Asamblea General. (20 de Diciembre de 1993). Declaración sobre la eliminación de la violencia contra la mujer. Recuperado el 16 de Mayo de 2010, de Resolución de la Asamblea General 48/104: http://www.unhchr.ch/huridocda/huridoca.nsf/(symbol)/a.res.48.104.sp?opend ocument

NASA. (13 de 10 de 2010). La gravedad duele (pero hace bien). Recuperado el 2010 de 11 de 2010, de La gravedad duele (pero hace bien): http://ciencia.nasa.gov/science-at-nasa/2001/ast02aug_1/

OMS, ORGANIZACIÓN MUNDIAL DE LA SALUD. (1995). CLASIFICACIÓN ESTADÍSTICA INTERNACIONAL DE ENFERMEDADES Y PROBLEMAS RELACIONADOS CON LA SALUD (CIE-10). Organización Mundial de la Salud.

Organización Mundial de la Salud-OMS. (07 de 04 de 1947). CONSTITUCIÓN DE LA ORGANIZACIÓN MUNDIAL DE LA SALUD. Recuperado el 2010 de 10 de 31, de http://apps.who.int/gb/bd/PDF/bd47/SP/constitucion-sp.pdf

Ovejero, B. (2006). El mobbing o acoso psicológico en el trabajo: Una perspectiva psicosocial. Revista de Psicología del Trabajo y de las Organizaciones, 101-121. 
Palací Descals, F., Agulló Tomás, E., Agulló Tomás, M. S., Alonso del Amo, E., Gomez Benabéu, A. M., Lisbona Bañuelos, A., y otros. (2005). Psicología de la Organización. Madrid: Pearson Educación, S.A.

Peralta Gómez, M. C. (2006). Manifestaciones del acoso laboral, mobbing y síntomas asociados al estrés postraumático: Estudio de caso. Psicología desde el Caribe. Universidad del Norte. No 17, 1-26.

Petri, H., \& Govern, J. (2006). Motivación. Teoría, investigación y aplicaciones. Buenos Aires: Thomson.

QUINTIN, O. (1999). Guía sobre el estrés relacionado con el trabajo ¿La «sal de la vida» 0 el «beso de la muerte»? Recuperado el 30 de 06 de 2010, de Universidad complutense de Madrid: http://www.ucm.es/info/seas/estres_lab/informes/Informe\%20europeo\%20Estr es\%20Laboral.pdf

Real Academia Española. (2001). DICCIONARIO DE LA LENGUA ESPAÑOLA Vigésima segunda edición. Recuperado el 2010, de DICCIONARIO DE LA LENGUA ESPAÑOLA - Vigésima segunda edición : http://www.rae.es

Roschild, M. (10 de 03 de 1996). Bionomía: La economía como ecosistema. Recuperado el 15 de 03 de 1997, de The Bionomics Institute: http://www.bionomics.org

Rubinstein, S. J. (2005). Código de tablas de incapacidades laborales. Buenos Aires: Lexis Nexos.

Sánchez, F. A. (29-30 de Noviembre de 2001). XI Reunión Interdisciplinar sobre Poblaciones de Alto Riesgo de Deficiencias. Factores emocionales del desarrollo temprano y modelos conceptuales en la intervención temprana. Recuperado el 17 de Mayo de 2010, de Modelo Ecológico-Modelo Integral de Intervención en atención temprana: http://www.sld.cu/galerias/pdf/sitios/rehabilitaciontemprana/modelo_ecologico_y_modelo_integral_de_intervencion.pdf

Schoderbek, C., Schoderbek, P., \& Kefalas, A. (1984). Sistemas Administrativos. Buenos Aires: El Ateneo.

Shaffer, D. (2002). Desarrollo Social y de la Personalidad. Esoaña: Thomson.

Shaffer, D. (2000). Psicología del desarrollo. Infancia y adolescencia. Quinta edición. México: International Thomson Editores S.A.

Stingo, N. R., Toro Martinez, E., Espiño, G., \& Zazzi, M. C. (2006). Diccionario de Psiquiatria y psicología forense. Buenos Aires: Editorial Polemos. 
Súñer, M. (2002). Maltratadas. Hablan las supervivientes. Barcelonaa: Plaza Janés.

Talarico Pinto, I. (2003). Pericia psicológica. Buenos Aires: Ediciones La Rocca.

Torrico Linares, E., Santín Vilariño, C., Andrés Villas, M., Menéndez ÁlvarezDardet, S., \& López López, M. J. (2002). El modelo ecológico de Bronfrenbrenner como marco teórico de la Psicooncología. anales de psicología. Servicio de Publicaciones de la Universidad de Murcia , 49-59.

Toselli, C. A., Grassis, P. M., \& Ferrer, J. I. (2007). Violencia en las relaciones laborales (Discriminación - mobbing - acoso sexual. Córdoba, Argentina: Ediciones Alveroni.

Valenzuela, M. E. (2003). Mujeres, Pobreza y Mercado de Trabajo. Argentina y Paraguay. Recuperado el 16 de Mayo de 2010, de Santiago, OIT, Proyecto "Incorporación de la Dimensión de Género: http://www.oit.org.ar/documentos/oitmujerespobreza.pdf

WIKIECONOMIA. (02 de Julio de 2009). Los sistemas económicos. Recuperado el 18 de 11 de 2010, de Concepto general: http://www.webeconomia.com/mediawiki/index.php?title=Los_sistemas_econ\% C3\%B3micos

Wikipedia. (20 de 02 de 2011). Albert Bandura. Recuperado el 03 de 04 de 2011, de Albert Bandura: http://es.wikipedia.org/wiki/Albert_Bandura

wikipedia. (04 de Marzo de 2011). Émile Durkheim. Recuperado el 06 de Marzo de 2011, de Émile Durkheim: http://es.wikipedia.org/wiki/\%C3\%89mile_Durkheim

Wikipedia. (11 de 02 de 2011). Gregory Bateson. Recuperado el 03 de 04 de 2011, de Gregory Bateson: http://es.wikipedia.org/wiki/Gregory_Bateson

wikipedia. (07 de Junio de 2010). Heinz Leymann. Recuperado el 06 de Marzo de 2011, de Heinz Leymann: http://es.wikipedia.org/wiki/Heinz_Leymann

Wikipedia. (04 de 02 de 2011). Justicia. Recuperado el 06 de 02 de 2011, de Justicia: http://es.wikipedia.org/wiki/Justicia

Wikipedia. (10 de Octubre de 2010). Siglo XVII. Recuperado el 27 de 10 de 2010, de Siglo XVII: http://es.wikipedia.org/wiki/Siglo_XVII

Wikipedia. (28 de 10 de 2010). Siglo XVIII. Recuperado el 2010 de 10 de 28, de Siglo XVIII: http://es.wikipedia.org/wiki/Siglo_XVIII 
wikipedia. (05 de 02 de 2011). Victor Hugo. Recuperado el 15 de 02 de 2011, de Victor Hugo: http://es.wikipedia.org/wiki/Victor_Hugo

Wikipedia. (23 de Septiembre de 2010). Zeitgeist. Recuperado el 2010 de Septiembre de 28, de Zeitgeist: http://es.wikipedia.org/wiki/Zeitgeist

Zula. (09 de 02 de 2009). ARGENPRESS.INFO. Violencia de género: 207 mujeres asesinadas en el 2008 págs. http://www.argenpress.info/2009/02/violencia-de-genero-207-mujeres.html. 


\section{ANEXOS}

\subsection{Presentación de los casos}

\subsubsection{CASO 1}

1. Fecha de inicio: $26 / 07 / 2005$

2. Fecha de resolución: $23 / 07 / 2007$

3. No Expediente: $33 . X X X$

4. Nombre: B. C. R. C/ L. M. ART Y OT P/ E. A.

5. Estado: Resuelto.

6. Resolución: Convenio

Fojas: 325 Expte no 33.XXX caratulados " B. C. R. C/ L. M. ART Y OT P/ E. A.".- MENDOZA, 23 de agosto de 2007.- Y VISTOS: Estos autos intitulados, convenio celebrado a fs.321 teniendo en cuenta asimismo la labor profesional desarrollada, dictamen del Sr. Fiscal de Cámaras y lo dispuesto por los arts. 40 y 108 del C.P.L. y 83 y 84 del C.P.C. y ley 3522 y 3641 y dec. modif.1304 el Tribunal, RESUELVE: 1)-HOMOLOGAR en cuanto hubiere lugar por derecho, el acuerdo conciliatorio obrante a fs.321 por la suma de PESOS NOVENTA $\mathbf{Y}$ CUATRO MIL SEISCIENTOS SESENTA (\$94.660).- 2)-Costas a cargo de JUMBO RETAIL S.A. y LA MERIDIONAL COMPAÑÍA ARGENTINA DE SEGUROS S.A. en la proporción establecida en el convenio de autos. 3)- Impónesele a las demandadas en la proporción convenida, la obligación de abonar los gastos del juicio que ascienden a la suma de $\mathbf{\$ 3 . 8 8 1 , 0 6}$ (PESOS TRES MIL OCHOCIENTOS OCHENTA Y UNO CON 06/100) correspondientes a $\$ 1.893,20$ (PESOS MIL OCHOCIENTOS NOVENTA Y TRES CON 20/100) a tasa de Justicia, $\$ 1.893,20$ (PESOS MIL OCHOCIEN-TOS NOVENTA Y TRES CON 20/100) aportes ley 5059, y $\$ 94,66$ (PESOS NOVENTA Y CUATRO CON 66/100) a Derecho Fijo, Colegio de Abogados, debiendo acompañar los comprobantes respectivos.- 4)Notifíquese el punto $3^{\circ}$ a la Dirección General de Rentas, Colegio de Abogados y Caja Forense.- 5)-Regular los honorarios profesionales de los Sres. Peritos Médica Psiquiatra L. P. A., Psicóloga M. L. F. y Contador R. D. D. en la suma de pesos TRES MIL SETECIENTOS OCHENTA Y SEIS CON 40/100 $(\$ 3.786,40)$ a cada uno.- 6) Póngase en conocimiento de la A.F.I.P. de la resolución recaída en las presentes actuaciones a los fines de lo prescripto por la Ley 25.345, en caso de corresponder.- COPIESE. REGISTRESE.

Total $=\$ 109905$ (Acuerdo: $\$ 94.660 ;$ gastos del juicio: $\$ 3.881,06$; honorarios profesionales: $\mathbf{\$ 3 . 7 8 6 , 4 0 * 3 = \$ 1 1 3 5 8 )}+$ afip

\section{Hechos y exordio}




\section{III.- OBJETO:}

Que en el carácter invocado y siguiendo expresas instrucciones de $\mathrm{mi}$ mandante vengo a interponer formal demanda ordinaria contra de_, con domicilio en $\quad$ a, por la suma de PESOS TREINTA Y CINCO MIL TRESCIENTOS CUARENTA Y CINCO CON 50/100 (\$35.345,50), en concepto prestaciones dinerarias de pago mensual por Incapacidad Laboral Transitoria (ILT), por Incapacidad Laboral Permanente Parcial Provisoria (I.P.P. Provisoria) hasta la fecha del reclamo, debiendo adicionarse los meses correspondientes hasta la fecha de la incapacidad definitiva de la actora, y por Indemnización por Incapacidad derivada de enfermedad profesional conforme la Ley 24.557 ; y contra de

por la suma de PESOS NOVENTA Y CUATRO MIL CIENTO VEINTISIETE (\$94.127)en concepto de indemnización integral por daños y perjuicios por enfermedad ocasionada como consecuencia del trabajo (deducidos los importes por los que pueda ser condenada más la suma de PESOS SIETE MIL SEISCIENTOS SESENTA Y CINCO CON 12/100 $(\$ 7.665,12)$ correspondiente a los rubros indemnizatorios y remuneratorios que proceden por el despido indirecto de la actora o lo que en mas o en menos resulte de la prueba a rendirse en autos o que estime justo el Tribunal, con mas sus intereses legales y costas del proceso.

ACTORA.

\section{VIII- RECLAMO POR EL DESPIDO INDIRECTO DE LA}

A) Antecedentes.

Como ya expresáramos al inicio de esta demanda, mi mandantc ingresó a trabajar para la demandada en septiembre del 2001 desempeñándose como cajera. La empresa acordó pagarle a la actora un sueldo básico de $\$ 450$. Su jornada laboral inicialmente era desde las $7 \mathrm{hs}$ de la mañana hasta las $16 \mathrm{hs}$. de la tarde de lunes a domingo, teniendo 2 francos rotativos. Luego la empresa le cambió el horario a mi mandante siendo el mismo de $9 \mathrm{hs}$ de la mañana a $18 \mathrm{hs}$.

También dijimos oportunamente que al momento del ingreso de la actora a la empresa se encontraba apta para realizar cualquier tipo de tareas, no presentado ningún tipo de dolencia. Mi mandante era persona sana fisica y emocionalmente. Inclusive a parte de trabajar se encontraba finalizando sus estudios universitarios de Analista de Sistemas de Información y Analista programadora en el Instituto de Educación Superior Manuel Belgrano. Ya realizamos el relato de los hechos que originaron la enfermedad profesional que padece la actora y que fuera denunciada ante su empleador.

Sin embargo, en fecha 08/03/05 mi mandante recibió la carta documento N 029584011 AR remitida por su empleadora, cuyo texto decía: "Vencido el término del art. 211 Ley 20.744 comunicámosle extinción de contrato de trabajo conforme normas citadas".

La actora respondió a Cenconsud S.A. mediante Telegrama Ley N23.789 CD No034171698 AR, de fecha 11/03/05, que expresaba: "Rechazo vuestra carta documento $N^{\circ} 029584011$ AR de fecha 8 de marzo del 2005 por improcedente, ya que la reserva del puesto de trabajo por el término de un año es un régimen propio de las enfermedades inculpables, y yo denuncié en fecha 30 de agosto del 2004 mediante telegrama $N^{\circ} 021871087$ padecer una enfermedad profesional. Frente a ello los emplazo en el término de 48 hs a dejar sin efecto tal medida injustificada, bajo apercibimiento de considerar tal despido injustificado y por vuestra exclusiva culpa, con derecho a reclamar el pago de preaviso, indemnización por antigüedad, vacaciones proporcionales, y la doble indemnización del art.16 de la Ley 25.56I".

La empresa respondió mediante CD N0033561768 AR, de fecha 15/03/05 diciendo:"Rechazamos TCL 60815000 por inexacto e improcedente. Su denuncia por supuesta enfermedad profesional fue en tiempo y forma rechazada por la respectiva A.R.T. Reiteramos nuestra comunicación por CD No029584011 AR".

Mi mandante contestó a mediante Telegrama Ley No23.789 CDNo 038781329 AR, de fecha 18/03/05, en los siguientes términos: "Atento a vuestra falta de respuesta a mi emplazamiento de fecha 11 de marzo del 2005 realizado mediante telegrama $N^{\circ} C D N^{\circ} 034171698 \mathrm{AR}$, me considero en situación de despido sin justa causa y por vuestra exclusiva culpa. Asimismo los emplazo por el término de 48 hs. a hacer efectivo el pago de preaviso, indemnización por antigüedad, vacaciones proporcionales y la doble indemnización del art. 16 de la Ley 25.561 así como la entrega de mi certificado de servicios".

$\mathrm{La}$ actora no recibió ninguna respuesta al emplazamiento realizado a la empleadora de hacer efectivo el pago-de los rubros que proceden por despido indirecto (art.246 LCT) y sin justa causa, por lo que corresponde hacer lugar a la demanda en todas sus partes. 


\begin{abstract}
V.- HECHOS:
A) Antecedentes

1-Ingreso a la empresa en plenitud física y mental.

en el mes de septiembre del 2001 desempeñándose como cajera

trabajar para la demandada

Al momento del ingreso de la actora se encontraba apta para realizar cualquier tipo de tareas, no presentado ningún tipo de dolencia, mi mandante era persona sana física y emocionalmente. Inclusive a parte de trabajar se encontraba finalizando sus estudios universitarios de Analista de sistemas de Información y Analista programadora en el Instituto de Educación Superior Manuel Belgrano
\end{abstract} desencadenante de sus dolencias.

2-Trato humillante a la actora por supuesta falla de caja como

Las cajeras de

están sometidas a presiones inhumanas, no pudiendo durante su horario de trabajo ir al baño o tomar agua. El trato que le daba el jefe de caja a mi mandante siempre fue irrespetuoso y desconsiderado. Pero a continuación relataré el hecho que agravó la situación de acoso psicológico vivenciado por mi mandante y que terminó por sumir a la actora en un cuadro depresivo

8. Monto reclamado: $137.137,62$

9. Diagnóstico inicial, herramientas utilizadas, grado de incapacidad (de parte):

Fecha primer informe (28.06.2004)

Herramientas utilizadas. MINI MENTAL (evaluación de funciones cognitivas), PRIME - MD (Psicopatológico), MIPS (personalidad), BENDER (neurológico), H.T.P (Rasgos generales - proyectivo), RAIVEN (inteligencia) y entrevistas.

Diagnostico: "La Stra. C. R. B. según los criterios del DSM IV presenta un Trastorno Adaptativo con ansiedad y estado de ánimo depresivo (309.24) como característica esencial el desarrollo de síntomas emocionales y comportamentales en respuesta a un factor estresante psicosocial identificable (Presión laboral por parte de su jefe), que luego se agrava frente a la imposibilidad de seguir con su empleo y con ello enfrentarse a la paradoja de que para que cese el primer estresor debe elegir otro de quizás mayor cronicidad dado su actual estado de salud el desempleo.

La entrevistada tiene la vivencia de irrealidad al entrar en disonancia sus valores versus la acusación de su jefe de haber robado y el posterior maltrato recibido. A partir de este momento la condición psíquica de la entrevistada comienza a deteriorarse por su imposibilidad de establecer vínculos con otras personas por su estado de ánimo y sus crisis de angustia. Es importante destacar que la paciente ha tenido un fuerte correlato somático entre los que se halla trastornos en su ciclo menstrual, trastorno del sueño, dolorimientos, mareos que resultan incapacitantes en la vida de una persona y resultan comunes en situaciones donde la persona es sometida a un estresor crónico.

Aparece como comórbido Crisis de Angustia (300.21) la característica esencial es por la aparición súbita de síntomas de aprensión acompañados habitualmente de sensación de pérdida de control. 
Este desarrollo psicopatológico impacta de modo directo en el desempeño de la paciente el cual se manifiesta en un trastorno para llevar a cabo su vida"

Grado de incapacidad: Según anexo Decreto 659/96 de la ley 24557. -10\%- REACCIÓN VIVENCIAL ANORMAL NEURÓTICA (R.V.A.N.) CON MANIFESTACIÓN PSICOSOMATICA

Fecha informe reevaluación (01.07.2005)

Pruebas utilizadas. Escala de depresión de Beck, MBI (estrés crónico laboral), MINI MENTAL (evaluación de funciones cognitivas), PRIME - MD (Psicopatológico), BENDER (neurológico), H.T.P (Rasgos generales - proyectivo) y entrevistas.

Diagnostico: "Esta reevaluación es indicada ya que alrededor del 50\% de los pacientes que no siguen correctamente las indicaciones del médico o terapeuta tiene recaídas (Meichenbaum y Turk, 1991). La situación particular de la paciente $C$. B. es aún más delicada al no poder la misma continuar su tratamiento debido a dificultades económicas. Esto la empujo a suspender su tratamiento psiquiátrico y psicológico con aquellos profesionales con los que ha establecido rapport.

Esta situación de indefensión provoca emociones intensas contra aquellas personas que identifica como agresores y que se desempeñan en la empresa EASY en la cual la paciente era empleada.

En el caso de la Sita. C. B. el ser acosada psicológicamente por su jefe con la acusación de "ladrona", la llevo a desarrollar una reacción adaptativa con ansiedad y angustia. Síntomas que eran correlativos al estresor específico (la presión laboral). Al no poder completar el tratamiento indicado en el primer informe psicodiagnóstico redactado el 28.06.2004 la paciente desarrollo una Fobia especifica. Tipo situacional a su ámbito laboral (EASY).

La característica esencial de la fobia específica en la paciente C. B. es un miedo intenso y persistente a la situación claramente discernible y circunscripto (ámbito laboral: XXX). La exposición al estímulo fóbico provoca una respuesta inmediata de ansiedad. Esta respuesta en la paciente toma la forma de una crisis de angustia situacional. La paciente reconoce este temor es excesivo e irracional lo que la lleva a volver angustiarse por tener conciencia del asunto. Esta situación lleva a evitar por todos los medios el estímulo fóbico al vivenciar la experiencia de contacto con terror.

Debido a estas circunstancias de evitación, miedo y ansiedad de anticipación en relación con el estímulo fóbico la paciente visto interferido gravemente sus actividades cotidianas y sobre todo aquellas relacionadas al empleo. Al sentirse incapacitada de retomar una actividad laboral. 
Se presenta como comórbida la situación de tener que dar cuenta una y otra vez de su trastorno a fin de obtener una respuesta y una solución es vivenciado por la misma como un nueva victimización tal como ocurre con aquellas mujeres que han sido abusadas sexualmente y deben comparecer por su condición. Lo cual evoluciona en la paciente en un episodio depresivo mayor episodio único, moderado. Que tiene como característica en la paciente C. B. en una pérdida de interés o placer en casi todas sus actividades. Y que es acompañado de los siguientes síntomas falta del sueño; falta de energía; sentimientos de infravaloración; dificultad para pensar, concentrarse o tomar decisiones.

Al momento de la entrevista no se presentan otros trastornos psicopatológicos. Como se deja aclarado en la evaluación multiaxial no se registra ningún trastorno de personalidad."

Grado de incapacidad: baremo de la Dirección de Reconocimientos médicos de la provincia de Buenos Aires 3.2.3. Neurosis fóbica severa: $35 \%$ y 3.9.2. Depresión moderada: $10 \%$.

\section{Diagnóstico psicológico y grado de incapacidad (peritado)}

\subsection{Fecha informe: (09.08.2006)}

\subsection{Pruebas utilizadas}

Técnicas administradas: Entrevista, Bender, H.T.P., desiderativo, autobiografía y Rorschach.

\subsection{Diagnóstico}

1) De acuerdo con las técnicas administradas se puede percibir que la paciente estaría atravesando por una patología de tipo fóbica, aunque presenta rasgos depresivos en su personalidad.

Se pudo apreciar una marcada restricción de la motivación que provoca una marcada lentitud en el funcionamiento mental (Bradipsiquia), acompañado de conductas de tipo inhibidas y evitativas. También se observó una baja autoestima, tinte pesimista en la ideación y autocrítica negativa cuando se usa la introspección. También se observó dificultades en las relaciones interpersonales, escasas atribuciones emocionales a los objetos, aumento de la sobrecarga interna. Tendencia a sesgar sus preceptos y a recoger los datos del entorno con grandes interferencias de sus necesidades personales. Tendencia a simplificar excesivamente el campo estimular y sus percepciones, y con ello evitaría el procesamiento de las emociones y dejarse invadir por los afectos ( síntomas fóbicos). Tiene un estilo sobresimplificador que reflejaría la presencia de una actitud defensiva, resguardada y evitativa, muy caracteristica de la patología fóbica.

Se pudo apreciar también, una tendencia hacia la constricción afectiva, un freno a la expresión emocional, de manera que el malestar psíquico lo interioriza y con ello aumenta su malestar interno (rasgos depresivos de personalidad), dicha tendencia no depende de las fluctuaciones situacionales, sino que lleva un largo tiempo actuando en ella, de tipo crónico. Esto se acompaña de una tendencia a restringir las vivencias emocionales extremadamente dolorosas que pueden llegar a producir un impacto perturbador en casi todo su funcionamiento afectivo.

2) La actora presentaria una personalidad premórbida, debido a que se trataria de una estructura de personalidad de tipo depresivo, con mucha debilidad en sus recursos para hacer frente a situaciones conflictivas para su psiquismo. 
3) a) Se observó sintomatologia de tipo fóbico y depresiva. Se observaron signos de ansiedad sobre todo al intentar indagar acerca de lo sucedido en la empresa Se observó un temor irracional y excesivo ante la pronunciación de la persona de la empresa con la cual refiere haber tenido el incidente. Dicho nombre no podía ser pronunciado por la paciente. La exposición ante dicho estímulo provocó mucha ansiedad en la actora acompañado de mucha angustia con crisis de llanto, dificultad para respirar, constricción en el pecho, sensación de ahogo, aumento de las palpitaciones cardiacas, sintomatologia muy similar a una crisis de angustia situacional. Además la refiere tener sintomas de evitación con respecto a todo lo referente a la empresa

Los comportamientos de evitación, la anticipación ansiosa, el malestar provocado por la situación temida interfieren acusadamente con la rutina normal de la persona, como así también con las relaciones laborales (o académicas) o sociales, y provocan malestar clínicamente significativo.

b) De acuerdo a las técnicas administradas a la actora se pudo apreciar que presentaría un personalidad débil y con escasos recursos, por lo cual ante una situación de estrés importante como la padecida por la misma podria haber sido ente cuasal de la sintomatología fóbica padecida por la actora.

c) De acuerdo con las técnicas administradas (entrevista y autobiografía) solamente se vieron afectados los vínculos con su familia al comenzar los trastornos luego de tener el incidente, donde refiere no poder ir sola a ningún lado, habian fluctuaciones en su estado de ánimo, estaba malhumorada. Sí se encontraron afectadas las relaciones interpersonales, ya que no pudo volver a desempeñarse laboralmente en ningún lado.

d) La actora necesita apoyo psicofarmacológico en su tratamiento de rehabilitación, sobre todo para disminuir sus sintomas de ansiedad.

e) De acuerdo a lo que se pudo observar en las técnicas administradas, la actora no se encontraba en condiciones de ser reinsertada en su lugar de trabajo en la época del despido indirecto, debido a que el agente fobígeno era la empresa anteriormente citada y esto provocaba la aparición de una crisis de angustia. En la actualidad no se encuentra aún en condiciones de afrontar una actividad laboral debido a que su sintomatología fóbica y depresiva aún subsisten.

f) Pareciera tener un correlato somático debido a que la actora refiere presentar: mucho estrés psicológico, palpitaciones, sudoración en las manos, tenía trastornos del sueño (insomnio y pesadillas), trastonos de su humor y de su estado de ánimo, crisis de llanto.

\subsection{Grado de incapacidad}

h) De acuerdo al Decreto 659/96 de la Ley 24.557, la

presenta un $20 \%$ de incapacidad tendiendo en cuenta que el rango va de un $0 \%$ a un $30 \%$ como máximo. Por lo que el desempeño laboral de la paciente se encuentra deteriorado. Este porcentaje se funda en la parte psiquíatrica del decreto

citado correspondiente a la clasificación de Reacción Vivencial Anormal Neurótica R.V.A.N. con manifestaciones depresivas. Definición: Requieren un tratamiento más intensivo. Hay remisión de los sintomas más agudos antes de los 3 meses. Se verifican trastornos de memoria y concentración durante el examen psiquiátrico y psicodiagnóstico. Las formas de presentación sön desde la depresión, las crisis conversivas, las crisis de pánico ( = crisis de angustia), fobias y obsesiones. Son reversibles con el tratamiento psicofarmacológico y psicoterapéutico adecuado. Al an̂o continúan los controles.

\subsection{Diagnóstico psiquiátrico y grado de incapacidad (peritado) Fecha informe: (02.10.2006)}




\subsection{Pruebas utilizadas}

\section{DIAGNÓSTICO}

Se le realizaron entrevistas clínicas psiquiátrico, test de Bender y HTP y se solicito autobiografía.

\subsection{Diagnóstico y grado de incapacidad}

De lo expresado y del estudio minucioso del expediente se concluye que la

con una reacción vivencial anorinal meurotica con ha con mormal neurótica con manifestación fóbica y depresiva GRADO III. Esta patología se gradúa de grado cero a grado cuatro, en el grado III "Requieren un tratamiento mas intensivo. Hay remisión de los sintomas mas agudos ante de los tres neses se verifican trastornos de memoria y concentración durante el examen psiquiátrico y psicodiagnóstico. La forma de presentacián van desde la depresión, las crisis conversivas, las crisis de pánico, fobias y obsesiones. Son reversibles con el tratamiento psicofarmacológico y psicoterapéutico adecuado. La incapacidad es del $20 \%$ "El porcentaje se funda en la descripción específica citada en la parte de Psiquiatría del decreto $659 / 96$ de la ley $24557^{\prime \prime}$

\section{Reevaluación actual resultado:}

\begin{tabular}{|c|c|c|c|c|c|c|}
\hline Somatizaciones & 36 & total de & 48 & 3,00 & T75 & SOM \\
\hline Obsesiones y compulsiones & 28 & total de & 40 & 2,80 & T63 & OBS \\
\hline Sensitividad interpersonal & 16 & total de & 36 & 1,78 & T63 & S.I. \\
\hline Depresión & 37 & total de & 52 & 2,85 & T63 & DEP \\
\hline Ansiedad & 27 & total de & 40 & 2,70 & T63 & ANS \\
\hline Hostilidad & 15 & total de & 28 & 2,14 & T63 & HOS \\
\hline Ansiedad fóbica & 12 & total de & 24 & 2,00 & T63 & FOB \\
\hline Ideación paranoide & 9 & total de & 24 & 1,50 & T50 & PAR \\
\hline Psicoticismo & 11 & total de & 40 & 1,10 & T63 & PSIC \\
\hline Items adicionales & 22 & total de & 28 & 3,14 & & \\
\hline INDICE DE SEVERIDAD GLOBAL (IGS) & 2,37 & T63 & & & & \\
\hline INDICE DE MALESTAR SINTOMATICO POSITIVO (IMSP) & 2,48 & T50 & & & & \\
\hline TOTAL DE SINTOMAS POSITIVOS (STP) & 86 & T75 & & Impresión & Negativa & \\
\hline ITEMS ADICIONALES & \multicolumn{5}{|c|}{ Puntaje $\quad$ Significativo } & \\
\hline 5: Falta de interes en las relaciones sexuales & & 2 & & NO & & \\
\hline 19: Poco apetito & & 3 & & SI & & \\
\hline 44: Problemas para dormir & & 4 & & SI & & \\
\hline 59: Pensamientos acerca de la muerte o el morirse & & 2 & & NO & & \\
\hline 60: Comer en exceso & & 4 & & SI & & \\
\hline 64: Despertarse muy temprano. & & 4 & & SI & & \\
\hline 66: Sueño intranquilo. & & 4 & & SI & & \\
\hline 89: Sentimientos de culpa. & & 1 & & NO & & \\
\hline ITEMS CRITICOS & $\mathbf{P u}$ & Intaje & Sigr & ificativo & & \\
\hline 15: Pensar en quitarme la vida & & 2 & & NO & & \\
\hline 16. Escuchar voces que otras personas no oyen & & 2 & & NO & & \\
\hline 54. Perder las esperanzas en el futuro & & 3 & & SI & & \\
\hline
\end{tabular}

12. Conclusión del caso: Se verificó coincidencia de la resolución del juez respecto al daño psíquico y moral producido, atendiendo a un deterioro traducido en un porcentaje que se mantuvo en forma crónica relevado por evaluadores imparciales (peritos) y en la post evaluación, se constató que la empleada evaluada aun no podía insertarse y presentaba sintomatología psicopatológica. 


\subsubsection{CASO 2}

1. Fecha de inicio: $15 / 12 / 2006$

2. Fecha de resolución (1): $08 / 09 / 2010$

3. Fecha de resolución (2): $S / \mathrm{N}^{39}$

4. No Expediente: $35 . X X X$

5. Nombre: C. C. F. C/ L. S. ART S.A. Y OT. P. E. A.

6. Estado: Resuelto contra ART y sigue en litigio contra M. S. R.

7. Resolución (1): Convenio.

8. Resolución (2): En juicio.

Expte: 35.629 Fojas: 506 EXPTE N035.629 CARATULADOS: C. C. F. C/ L. S. ART S.A. Y OT. P. E. A. MENDOZA 08 de setiembre de 2.010 Y VISTOS: Estos autos intitulados, convenio celebrado a fs.493 teniendo en cuenta asimismo la labor profesional desarrollada, dictamen del Sr. Fiscal de Cámaras y lo dispuesto por los arts. 40 y 108 del C.P.L ley 3522, 3641, dec. modif.1304, debemos destacar que el convenio de autos no es por la totalidad que se ha reclamado sino que se ha hecho reserva de continuar contra la codemandada: M. D. S. R., por lo tanto, lo que se está transando es única y exclusivamente el porcentaje que le corresponde solventar a la A.R.T., quedando incólume el derecho de reclamar a las resultas del juicio el resto del reclamo. A lo que el Tribunal, RESUELVE: 1) HOMOLOGAR en cuanto hubiere lugar por derecho, el acuerdo conciliatorio obrante a fs. 493 con la codemandada L. S. A.R.T. S.A., por la suma de PESOS VEINTE MIL (\$20.000).- 2) Costas a cargo de LA SEGUNDA ART. S.A. y respecto al convenio celebrado en autos por este codemandado y respecto de los honorarios profesionales según lo convenido en autos.- 3) Escíndase la presente causa y continúe la misma según su estado respecto del codemandado: M. D. S. R.- 4) Impónesele a la codemandada L. S. A.R.T. S.A. la obligación de abonar los gastos del juicio que ascienden a la suma de \$820.-(PESOS OCHOCIENTOS VEINTE) correspondientes \$400-(PESOS CUATOCIENTOS) a tasa de Justicia, $\$ 400$.-(PESOS CUATROCIENTOS) aportes ley 5059 y \$20.-(PESOS VEINTE) a Derecho Fijo del Colegio de Abogados, de acuerdo al convenio celebrado, debiendo acompañar los comprobantes respectivos y dejando a salvo el reclamo contra M. D. S. R.- 5)- Diferir la regulación de los honorarios profesionales de los peritos intervinientes para la etapa procesal oportuna 6)- Emplazar en el término de TRES DÍAS a cumplir con el pago ordenado.- 7) Notifíquese el punto $4^{\circ}$ a la Dirección General de Rentas, Colegio de Abogados y Caja Forense. 8)- Póngase en conocimiento de la A.F.I.P. de la resolución recaída en las presentes actuaciones a los fines de lo prescripto por la Ley 25.345, en caso de corresponder. 9)- Agregar para el bibliorato de Sentencia, Copia Certificada del Convenio homologado precedentemente, extracción que queda a cargo de las partes.-

Total = \$20820* (Acuerdo: \$20.000; gastos del juicio: \$820; honorarios profesionales: sin resolución*) + afip

\section{Hechos y exordio}

39 Sin Novedad 


\section{III.- OBJETO:}

A) Que en el carácter invocado y siguiendo expresas instrucciones de mi mandante, vengo a interponer formal demanda ordinaria en contra de

, con domicilio en calle

por la suma de PESOS

DIECINUEVE MIL DOSCIENTOS SESENTA Y SIETE (\$19.267-), en concepto de Indemnización por Incapacidad derivada de enfermedad profesional conforme la Ley 24.557, o lo que en mas o en menos resulte de la prueba a rendirse en autos o que estime justo el Tribunal, con mas sus intereses legales y costas del proceso; y en contra de

, con domicilio

PESOS SETENTA Y SEIS MIL CUATROCIENTOS SESENTA (\$ 76.460) en concepto de indemnización integral por daños y perjuicios por enfermedad ocasionada como consecuencia del trabajo (deducidos en su caso los importes por los que pueda ser condenada

).o lo que en mas o en menos resulte de la prueba a rendirse en autos o que estime justo el Tribunal, con mas sus intereses legales y costas del proceso.

b) Asimismo, siguiendo expresas instrucciones de mi mandante, y conforme lo autoriza el art. 32 del Código Procesal Laboral, mi parte viene a solicitar a V.E. que previo a correr traslado de la demanda, disponga la MEDIDA CAUTELAR solicitada en la parte final del presente escrito, ordenando a 1 , depositar mensualmente a la orden de estos autos, la suma de dinero que V.E. estime prudencial, a fin de solventar los gastos' necesarios para que la actora continúe los tratamientos farmacológicos, psicológicos y psiquiátricos con los profesionales que la estaban atendiendo hasta antes de la interrupción de los mismos por falta de recursos económicos. En subsidio, para el supuesto que V.E. considere que no procede contra la A.R.T. la medida cautelar, solicitamos se haga efectiva la misma en contra de su empleador

psicológico.

i) - Encuadre del caso en la figura de mobbing o acoso

La situación vivida por mi mandante en su lugar de trabajo se denomina mobbing o acoso psicológico, figura de la que ha comenzado a hablarse en nuestra doctrina a raiz de su inclusión en leyes laborales europeas.

Desde hace unos años, tanto en Europa como en E.E.U.U. se está difundiendo un fenómeno de patología laboral denominado "mobbing". Psicólogos, psiquiatras, médicos laborales, sociólogos y más en general aquellos que se ocupan de estudiar el sistema jerárquico existente en las fábricas y oficinas, sus reflejos sobre la vida de los trabajadores, han individualizado algunas graves y reiteradas distorsiones, capaces de incidir pesadamente sobre la salud individual.

Se trata de un fenómeno conocido como "mobbing". El término proveniente de la lengua inglesa, y del verbo "to mob"(atacar) y de la etología, se refiere al comportamiento - de algunos animales, que generalmente acosan minuciosamente a un miembro del grupo para alejarlo. A menudo en la empresas o en la administración pública ocurre algo similar, de manera que el trabajador es objeto repetido de abuso por parte de sus superiores, y en particular víctima de prácticas destinadas a aislarlo del ambiente de trabajo y en los casos más graves de repelerlo, prácticas cuyo efecto es atacar gravemente el equilibrio psíquico del trabajador, disminuyendo su capacidad laboral y la confianza en sí mismo y provocándole catástrofe emotiva, depresión y en los peores casos el suicidio(Revista Derecho del Trabajo-2000 B, Jurisprudencia Extranjera, Contrato de Trabajo, Extinción, despido, mobbing, discriminación, Sentencia del Tribunal de Turin, Italia, 16/11/1999-Erriquez, Giacomina c. Eergom Materie Plastiche s.p.a., pag.2013).

Por otra parte, la estrategia de persecución del mobbing puede provenir de sujetos diversos. El mobber (o sujeto activo del mobbing) puede ser tanto uno o más colegas del trabajador que pretenden excluirlo por resultarles incómodo(v.g. por su alto nivel de eficiencia), como, desde luego la misma empresa, en cuyo caso el fenómeno es conocido como bossing o mobbing vertical. En estos casos la presión psicológica de la empresa está acompañada por los side mobbers (colegas, superiores, gerentes de recursos humanos, etc ) que aún no participando directamente del acoso, por razones de posicionamiento dentro de las preferencias jerárquicas, excluyen o evitan todo tipo de solidaridad con la víctima.

Como es de esperarse, el mobbing desemboca generalmente en una renuncia del trabajador a su empleo, no sin antes haber sufrido, seguramente, patologias psíquicas y psicosomáticas. 
El "mobbing" aparece muchas veces en forma directa y en otras oportunidades lo hace a través de una estrategia de hostigamiento sutil. A manera de ejemplo mencionaremos:

1) El aislamiento físico del trabajador; 2) El hostigamiento y la falta de comunicación; 3) La propagación de conceptos peyorativos; 4) La asignación de tareas humillantes o vergonzantes; 5) Tratar de darle al trabajador tareas de muy dificil realización; 6) Retar al trabajador en público, agraviarlo o menoscabar su imagen; 7) Cambiarle constantemente y en forma arbitraria las modalidades de trabajo; 8) Hacerlo trabajar en condiciones antiergonómicas, sabiendo que ello constituye un daño para el trabajador; 9) Acusar y culpar injustamente al trabajador por hechos que le son ajenos; 10) Utilizar técnicas para sabotear las tareas del trabajador; 11) Molestar e interrumpir los trabajos que intenta realizar el trabajador;12) Insultar y ridiculizar al trabajador; 13) intentar agredir fisicamente al trabajador;14) Impedir que el trabajador utilice los sanitarios para sus necesidades fisiológicas.

\section{dan en este caso}

\section{La mayoría de las características enunciadas del mobbing se}

En países, como España la jurisprudencia ha acogido ampliamente la figura del mobbing ordenando a la empleadora responder por los daños y perjuicios ocasionados al trabajador, pese a que el acoso moral no se encuentra legislado en el citado país.

Citamos a continuación un importante antecedente de la jurisprudencia española en un caso de acoso psicológico en el ámbito de la administración pública. La U.G.T, publicó el 20 de enero del 2004, un fallo del Juzgado de lo Contencioso -Administrativo $\mathrm{N}^{0} 2$ de Zaragoza, España, por el que un funcionario del municipio de dicha ciudad, al haber sido objeto de acoso laboral exige se dé por finiquitada dicha situación. La importancia de esta sentencia radica en que es pionera en el reconocimiento del acoso laboral en la Administración pública española.

Los antecedentes del caso se remontan al año 2000 en el que el Ayuntamiento de Zaragoza convocó a concurso de méritos para la provisión de plazas, entre ellas la de jefe de compras del Servicio de Conservación de Infraestructuras. El recurrente participó de dicho concurso y finalmente obtuvo la plaza de la que tomó posesión el 14 de enero del 2002 sin que este hecho supusiera su efectiva incorporación al puesto de trabajo obtenido ya que éste se hallaba ocupado provisionalmente por otro funcionario cuyo destino era topográfico. No conforme con impedirle la efectiva ocupación del puesto de trabajo asignado por concurso de méritos, sus superiores más inmediatos llevaron a cabo todo tipo de argucias para impedir el desempeño de las funciones propias de jefe de compras. Mantuvieron al funcionario provisional, asignándole al reclamante otro despacho y funciones, además de darle órdenes contradictorias; lo que le ocasionó una baja o licencia por depresión. El fallo termina otorgando derecho al recurrente ha considerarlo incurso en acoso laboral en el Ayuntamiento, exigiéndole a este último que haga cesar tal actitud.(www.ugt.es(mobbing/za20.htlm) fallo citado por CAMPEOTO, Claudio, "Mobbing. Creencias y ficciones",Rev. Derecho del Trabajo, Año LXVI-número III, marzo 2006, pág.321) Existen grandes similitudes entre las caracteristicas de la instrumentación del mobbing en el caso del Ayuntamiento de Zaragoza y el mobbing sufrido por mi mandante en el ámbito de la

de ahí la importancia de un precedente judicial de la doctrina extranjera.

Molina Navarrete ha expresado que los tribunales Supremos de los países comunitarios, como los tribunales comunitarios, -por ejemplo, la sentencia del 23/01/2002 del Tribunal de lera instancia de la Unión Europea, cuyo análisis puede encontrarse en RMTAS $\mathrm{n}^{\circ} 37$ español, disponible en la página web http://www.mtas. es-, ya han aportado ilustrativos pronunciamientos favorables a un uso intenso del derecho para erradicar de las Administraciones Públicas el ejercicio del poder en forma de crueles e intolerables formas de violencia psicológica (Conf. MOLINA NAVARRETE, Cristóbal, "La lucha por el derecho de los empleados públicos a un ambiente laboral libre de acoso o asedio moral": una mirada europea e hispanoamericana, Revista JA, 2005-II, Número Especial de Mobbing, pag. 41 ).

De lo expuesto surge claramente que las dolencias sufridas por la actora fueron consecuencia directa de las tareas realizadas para su empleador,

Al respecto es importante señalar que tanto la A.R.T. como su empleador incumplieron con las obligaciones impuestas por la Ley de Riesgos del Trabajo como por la Ley de Higiene y Seguridad en el Trabajo, deiándola desamparada sin ningún tipo de prestación, teniendo en cuenta la dificultad económica de la actora (tiene 4 hijos menores) de solventar los gastos de tratamiento psiquiátrico y medicamento recetados que podían aliviar su malestar psíquico que lo limita en el desenvolvimiento de una vida normal, todo lo cual produjo además un agravamiento de su enfermedad. 


\section{VI. - DAÑOS SUFRIDOS POR LA ACTORA:}

Conforme el informe psicológico expedido por el Lic. Mario Lamagrande (acompañado en autos) de fecha 10/04/06, las dolencias sufridas por la actora son:

Diagnóstico Clínico: "La paciente según los criterios del DSM IV presenta un trastorno Adapatativo con ansiedad y estado de ánimo depresivo (309.24).

La característica esencial del trastorno adaptativo en la entrevistada es el desarrollo de síntomas emocionales y comportamentales en respuesta a un estresor psicosocial identificable: acoso psicológico. Cito a modo ejemplo de la paciente:

1."mi encargada no me asigna ninguna tarea y cuando lo hace son tareas sin sentido o degradantes, por ejemplo: controlar planillas telefónicas por abecederario y las mismas por números telefónicos, limpiar muebles o cambiar vitrinas de lugar, o limpiar cuadros siendo mi cargo administrativo ". Esta es una situación de violencia recurrente y sostenida en el tiempo, la paciente lleva afrontándola más de tres meses. Como se observa el poder se ejerce en forma abusiva; que en la dinámica de la violencia (víctima)vs. (victimario/entorno/organización), es siempre la víctima quien está en inferioridad de condiciones, al menos respecto a la organización...."

"2.Cito textual a la paciente:"Mi jefa me critica ante mis compañeros, logrando que éstos no me hablen prácticamente y si lo hacen, comienzan a tener problemas, lo que les facilita que también me traten mal o no tengan ningún trato conmigo, debido a que muchos son contratados y por temor a perder su trabajo consienten sus caprichos. Provocándome de esta manera un aislamiento total. Hace correr falsos rumores, me menosprecia delante de los demás, con los cuales ríe, hace chistes, pero a mí me ignora en el grupo totalmente, $y$ si hablo es como si no lo hiciera nadie".

Este "proceso" de acoso se conoce como mobbing y es definido como:"el fenómeno en el que una persona o un grupo de personas ejerce una violencia psicológica extrema, de forma sistemática y recurrente-al menos una vez a la semana-durahté un tiempo prolongado -más de seis meses-sobre otra persona en el lugar de trabajo, con la finalidad de destruir las redes de comunicación de la víctima o víctimas, destruir su reputación, perturbar el ejercicio de sus labores y lograr que finalmente esa persona o personas terminen abandonando el trabajo"

Más adelante el Lic. Mario Lamagrande expresa:"Por lo expuesto puede observarse que el cuadro aparece de un modo reactivo y se ha sostenido por más de tres meses frente a la presentación del estresor (Criterio A). La expresión clínica de la reacción ha consistido en la paciente en un deterioro significativo de su actividad social y laboral (Criterio B) "siento miedo y tristeza, sin ganas de ir a trabajar, lo cual me produce un enorme esfuerzo diario hacerlo sabiendo que debo encontrarme a diario con su mal humor, su mal carácter, sus malos gestos y expresiones hacia mi. Esto me lleva a que me refugie en total silencio y aislamiento, haciendo mis horas interminables (....) Me siento triste y hasta he perdido el buen humor y risa, siendo en mi una cualidad personal ". Los síntomas de la paciente no son la expresión de una reacción de duelo (Criterio D). Estos síntomas pueden persistir por un período prolongado de tiempo (más de 6 meses) en respuesta a la posibilidad de perder su empleo ".

Luego el Lic. Lamagrande, citando a Rubenstein, señala: "Es importante como destaca este experto que la persona al exponer su situación no exista una "intención finalista". Esto es claro a lo largo de las entrevistas donde la intención de la entrevistada es volver a restablecer su vida y sobre todo el plano laboral que a ella le permite manejarse en su vida. De alli que la misma acepte la recomendación de complementar el tratamiento psicológico con un tratamiento psiquiátrico pues en la actualidad el cuadro tiene un fuerte correlato somático."

"Los síntomas depresivos asociados que se manifiestas en su casancio, desgano, ideas de culpa, dolorimientos, falta de concentración. Cito textual a la paciente: He llegado a tirarme en la cama sin la mera voluntad de hacer nada o levantarme. Todo esto me provoca que se desestabilice mi salud, teniendo serios problemas estomacales y otros por lo cual me veo obligada a estar en constante observación y tratamiento".

El psicólogo que venimos citando agrega más adelante: “Aparece como comórbido al cuadro principal la crisis de angustia (ataques de pánico) (300.21) que tienen como característica esencial la aparición súbita de síntomas de aprensión, miedo intenso, opresión cordial, mareos, visión borrosa que se acompaña de la sensación de pérdida de control cuadros que deben ser compensados en muchos casos médicamente y que provocan en la paciente la sensación de irrealidad lo que le impide llevar a cabo su vida normalmente. Estos síntomas no resultan coincidentes con la personalidad premórbida de la paciente y son coincidentes con los síntomas físicos v nsicosomáticos producidos por el acoso psicologico o mobbing" 
En el psicodiagnóstico al que venimos refiriéndonos, se dice con relación a la incapacidad de la actora, "Al momento de la entrevista no se presentan otros trastornos psicopatológicos. Como se deja aclarado en la evaluación multiaxial no se registra ningún trastorno de personalidad".

Como conclusión el Lic. Mario Lamagrande dice que "...los trastornos presentados por la paciente son según el manual internacional de trastornos mentales DSMIV:

\begin{tabular}{|l|l|l|l|}
\hline \multicolumn{2}{|l|}{ Diagnóstico } & Nombre DSM-IV \\
\hline 309 & 28 & & Trastorno adapatativo con ansiedad y estado de ánimo depresivo \\
\hline 300 & 21 & & Crisis de Angustia (panik attack) \\
\hline
\end{tabular}

"Según el código de tablas de incapacidades laborales del Dr. Santiago Rubinstein (cuarta edición ampliada y actualizada) la paciente presenta:

REACCIÓN VIVENCIAL ANORMAL GRADO III (30\%) por presentar en su cuadro manifestaciones psíquicas y somáticas lo que requiere un tratamiento más intensivo psicológico $y$ psiquiátrico".

Por lo tanto, de lo expuesto y del informe psicodiágnostico citado, surge claramente que las dolencias sufridas por la actora son consecuencia directa del trabajo, por lo que corresponde condenar a la ART al pago de las prestaciones dispuestas por la LRT, y al empleador, como deudor del deber de seguridad a su personal (normas de raigambre Constitucional y Supra constitucional como lo son los Tratados Internacionales incorporados a nuestra Carta Magna después de la Reforma de 1994 y la normativa que emana de la Ley 19.587, denominada Ley Básica de Higiene y. Seguridad en el Trabajo.) por la reparación integral por los daños y perjuicios por enfermedad ocasionada como consecuencia del trabajo, y en aplicación de lo dispuesto por el art. 1113 del Código Civil, de la que resulta que el principal es responsable en forma inexcusable de los daños causados nor sus denendientes a terceros.

13. Monto reclamado: contra A.R.T: $\$ 19.267$ y M. D. S. R. $\$ 76.460$ (total: $\$ 96.420)$

\subsection{Diagnóstico inicial, herramientas utilizadas, grado de incapacidad (de parte):}

\subsection{Fecha de informe (10.04.2006)}

13.3. Herramientas utilizadas. MINI MENTAL (evaluación de funciones cognitivas), Inventario de Beck (evaluación depresión), PRIME - MD (Psicopatológico), MIPS (personalidad), BENDER (neurológico), H.T.P (Rasgos generales - proyectivo), MBI (estrés laboral), RAIVEN (inteligencia) y entrevistas.

13.4. Diagnostico: "La paciente C. C. F. según los criterios del DSM IV presenta un Trastorno Adaptativo con ansiedad y estado de ánimo depresivo (309.24)

13.5. Grado de incapacidad: "Según el código de tablas de incapacidades laborales del Dr. Santiago Rubinstein (cuarta edición ampliada y actualizada) la paciente presenta: Reacción vivencial anormal grado III (30 \%) por presentar en su cuadro manifestaciones psíquicas y somáticas lo que requiere un tratamiento más intensivo psicológico y psiquiátrico"

\subsection{Diagnóstico psicológico y grado de incapacidad (peritado)}

\subsection{Fecha informe: $(01.04 .2009)$}




\subsection{Pruebas utilizadas}

Que en legal tiempo y forma, vengo a presentar el me pericial, el cual se ha llevado a cabo a través de las entes técnicas: Entrevista Clínica, Inventario fásico de la Personalidad de Minnesota (MMPI- 2), el que se siguen los criterios de corrección propuestos Brenlla, Diuk y Maristany (1992) para poblaciones uiátricas argentinas, PRIME MD (Evaluación spatológica estructurada según normas del DSM IV), entario para la Depresión de Beck y Cuestionario leros para la detección de Mobbing.

\subsection{Diagnóstico}

No se considera que la reevaluación constante de la a pudiese agudizar se Episodio Depresivo Mayor, ya esto no sucedió en el peritaje en cuestión.

Es muy probable que al momento de la entrevista la ra haya presentado mejorías como consecuencia de los mientos recibidos y el haber estado alejada de su iente laboral, sin embargo se consideran estos son mos debido al tiempo transcurrido del hecho mático y el momento actual en que tuvo parte la uación, con las consecuencias que la misma tuvo lugar uanto a diagnósticos y estados psicológicos. Es decir, ctora todavía reviste de profundos estados y rasgos lógicos. Con respecto a las mejorías, éstas pueden r que ver con los estados ligados a ataques de pánico se daban en los momentos en que trabajaba.

En referencia a la PARTE A de la pericia psicológica, no la llevado a cabo debido a que el abogado de la parte ra me hizo saber de su decisión de anularla.

\subsection{Grado de incapacidad}


No da

\subsection{Diagnóstico psiquiátrico y grado de incapacidad (peritado)}

\subsection{Fecha informe: (22.08.2008)}

\subsection{Pruebas utilizadas}

a. ENTREVISTAS MEDICO-PSIQUIÁTRICAS con la Sra.

b. ELABORACIÓN DE LA HISTORIA CLÍNICA.

c. ESTUDIO PSICOLOGICO basado en los siguientes tests para investigación de la personalidad:

1. TEST DE LA FIGURA HUMANA (MACHOVER) y HTP.

2. TEST DE LA FAMILIA.

3. TEST DESIDERATIVO.

4. TEST DE MURRAY (TAT).

5. AUTOBIOGRAFÍA. Realizada en forma incompleta.

d. ANALISIS EN GABINETE acerca de los datos obtenidos a partir de las entrevistas y el Estudio Psicológico.

e. ESTUDIO DE LA DOCUMENTACIÓN EXISTENTE EN EL EXPEDIENTE.

\subsection{Diagnóstico y grado de incapacidad}

DIAGNÓSTICO Y PRONÓSTICO: Esta pericia coincide con el diagnóstico elaborado por los profesionales tratantes y por el

Evidentemente, el cuadro no reviste la misma intensidad que en épocas en que la actora atravesaba los conflictos laborales, o en la etapa inmediata a la pérdida del trabajo.

En conclusión: La actora presenta, en la actualidad, un "TRASTORNO ADAPTATIVO MIXTO, CON ANSIEDAD Y ESTADO

DE ÁNIMO DEPRESIVO. Éste cuadro se saracteriza con los códigos F43.22 y [309.28] de la CLASIFICACIÓN ESTADISTICA INTERNACIONAL DE ENFERMEDADES Y PROBLEMAS DE SALUD (CIE-10), y el "MANUAL DIAGNÓSTICO Y ESTADISTICO DE LOS TRASTORNOS MENTALES DSM-IV. Barcelona, Ed. Masson, 1995. (Pág. 639-643). 
De acuerdo con el BAREMO de la Dirección de Reconocimientos Médicos de la Provincia de Buenos Aires y la Tabla de Valoración de Disminución de la capacidad laborativa básica para la actividad civil de los aspirantes a ingresar como agentes civiles del Ejército Argentino, la actora padece una "SINDROME DEPRE- SIVO-ANSIOSO REACTIVO EN PERIODO DE ESTADO, LEVE". Este diagnóstico, de acuerdo con la tabla aludida, amerita un porcentaje de incapacidad del $10 \%$ al $20 \%$. (Rubinstein, Santiago. Código de Tablas de Incapacidades Laborativas. Buenos Aires. Ed. Depalma.1996. Pág. 57 y 239).

De acuerdo con la GUÍA PARA LA EVALUACIÓN DE LAS INCAPACIDADES DEL CEREBRO, de la Asociación Médica Americana. USA, el cuadro debe diagnosticarse como "ALTERACIÓN EMOCIONAL LEVE A MODERADA EN SITUACIONES DE STRESS POCO HABITUALES". A este trastorno le corresponde, de acuerdo con la tabla mencionada, un porcentaje de incapacidad entre $5 \%$ y $15 \%$. (Texto citado. Pág 261).

De acuerdo con el BAREMO NACIONAL. LEY 24.557, a la "REACCIÓN VIVENCIAL ANORMAL NEURÓTICA FÓBICO-DEPRESIVA, GRADO II", le corresponde un porcentaje de incapacidad de 10\%. Texto citado. Pág. 400-401).

Por otro lado, Vázquez Vialard recomienda que "debe determinarse el grado de incapacidad en función de la persona que la sufre, y no por simple aplicación en forma abstracta de determinadas tablas. (Accidentes y enfermedades del trabajo". Bs. Aires. Hammurabi. 1986. Pág. 325).

\section{Reevaluación actual:}

\begin{tabular}{|c|c|c|c|c|c|c|}
\hline Somatizaciones & 25 & total de & 48 & 2,08 & T63 & SOM \\
\hline Obsesiones y compulsiones & 33 & total de & 40 & 3,30 & T63 & OBS \\
\hline Sensitividad interpersonal & 19 & total de & 36 & 2,11 & T63 & S.I. \\
\hline Depresión & 38 & total de & 52 & 2,92 & T63 & DEP \\
\hline Ansiedad & 21 & total de & 40 & 2,10 & T63 & ANS \\
\hline Hostilidad & 13 & total de & 28 & 1,86 & T63 & HOS \\
\hline Ansiedad fóbica & 11 & total de & 24 & 1,83 & T63 & FOB \\
\hline Ideación paranoide & 13 & total de & 24 & 2,17 & T63 & PAR \\
\hline Psicoticismo & 26 & total de & 40 & 2,60 & T75 & PSIC \\
\hline Items adicionales & 23 & total de & 28 & 3,29 & & \\
\hline INDICE DE SEVERIDAD GLOBAL (IGS) & 2,47 & T75 & & & & \\
\hline INDICE DE MALESTAR SINTOMATICO POSITIVO (IMSP) & 2,81 & T63 & & & & \\
\hline TOTAL DE SINTOMAS POSITIVOS (STP) & 79 & T75 & & Impresión I & Negativa & \\
\hline ITEMS ADICIONALES & \multicolumn{5}{|c|}{ Puntaje $\quad$ Significativo } & \\
\hline 5: Falta de interes en las relaciones sexuales & \multicolumn{5}{|c|}{\begin{tabular}{|l|l|}
2 & NO \\
\end{tabular}} & \\
\hline 19: Poco apetito & \multicolumn{5}{|c|}{ SI } & \\
\hline 44: Problemas para dormir & \multicolumn{5}{|c|}{ SI } & \\
\hline 59: Pensamientos acerca de la muerte o el morirse & \multicolumn{5}{|c|}{ SI } & \\
\hline 60: Comer en exceso & \multicolumn{5}{|c|}{ NO } & \\
\hline 64: Despertarse muy temprano. & \multicolumn{5}{|c|}{ SI } & \\
\hline 66: Sueño intranquilo. & \multicolumn{5}{|c|}{ SI } & \\
\hline 89: Sentimientos de culpa. & \multicolumn{5}{|c|}{ SI } & \\
\hline ITEMS CRITICOS & \multicolumn{2}{|c|}{ Puntaje } & \multicolumn{2}{|c|}{ Significativo } & & \\
\hline 15: Pensar en quitarme la vida & & $\mathbf{0}$ & & NO & & \\
\hline 16. Escuchar voces que otras personas no oyen & & $\mathbf{0}$ & & NO & & \\
\hline 54. Perder las esperanzas en el futuro & & 3 & & SI & & \\
\hline
\end{tabular}


15. Conclusión del caso: Se verificó coincidencia de la resolución del juez respecto al daño psíquico y moral producido, atendiendo a un deterioro traducido en un porcentaje que se mantuvo en forma crónica relevado solamente en este caso por la psiquiatra (perito) no así por la psicóloga quien sólo se expide en las consecuencias, en la post evaluación, se constató que la empleada evaluada aun no podía insertarse y presentaba sintomatología psicopatológica.

\subsubsection{CASO 3}

1. Fecha de inicio: $07 / 02 / 2008$

2. Fecha de resolución (1): 25/11/2009

3. Fecha de resolución (2): 08/06/2010

4. $\quad N^{0}$ Expediente: 30171 (en la presentación de caso no va el $N^{\circ}$ )

5. Nombre: L, C. A. C/ L. C. ART SA Y M. R. D. L. P. SA P/ A.

6. Estado: Resuelto

7. Resolución: Acuerdos

Resolución (1) - Fojas: 356. Caratulados L, C. A. C/ L. C. ART SA Y M. R. D. L. P. SA P/ A MENDOZA, 25 de noviembre de 2009.- AUTOS Y VISTOS: Que el art. 15 de la LCT establece que los acuerdos conciliatorios pueden celebrarse tanto con la autoridad judicial como administrativa por lo que formalmente el convenio presentado se ajusta a la normativa citada. Sustancialmente, teniendo en cuenta los términos de la presentación efectuada y los elementos de juicio disponibles, no se advierte que la formulación autocompositiva en estudio importe un menoscabo de las garantías y derechos consagrados como mínimos inderogables por el orden público laboral. Consecuentemente se concluye que en el caso se ha alcanzado una justa composición de los derechos e intereses de las partes por lo que corresponde otorgar la homologación solicitada de conformidad con el dictamen evacuado por la Fiscalía de Cámara y lo dispuesto por los arts 15 y concordantes de la LCT; ARTS 83/85 DEL CPC y art 108 del CPL. LEY 3800 RESUELVE: 10)HOMOLOGAR JUDICIALMENTE el convenio de fs.352 teniéndolo por Ley para las partes.- 2)- EMPLAZASE a la DEMANDADA en el término de DIEZ DIAS para hacer efectivo aportes: art. 16 LEY 5059: \$1400,00 art. 96 LEY 4976 DERECHO FIJO: \$70,00 y en el término de TREINTA DIAS para hacer efectivo art. 297 inc. f) Código Fiscal TASA DE JUSTICIA: $\$ 1400,00$ rigiendo ambos plazos una vez firme la presente resolución, bajo apercibimiento de darle intervención a la Dirección General de Rentas, Caja Forense y Colegio de Abogados a efectos de su percepción en forma compulsiva, los cuales han sido calculados sobre el monto de convenio y a la fecha de la presente resolución. $3^{\circ}$ )- Notifíquese el punto $2^{\circ}$ a la Dirección General de Rentas, Caja Forense y Colegio de Abogados.- 40)- Las costas son a cargo de la DEMANDADA.- 50)- Regular los honorarios profesionales del Perito CONTADOR SRA. E. G. D. G., PERITO MEDICO PSIQUIATRA DRA. L. P. A., en la suma de PESOS TRES MIL QUINIENTOS $\$ 3500,00$ para cada uno de los peritos mencionados y PERITO 
PSICOLOGO LIC. M. S., en la suma de PESOS CIEN (\$100).- $6^{\circ}$ )-La Demandada deberá efectuar los pagos convenidos al accionante en los términos y fechas convenidos en el mismo .- $7^{\circ}$ )- Emplazar a los profesionales no interviniente en el convenio, en el plazo de TRES DIAS para que se expidan sobre las conformidades faltantes, bajo apercibimiento de ley.-

\section{Total (1)=\$ 79990 (Acuerdo: \$70.000; gastos del juicio: \$2890; honorarios profesionales: \$ 7100) + afip}

Resolución (2) - Fojas: 444. Caratulados L, C. A. C/ L. C. ART SA Y M. R. D. L. P. SA P/ A.- MENDOZA, 8 de junio de 2010.- AUTOS Y VISTOS: Que el art. 15 de la LCT establece que los acuerdos conciliatorios pueden celebrarse tanto con la autoridad judicial como administrativa por lo que formalmente el convenio presentado se ajusta a la normativa citada. Sustancialmente, teniendo en cuenta los términos de la presentación efectuada y los elementos de juicio disponibles, no se advierte que la formulación autocompositiva en estudio importe un menoscabo de las garantías y derechos consagrados como mínimos inderogables por el orden público laboral. Consecuentemente se concluye que en el caso se ha alcanzado una justa composición de los derechos e intereses de las partes por lo que corresponde otorgar la homologación solicitada de conformidad con el dictamen evacuado por la Fiscalía de Cámara y lo dispuesto por los arts 15 y concordantes de la LCT; ARTS 83/85 DEL CPC y art 108 del CPL. RESUELVE: $1^{\circ}$ )- HOMOLOGAR JUDICIALMENTE el convenio celebrado entre las partes de fs 425 teniendolo por ley para las partes.- ${ }^{\circ}$ )- Téngase presente el pago efectuado a fs.440/443 por la DEMANDADA de los aportes: art. 16 inc. a) LEY 5059: $\$ 500,00$ art.96 LEY 4976 DERECHO FIJO: $\$ 25,00$ y el pago del art 297 inc. f) Código Fiscal TASA DE JUSTICIA: $\$ 500,00$ los cuales han sido calculados sobre el monto de convenio y a la fecha de la presente resolución.- $3^{\circ}$ )- Notífiquese el punto $2^{\circ}$ a la Dirección General de Rentas, Caja Forense y Colegio de Abogados.- $4^{\circ}$ )- Las COSTAS son a cargo de la DEMANDADA. LA CAJA ART. SA. - 50)-La Demandada deberá efectuar los pagos convenidos al accionante en los términos y fechas convenidos en el mismo.$6^{\circ}$ )- Regular los honorarios profesionales del Perito Contador SR. E. G. G., PERITO MEDICO PSIQUIATRA, DRA. L. P. A., en la suma de pesos SETECIENTOS CINCUENTA \$750. PARA LOS PERITOS MENCIONADOS Y PERITO PSICÓlOGO LIC. M. S., en la suma de pesos CIEN\$100. - $7^{\circ}$ )Emplazar a los profesionales no interviniente en el convenio, en el plazo de TRES DIAS para que se expidan sobre las conformidades faltantes, bajo apercibimiento de ley.- $8^{\circ}$ )-Emplazar a las partes en el término de DIEZ DÍAS a los fines de que proceda al retiro de la documentación oportunamente acompañada por las mismas, bajo apercibimiento de proceder a su archivo por secretaria.- $9^{\circ}$ )DEJESE CONSTANCIA QUE LA PRESENTE RESOLUCIÓN NO IMPLICA AUTORIZACIÓN JUDICIAL PARA IMPUTAR EL MONTO ACORDADO AL FONDO FIDUCIARIO DE ENFERMEDADES PROFESIONALES, EXTREMO ESTE QUE DEBERÁ SER EXPRESAMENTE AUTORIZADO POR LA SUPERINTENDENCIA DE RIESGOS DEL TRABAJO EN SU CARÁCTER DE AUTORIDAD DE CONTRALOR DE LA APLICACIÓN DE LAS SUMAS QUE INTEGRA EL REFERIDO FONDO (DEC. 590/97 MOD. POR EL DEC. 1278/00). COPIESE, REGISTRESE Y NOTIFIQUESE.- 


\section{Total (2)=\$28075 (Acuerdo: \$25.000; gastos del juicio: \$525; honorarios profesionales: \$2650) + afip}

\section{Total $(1) \&(2)=108065$}

\section{Hechos y exordio}

III.- OBJETO:

Que en el carácter invocado y siguiendo expresas instrucciones de mi mandante vengo a interponer formal demanda ordinaria contra de con domicilio en calle por la suma de PESOS CINCUENTA Y SEIS MIL DOCIENTOS CINCUENTA Y CINCO (\$56.255), en concepto de Indemnización por Incapacidad Laboral Permanente Parcial derivada de enfermedad profesional conforme la Ley 24.557 o lo que en mas o en menos resulte de la prueba a rendirse en autos o que estime justo el Tribunal, con mas sus intereses legales y costas del proceso; y contra del empleador

$$
\text { , con domicilio en calle }
$$

Mendoza, por la suma de PESOS OCHENTA Y CUATRO MIL SETECIENTOS CINCUNTA Y UNO (\$84.751) en concepto de DIFERENCIA PROVISORIA por indemnización integral por daños y perjuicios por enfermedad derivada del trabajo, o lo que en mas o en menos resulte de la prueba a rendirse en autos o que estime justo el Tribunal, con mas sus intereses legales y costas del proceso.

B) Lesiones sufridas por la actora:

B.1) Informe psicodiagnóstico:

Conforme el informe psicológico expedido por la Lic. Mario Lamagrande (acompañado en autos) de fecha 06/03/07 las dolencias sufridas por la actora son las siguientes: "Diagnóstico clínico:"La paciente presenta un trastorno mixto con ansiedad y estado de ánimo depresivo (309.28), según los criterios propuestos por el DSM-IV, en el Eje I. La caracteristica esencial del trastorno adaptativo en la entrevistada es el desarrollo de sintomas emocionales y comportamentales en repuesta a un estresante psicosocial identificable, en el caso de la la presión laboral y hostigamiento de carácter crónico. Este subtipo se usa con la paciente pues presenta manifestaciones dominantes donde hay una combinación de ansiedad y depresión.

Aparece como comórbido a la reacción adaptativa mixta. Crisis de angustia, panic attack (300.21), según criterios propuestos por DSM IV, en el Eje I.

Aclaramos que en honor a la brevedad sólo transcribiremos aquellos tramos más importantes del informe del Lic. Lamagrande.

"La caracteristica principal de las crisis de angustia en la paciente fue la aparición aislada y temporal de miedo y malestar de carácter intenso, que se acompaña de sintomas somáticos y cognoscitivos. Las crisis se iniciaron de forma brusca y alcanzaron su. máxima expresión con rápidez (en diez minutos o menos), acompañándose a menudo de una sensación de malestar y en el caso de la paciente de buscar un lugar seguro a fin de manjar los síntomas. El primer episodio fue realizando sus actividades laborales. Los sintomas somáticos y cognoscitivos estuvieron constituidos por palpitaciones, sudoración, temblores, sensación de

En el apartado de Diagnóstico de Personalidad el Lic. Lamagrande ;ostiene:"En resumen la paciente no presenta trastorno de la personalidad al momento de la entrevista". También el informe psicológico agrega un punto importante que el lugar laboral donde se lesempeñaba mi mandante era un espacio condicionado a una cultura machista y eso llevó a la actora i mantenerse en un permanente estado de alerta desde la vestimenta hasta la comunicación para evitar ser mal interpretada.

Luego el informe psicológico tiene un apartado dedicado al síndrome de burn out con relación al cuadro y sintomatología de la actora. En tal sentido al analizar el caso de la actora Lamagrande dice:"Esta situación no mejoró porque la paciente fue sometida al hostigamiento laboral de un modo persistente lo que se trasformó e un estresor crónico lo que la llevó a desmejorar. En este caso vemos que el mobbing y el burn out han funcionado al mismo tiempo dando por resultado el cuadro psicopatológico citado en el diagnóstico clínico". Agrega Lamagrande:"Por último es importante destacar que la entrevistada es una persona que al exponer su situación no tiene una "intención finalista".Esto es claro a lo largo de las entrevistas donde la intención de la Sra. Claudia Lledó es volver a restablecer su vida y sobre todo la actividad laboral". 
En cuanto a la recomendación terapéutica, el citado psicólogo considera que es esencial que la actora inicie un tratamiento intensivo que la lleve a paliar su sintomatología anímica. Esto hace necesario un trabajo psicoterapéutico integrado a un tratamiento psiquiátrico que brinde el soporte farmacológico para evitar recaídas. La estimación de duración del tratamiento se calcula en un promedio de un año a tres dada la comorbilidad del cuadro. Las sesiones tienen un costo estimado entre $\$ 50$ y $\$ 100$ por sesión.

Por lo tanto, de lo expuesto y del informe psicodiágnostico, y certificados expedidos por los médicos psiquiatras y los psicólogos, surge claramente que las dolencias sufridas por la actora son consecuencia directa del trabajo, por lo que corresponde condenar a la ART al pago de las prestaciones dispuestas por la LRT, y al empleador, como deudor del deber de seguridad a su personal (art.75 LCT) por la reparación integral por los daños y perjuicios por enfermedad ocasionada como consecuencia del trabajo, y en aplicación de lo dispuesto por el art. 1113 del Código Civil, de la que resulta que el principal es responsable en forma inexcusable de los daños causados por sus dependientes a terceros, en este caso la sobrecarga de tareas asignadas a la actora y el clima de hostilidad laboral vivenciado en su lugar de trabajo por la

\section{B-2) Informe del Hospital El Sauce con motivo de la Junta} Médica efectuada en el ámbito de la Subsecretaria del Trabajo y Seguridad Social:

Con motivo de la Junta Médica en el ámbito de la Subsecretaria del Trabajo y Seguridad Social solicitada por la empleadora se realizó audiencia en fecha 09/04/07 en el Cuerpo Médico dictamina que se solicitara al Hospital "El Sauce" evaluar a la paciente para informar sobre su estado actual y pronostico.

El informe expedido por el Hospital del Sauce, por la Dra.

médica psiquiatra, dice que después de haber examinado a la actora en fecha 14/06/07, se comprobó que la paciente presentaba sintomatología compatible con el diagnóstico de su médico tratante y su psicólogo, quien realizó completo estudio de psicodiagnóstico en mes de marzo đeI corriente. Agrega que la se encuentra imposibilitada para recibir un tratamiento farmacológico debido a su embarazo de siete semanas. Luego señala dicho informe:"No creemos ético someterla nuevamente a otro proceso de psicodiagnóstico por la proximidad del anterior. realizado. Estamos de acuerdo con el mismo tomado por el Lic. Mario Lamagrande, considerando que la paciente no estaria en condiciones de volver a su función laboral actual si no se modificaran algunos factores que propiciaran una buena evolución. Además, teniendo en cuenta que la situación económica de la paciente la limita para una posible pérdida de trabajo, adherimos al mantenimiento de su licencia y a la continuidad del tratamiento realizado por sus terapeutas ".

En fecha 13/07/07 se reunió nuevamente la Junta Médica, y aunque el médico de la empresa ratificó sus dichos respecto de que la actora se encontraba en condiciones de reintegrarse a su trabajo, el por la Subsecretaria de Trabajo expresó:"Que la paciente fue evaluada en el Hospital El Sauce y de su evaluación surge la ratificación sobre su psicodiagnóstico la restricción para recibir tratamiento farmacológico debido a su embarazo y la imposibilidad de volver a sus tareas habituales en la medida que no se modifiquen algunos factores que propicien su buena evolución"

Vemos que el dictamen de la Junta Médica y el examen del Hospital El Sauce dan cuenta de la relación causal entre el ambiente laboral, la sobrecarga de tareas y la patologia que presenta la actora. 


\section{V.- HECHOS:}

\section{A) Antecedentes}

1-Ingreso a la empresa en plenitud fisica y mental

Mi mandante en fecha 28 de abril de 1998 ingresó a trabajar en a través de una pasantia entre la UNC y la empresa. La pasantia se extendió hasta febrero de 1999 , en que a mi mandante le ofrecieron quedar como efectiva en la empresa, sin embargo ese primer periodo la estuvo a cargo de una empresa tercerizadora de servicios y recién en noviembre de 1999 fue registrada laboralmente en

Desde el primer momento que la actora ingresó a la empresa se desempeñó en el Sector Administrativo del Área Cuyo, a cargo del análisis de cuentas corrientes. En esa época, el horario de trabajo era de lunes a viernes de $8 \mathrm{hs}$. a $17 \mathrm{hs}$, pero mi mandante nunca abandonaba la empresa antes de las 18 o 18:30 hs. La empresa les hacía recuperar la hora del almuerzo a todos sus empleados. Nunca le abonaron las horas extras que realizaba. Por otra parte, no habia ningún sistema de control horario.

Al momento de su ingreso, la actora se encontraba apta para realizar cualquier tarea, no presentado ningún tipo de dolencia. Era una persona sana fisica y emocionalmente al punto que podia realizar simultáneamente su trabajo en la empresa y continuar con sus estudios universitarios de contadora pública.

de embarazo.

2-Licencia sin goce de sueldo por motivos vinculados a su pérdida

En el mes de noviembre del 2000 , la actora solicitó a su empleadora una licencia sin goce de haberes debido a su estado anímico provocado por la pérdida de su segundo embarazo que se produjo en horario y lugar de trabajo (ya había perdido otro embarazo con anterioridad). Esta circunstancia la habló con la gente de Recursos Humanos de la empresa y con su jefe directo el y la empleadora accedió a otorgarle 3 meses de licencia sin goce de haberes.

9. Monto reclamado: (1) L. C. ART: $\$ 56.255$; (2) M. R. D. L. P.: $\$ 84.751$

10. Diagnóstico inicial, herramientas utilizadas, grado de incapacidad (de parte):

10.1. Fecha de informe: (06/03/2007)

10.2. Herramientas utilizadas: Entrevistas, H.T.P. (prueba proyectiva: funciones yoicas y mecanismos de defensa), M.B.I (Test para la evaluación del Síndrome de Burnout), L.I.P.T (Inventario de Acoso Laboral de Leymann), PRIME - MD (Evaluación de las funciones psicopatológicas), MIPS (Evaluación validada para la República Argentina de la personalidad), BENDER (evaluación psiconeurológica) y BETA II-R (Test de inteligencia).

\subsection{Diagnostico:}

La paciente C. A. L. presenta un trastorno mixto con ansiedad y estado de ánimo depresivo (309.28), según los criterios propuestos por el $\mathbf{D S M - I V}{ }^{\mathbf{4 0}}$, en el Eje I:

La característica esencial del trastorno adaptativo en la entrevistada es el desarrollo de síntomas emocionales y comportamentales en respuesta a un

40 Fuente citada: Manual diagnóstico y estadístico de los trastornos mentales. 
estresante psicosocial identificable, en el caso de la Sra. C. A. L., la presión laboral y hostigamiento de carácter crónico. Este subtipo se usa con la paciente pues presenta manifestaciones dominantes donde hay una combinación de ansiedad y depresión.

Criterio A: Los síntomas han estado presentes durante los 3 meses siguientes al inicio de la situación estresante.

Criterio B: La expresión clínica de la reacción consiste en un acusado malestar y sobre todo en un deterioro significativo de la actividad social y laboral de la entrevistada.

Criterio C: El trastorno no cumple con los criterios para otro trastorno específico del Eje I (por ejemplo un trastorno por ansiedad o del estado de ánimo) y no es simplemente una exacerbación de un trastorno preexistente del Eje I o del Eje II. Sin embargo, puede diagnosticarse un trastorno adaptativo en presencia de otro trastorno del Eje I o del Eje II si este último no explica el conjunto de síntomas que han aparecido en respuesta al estresante. Por eso aparece como comórbido crisis de angustia. Cito textual a la paciente: "Siento que se me agoto la mente a partir de septiembre, tenía crisis de llanto. Fue un año duro en el trabajo. Eran tantas las presiones que me paralizaba, no podía pensar y ahí empezaba a sentir que me iba a pasar algo".

Criterio D: El diagnóstico de trastorno adaptativo en la paciente no representa una reacción de duelo.

Criterio E: El trastorno adaptativo podría resolverse dentro de los 6 meses según los criterios internacionales que siguen a la desaparición de la situación estresante (o de sus consecuencias). Sin embargo, en la paciente los síntomas han persistido por un período más prolongado de tiempo (más de 6 meses) y aparecen en respuesta a un factor estresor identificable (la presión laboral). En el caso de la paciente la posibilidad de quedar sin empleo por la sobrecarga de tareas que se traduce en una mayor cantidad de tiempo y atención sin considerar la etapa vital de la paciente: ser madre primeriza.

Asunto que tiene antecedentes previos que hacen que la paciente genere un estado de malestar continuo que se manifiesta en la expectativa de una posible dificultad económica que pueda devenir si pierde su empleo y el de dar calidad de tiempo a su hija.

Cito textual a la paciente: "Yo pedí una licencia sin goce de sueldo en Noviembre del 2000 por la pérdida de mi embarazo, se lo mande a Recursos Humanos, le pedí a mi jefe un distanciamiento y lo aceptaron... a pesar de las circunstancias retome. Me lo facturaron todo el tiempo me quitaron el rango, los recursos, me costó mucho tiempo acomodarme. Uno de los vendedores me dijo que no era bien visto en la empresa tomarse licencia. $Y$ yo aclaré que no tuve beneficio económico pero este compañero me dijo: 'Te tenes que hacer cargo de tu decisión'... en el 2005 me casé por segunda vez $\boldsymbol{V}$ trabaje hasta cinco (5) días antes de tener a G. tome mi licencia y volví en noviembre por lo que no complique a mis compañeros... Cuando volví cada vez estuve más recargada y el mismo sueldo. En el mes de Agosto del 2006, mi compañero de sector, el Sr. C. N., decide renunciar por una mejor propuesta de trabajo. La decisión ante esta novedad, por parte de la empresa, fue no tomar 
un reemplazante. Esta decisión nos fue comunicada a fines del mes de Julio, cuando todavía N. pertenecía a la empresa. Cuando nuestro Jefe nos lo comento, le comunicamos ambos, que era imposible que yo me hiciera cargo de todas las tareas del área. Mi jefe estuvo de acuerdo con lo expuesto pero nada pudo hacer. Incluso recibí un comentario, de que la empresa veía con buenos ojos el alejamiento de N. por propia cuenta, dado que tenían prevista su desvinculación a fin de año, ya que la decisión había sido tomada en función de reducción de costos. Prometieron ayudarme a presentar informes y no lo hicieron. Lo que hacían entorpecía el normal desempeño.

Entre las listas de precio, facturar y lo que tuve que hacer con todas las cuentas fue generar un estado de fatiga de la cabeza increíble".

Aparece como comórbido a la reacción adaptativa mixta. Crisis de angustia,

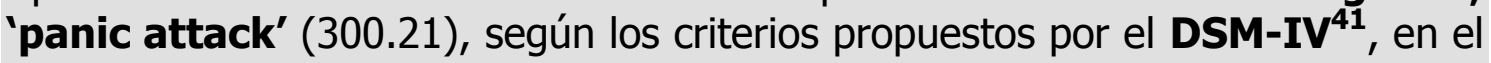
Eje I:

El pánico, desde el punto de vista psiquiátrico y psicológico, actualmente es considerado como una vivencia de miedo o terror intenso, con sensación de descontrol, desmayo o muerte inminente, que forma parte del cotejo de síntomas de una crisis o ataque de pánico [...] Su etimología griega nos recuerda al Dios Pan, un niño solitario, triste y taciturno, que solía esconderse en una caverna. Si algún extraño se acercaba a perturbarlo, lanzaba un grito espantoso que atemorizaba y hacía huir al intruso, con un miedo intenso al que se llamó luego "pánico". (Cia A.,1999). La característica principal de las crisis de angustia en el paciente fue la aparición aislada y temporal de miedo y malestar de carácter intenso, que se acompaña de síntomas somáticos y cognoscitivos. La crisis se inició de forma brusca y alcanzaron su máxima expresión con rapidez (en 10 minutos 0 menos), acompañándose a menudo de una sensación de malestar y en el caso de la paciente de buscar un lugar seguro a fin de manejar sus síntomas.

El primer episodio fue realizando sus actividades laborales. Los síntomas somáticos y cognoscitivos estuvieron constituidos por palpitaciones, sudoración, temblores, sensación de ahogo, malestar torácico, náuseas y molestias abdominales, inestabilidad (aturdimiento), imposibilidad de controlarse por el dolor, parestesias y escalofríos. Esto la llevo a solicitar ayuda por el miedo intenso a que algo le sucediese.

Cito Textual a la paciente: "Sentí que me iba a morir. Tome un tranquilizante".

Sus crisis de angustia son relacionadas con una situación determinada, las cuales tienen simplemente más probabilidades de aparecer al exponerse la paciente a su ámbito de trabajo.

10.4. Grado de incapacidad: Según el código de tablas de incapacidades laborales del Dr. Castex la paciente presenta: Neurosis de angustia severa (35\%) por presentar en su cuadro manifestaciones psíquicas y somáticas graves asociadas a crisis de angustia que requieren de un tratamiento integrado psicológico y psiquiátrico.

41 Fuente citada: Manual diagnóstico y estadístico de los trastornos mentales. 


\subsection{Diagnóstico psiquiátrico y grado de incapacidad (peritado)}

\subsection{Fecha informe: $(06 / 03 / 2007)$}

\subsection{Pruebas utilizadas}

Se le realizaron entrevistas clínico-psiquiátricas y los test psicológicos de Bender y H.T.P.

\subsection{Diagnóstico}

Punto a): presenta una Reacción Vivencial Anormal

Neurótica con manifestación fóbica y depresiva Grado II. Con respecto a la sintomatología detectada por los profesionales citados ha disminuido notablemente su intensidad dado los tratamientos realizados y el tiempo transcurrido.

Punto b):En el momento del examen pericial, no se han detectado estos síntomas

\subsection{Grado de incapacidad}

Punto c): La patología que presenta la actora le confiere una incapacidad del 10\% según Baremo Nacional de las Aseguradoras de Riesgos del Trabajo. Esta dolencia puede encuadrarse según el Baremo de Castex como una Neurosis de Angustia leve que le otorga una incapacidad del $10 \%$.

\section{Reevaluación actual:}

\begin{tabular}{|c|c|c|c|c|c|}
\hline Somatizaciones & 0 & total de 4 & 0,00 & T50 & SOM \\
\hline Obsesiones y compulsiones & 0 & total de 4 & 0,00 & T50 & OBS \\
\hline Sensitividad interpersonal & 1 & total de 3 & 0,11 & T50 & S.I. \\
\hline Depresión & 0 & total de 5 & 0,00 & T50 & DEP \\
\hline Ansiedad & 2 & total de 4 & 0,20 & T50 & ANS \\
\hline Hostilidad & 0 & total de 2 & 0,00 & T50 & HOS \\
\hline Ansiedad fóbica & 0 & total de 2 & 0,00 & T50 & FOB \\
\hline Ideación paranoide & 0 & total de 2 & 0,00 & T50 & PAR \\
\hline Psicoticismo & 0 & total de 4 & 0,00 & T50 & PSIC \\
\hline Items adicionales & 0 & total de 2 & 0,00 & & \\
\hline $\begin{array}{l}\text { INDICE DE SEVERIDAD GLOBAL (IGS) } \\
\end{array}$ & 0,03 & T50 & & & \\
\hline INDICE DE MALESTAR SINTOMATICO POSITIVO (IMSP) & 1,50 & T50 & & & \\
\hline TOTAL DE SINTOMAS POSITIVOS (STP) & 2 & T50 & Impresión & Positiva & \\
\hline ITEMS ADICIONALES & & ntaje & Significativo & & \\
\hline 5: Falta de interes en las relaciones sexuales & & 0 & NO & & \\
\hline 19: Poco apetito & & $\mathbf{0}$ & NO & & \\
\hline 44: Problemas para dormir & & $\mathbf{0}$ & NO & & \\
\hline 59: Pensamientos acerca de la muerte o el morirse & & $\mathbf{0}$ & NO & & \\
\hline 60: Comer en exceso & & $\mathbf{0}$ & NO & & \\
\hline 64: Despertarse muy temprano. & & $\mathbf{0}$ & NO & & \\
\hline 66: Sueño intranquilo. & & $\mathbf{0}$ & NO & & \\
\hline 89: Sentimientos de culpa. & & $\mathbf{0}$ & NO & & \\
\hline ITEMS CRITICOS & & ntaje & Significativo & & \\
\hline 15: Pensar en quitarme la vida & & 0 & NO & & \\
\hline 16. Escuchar voces que otras personas no oyen & & $\mathbf{0}$ & NO & & \\
\hline 54. Perder las esperanzas en el futuro & & $\mathbf{0}$ & NO & & \\
\hline
\end{tabular}

17. Conclusión del caso: Se verificó coincidencia de la resolución del juez respecto al daño psíquico y moral producido, atendiendo a un deterioro traducido en un porcentaje que se mantuvo en forma crónica. En este caso se 
agrega la valoración en proceso por la junta médica de la Subsecretaria de trabajo y afirmada por la perito psicólogo de la Suprema Corte provincial, en la post evaluación, se constató que la empleada evaluada aun no podía insertarse laboralmente y presentaba sintomatología psicopatológica.

\subsubsection{CASO 4}

1. Fecha de inicio: $21 / 02 / 2006$

2. Fecha de resolución: 05/04/2010

3. No Expediente: $x x x$

4. Nombre: R. R. A. C/ L. C. ART Y OT P/ E. A.

5. Estado: Resuelto

6. Resolución: Sentencia

Fojas: 691 En la Ciudad de Mendoza, a los 5 días del mes de abril de 2010, se constituye la Excma. Cámara Segunda del Trabajo, con los Dres. Norma Liliana Llatser, José Javier Balducci, y Jorge Guido Gabutti - Conjuez- de este Tribunal, con el objeto de dictar sentencia en los autos $\mathrm{N}^{\circ} \mathrm{xxx}$, carat.: R. R. A. C/ L. C. ART Y OT P/ E. A., de los que resulta: RESULTA: 1) A fs. 93/105 interpone demanda la Sra. R. R., por intermedio de su apoderada, en contra de L. C. ART por $\$ 42.672,27$, en concepto de prestaciones dinerarias por ILT y por indemnización por incapacidad conforme la ley 24.557, más la suma por I.P.P. Provisoria, hasta la fecha de la incapacidad definitiva; y contra C. S.A. E. M. S. por el monto de $\$ 127.962,74$, en concepto de indemnización integral por daños y perjuicios por enfermedad ocasionada como consecuencia del trabajo (deducidos los importes por lo que pueda ser condenada L. C. ART), o lo que en más o menos resulte de las pruebas. Solicita medida cautelar. Plantea la competencia de la justicia provincial y plantea la inconstitucionalidad de los arts. 46, 21 y 22 de la L.R.T. Cita jurisprudencia en su abono. Relata que ingresó a la empresa en plenitud física y mental, en fecha 17/09/01, desempeñándose como cajera, de 9 hs. a 18 hs., señala que se encontraba apta para realizar cualquier tipo de tareas, no presentando ningún tipo de dolencia. Señala que $C$. le practicó examen físico y psicosocial en el mes de julio de 2001, que consta en el legajo. Argumenta el incumplimiento de las normas de higiene y seguridad en la provisión de alimentos, refiere que en reiteradas oportunidades sufrió intoxicaciones producidas por alimentos provistos por el catering contratado por la empresa, que le provocaron cuadros de diarrea, vómitos y malestar estomacal, las que le ocasionaron la pérdida de $25 \mathrm{ks}$. en 3 años. Destaca y detalla las fotografías que se acompañan donde aparece la actora, acreditan el tiempo transcurrido y que en todas ellas (ocho fotos) se puede apreciar el notable descenso de peso que sufrió la actora como consecuencia de las intoxicaciones y el estado de estrés vivenciado en su lugar de trabajo. Relata que la actora debió soportar el malestar físico producido por las intoxicaciones, señala que las mismas fueron colectivas, y que la empleadora había dispuesto graves restricciones a su mandante y otros empleados para concurrir a los sanitarios en dichas ocasiones durante su 
jornada laboral. Manifiesta que las intoxicaciones sólo representan la primera etapa de su deterioro, ya que la presión laboral, el acoso psicológico orquestado por su superior jerárquico provocó como consecuencia de la angustia que vivía en su lugar de trabajo, perdiese el apetito, es decir su cuerpo acusó recibo de los embates psicológicos que le tocaba soportar día a día en $\mathrm{E}$. Refiere que la actora siempre concurrió a trabajar para no perder el presentismo, ya que la empresa le había informado que podría perderlo. Señala que en general las cajeras de la empresa tienen restricciones para ir al baño o tomar agua. Continúa el relato y detalla un accidente de trabajo ocurrido el $12 / 04 / 03$, en oportunidad que una clienta empujó una puerta rebatible provocándole una lesión en los dedos de una mano, dice que recibió rehabilitación de la M. ART; la que debía hacer de 16 a 17 hs., horario en que atendía el kinesiólogo, ello señala que produjo un gran malestar en el Jefe de cajas Sr. G., quien comenzó a hostigar a la actora, expresa que presentaba los certificados médicos ante el jefe de cajas y luego se dirigía a la ART para recibir el tratamiento médico, luego de la sesión regresaba al trabajo. Manifiesta que luego de unos días, el Sr. G. Ilamó por teléfono a S. \& C., solicitando le cambiaran el turno de rehabilitación, señalando la clínica que era imposible porque el kinesiólogo sólo disponía de ese horario. Ante las presiones de la empresa, refiere que la ART accedió. Al suspender el tratamiento, debió retomarlo dos meses después, le dieron dos meses de licencia para finalizar la fisioterapia. En otro acápite del relato, argumenta la actora trato discriminatorio, expresa que luego del incidente relatado, se reintegra al trabajo bajo las órdenes del nuevo jefe S. E., comenzó a notar trato discriminatorio, detalla que se traducía en enviar a todo el personal a almorzar en el primer y segundo turno y a ella asignarle el último sola y cuando se había terminado las raciones de comida, o amenazar a empleados que mantenían amistad con R., haciendo peligrar sus puestos de trabajo. Sumados a la práctica de controles permanentes, injustificantes e intimidantes, ejemplifica que se paraba detrás de ella y ante el mínimo error le llamaba la atención frente a los clientes. Señala que al resto de los cajeros no se las realizaba con la misma frecuencia. Califica de trato humillante el que recibía de parte de E., relata que él todo el tiempo le repetía que tenía sus días contados en la empresa, lo que la angustiaba enormemente. También señala trato discriminatorio por cuanto el jefe de caja se negaba a cambiarle los francos y si al resto de los empleados. Manifiesta que tampoco se cumplía la jornada laboral, nunca se respetaba el horario de salida. Detalla las dolencias físicas hasta que se desencadenó el síndrome de colon irritable, patologías vinculadas a la gran situación de stress y maltrato psicológico al que estaba expuesta en su trabajo. Señala que pese haber acompañado certificado médico la empresa se negaba sistemáticamente a respetar su dieta. Destaca las frases que le dispensaba su jefe. Reitera las intoxicaciones colectivas debidas al servicio de catering. Cita doctrina. Otro punto del relato lo constituye el trato humillante hacia la actora por supuesto faltante de caja, configurando trato discriminatorio y persecutorio. Destaca que los cajeros tiene una falla de caja de $\$ 60$, si excede se le realiza el descuento de su sueldo, lo refiere como habitual en la función de cajero; relata que el Sr. E. a la actora le descontaba cualquier falta sin importar el monto, además señala que se le aplicaban sanciones disciplinarias como apercibimiento, 
suspensiones y comentarios ofensivos. Detalla que en abril de $2004 \mathrm{E}$. la suspendió por un faltante de caja, vencida por el cansancio moral y temerosa, la firmó. En agosto de 2004 le aplica otra suspensión por el faltante de $\$ 48,60$ que la actora se niega a firmar. El 10/08/04 señala que se presenta a trabajar y seguridad le impide marcar tarjeta, por orden de E., quien al advertir la discusión se acerca, le indica que debe esperar a la Encargada de RRHH Sra. J.. Mantiene una reunión E., la encargada y la actora, manifiesta que en forma intimidatoria la quieren hacer firmar. Mantiene su postura y espera la notificación por $C D$, ese mismo día recibe $C D$ notificándole que por un déficit el 02/08/04 se la suspende el día 10/08. Manifiesta el tono amenazante de la notificación además de extemporánea, improcedente porque no superaba el monto de falla de caja. Refiere que ese día de regreso a su casa, la actora sufre una crisis de nervios por la impotencia, destaca el estado de angustia generada por los constantes conflictos y decide pedir ayuda a un psiquiatra Dr. J. H. Expresa que éste le informó que padecía de un fenómeno denominado mobbing y le recomendó no reintegrarse a su trabajo, extendiendo un certificado por 30 días y otros sucesivos. Señala que el día 22/03/05 envía una $C D$ en la que comunica el certificado que señala "tener en tratamiento a la Sra. R. R., quien continúa evolucionando de un cuadro depresivo. Se indica tratamiento de medicamentos y reposo relativo por 30 días a partir de la fecha". Este certificado es entregado por este medio ante la negativa de firmar la copia. Continúa el relato y expresa que a la semana de encontrarse de licencia le confirman que estaba embarazada, envió certificado, el que fue rechazado por la enfermería y la gerencia de recursos humanos, alegando que debía presentarse al $3^{\circ}$ mes. Asesorada por la Subsecretaría de Trabajo, en oportunidad de la Junta Médica se le exigió al Dr. J. V. (médico laboral de E.), a recibir el certificado de embarazo. El 02/09/04 la actora fue notificada de una Junta Médica a realizarse el 30/09/04 para establecer grado de incapacidad. Refiere que desde el comienzo de la licencia psiquiátrica la empresa se negaba a entregarle el bono de sueldo y tickets canasta a su marido, señala que su mandante no podía concurrir porque la sola aproximación al Supermercado le producía ataques de pánico. Describe que pasados 3 meses de su licencia psiquiátrica la empresa le comunicó que a partir del día 08/11/04 comenzaba su período de conservación de empleo conforme el 211 de la LCT. Asesorada, envía la actora misiva refiriendo que tenía cargas de familia y que le correspondía 6 meses; la demandada la emplaza a presentar certificado a fin de acreditarlo. Señala que la empresa accedió y la reserva del puesto se extendió al 06/02/05. En febrero el psiquiatra le recomienda terapia con psicólogo. El 12/03 le comunica por CD 10 días de licencia por presentar cuadro de recesión adaptativa con crisis de angustia. La empresa comunica a partir del 06/02/05 comienzo de conservación de empleo art. 211 LCT. Luego en fecha 30/05, le envía CD la empleadora y refiere que el 31/05/05 continúa con la reserva, ya que ese día finaliza su licencia por maternidad. Señala que el día 04/06/05 notifica otro certificado comunicando que continúa con su sintomatología depresión angustiosa con episodios fóbicos de contenido laboral, con 30 días más de reposo relativo. Detalla todo el intercambio telegráfico habido entre las partes, por la negativa de la empresa y la ART de reconocer el origen laboral de las dolencias y las prestaciones de servicios médicos. Transcribe las CD de 
fecha 11/07/05 enviada por la actora; la del 14/07/05 por la empresa, la respuesta de la actora y por último transcribe la enviada por La Caja ART, por la cual comunica la no aceptación del siniestro. La actora en un punto más formula el encuadre del caso en la figura de mobbing o acoso psicológico, cita doctrina en su abono, ofrece prueba y expresa claramente las dolencias sufridas por la actora como consecuencia directa de las tareas realizadas para su empleador. Señala que tanto su empleador como la ART incumplieron obligaciones impuestas por la ley de riesgos de trabajo y por la ley de higiene y seguridad, dejándola desamparada. En el acápite IV describe las lesiones sufridas y transcribe el informe psicológico expedido por el Lic. Lamagrande, quien le otorga un $30 \%$ de incapacidad correspondiente a la clasificación de Depresión grave. En el punto VII formula la línea argumentativa respecto de la responsabilidad de la ART, plantea la inconstitucionalidad del art. $6^{\circ}$, inc. $2^{\circ}$ de la ley de riesgos de trabajo; cita jurisprudencia; señala incumplimientos de prestaciones dinerarias de pago mensual; formula el reclamo según la L.R.T., por un total de $\$ 42.672,27$. Sin perjuicio del reclamo sistémico, funda el reclamo por responsabilidad civil de la empleadora, plantea la inconstitucionalidad de los art. 39 y 6 de la LRT, con base en "Aquino", profusamente relata la subsistencia del núcleo obligacional del art. 75 de la L.C.T., cita doctrina; funda en el C.C.; en la doctrina sentada por la CSJN en el caso "Aquino"; fundamenta la inconstitucionalidad del art. 39 y 6 de la L.R.T. Cita jurisprudencia en su abono. Plantea en subsidio dolo eventual, también cita doctrina y fallos. Finalmente concreta el reclamo según el derecho civil por el daño físico y lucro cesante, practica cálculo lineal que arroja $\$ 98.432,88$, cita jurisprudencia. En cuanto al daño moral reclama el 30\% de anterior, determina la cantidad de $\$ 29.529$. Totaliza un monto de reclamo de $\$ 127.962,74$, destaca que deberá descontarse el monto al que sea condenada la ART. Señala diferencia cuantitativa entre la suma que acuerda el régimen especial y la reparación del derecho común, por lo que corresponde la declaración de inconstitucionalidad del art. 39. Plantea la inconstitucionalidad de la ley 7198. Funda en derecho. Ofrece Pruebas. Plantea medida cautelar; ofrece pruebas; funda en derecho. A fs. 110/113 vta. se sustanció la medida, resuelta a fs. 117. 2) A fs. $129 / 138$ se presenta el Dr. H. D. Sá. por L. C. A.R.T. Contesta y destaca que el actor ha definido la base normativa de su reclamo en la ley 24.557; refiere que las dolencias fueron puestas en conocimiento en el mes de agosto de 2004. Reconoce el contrato de afiliación de C. S.A. Opone defensa de falta de acción, tacha a la enfermedad a la luz de la L.R.T. como inexistente. Cita jurisprudencia en su abono. Plantea falta de legitimación sustancial pasiva, no cubre enfermedad fuera del listado y falta de relación de causalidad. Contesta demanda y plantea inconstitucionalidad. Pide aplicación de las leyes 24.307, 24.932; dec. $1813 / 92$. Ofrece prueba. Subsidiariamente manifiesta y solicita se habilite la repetición del fondo fiduciario. A fs. 140 la actora solicita se emplace a L. C. el cumplimiento de la medida cautelar; a fs. 142/143 el apoderado de L. C. ART amplia puntos de la pericia médica; a fs. 147 vta. se ordena correr traslado a la firma C.; a fs. 152 y vta. la Aseguradora eleva informe del psicodiagnóstico elaborado. 3) A fs. 175/192 contesta demanda por intermedio de su apoderado la firma C.; formula negativa general y particular. Cita en garantía a L. C. ART. Relata los hechos y puntualiza que la actora se 
desempeñó en C. SA E., bajo la categoría de Cajera A. Desconoce las dolencias que provienen de un supuesto acoso psicológico, califica el relato como confuso; entiende que la actora ha procurado colocarse en situación de despido indirecto; señala como acusaciones infundadas a las intoxicaciones que denuncia. Refiere como llamativo que a partir de la sanción del 10/08/06 el encadenamiento de hechos: crisis de nervios, embarazo, licencia psiquiátrica, matrimonio, nuevos certificados, embarazo nuevamente, mientras se encontraba en una situación que la actora describe de "angustia y depresión". Señala como falsas las imputaciones relativas a las normas de higiene y seguridad en la provisión de alimentos y las referencias a las presiones para que se le otorgara el alta médica, sin haber completado el tratamiento. Manifiesta como párrafo aparte las supuestas presiones sufridas por la actora en cuanto a los descuentos y sanciones que se le aplicaran por los "faltantes de caja", describe como se procede en estos casos. Refiere que su mandante ejerció las facultades de dirección y control en la conducta de sus dependientes, debidamente. Respecto del mobbing, enumera algunas de las alteraciones que produce y expresa que pese que algunas de esas características están dentro de la descripción de la actora, llama la atención que fuese capaz de enfrentar situaciones claves en la vida, como los embarazos y el matrimonio. Contesta profusamente los planteos de inconstitucionalidad formulados por la actora. Cita doctrina al respecto. Afirma la constitucionalidad de todos y cada uno de los artículos incluidos en la L.R.T. Respecto del reclamo civil lo señala como infundado, en consideración a un reclamo formulado sobre nomas expresamente derogadas, considera inaplicable el art. 1.113 del C.C.; así también refiere la inexistencia de culpa en su representada, resultando inadmisible extender la aplicación del art. 1078; cita doctrina y jurisprudencia que hace a sus argumentos. Contesta la inconstitucionalidad de la ley 7198. Formula conclusiones. Impugna liquidación. Hace reserva del caso federal. Ofrece pruebas. 4) A fs. 195/198 la actora contesta el traslado del art. 47 del C.P.L.; ratifica los términos de la demanda y la prueba, ofrece contraprueba e individualiza los nuevos hechos introducidos por la contestación de la demandada empleadora. Formula un análisis pormenorizado de todos los argumentos de la empleadora y los niega detalladamente. Cita jurisprudencia en su abono. A continuación rebate los argumentos de la Aseguradora, solicita el desglose de la presentación de la aseguradora, sostiene que de modo encubierto ofrece prueba instrumental. Ofrece contraprueba. A fs. 202 interviene la Sra. Agente Fiscal, aconseja la declaración de inconstitucionalidad de los art. 21,22 y 46 y desestima por abstracto el planteo de la inconstitucionalidad de la ley 7198. A fs. 207 y vta. obra el auto de sustanciación. A fs. 209 la actora denuncia los domicilios de reconocimientos. A fs. 251/254 obra el informe de DEIE; a fs. 255/258 obra el informe de la Municipalidad de Godoy Cruz, respecto al control bromatológico; a fs. 259/278 obra las escalas salariales remitidas por el C.E.E.; a fs. 279/296 la S.R.T. remite copia fiel de los antecedentes de la actora; a fs. 304/307 corre el informe del libro de guardia del Hospital Militar; a fs. 312 reconoce contenido y firma el Lic. Lamagrande de un informe psicodiagnóstico y de dos certificados; a fs. 336/353 obra informe del Correo Argentino y copias de las C.D. ; fs. 371 se encuentra el informe del Hospital Español; fs. 382/385 obra otro informe Correo Argentino; 
fs. 400 obra reconocimiento de Dr. V. D. V.; fs. 402/403 corre agregada la pericia del médico psiquiatra, impugnada a fs. 411 / y vta. y 413 por la actora y a fs. $425 / 426$ por L. C. ART, obran contestadas las observaciones a fs. 455 y vta.; a fs. 420/423 informe de Asistir; a fs. 443/447 presenta el informe pericial psicológico, impugnado por La Caja a fs. 453 y vta. y contestadas a fs. $459 / 460$ y 530; a fs. 489/501 se acompaña el historial médico de la actora realizado por la C. S. A fs. 513/516 obra el informe pericial contable, impugnada por L. C. a fs. 524 y vta. y contestada a fs. 531 . A fs. 570 y vta. obra acta en la cual se fija fecha de audiencia; a fs. 581/689 se agrega la prueba instrumental y a fs. 690 corre el acta de audiencia de vista de causa y quedan los autos en estado de dictar sentencia. De conformidad con lo dispuesto en el art. 69 del C.P.L. el tribunal se plantea las siguientes cuestiones a resolver: PRIMERA CUESTIÓN: Existencia de la relación laboral? SEGUNDA CUESTIÓN: Procedencia de los rubros reclamados? TERCERA CUESTIÓN: Costas? A LA PRIMERA CUESTIÓN LA DRA. N. L. L. DIJO: El vínculo laboral invocado por la Sra. R. en su demanda queda acreditado con los recibos de sueldos acompañados por la actora, el expreso reconocimiento formulado por la empleadora en su responde, corroborado además por el cúmulo de misivas intercambiadas entre las partes. Toda documentación que obra en original ( fs. 581/687). Confirman el vínculo laboral, las testimoniales rendidas en la audiencia de vista de causa, que pasamos a relatar, con el objeto de completar el panorama probatorio existente en autos, previo referir que la demandada desistió en la audiencia de la absolución de posiciones de la actora: En primer término prestó declaración la Sra. V. A. N., quien respondió a tenor de las siguientes preguntas: Conoce a R. R.? Del Hipermercado E.. Durante que épocas? Desde el año 2001 hasta el 2004. Empezamos desde que ocurrió lo de las torres gemelas. Hasta el 2004. Tiene amistad intima? No, simplemente laboralmente. Estar en líneas de cajas. Éramos cajeras. Le debe algo el E.? No. Para que diga si sabe si se produjo algún cambio en la actora? Si, nos preparaban en San Juan y el humor de ella era bastante bueno, era agradable. Luego estaba contenta porque podía llegar a ascender en la línea de cajas. Entonces en un principio trabajaba contenta e incentivada. Y después no sé porque al cambiar de jefe de cajas (S. E.) y de repente sus posibilidades de ascenso se vieron frustradas. Cómo lo sabe? Porque cuando estábamos en la línea de cajas había chicos que podían ayudar a supervisores, les daban otras posibilidades a esos chicos. Ellos podían resolver algunos problemas. Pero al haber cambio de jefe, se notó que directamente en la línea de cajas había reglas que ya eran muy específicas que a cada rato se la llamaba por el intercomunicador diciéndole que las manos estuvieran siempre sobre el mostrador. $\mathrm{Y}$ con respecto a la cara que pusiera buena cara, que sonriera, que controlara bien la mercadería que cobraba, que el sello lo pusiera abajo. Era constante la vigilancia que se hacía, colocándose atrás de ella. Era siempre el jefe. Y por ahí si jefe estaba en otro lugar, el supervisor de turno, también se tenía que poner atrás de ella y marcarle esos detalles. Todo eso se lo hacían a la Sra. R.? No, había un par de chicos que se veían con posibilidades, pero al haber cambio de jefe, se la notaba a ella con todo esto que mencioné anteriormente. A usted le ocurrió? No. Las pautas eran para todas. Pero el hostigamiento era muy seguido. A usted le contaba todo esto? No, se le notaba en la cara, no hacía falta que me lo dijera. Para que diga 
si sabe que la actora sufriera durante la relación laboral algún tipo de violencia física? Se descomponía mucho, tenía gastritis, estomacales. Varias veces se intoxicó. Se les daba el almuerzo al estar todo el día. Durante cuánto tiempo usted vio estas circunstancias? Habrá sido un año bueno, pero al cambiar de jefe, empezó todo. Yo renuncié pero ella siguió. Para que diga si las cajeras podían ir al baño? No era tan libre. Si había cola, había que esperar hasta el último cliente. Y que pasaba si alguna cajera estaba descompuesta? Había que esperar a otro reemplazo. Y con la actora recuerda algo puntualmente? Si, haber pedido ir al baño y no la asistían. Hasta incluso en una oportunidad, tuvo un desmayo por esperar. Para que amplíe la relación de la actora con el jefe de caja. Era todo el tiempo marcarle cosas constantemente, sentirse incómoda, no se le escuchaba si tenía algún pedido de ir al baño. El decidía quien iba primero. Siempre quedaba para el último pero de ir sola. $Y$ en un horario donde ya no quedaba más gente. Para que diga si esto afectó la relación de la actora con sus compañeras. $\mathrm{Si}$, bastante, porque había chicos que según los jefes eran los que preparaban para hacer carrera y ella había hecho amistad con alguno de ellos, y el jefe en algunos casos dijo que al juntarse con ella, se tenía que pensar en el tema del puesto de trabajo. Para que diga si la Sra. R., sufrió algún tipo de accidente laboral? Si, se le cayó una tapa sobre los dedos. Se encuentra al costado de la caja. Que eso le complicó se que le tuvieron que hacer rehabilitación en los dedos. Y en esas horas el jefe no quería darle el permiso para la rehabilitación. Para que diga en qué consistía el ítem fallo de caja? Era si nos faltaba, nos podían ir sancionando incluso. Ahora si sobraba, bienvenido para la empresa. Recuerda alguna situación puntual? No. De qué manera la sancionaban? Primero era el apercibimiento y luego venía la suspensión. Pero sé que había unas cajas que por casualidad, siempre faltaba plata, por lo tanto en esos cajoncitos se cuidaban mucho. Aparte cada vez que uno dejaba por algún motivo la caja, siempre se hacía el arqueo y uno no sabía cuánto tenía y el arqueo lo hacían los supervisores. El tema era cuando nos íbamos, teníamos que saber cuánto había. Esta circunstancia ustedes la pusieron en conocimiento de los jefes? Si. Porque él era el que nos retaba. Sabe si las compañeras de trabajo tenían libertad para hablar con la actora? No, cuando ella había hecho amistad con algunos chicos, al pasar a otra etapa, los chicos que hablaban con ella se les decía que si les convenía el trabajo o la amistad. Había una chica F. R., que estaba en atención al cliente. Ellos tenían un poco más de grado que nosotros. Quien se los dijo? S. E. Sabe si la actora recibió alguna amenaza respecto del Sr. E.? No, no me consta. Lo que si vi era que la hostigaba constantemente. No sé si la amenazaba. Sabe si alguna vez la puso mal delante de los clientes? Si, en una oportunidad le dijo si había controlado bien la mercadería, se paraba atrás de ella y le decía el tema del sello, "te dije que el sello va debajo del teclado". "sos tonta, no entendés"? La trataba mal delante de la gente. Hubo un cambio en ella desde cuando empezó a cuando dejó de trabajar. Ustedes podían recurrir a Recursos Humanos de la empresa? Sí, pero ahí se dedicaban a hacer selección de personal. Todo lo que había era cajero, supervisor, jefe de caja. Y todo ahí quedaba. Ni siquiera había gerente. El gerente no escuchaba al personal. Sabe por cuánto tiempo siguió trabajando la actora? No lo sé. No quise ir más ahí. Para que diga en qué fecha fue el accidente. No sé. Cuando ingresaron sabían que A.R.T. les correspondía? 
$\mathrm{Si}$, entre todos los papeles debe de haber estado. Porque no quiso volver más al Hiper? Porque el trato no era bueno, era cansador para todos. Mi meta fue entrar para pagarme la facultad. Lo cumplí y bueno, todo terminó. Nos hacían pasar vergüenza delante de los clientes. Para que diga que horarios incluía lo que realizaba? Entraba como a las 07:00 y salía a las 14:00 horas aproximadamente. Nunca se respetaba el horario. Jamás tuve un reconocimiento monetario. Para que diga si alguna vez hubo intoxicación colectiva? $\mathrm{Si}$, es mas iban de una empresa T. R. que llevaba la comida y cuando hubo cambio de empresa, si hubo casos. Para que diga cuantos empleados tuvieron intoxicación? No lo sé. Para que diga si alguna vez almorzó alimentos en horarios de trabajo? Si en los fines de semana. Alguna vez se intoxicó? No. Para que diga si alguna vez hubo algún conflicto gremial o sindical? No. Ahí si nos enterábamos que había algún faltante, no considero que mis compañeros tuvieran contacto sindical. Entonces no me enteraba si había algún problema. Había delegado gremial? No lo sé. Para que diga cómo le consta de las descomposturas de la actora? No sé, lo de la gastritis no lo sé pero creo que era por la misma situación de estrés. Cuanto tiempo le daban para comer? Treinta o veinte minutos. Para que diga si existía algún seguro por faltante de caja? Inmediatamente se nos descontaba. No había. Para que diga si a algún empleado se le perdonaba el faltante de caja. No, el descuento venía a fin de mes. A continuación declaró el Sr. C. F. T.: Conoce a la Sra. R.? Si. Del Hiper Easy. Eran compañeros? Si. Recuerda en que época? Desde 2002 hasta el 2004. Eso hace que fueran amigos íntimos? No. Se deben algo? No. Porque dejó de trabajar? Me despidieron? Si. Tiene juicio? Si. A la C. A.R.T la conoce? No, sé que es una A.R.T.. Sabe si se produjo algún cambio en la actora desde que empezó a trabajar? Era una persona normal de buen genio. Advirtió alguna modificación en el carácter? Si. Teníamos al ingresar buen carácter. Porque la vio con mal carácter? Trabajó con mucha presión. Hacía lo mismo que la actora? No, yo era supervisor de caja. Quien era su superior jerárquico? Tenía dos jefes de turno y un jefe de Caja. Quienes? A. G., M. Z. y S. E. Durante cuánto tiempo fue jefe de caja de este señor E.? El estuvo menos de un año como jefe mío. Para que diga si sabe cómo era la relación de la actora con el Sr. E.? Era regular. De por sí no había buena relación con la jefatura. Cómo era? Habían cajeros muy apegados a los jefes y otros que no, había distinto trato. En el caso de la actora? Era distinto el trato. Esto ocurría con E.? No con todos. Porque se trabajaba con mucha presión? Quiere decir, con sonrisa, atención, manos arriba del mostrador. Y si no, nosotros teníamos que llamarles la atención a ellos. Esta actitud era general? Si, los amigos de. Porqué la trataban distinto a la Sra. R.? Porque no se le tenía confianza y pertenecía a otro grupo. Alguna vez presenció mal trato hacia la Sra. R.? No. Era notorio hacia ella o hacia el grupo? No, hacia el grupo. Para que diga si alguna vez la actora se desmayó en el lugar de trabajo? Sé que estuvo enferma, se adelgazó mucho. Desde cuando entró hasta que se fue, se la vio distinta totalmente. Para que diga si sabe cuál era el horario de la Sra. R. para comer? A partir de las 12:00 del mediodía, era por tanda. Era siempre una de las últimas en comer. Por qué? Por amiguismo con otros y no con ella. Sabe si había restricciones para ir al baño? No, pero se trataba de que no hubiese nadie en la cola de cajas. Si la persona de la caja tenía mucha gente y tenía necesidades 
como hacía? Se la trataba de reemplazar, pero era muy difícil que esto pasara. Tiene conocimiento de intoxicación por alimentos en mal estado en el E.? Que yo recuerde no, podía caer mal la comida pero no por mal estado. Sabe cómo funcionaba antes de E. la cuestión de cajas (faltante de caja)? El procedimiento era cuando faltaba \$10 se aplicaba apercibimiento. Y antes con G.? Al principio no hacía mucho hincapié en el faltante de caja. Y se podía llegar a una suspensión? No en ese momento era apercibimiento. El trato era distinto con otros jefes? Si. Y a la actora la siguió viendo? No. Para que diga en cuanto al amiguismo y en cuanto al trato de personal con el resto, si sabe cuántos empleados eran considerados amigos? Era un grupo. Seis o siete personas en la caja. Para que diga cuantos cajeros había en E. cuando usted trabajó? Más de veinte, seguro. Para que diga los nombres de amigos. E., J. D. En alguna ocasión se hizo alguna reunión? $\mathrm{Si}$, era para darnos directivas. En alguna ocasiones el personal podía manifestarse de alguna forma? Nadie. Y que ocurría si alguna vez se hacía algún planteo? Se lo hablaba al tema pero se escuchaba, daban las explicaciones que tenían que dar. Alguna vez se solucionaba el tema? No. Para que diga cómo funcionaba el sistema de control de caja y en su caso si había faltante? Cada cajero iba a rendir, se hacía el arqueo no me acuerdo la cantidad que se hacía por día y se nos hacía retirar el dinero. Para que diga si había algún faltante? Al cajero no se le decía y entonces en la rendición final se nos avisaba a nosotros. Para que diga si alguna vez se perdonaba el faltante de caja? En un principio sí. No eran tan estrictos. Para que diga si alguna vez algún supervisor tuvo relación con alguna A.R.T.? $\mathrm{Si}$, cuando me fracture el dedo. Alguna vez solicitó la suspensión del tratamiento médico? No. Tiene conocimiento de que alguien de la empresa lo haya hecho? Yo cuando me accidente el dedo tuve que volver antes el primer jefe G., era por la falta de personal. Yo no tuve inconvenientes. Lo solicitó? No, lo hice por voluntad propia. Para que diga si existe algún delegado gremial? No, después que yo me fui se que hubo uno. Prestó luego declaración el Sr. S. R. E.: Conoce a la Sra. R.? Si. Desde cuándo? Desde 2003. En el XXX. Son amigos? No. Tienen parentesco? No. Sigue trabajando en la empresa? Sí, soy subgerente. Conoce a la C. A.R.T. Si. Para que diga si sabe las normas que rigen el trabajo de las cajeras en el E.? Cobrar la mercadería que sale por línea de cajas, tienen capacitación, un proceso sistemático. Aprenden a manejarlas y hay una serie de procedimiento que va desde abrir las cajas, corroborar el interior de las mismas, verificar que los productos sean específicamente los correctos y que los códigos que se escanean sean los correctos. Este proceso interno se lo comunican a las cajeras? $\mathrm{Si}$, se hace un entrenamiento a los cajeros se los prepara antes para que tengan práctica en su trabajo. Para que diga cómo funciona el tema de arqueo de caja y en su caso el faltante. Son los supervisores los que controlan las cajas. Si algo fue mal cobrado se hace un arqueo de caja. Eso pasa cuando el cliente duda del precio del producto. Se hace un arqueo de caja y ahí se sabe por el sistema si es correcto. Para que diga si existe un seguro de caja? Sí, hay uno que se llama fallo de cajas. Ahora existe eso, es de \$ 65 . Generalmente las rendiciones no son exactas en más o en menos y durante el arqueo mensual este seguro lo cubre. Este seguro estuvo siempre? Desde que yo ingresé a la compañía siempre estuvo. Para que diga cómo funciona en el caso que falte más del seguro. Ese seguro de $\$ 65$, en 
el caso de que el cajero tenga una diferencia mayor, se le descuenta al empleado. Para que diga si alguna vez se perdona algún faltante de caja? No. Para que diga cómo funciona el procedimiento de los cajeros con las idas al baño o situaciones de emergencia en el local, es decir cuando hay apuro de baño. Le da aviso al supervisor y se lo reemplaza con otro. $Y$ cuando hay mucha gente? Se cierra y se pasa a la de al lado. Como se organizaba el tema de las comidas? Por turnos. Se van turnando que lo maneja el supervisor. Una persona por vez. Para que diga si había alguna diferencia en los alimentos? El servicio lo brinda el Xxx. Y antes en la época de la Sra. R..? No sé, yo siempre supe que era ese. Tenían una vianda? Vienen con unos recipientes especiales y se les da la comida. Alguna vez se enteró por alguna intoxicación? No. Puede que a alguna persona le haya caído mal, pero en general no. Para que diga si ese suministro de alimentos recibe controles de calidad? Si. Tiene controles bromatológicos. Cuanto tiempo tenía el personal para comer? No sé si 45 minutos o media hora. Hoy, es media hora. Para que diga como otorgaba las instrucciones cuando notaba falta en el cajero? Si el supervisor detectaba algo, se toma sanciones al reincidir. Tiene algún sistema el E., para comunicar cada situación? Si, tiene una central en cada caja. Para que se usa? Para llamar al cajero cuando tiene alguna necesidad. Y los supervisores los ocupan también? Si. Por medio del intercomunicador. Para que diga si en el E., existe algún delegado gremial? Creo que no. Y en la época de la actora? No. Para que diga si tuvo algún trato preferencial respecto de algunos cajeros? No. Para que diga dentro de los cajeros del E. tuvo amigos? No. Para que diga cuantos cajeros hay? En aquel entonces creo que eran cincuenta y cinco. Y en la línea de caja? 14 o 15 en la mañana y lo mismo por la tarde. Recuerda cuantas horas trabajaba la señora R.? Creo que nueve. Dentro de esa hora también está el horario de tesorería. Si. Para que diga si alguna vez la maltrató a la actora? No. Para que diga a quien respondían los supervisores en esa época? Al Jefe de Turno. Yo era el Jefe Superior de todos ellos. Quien daba las instrucciones de cómo proceder en cada caso? El Jefe que esté de turno, podía ser yo u otro y las pautas las daba la compañía. Cuál era el concepto que usted tenía respecto de la actora? Bueno. Como es eso? Era buena cajera, trabajaba bien. Hubo una sanción que se le había aplicado a la actora por faltante de dinero y eso no refleja que sea mala empleada. Que sanción tuvo? No recuerdo que fue, si apercibimiento o suspensión. Para que diga si nos ha dicho que cuando faltaba dinero, porque razón se le aplicó una sanción a la actora? Porque seguramente había reincidido y superaba los $\$ 65$ de seguro de caja. Porque se la suspendió entonces? Porque son los lineamientos de la empresa. Es para que el empleado no vuelva a reincidir. Y que tal común es en los cajeros el faltante de caja? No, no es común que falte. Suele pasar pero no es cotidiano. A otro cajero se le aplicó sanción por falla de caja? Si. Para que diga si él como jefe, en algún momento se ponía detrás de la actora para darle indicaciones? No, que yo recuerde no. Para que diga si le dio instrucciones a los supervisores para controlar a la actora? No, específicamente no. Para que diga si recuerda en qué horario se le enviaba a la actora a comer? No recuerdo. Era obligatorio y se iba siempre de una manera. Recuerda cómo era la relación de la actora con los demás compañeros de trabajo? Era normal, no había una mala relación. Recuerda que la actora haya sufrido una descompostura en el lugar de trabajo? 
No recuerdo. Sabe si alguna vez hubo situación que se le tuvo que llamar la atención a la actora, delante de los clientes?. No. SE TACHA EL TESTIGO POR LA PARTE ACTORA. Procede a fundar la misma con los siguientes argumentos: El testimonio está en contradicción con la documentación aportada (carta documento donde se la suspende, las sanciones por faltantes de cajas, importes menores a $\$ 65$ y el testigo no recuerda lo que le conviene. Asimismo, surge que el mismo se contradice, porque la sanción de falta de caja, se contradice con lo que dice. La testigo $\mathrm{N}$. por ejemplo se explayó con todo lo que dijo. $\mathrm{Y}$ el testigo no recuerda en que horario la actora iba a comer. Entonces hay dos testigos que contradicen lo que él dice. Además es empleado y jefe de la actora he indicado como acosador por tanto no es sincero, favorece a la empresa. Se corre el traslado de la tacha y la parte demandada (C.) se opone a la tacha formulada. No veo motivo alguno para tacharlo en cuanto a la prueba documental aportada, fue claro, objetivo. A la tacha formulada el Tribunal resuelve que será merituada en el momento de dictar sentencia. El Sr. J. A. V. declaró: Conoce a la Sra. R.? Si por relación laboral. Como es esto? Yo estoy a cargo del Centro Asistencial de C. S.A. desde el año 2002 y una función es auditar la parte médica de los empleados de la empresa. No tiene parentesco con ella? No. Sigue trabajando para C.? Si. A la C. ART la conoce? Si. Para que diga si alguna vez examinó a la actora y porque motivo? La función no es examinar o revisarla, por situación de problema por el ausentismo que le provocó la relación con la empresa. Para que diga si notó que la actora tenía grado de depresión? Yo me atengo a los certificados médicos que se expidan y si, presentaba síntomas relativos con su actividad laboral. Para que diga si recuerda si esos certificados determinaron algún grado de incapacidad? No recuerdo exactamente pero le diría que eso no ocurrió nunca porque como se sabe, las incapacidades se da de alta cuando ha cumplido un año luego de su incapacidad. Nunca hubo participación de la A.R.T. porque es uno de los temas de discusión de opinión si estas relaciones laborales por disgustos se podían hacer denuncia en la A.R.T. A raíz de estos certificados se hicieron denuncias? No. La empresa consulta con otro psiquiatra o especialista y creo que a ella se la trató con otros especialistas. Sabe los resultados? No, pero deben estar, seguro. Para que diga si la Sra. R., sufrió descompostura en su trabajo? No lo recuerdo. Pero es muy común que ocurra algo. Para que diga si ha tenido oportunidad de tomar conocimiento de que haya habido ingesta en mal estado de comida? Debemos de saber si hubo síntomas o no, pero no se lo cataloga como intoxicación, alguna vez vinieron empleados diciendo que le había caído mal la comida. En consecuencia, esta primera cuestión debe ser contestada afirmativamente, encuadrando el vínculo que los unía en lo establecido por los artículos 21,22, 23, 90 y cc. de la L.C.T., dándose por cumplido el art. 45 "in fine" del C.P.L.. La legitimación sustancial pasiva de La Caja ART, surge acreditada cabalmente, por una parte reconoce expresamente en su responde ser la Aseguradora contratada por la empleadora C. S.A. (fs. 129); el contrato acompañado a fs. 120/124 corrobora el extremo y la propia demandada empleadora, en oportunidad de contestar solicita su citación. Respecto a la competencia del Tribunal, la actora planteó la inconstitucionalidad de los arts. 21,22 y 46 de la ley de riesgos y quedó pendiente para ser resuelta con la sentencia. A fs. 202 y vta. dictamina la Sra. Fiscal de Cámara expidiéndose 
respecto de la cuestión en tratamiento. Expresa que las normas cuya inconstitucionalidad se reclama atentan contra el sistema federal de gobierno adoptado por la Nación argentina (art. 1 C.N.), desconocen los poderes no delegados por las provincias al Gobierno Nacional y las facultades reservadas (art. 121); violan lo dispuesto en el art. 116 C.N. al desconocer el principio de exclusividad del Poder Judicial en el ejercicio de la jurisdicción y viola el principio tripartito de los poderes del Estado y de igualdad ante la ley (art. 16 C.N.) Cita jurisprudencia. De la compulsa de autos y según pacífica y reiterada jurisprudencia de esta Excma. Cámara, adelantamos desde ya la competencia de la misma en la presente causa. Respecto de los arts. 21 y 22, es clara la atribución al Poder Ejecutivo Nacional de funciones de corte netamente jurisdiccional a través de las Comisiones Médicas. Que se comparte el criterio sustentado por Fiscalía de Cámaras cuando en su dictamen obrante a fs. 202, expresa que "no se desconoce la doctrina de la Corte Suprema de Justicia de la Nación en el sentido que las leyes de fondo pueden determinar procedimientos especiales, pero esa facultad no puede legitimar el otorgamiento de potestades jurisdiccionales a órganos administrativos (arts. 16 y 116 C.N.), ni violentar la garantía del juez natural (art. 18) y mucho menos privar a las personas del libre acceso a la justicia". La doctrina ha expresado al respecto que "...Existirá una inconstitucionalidad directa y absoluta en el caso del art. 21 como también en el apartado 3 del art. 8, que aunque parcialmente, anticipa una de las funciones de la Comisión Médica, en cuanto atribuye a un órgano administrativo federal funciones propias de los gobiernos provinciales..."( Ley sobre Riesgos del Trabajo. Aspectos constitucionales y procesales. Ackerman-Maza, Rubinzal Culzoni Ed. 1.999, pags.53 y ss) La Cámara Federal de Seguridad Social Sala II, en fallo del 15/02/99, caratulado " LUQUE JOSÉ c/ MAPFRE ACONCAGUA A.R.T. s/Ley 24.557, entendió que para que el cuestionamiento con base constitucional del sistema fijado por la ley 24.557 pudiese por vía de hipótesis ser receptado, el trabajador tendría que haber acudido directamente ante los jueces laborales de la provincia en defensa de sus derechos"...( Ley sobre Riesgos del Trabajo. Aspectos constitucionales y procesales. Ackerman-Maza, Rubinzal Culzoni Ed. 1.999, pags.53 y ss) De oficio, para rechazar una excepción de incompetencia el Tribunal de Trabajo $n^{\circ} 4$ de La Plata (Prov. De Buenos Aires) declaró la inconstitucionalidad de los arts. 21, 22 y 46 de la Ley de Riesgos del Trabajo. "Alonso c/ IN-DE-CO Minoli S.A.I.C., falo del 11-121997. En el mismo sentido el Juzgado de Primera Instancia del Trabajo $n^{\circ} 2$ de Gualeguaychú (Prov. Entre Ríos), en el expte. "Vázquez c/ Villalba y otro", de fecha 16/02/98, publicado en T.S.S. 1.998 pág. 614, concluye el sentenciante en que "la imposición federativa se debió a un mero arbitrio legislativo (en atención a la ausencia de motivos) con el que se restringe indebidamente las facultades jurisdiccionales de las provincias en una materia (como es la de accidentes de trabajo) que le es propia por aplicación del art. 75 inc. 12 de la Constitución Nacional"... La jurisprudencia de nuestra provincia se ha inclinado por un criterio coincidente con el expuesto anteriormente: "...Los arts. 21, 22 y 46 de la L.R.T. son inconstitucionales en cuanto sustraen un conflicto de naturaleza laboral de las Cámaras Laborales, y siendo inconstitucionales los referidos artículos, los Tribunales del Trabajo son competentes para entender en la presente causa a tenor de lo dispuesto por el art. $1^{\circ}$ del C.P.L."... Cámara 
Tercera del Trabajo. Autos $\mathrm{n}^{\circ} 28.355$ caratulados: "FUNES, RICARDO R. SERVICIOS ROYAR S.R.L. p/ ORDINARIO de fecha 05-07-2000. Ello implica que se establecen normas de procedimiento en la esfera del derecho administrativo, en desconocimiento de las facultades reservadas por las provincias, desplazando la actividad jurisdiccional reservada constitucionalmente sólo al Poder Judicial. Respecto del art. 46 de la L.R.T. considera el Tribunal que al sustraer del ámbito de los Tribunales Provinciales el conocimiento y decisión de la materia laboral que corresponde a la Jurisdicción de los Jueces de la Nación o de los jueces de provincia según que las cosas o las personas correspondan a las respectivas jurisdicciones, resulta violatorio de expresas normas constitucionales, concretamente los arts. 16 y 18 de la Ley Fundamental, amén de lo previsto en el art. 75 inc. 12 . Tiene dicho la Jurisprudencia. "...la materia objeto del primer párrafo del art. 46 afecta los principios del Juez natural y de acceso a la Justicia... resultando también afectadas por la norma en crítica las facultades no delegadas al gobierno nacional por las provincias y las que expresamente se han reservado al momento de constituir la unión nacional, al atribuirle el art. 46 de la LRT jurisdicción para conocer en causas en tramitación por ante la Provincia, al Juez Federal con jurisdicción en cada provincia y lo que resulta más criticable desde el punto de vista republicano federal, es acordarle jurisdicción en forma expresa a la Comisión Médica Central, organismo dependiente del Poder Administrador del Estado Nacional..."(Tribunal del Trabajo No 2 de Lanús en autos No 4364 "QUINTANA, MARIO HECTOR C/MULTISHEEP S.A. S/ACC. DE TRABAJO). Sobre la misma cuestión y en idéntico sentido se ha expedido la Suprema Corte de Justicia de la Nación in re "Recurso de hecho deducido por La Segunda Aseguradora de Riegos del Trabajo S.A. en la causa Castillo Angel Santos c/ Cerámica Alberdi S.A. por Queja", autos en los que intervino a efectos de resolver sobre el recurso extraordinario interpuesto por la citada en garantía, La Segunda A.R.T. S.A, contra la resolución de la Sala Primera de la Suprema Corte de Justicia de la Provincia de Mendoza que mantuvo la resolución de esta Segunda Cámara del Trabajo que declaró la inconstitucionalidad del art. 46 de la Ley 24.557 y desestimó la excepción de incompetencia de las reclamadas. En definitiva de acuerdo a las normas citadas, y compartiendo los criterios doctrinarios y jurisprudenciales contenidos en el dictamen de la Sra. Fiscal de Cámaras, y conforme criterio reiterado, considera el Tribunal que en el presente caso, los arts. 21,22 y 46 de la L.R.T., resultan sin duda inconstitucionales. En consecuencia y de acuerdo a lo dispuesto por las normas del C.P.L citadas precedentemente, es competente este Tribunal para entender en la presente causa. El resto de los planteos de inconstitucionalidad deducidos contra la ley de riesgos corresponde prima facie analizar la plataforma fáctica invocada por el actor, esto es determinar el nexo o no de causalidad entre las tareas realizadas y las patologías que dice padecer, lo cual debe dilucidarse en el tratamiento de la segunda cuestión. ASÍ VOTO A LA SEGUNDA CUESTIÓN LA DRA. NORMA LILIANA LLATSER DIJO: Acreditada la existencia de la relación de trabajo y las tareas realizadas, corresponde el tratamiento del reclamo formulado por la Sra. $R_{\text {., }}$ el que consiste en el pago de la reparación tanto sistémica como extrasistémica derivada de las patologías que padece en ocasión de las tareas desarrolladas para la empresa C. S.A. E., en consecuencia 
el reclamo lo dirige tanto a su empleadora como a la Aseguradora de Riesgos. En apretada síntesis podemos establecer que la actora reclama indemnización, basada en las prestaciones derivadas de la L.R.T., responsabilizando a la A.R.T. y en las normas de la reparación integral imputándoselas a la Empleadora, por incapacidad que dice padecer como consecuencia de las labores desempeñadas en su carácter dependiente para C., atribuye la incapacidad del $30 \%$ que padece a: incumplimientos a las normas de higiene y seguridad en la provisión de alimentos, lo que le provocó reiteradas intoxicaciones, perdiendo $25 \mathrm{~kg}$. en tres años; presión laboral y acoso psicológico orquestado por su superior, de los cuales su cuerpo acusó recibo; restricciones para ir al baño o tomar agua; refiere un accidente en la mano y la imposibilidad de culminar su rehabilitación por impedimento de la empresa; tratos discriminatorios y humillantes por parte de nuevo jefe Sr. E.; sanciones disciplinarias, generándole todo ello la patología de depresión grave que la incapacita laboralmente. Realiza asimismo un encuadre de sus dolencias en la figura del mobbing o acoso psicológico. Por su parte la demandada L. C. A.R.T. resiste el planteo con el argumento básicamente del reclamo por una patología inexistente a los términos de la L.R.T., refiere que la patología no está listada y falta la relación de causalidad. Subsidiariamente solicita se habilite la repetición del fondo fiduciario. La empleadora C. S.A. E. sintéticamente niega y desconoce las dolencias por supuesto acoso; señala como infundadas las intoxicaciones denunciadas; califica como supuestas a las presiones sufridas por la actora. Señala que su mandante ejerció debidamente las facultades de dirección y control. Rechaza enfáticamente el reclamo civil formulado a su parte, por ser normas derogadas. Señala inexistencia de culpa de su representada. En razón de los términos en que se encuentra trabada la litis, y acreditadas las tareas realizadas para su empleadora, impone plantearse algunos interrogatorios, los que formulados en forma ordenada y conforme el mérito de la prueba rendida, nos llevarán a la solución de los puntos controvertidos: 1) Existencia de nexo casual entre las tareas y las patologías? ; 2) Frente al planteo de inconstitucionalidad del art. 6.2, competencia del Tribunal para de-terminar la naturaleza y grado de las dolencias?; 3) Imputación de responsabilidad en términos de reparación integral y/o L.R.T., sujetos responsables, alcance?. 1) Nexo causal a) En la audiencia de vista de causa los testigos - declaraciones que ya fueron transcriptas en la primera cuestión- en forma clara y coincidente dos de ellos, relataron detalladamente cuales fueron las tareas que realizó la actora a lo largo de su desempeño para la empleadora, los testigos fueron coincidentes en que las tareas se desarrollaban en un clima de presión constante, refirieron de bueno el carácter de la actora, señalaron la existencia de un grupo más apegado a la Jefatura (con mayores beneficios) y otro no (donde se encontraba la actora); la testigo N., compañera de trabajo, cajera al igual que la actora, refirió que la Sra. R. en un comienzo trabajaba contenta e incentivada, por un probable ascenso, pero al cambiar de Jefe de Cajas por E. sus posibilidades se vieron frustradas; señala como constante la vigilancia que se le hacía a la actora; si bien no era sólo a R. También relató que ella se descomponía mucho, no así la dicente. Recordó que en una oportunidad E. la trató de tonta. Además señaló que el Gerente no los escuchaba. La testigo expresó que luego de dejar de trabajar no quiso ir más al Hiper, porque el trato no era bueno, lo refirió 
"cansador para todos". El Sr. T. coincidió en señalar una cambio de carácter de la actora, al ingresar lo señaló como bueno y luego manifestó que trabajó con mucha presión, era el supervisor de caja, calificó como regular la relación de E. con la actora, pero describió que había cajeros apegados al jefe y otros no, era el caso de la actora, manifestó que a ella no le tenía confianza de turno, el maltrato era hacía el grupo. Sabía que la Sra. R. había estado enferma y se adelgazó mucho. Señaló que era una de las últimas en comer. Estos testimonios, son relevantes y me lleva en convicción a sostener que las tareas se desarrollaban en un clima de tensión importante capaz de provocar las patologías que desarrolló la actora, resultan significativos los dichos de la testigo, cuando refirió como cansador para todos el trato que se les dispensaba, al punto de no querer volver al E., este clima de presión me lleva a la íntima convicción que la salud de la actora sufrió menoscabo, la actitud permanente de presión por parte de los jefes o supervisores, si bien no se acredita que lo fuera únicamente hacía la actora, sí se prueba que lo era hacía un grupo con menos apego a la superioridad, ello sin dudas. Al testimonio de E., esta preopinante cotejando el resto de la prueba, le atribuye al menos parcialidad, por cuanto en la actualidad es subgerente de la firma demandada, y signado por la actora como unos de los hostigadores, su declaración en las respuestas relativas a la actora aparecen poco claras, restándole veracidad a sus dichos. Resulta relevante en este punto el análisis del expte. agregado como A.E.V. originario de la Subsecretaría de Trabajo No 5940-C-04, iniciado en agosto de 2004, en el cual la propia empleadora solicita la constitución de Junta Médica para la Sra. R., en consideración a un certificado médico emitido por un médico particular en el cual se diagnostica cuadro depresivo ansioso, y le requieren al organismo le indiquen si éste diagnóstico es correcto, para acceder al otorgamiento de licencia o les suministren la normativa a seguir. En esa instancia acompaña C. S.A. los antecedentes y certificados médicos presentados a la Empresa desde su ingreso hasta esa fecha. De la lectura de esa certificación puede claramente leerse que el diagnóstico es cuadro depresivo de tipo reactivo debido a una conflictiva laboral de larga data (fs.2 de autos); los certificados de fs. 3/15 hacen alusión al accidente sufrido en el dedo, que si bien es referenciado por la actora en la demanda, la incapacidad no es objeto de este proceso y de fs. 16 a 20 la dolencia que certifica son de gastroenteritis producida por probable intoxicación por alimentos. La junta médica no se expide sobre la atribución de la dolencia al trabajo, sino que considera criterioso realizarla por intermedio del Hospital Pereyra, la actuación administrativa queda en más sin movimiento. Esta presentación realizada a instancia de la empleadora, nos prueba que tenía conocimiento de la dolencia que le aquejaba. Los certificados médicos presentados con posterioridad dan cuenta de la continuidad de su patología (fs. 645/655), y que algunos fueran puesto en conocimiento de la empleadora mediante comunicaciones postales (ver originales fs. 625/632). Frente a estas certificaciones, la empleadora adopta el criterio de considerar, pese a la atribución de la patología depresiva a los conflictos laborales (fs. 646/648), como enfermedad inculpable y encuadrarlo en las previsiones de la L.C.T. arts. 208 y ss.. En este sentido, es que envía las C.D. donde le notifica a la actora la reserva del puesto (fs. 338), la que luego rectifica por tener cargas de familia. Lo cierto y concreto 
es que además de las certificaciones y misivas donde informa su patología, con fecha 11/07/05 la actora por C.D. (original fs. 629), denuncia una serie de hechos por los cuales concluye que su dolencia guarda directa relación con la experiencia traumática y de acoso moral en su lugar de trabajo por lo cual se trata de una enfermedad profesional y emplaza a la empleadora a denunciarla a L. C. A.R.T. para que haga efectiva las prestaciones dinerarias y en especie. La empleadora por C.D. del $14 / 07 / 05$, niega y rechaza todos los hechos imputados e informa que procederá a denunciarlo a la ART, como pide, califica de absurdos los reclamos y afirma conducirse con buena fe (fs. 639/640). La respuesta de la Sra. $R$. a esta misiva la realiza el día 30/07/05, señala que la negativa formulada evidencia la falta de cumplimiento del deber de previsión y buena fe contractual, en definitiva reitera que su dolencia es de carácter profesional por guardar relación directa con la experiencia traumática y de acoso moral en su lugar de trabajo (fs. 630); la demandada la rechaza el 02/08/05 informa que comunicó la situación a la ART y que cualquier reclamo debe dirigirlo a la aseguradora; reitera que se encuentra en reserva de puesto. Por su parte La caja ART, mediante C.D. de fecha 26/07/05, rechaza el siniestro toda vez que la enfermedad denunciada (Depresión reactiva) no se encuentra incluida en el listado de enfermedades profesionales (dec. 658/96). El mérito de las pericias médicas La pericia realizada por el especialista en psiquiatría, quien realiza su informe utilizando como técnica la entrevista clínica- psiquiátrica semidirigida, establece que la patología que padece la actora se correlaciona con Reacción Vivencial Anormal Neurótica (R.V.A.N.) con manifestación depresiva Grado II (dec. 659/96), y con la Neurósis Depresiva grado II, según478/98. Le asigna una incapacidad entre 5-10\%. Señala que "la sintomatología descripta que conforma el trastorno es consecuencia directa del fenómeno de hostigamiento que sufrió la actora durante su desempeño laboral. Dichos síntomas explicitados en el informe del estado actual se vinculan directamente con la vivencia de maltrato institucional sufrido por la actora". El informe impugnado por la actora en cuanto al porcentaje y los baremos utilizados y por la demandada al considerar que la patología descripta no aparece según la normativa vigente, por tanto no la consiente. El experto al contestar las observaciones a su informe destaca que la actora posee un $10 \%$ de incapacidad laborativa y en respuesta a la demandada claramente expone que "En el caso de autos existen síntomas y signos orientativos de patología que se gestan y agravan en un ámbito laboral con determinadas características, y que son objetivados durante el examen pericial. Cabe destacar que primariamente se descartaron todas las casas ajenas a esta etiología, como la personalidad predisponente, factores socioeconómicos, factores familiares." Por su parte el detallado informe realizado por la perito psicóloga, coincide en relacionar el trato recibido con la dolencia, considera respecto de las posibilidades de reinserción que no sería conveniente en su lugar de trabajo, por conllevar un riesgo de agravamiento de la sintomatología y en cuanto al porcentaje de incapacidad le asigna un $20 \%$ más factores de ponderación que estima en $13 \%$ más y que luego de ser impugnado el informe rectifica 
en sólo 5\% más. En razón del análisis armónico y detallado de la totalidad de la prueba colectada, la respuesta al primer interrogante queda zanjada, es mi plena convicción que la responsabilidad por la patología diagnósticada correspondiente a R.V.A.N resultó acreditada como derivadas de las tareas desarrolladas por la empleadora en un ambiente de presión que la provocó, esto es el nexo causal necesario para imputarla, corroborado con las testimoniales rendidas $y$ las periciales tanto médica como psicológica rendidas. El informe psicodiagnóstico realizado por el Lic. Mario Lamagrande en fecha 01/08/05, señala que en la paciente al principio de presentó un cuadro reactivo, con sintomatología ansiosa $y$ depresiva, evolucionando hasta convertirse en un episodio depresivo mayor, concluye que según el manual internacional de trastornos mentales, presenta DSM IV Episodio depresivo mayor, primer episodio. Grave $y$ Crisis de angustia (panick attack), le asigna un porcentaje de incapacidad del 30\%, correspondiendo a depresión grave. Por su parte el informe del experto en psiquiatría, le asignó un porcentaje del 10\% (fs. 402/402-455), y la perito en psicología del 20\%, más factores de ponderación (fs. 443/447-459). Del análisis detallado de las pericias rendidas en autos y el informe acompañado por la actora, surge la patología depresiva que sufre la actora, asociada directamente al ámbito laboral, sin dudas la Sra. R. expuesta a constantes presiones desarrolló la dolencia incapacitante, lo que también puede advertirse que desde el informe realizado por el Lic. Lamagrande hasta la realización de las pericias encomendadas en autos, la patología al menos disminuyó, al desaparecer el contacto con el ambiente de trabajo desfavorable, los dos informes realizados por los peritos dan cuenta que la gravedad disminuyó. Sin dudas que el daño en la psiquís de la actora se produjo a consecuencia de las tareas que desempeño bajo dependencia de la empleadora, daños que deben ser reparados y concluyo que siendo los baremos establecidos meros indicadores para el Tribunal, luego del mérito de los informes médicos y psicológicos rendidos luce justo y razonable establece el porcentaje de incapacidad parcial y permanente del $20 \%$, teniendo en cuenta los padecimientos sufridos, la edad de la actora y las posibilidades de reinserción laboral. 2) Inconstitucionalidad del art. 6.2. La actora dedujo el planteo de inconstitucionalidad del art. 6.2., resistidos por las demandadas. En éste caso había operado la reforma del decreto 1278/00, con entrada en vigencia el 01-03-01, que posibilitó una apertura del listado cerrado de enfermedades previsto por la redacción original de la ley de riesgos. Sin embargo, y pese a la reforma, la normativa estableció un procedimiento para la inclusión de enfermedades no previstas, y que en CADA CASO CONCRETO, pueda la Comisión Médica Central determinar como provocadas por causa directa e inmediata de la ejecución del trabajo, excluyendo la influencia de factores atribuibles al trabajador o ajenos al trabajo. Debiendo garantizar el debido proceso, produciendo las pruebas necesarias y emitiendo resolución debidamente fundadas. Si este procedimiento lo puede cumplir un órgano administrativo, con mayor razón este proceso lo cumple el órgano jurisdiccional, aquí resultan aplicables todos los argumentos que se darán al resolver la inconstitucionalidad de los art. 21 y 22 de la ley de riesgos. 
El debido proceso receptado en nuestra Constitución Nacional es el que ejercen los jueces naturales, quienes tienen el mandato constitucional para hacerlo (art. 18 C.N.). De modo acreditado en nexo causal, establecido el porcentaje de incapacidad parcial y permanente se declara la inconstitucionalidad del art. 6.2, y corresponde avanzar en el tercer interrogante. 3) Corresponde en estas circunstancias determinar si la pretensión esgrimida por la actora con sustento en la reparación integral reguladas por el Código Civil, tienen andamiaje suficiente para imputar responsabilidad fuera del sistema que rige los infortunios y enfermedades profesionales derivadas del trabajo. Soluciones diversas hemos adoptado frente a estos planteos, hemos sostenido: "Este Tribunal respecto a la reparación por la vía civil, extrasistémica ha tenido soluciones diversas, conforme la plataforma fáctica acreditada en cada uno de los casos concretos, por cuanto es nuestra tarea hacer justicia en el caso concreto, reflejando de este modo el principio de equidad, que debe imperar en las resoluciones, de modo que nos avocaremos a su estudio, el que nos llevará a resolver las defensas articuladas de falta de acción por las demandadas. "Autos No 35.158, carat.: "GARAY, CARLOS ALERTO C/MUNICIPALIDAD DE LA CAPITAL DE MENDOZA y ots. P/enf.acc." y $\mathrm{N}^{\circ} 30.310$, carat.: "JOFRE, JUAN GUILLERMO C/CABLE COR S.R.L. y ots. P/acc." (23/09/09). La actora en su demanda hizo referencia a distintos fallos para fundar la responsabilidad extrasistémica de la empleadora, así citó "Aquino" (C.S.J.N.), en subsidio "Olavarría" (S.C.J.M.), sin embargo en este caso traído a examen, no se advierte un grosero incumplimiento a las normas de higiene y seguridad, que resulte aplicable la doctrina sentada por nuestro Superior Tribunal en Olavarria. Desde la sanción de la L.R.T., han sido innumerables las sentencias recaídas con respecto a esta temática, que gracias a la doctrina y jurisprudencia, permitieron hacer permeable al sistema reparatorio, ampliando en algunos supuestos el listado cerrado de patologías, devolviendo en todo caso la competencia a los Juzgados para determinar el grado y naturaleza de las dolencias, declarando inconstitucional varios de sus artículos. La solución en el caso concreto. La actora en su demanda y en sus alegatos hizo referencia a la procedencia de los rubros reclamados. Fundo jurídicamente su planteo en los art. 512, 1072, 1074, 1109, 1113 del C.C., 75 de la L.C.T. y en la ley 19.549, consideró en este caso "La empresa a través de las instrucciones que le da a los jefes de sección o al personal jerárquico, estructura su política comercial pero también su política de trato o vinculación con los empleados... La empresa debió acentuar los controles sobre los jefes de secciones y desplegar a través de la dependencia de Recursos Humanos una encuesta ambiental que le permitiese corroborar las condiciones psicofísicas en que sus dependientes desempeñaban sus tareas...". En consecuencia, dedujo la inconstitucionalidad del art. 39 de la L.R.T. invocando la irrazonabilidad de la norma, citando doctrina y jurisprudencia en su abono. Sintéticamente, funda los distintos argumentos de responsabilidad que le asigna a la empleadora C. S.A., en su carácter de tal, conforme al deber se seguridad que le corresponde y la responsabilidad contractual, funda en los art. 75 y 76 de la L.C.T. , básicamente en la responsabilidad del empleador de resarcir los daños ocasionados en la salud del trabajador. En este caso traído a examen, se advierte que pese a los certificados médicos que informaban la existencia de una patología vinculada a 
las tareas que desarrollaba para la demandada, la empleadora tuvo una actitud violatoria del deber de buena fe que impone, al menos frente a la notificación de una presunta existencia de una enfermedad que aqueja al trabajador y que la vincula al contrato de trabajo, realizar las medidas necesarias para evitar el daño, ponderar el cuidado de la integridad psicofísica del trabajador, comunicar de inmediato a la ART, para que se le brindara la asistencia médica necesaria, en forma oportuna (art. 63, 75 y 79 L.C.T.). Sin embargo, la conducta asumida, frente a la comunicación de la enfermedad, la firma solicita la intervención de la autoridad administrativa para que le indique el camino a seguir. Confirma el accionar de la empresa, el testimonio del médico de la empresa Dr. V., quien tiene a su cargo el Centro Asistencial de C., quien reconoció que no hubo participación de la ART "porque es uno de los temas de discusión, de opinión si estas relaciones laborales por disgustos se podía hacer denuncia en la ART". En consecuencia corresponde, realizado el mérito armónico, detenido y meduloso de toda la prueba aportada y que nos llevará a concluir en la respuesta al primer interrogante a establecer el nexo causal entre las patologías y las tareas realizadas por la actora para la demandada; a la luz de los criterios seguidos por nuestra Suprema Corte de Justicia, los lineamientos que demarca el Superior Tribunal de la Nación en sus más recientes pronunciamientos y la aplicación de los Tratados internacionales con jerarquía constitucional (art. 75 inc. 22), conducen al favorable acogimiento de la pretensión en la reparación integral, sobre la base de los dispuesto por los art. 512, 1109, 1113 del Código Civil. Concluyendo, la empleadora C. S.A. E. debe responder con el objeto de promover una justa y equitativa reparación del real perjuicio, en tanto la respuesta reparadora del sistema especial, art. 14 de la ley 24.557, luce insuficiente comparado con los resultados de la reparación integral, que contempla la integridad física, psíquica y moral del trabajador (art. 1109 y 1078 C.C.), en concordancia con las disposiciones fundamentales de los art. 14 bis y 19 de la Carta Magna, tal como lo sostiene la Excma. C.S.J.N. desde el pronunciamiento de "Aquino" en adelante. Sin perjuicio de los argumentos señalados y a modo de comparación, señaló que de aplicarse exclusivamente el art. 14 y cc. de la ley de riesgos, conforme la siguiente operación y teniendo en cuenta el salario denunciado por la actora al interponer la demanda que asciende al monto de $\$ 901,40$, idéntico al IBM determinado por la pericia contable (fs. 513), (art. 12 y cc. L.R.T.), que multiplicado por 53, por el coeficiente de edad $2,6(65 / 25)$ y por el porcentaje de incapacidad de $20 \%$, arroja un monto de $\$ 24.843$ (Art. 14 ap.2 inc.a Ley 24.557). Por el contrario, si aplicamos la denominada fórmula Vázquez Vialard, $\left(C=a\left(1-(1 /(1+i) n)^{*}\right.\right.$ $1 / \mathrm{i})$, por el mismo daño y a la misma fecha corresponde un monto resarcitorio de $\$ 40.214,72$ computando el ingreso de $\$ 901,4$; la edad de 25 años y el porcentaje de incapacidad del $20 \%$. Fórmula que es criterio habitual del Tribunal aplicar para el resarcimiento por la vía de la reparación integral y no la lineal que aplica la actora en su petición, la que refiere una edad de 25 años y 35 de vida útil y una amortización del $20 \%$. Además, debe agregarse la reparación por el daño moral indudablemente padecido que se estima justo en el caso de autos reconocer en la suma de $\$ 12.064$ de conformidad con lo establecido en el art 1078 y concordantes del C.C. suma que hace un total de \$ $52.278,72$ por ambos conceptos. Monto al cual se le descuenta el 
correspondiente al determinado por las prestaciones dinerarias de la L.R.T. de $\$ 24.843$, resultando en definitiva un total de $\$ 27.435,72$.- Lo cual demuestra acabadamente que la exclusiva o excluyente aplicación de las previsiones de la LRT al caso de autos hubiera importado para el demandante una suma irrazonablemente inferior a la que le correspondería en virtud de una reparación integral de los daños y perjuicios ocasionados por la incapacidad que padece el ac-tor. Consecuentemente, en el presente decisorio resulta necesario declarar la inconstitucionalidad del art 39.1 de la ley 24557, por haberse dado los presupuestos del citado fallo "Aquino". Reiterando los términos expuestos en la causa $\mathrm{N}^{\circ} 32.498$, referimos Nuestro Máximo Tribunal Provincial tiene dicho a partir de la causa $\mathrm{N}^{\circ} 68.767$ "Pride Internacional SA en J 7871 "Acordino Graciela p/sí y p/su hijo Menor c/ Pride Petrotech internacional S.A.M.P.I.C. p/ Sum" S/Inc.-Cas" ( 13/03/01)que en relación a la LRT "...el sistema será o no constitucional en cada caso concreto, cuando se visualice el contenido reparador o si económicamente es justo o no el mismo..." y que "...Una de las críticas centrales a la ley es la exiguidad de las prestaciones. De eso se trata, de verificar en cada caso concreto si la prestación es o no exigua o razonable en términos de equidad y relacionada con el daño futuro que se quiere prever". Ahora bien, como lo ha aclarado la Excma SCJN en el precedente "Aquino" ello no acarrea la frustración de los elevados propósitos de automaticidad y celeridad del otorgamiento de las prestaciones perseguidas por la LRT porque de la invalidez constitucional del art 39.1 no se sigue que las ART queden relevadas de satisfacer las obligaciones que han contraído en el marco de la citada ley. En la misma vertiente se inscribe el criterio sustentado por Excma. CSJM en numerosos precedentes (incluidos "Olavarría") donde ha tenido ocasión de sostener que la responsabilidad del empleador no debe considerarse como solidaria, sino como sucesiva y excluyente de modo tal que la aseguradora tendría a su cargo las prestaciones de la ley ( arts 11 y sgtes y 20 de la ley 24557) y el empleador responderá por la responsabilidad extrasistémica, agregando el Máximo Tribunal que en algunos supuestos lo que se da es la coexistencia de dos sistemas de reparación: uno atribuible a la ART y dentro de los límites establecidos en la ley especial (contractual) y otro atribuible sólo al empleador (extracontractual), que corresponde a los conceptos de integralidad de la indemnización y como principal obligado al cumplimiento de las normas de higiene y seguridad. Ambas responsabilidades actúan en forma complementaria, una para la faz tarifada y genérica del sistema, y la otra para el caso de reparación integral por incumplimiento a las normas de higiene y seguridad..." (SCJM; Autos $\mathrm{N}^{\circ} 73.515$ "Asociart SA en J: 9.846 "Marquez D.F. c/ Agroindustrias Molto SA p/ Ord" S/ Inc. Cas", fallo del 09/06/03; ídem: Expte No 74.087 "Asociart en J: 30.365 "Delgado L.A. c/ O.H.A. Construcciones SRL y Ots p/ Ord." s/ Inc . Cas" fallo del 26/05/03). En consecuencia, dejó establecido la responsabilidad que le cabe por la incapacidad del $20 \%$ que padece la actora encuadrable en las previsiones de la L.R.T., ello también ha sido resuelto en forma pacífica, pues el Tribunal es el que encuadra en derecho la pretensión del actor. En concordancia con lo expuesto, lo establecido por el art. 14 de la ley 24.557 se procede a realizar el cálculo de la indemnización por incapacidad laboral. Conforme a la pericia contable el cálculo, se reitera el cálculo realizado supra que determinó un 
ingreso base mensual de la actora de $\$ 901,40, *(65 / 25=2,6) 2,6 * 53 * 20 \%=$ $\$ 24.843$. También reclama la actora de la Aseguradora de Riesgos las sumas correspondientes a los seis meses restantes a la incapacidad transitoria desde febrero de 2005 a agosto de 05, teniendo en cuenta el tratamiento de enfermedad inculpable que se le dio a la trabajadora y resuelto el nexo causal, luce procedente el rubro por $\$ 5.408,40$. Respecto del reclamo por incapacidad provisoria, no resulta procedente atento la solución que se dará respecto al cómputo de intereses que adelanto se determinará desde la fecha del certificado otorgado por el Lic. Lamagrande de fecha 01/08/2005. Concluyendo, la demanda debe prosperar contra C. S.A. E. por responsabilidad extrasistémica en la suma de $\$ 27.435,72$ y contra L. C. A.R.T. por responsabilidad sistémica por la suma de $\$ 30251,40$ con más intereses desde el certificado médico de fecha 01 de agosto de 2005 que obra en autos, equivalente a la tasa activa que informa el Banco de la Nación Argentina a partir de esa fecha del dictado de la sentencia, que arroja un porcentaje de $88,25 \%$ y de $\$ 24.212,02$, totalizando un monto de PESOS CINCUENTA Y UN MIL SEISCIENTOS CUARENTA Y SIETE CON $74 / 00(\$ 51.647,74)$ a cargo de C. S.A. E. y de $\$ 29.696,86$, suma que arroja el monto de PESOS CINCUENTA Y SEIS MIL NOVECIENTOS CUARENTA Y OCHO CON 26/00 $(\$ 56.948,26)$ a cargo de L. C. A.R.T. hasta la fecha de esta resolución, (res. SRT. N414/99). Nuestra Suprema Corte así resolvió la determinación del cómputo de los intereses en los autos No 74.893, carat.: "ASOCIART A.R.T. S.A. EN j.: 9272 "LUNA FANNY L. C/DISCO S.A. P/ACCIDENTE" S/CAS"; No 81637, carat:: "ASOCIART ART EN J: 9613 'CHACON, JUAN C. V. INDUSTRIAS METALÚGICAS PESCARMONA S.A. P/OR. S/CAS (8/8/2005). Conforme el cálculo de intereses formulado en autos, el tratamiento del planteo de inconstitucionalidad de la Ley 7198, luce inoficioso. En cuanto a la solicitud de habilitación para repetir del fondo fiduciario formulado por La Caja ART, debe estarse a lo dispuesto por las resoluciones N590/97; 58/98 y 190/98 (conjunta SRT Y SAFJP); 432/99; 744/03; 460/08 de la S.R.T. y dec. $1278 / 00$ modificatorio del dec. 590/97 y cc., sin perjuicio de la posibilidad que le cabe a la Aseguradora de repetir los montos de condena, conforme la resolución adoptada en estos autos respecto del carácter y naturaleza de la patología que incapacita a la actora. ASÍ VOTO. A LA TERCERA CUESTION LA DRA. N. L. L. DIJO: En consideración con el principio chiovendano de la derrota las costas deberán ser soportadas por la demandadas C. SA E. y L. C. ART en cuanto prospera la demanda y por los montos establecidos para cada una de ellas, conforme el criterio sentado por la Excma. Suprema Corte de Justicia de Mendoza en el sentido de que las mismas se aplican por la procedencia del rubro, es decir por la calidad independientemente de la cantidad (causa "Delgado c/ OHA Construcciones...). (art. 31 y 108 C.P.L. y 36 C.P.C.). ASÍ VOTO Los Dres. J. J. B. y J. G. G. por sus fundamentos adhieren a los votos que anteceden. Con lo que se dio por terminado el acto, pasándose a dictar sentencia que a continuación se inserta: Mendoza, 05 de abril de 2010.- Y VISTOS: El acuerdo arribado el Tribunal RESUELVE: I.- Declarar la inconstitucionalidad de los artículos 6.2, 21, 22, 39 y 46 de la ley 25.557.- II.- Hacer lugar a la demanda interpuesta por la Sra. R. A. R. y condenar a pagar la suma de PESOS CINCUENTA Y UN MIL SEISCIENTOS CUARENTA Y SIETE CON 74/00 $(\$ 51.647,74)$ a C. S.A. E., y a cargo de L. C. 
A.R.T. la suma de PESOS CINCUENTA Y SEIS MIL NOVECIENTOS CUARENTA Y OCHO CON 26/00 $(\$ 56.948,26)$ montos calculados hasta la fecha de esta resolución, en concepto de incapacidad parcial y permanente. En caso de incumplimiento, se deberá computar el interés equivalente a la tasa activa res. (SRT. N²14/99), hasta el momento del efectivo pago. III.- Las costas son a cargo de las demandadas en la proporción que prospera (art. 31 C.P.L. y 36 C.P.C), conforme lo resuelto en la tercera cuestión. IV.- Regular los honorarios profesionales teniendo en cuenta la labor desarrollada y a cargo de C. S.A. E. de los Dres. S. L. en $\$ 2.820$, C. L. en $\$ 1.897,9$ y C. L. (h) en $\$ 3.760 ;$ Dr. H. D. S. en $\$ 2.892$ y Dra. C. Mo. en $\$ 1446$; Dres. J. P. M. en $\$ 723$ y Dr. R. Z. en $\$ 1.446$ y Dr. P. B. en $\$ 1.446$ al Sr. Perito Contador S. C. M. en $\$ 1.484$ y al Sr. Perito Psiquiatra Dr. J. A. P. en $\$ 1.484$ y Psicóloga M. P. C. en $\$ 1.484 ;$ a cargo de L. C. A.R.T. de los Dres. S. L. en $\$ 3.108$, C. L. en $\$ 2.072$ y C. L. (h) en $\$ 4.145$; Dr. H. D. S.en $\$ 3.189$ y Dra. C. M. en $\$ 1.594$; Dres. J. P. M. en $\$ 797$ y Dr. Raúl Z. en $\$ 1.594$ y Dr. P. B. en $\$ 1.594$ al Sr. P. C. S. C. M. en $\$ 1.637$ y al Sr. Perito Psiquiatra Dr. J. A. P. en $\$ 1.637$ y Psicóloga M. P. C. en $\$ 1.637$ (arts. 2, 3, 4, 31 Ley 3641,7 Ley 3522 y art. 505 C.C.).- V.- Emplazar a las partes demandadas en TREINTA DÍAS, para que abone en autos la TASA DE JUSTICIA por $\$ 1.032,96$ C. S.A. E. y $\$ 1.138,96$ L. C. A.R.T., y a las partes en DIEZ DÍAS, para que abonen los APORTES DE LA LEY 5059 por $\$ 2.171,92$, y a los profesionales intervinientes en $\$ 108,59$ correspondientes a Derecho Fijo, todo bajo apercibimiento de ley. VI.- Firme y ejecutoriada la presente resolución, emplazase a las partes en DIEZ DÍAS a retirar la documentación original acompañada, bajo apercibimiento de proceder por Secretaría a su archivo NOTIFIQUESE A LA DIRECCIÓN GENERAL DE RENTAS DE LA PROVINCIA, AL COLEGIO DE ABOGADOS Y A LA CAJA FORENSE. REGÍSTRESE, NOTIFÍQUESE Y CÚMPLASE.- Con Juez Dr. J. G. G. Dra. N. L. L. Dr. J. J. B.

Total (1) - C. S.A. E. $=\$ 109905$ (Acuerdo: $\$ 51.647,74 ;$ gastos del juicio: \$ 4343,84; honorarios profesionales: $\$ 43.163,40)+$ afip

\section{Hechos y exordio}

III.- OBJETO:

a) Que en el carácter invocado y siguiendo expresas instrucciones de mi mandante, vengo a interponer formal demanda ordinaria en contra de domicilio en por la suma de PESOS CUARENTA Y DOS MIL SEISCIENTOS SETENTA Y DOS CON 27/100 (\$ 42.672,27), en concepto prestaciones dinerarias de pago mensual por Incapacidad Laboral Transitoria (ILT), y en concepto de Indemnización por Incapacidad derivada de enfermedad profesional conforme la Ley 24.557, más la suma que fije el Tribunal por Incapacidad Laboral Permanente Parcial Provisoria (I.P.P. Provisoria) hasta la fecha de la incapacidad definitiva de la actora; y en contra de

con domicilio en

Mendoza, por la suma de PESOS CIENTO VEINTISIETE MIL NOVECIENTOS SESENTA Y DOS CON 74/100 (\$ 127.962,74) en concepto de indemnización integral por daños y perjuicios por enfermedad ocasionada como consecuencia del trabajo (deducidos los importes por los que pueda ser condenada o lo que en mas o en menos resulte de la prueba a rendirse en autos o que estime justo el Tribunal, con mas sus intereses legales y costas del proceso.

b) Asimismo, siguiendo expresas instrucciones de mi mandante, y conforme lo autoriza el art. 32 del Código Procesal Laboral, mi parte viene a solicitar a V.E. que previo a correr traslado de la demanda, disponga la MEDIDA CAUTELAR solicitada en la parte final del presente escrito, ordenando a 1 ., suministrar a la actora las prestaciones médicas, farmacológicas y apoyo terapéutico psicológico a la brevedad por la enfermedad profesional que se reclama en la presente, y en subsidio para el supuesto que V.E. considere que no procede contra la A.R.T. la medida cautelar, solicitamos se haga efectiva la misma en contra de su empleador 
8. Monto reclamado: $127.962,74$

9. Diagnóstico inicial, herramientas utilizadas, grado de incapacidad (de parte):

\subsection{Fecha informe: 04/03/2005}

9.2. Herramientas utilizadas. MINI MENTAL (evaluación de funciones cognitivas), PRIME - MD (Psicopatológico), MIPS (personalidad), BENDER (neurológico), H.T.P (Rasgos generales - proyectivo) y RAIVEN (inteligencia) y entrevistas.

\subsection{Diagnostico:}

La Sra. R. A. R. según los criterios del DSM IV presenta un Trastorno Adaptativo con ansiedad y estado de ánimo depresivo (309.24) como característica esencial el desarrollo de síntomas emocionales y comportamentales en respuesta a un factor estresante psicosocial identificable (presión laboral por su jefe directo)

Aparece como comórbido Crisis de Angustia (300.21) la característica esencial es por la aparición súbita de síntomas de aprensión acompañados habitualmente de sensación de pérdida de control y la sensación de muerte. Que se acompaña de tensión física, malestar y sobre todo la aprensión que es el estado de "miedo al miedo"

9.4. Grado de incapacidad: Según el código de tablas de incapacidades laborales del Dr. Castex la paciente presenta Neurosis de angustia severa $35 \%$ por presentar en su cuadro manifestaciones psíquicas y somáticas graves asociadas a crisis de angustia que requieren de un tratamiento integrado psicológico y psiquiátrico.

\subsection{Diagnóstico psicológico y grado de incapacidad (peritado)}

9.6. Fecha informe: $19 / 03 / 2008$

\subsection{Pruebas utilizadas}


-Entrevista psicológica directa.

-Test Gestáltico Visomotor de Bender.

-WAIS.

(ref.por

-Tests proyectivos gráficos.

-MIPS.

-MMPI-2.

-Test de Rorschach (Sistema Comprehensivo de Exner).

\subsection{Diagnóstico}

Como ya fue señalado, la actora presenta un estado de sobrecarga erna de tipo crónico potenciado por la presencia de factores externos.

\subsection{Grado de incapacidad}

Siguiendo el baremo de evaluación de incapacidades laborales Jecreto $N^{\circ} 659 / 96$ se estima un porcentaje de incapacidad de $20 \%$ correspondiente a una R.V.A.N. con manifestación psicosomática grado III). $\downarrow$ esto se agrega un $13 \%$ que surge de la aplicación de los factores de onderación (incluyendo tipo de actividad, posibilidades de reubicación aboral y edad), lo que deriva en un total del $33 \%$ de incapacidad.

\subsection{Diagnóstico psiquiátrico y grado de incapacidad (peritado)}

\subsection{Fecha informe:}

\subsection{Pruebas utilizadas}

\section{II.- ACTUACIÓN PERICIAL:}

Que para llevar a cabo el informe pericial procedí a examinar a la actora utilizando como técnica la entrevista clínico-psiquiátrica semidirigida.

\subsection{Diagnóstico y grado de incapacidad}

Pueden observarse a través del relato de la actorá síntomas ansiosos y angustia en relación al fenómeno de persecución laborat vivenciado en lo que fue su ámbito y circunstancias de trabajo.

\section{Reevaluación actual resultado:}




\begin{tabular}{|c|c|c|c|c|c|}
\hline Somatizaciones & 28 & \multirow{2}{*}{$\begin{array}{l}\text { total de } 48 \\
\text { total de } 40\end{array}$} & 2,33 & T63 & SOM \\
\hline Obsesiones y compulsiones & 25 & & 2,50 & T63 & OBS \\
\hline Sensitividad interpersonal & 15 & total de 36 & 1,67 & T50 & S.I. \\
\hline Depresión & 40 & \multirow{2}{*}{$\begin{array}{l}\text { total de } 52 \\
\text { total de } 40\end{array}$} & 3,08 & T63 & DEP \\
\hline Ansiedad & 27 & & 2,70 & T63 & ANS \\
\hline Hostilidad & 14 & \multirow{2}{*}{$\begin{array}{l}\text { total de } 28 \\
\text { total de } 24\end{array}$} & 2,00 & T63 & HOS \\
\hline Ansiedad fóbica & 11 & & 1,83 & T63 & FOB \\
\hline Ideación paranoide & 11 & total de 24 & 1,83 & T50 & PAR \\
\hline Psicoticismo & 15 & total de 40 & 1,50 & T63 & PSIC \\
\hline Items adicionales & 10 & total de 28 & 1,43 & & \\
\hline INDICE DE SEVERIDAD GLOBAL (IGS) & 2,18 & T63 & & & \\
\hline INDICE DE MALESTAR SINTOMATICO POSITIVO (IMSP) & 2,97 & T63 & & & \\
\hline TOTAL DE SINTOMAS POSITIVOS (STP) & 66 & T63 & & & \\
\hline ITEMS ADICIONALES & \multicolumn{3}{|c|}{\begin{tabular}{l|l|} 
Puntaje & Significativo \\
\end{tabular}} & & \\
\hline 5: Falta de interes en las relaciones sexuales & \multicolumn{2}{|c|}{\begin{tabular}{l|l}
4 & \\
\end{tabular}} & SI & & \\
\hline 19: Poco apetito & \multicolumn{2}{|r|}{3} & SI & & \\
\hline 44: Problemas para dormir & \multicolumn{2}{|r|}{$\mathbf{0}$} & NO & & \\
\hline 59: Pensamientos acerca de la muerte o el morirse & \multicolumn{2}{|r|}{3} & SI & & \\
\hline 60: Comer en exceso & \multicolumn{2}{|r|}{3} & SI & & \\
\hline 64: Despertarse muy temprano. & \multicolumn{2}{|r|}{1} & NO & & \\
\hline 66: Sueño intranquilo. & \multicolumn{2}{|r|}{$\mathbf{0}$} & NO & & \\
\hline 89: Sentimientos de culpa. & \multicolumn{2}{|c|}{$\mathbf{0}$} & NO & & \\
\hline ITEMS CRITICOS & \multicolumn{2}{|c|}{ Puntaje } & ificativo & & \\
\hline 15: Pensar en quitarme la vida & \multicolumn{2}{|c|}{2} & NO & & \\
\hline 16. Escuchar voces que otras personas no oyen & \multicolumn{2}{|r|}{$\mathbf{0}$} & NO & & \\
\hline 54. Perder las esperanzas en el futuro & \multicolumn{2}{|r|}{4} & SI & & \\
\hline
\end{tabular}

11. Conclusión del caso: Se verificó coincidencia de la resolución del juez respecto al daño psíquico y moral producido, atendiendo a un deterioro traducido en un porcentaje que se mantuvo en forma crónica relevado la perito psicóloga y en la post evaluación, se constató que la empleada evaluada aun no podía insertarse laboralmente y presentaba sintomatología psicopatológica.

\subsubsection{CASO 5}

1. Fecha de inicio: $07 / 07 / 2006$

2. Fecha de resolución: $14 / 08 / 2006$

3. No Expediente: 14420

4. Nombre: L., M. L. Y H. S. S. A. P/ H.

5. Estado: Resuelto

6. Resolución: Convenio

7. Hechos y exordio

Fojas: 16 Expte. xxxx, "L., M. L. Y H. S. S. A. P/ H.". MENDOZA, 14 de agosto de 2006.- AUTOS Y VISTOS: Que mediante el acto conciliatorio que informa el acta de fs. 08/09 las partes han arribado a un acuerdo de sus intereses y derechos en litigio. Teniendo en cuenta lo establecido en el art. 15 de la ley 20.744 y en un todo de acuerdo con lo dictaminado por la Sra. Fiscal de Cámaras a fs.12, el Tribunal RESUELVE: I. HOMOLOGAR JUDICIALMENTE el convenio de fs. 08/09, teniéndolo por ley para las partes. II. La demandada deberá efectuar el depósito del monto convenido a favor del accionante, en los términos establecidos en el convenio. III. Las costas se establecen a cargo de la demandada. IV. EMPLAZAR a la demandada para que en el término de DIEZ DIAS haga efectivo aportes ley 5059 (art.16 inc.a)-\$6.000,00 (PESOS SEIS MIL 
CON 00/100),en el término de TRES DIAS art.96 ley 4976 Derecho Fijo$\$ 300,00$.- (PESOS TRES CIENTOS CON 00/100) y en el término de TREINTA DIAS haga efectivo art.297 inc.f) del Codigo Fiscal Tasa de Justicia - $\$ 6.000,00$ (PESOS SEIS MIL CON 00/100). V. Pongase en conocimiento a la AFIP de la resolución recaída en las presentes actuaciones a los fines que extraiga compulsa de las mismas de así corresponder, en virtud de lo prescripto por la ley 25.345. REGISTRESE Y NOTIFIQUESE.- M.A.B.

8. Monto reclamado: $\$ 300000$

9. Diagnóstico inicial, herramientas utilizadas, grado de incapacidad (de parte):

\section{Fecha primer informe: $10 / 10 / 2005$}

10.1. Herramientas utilizadas: Entrevistas, H.T.P. (prueba proyectiva: funciones yoicas y mecanismos de defensa), M.B.I (Test para la evaluación del Síndrome de Burnout), L.I.P.T (Inventario de Acoso Laboral de Leymann), PRIME - MD (Evaluación de las funciones psicopatológicas), MIPS (Evaluación validada para la República Argentina de la personalidad), BENDER (evaluación psiconeurológica) y BETA II-R (Test de inteligencia).

\subsection{Diagnostico:}

La Sra. Letizia Marina según los criterios del DSM IV presenta un Trastorno Adaptativo con ansiedad y estado de ánimo depresivo (309.24). Como característica esencial la paciente ha desarrollado síntomas emocionales y comportamentales en respuesta a un factor estresante psicosocial identificable; la presión laboral e inconvenientes clínicos surgidos de este acontecimiento.

10.3. Grado de incapacidad: Dada esta característica según el baremo de la Dirección de Reconocimientos médicos de la provincia de Buenos Aires. "El baremo revisado y establecido por el grupo de investigación de Castex..." (Talarico I., 2003). Da por resultado el siguiente grado de deterioro: 3.5. Desarrollos reactivos: c) Severo $25 \%$; 3.10. Síndrome de fatiga psicofísica: b) Moderado $25 \%$

\subsection{Diagnóstico psicológico y grado de incapacidad (peritado)}

No se realiza

10.5. Diagnóstico psiquiátrico y grado de incapacidad (peritado) 


\section{No se realiza}

\section{Reevaluación actual resultado:}

\begin{tabular}{|c|c|c|c|c|c|}
\hline Somatizaciones & 16 & total de & 1,33 & T50 & SOM \\
\hline Obsesiones y compulsiones & 19 & total de & 1,90 & T50 & OBS \\
\hline Sensitividad interpersonal & 13 & total de & 1,44 & T50 & S.I. \\
\hline Depresión & 27 & total de & 2,08 & T50 & DEP \\
\hline Ansiedad & 9 & total de & 0,90 & T50 & ANS \\
\hline Hostilidad & 9 & total de & 1,29 & T50 & HOS \\
\hline Ansiedad fóbica & 6 & total de & 1,00 & T50 & FOB \\
\hline Ideación paranoide & 12 & total de & 2,00 & T50 & PAR \\
\hline Psicoticismo & 9 & total de & 0,90 & T50 & PSIC \\
\hline Items adicionales & 9 & total de & 1,29 & & \\
\hline INDICE DE SEVERIDAD GLOBAL (IGS) & 1,43 & T50 & & & \\
\hline INDICE DE MALESTAR SINTOMATICO POSITIVO (IMSP) & 2,19 & T50 & & & \\
\hline TOTAL DE SINTOMAS POSITIVOS (STP) & 59 & T50 & & & \\
\hline ITEMS ADICIONALES & \multicolumn{4}{|c|}{ Puntaje Significativo } & \\
\hline 5: Falta de interes en las relaciones sexuales & & $\mathbf{3} \quad \mid$ & SI & & \\
\hline 19: Poco apetito & & 3 & SI & & \\
\hline 44: Problemas para dormir & & 2 & NO & & \\
\hline 59: Pensamientos acerca de la muerte o el morirse & & $\mathbf{0}$ & NO & & \\
\hline 60: Comer en exceso & & $\mathbf{0}$ & NO & & \\
\hline 64: Despertarse muy temprano. & & $\mathbf{0}$ & NO & & \\
\hline 66: Sueño intranquilo. & & 2 & NO & & \\
\hline 89: Sentimientos de culpa. & & 2 & NO & & \\
\hline ITEMS CRITICOS & & intaje & Significativo & & \\
\hline 15: Pensar en quitarme la vida & & $\mathbf{0}$ & NO & & \\
\hline 16. Escuchar voces que otras personas no oyen & & $\mathbf{0}$ & NO & & \\
\hline 54. Perder las esperanzas en el futuro & & 2 & NO & & \\
\hline
\end{tabular}

12. Conclusión del caso: En este caso la empresa, a fin de evitar la exposición mediática una vez presentada la demanda decidió resarcir el cien por ciento de lo reclamado por las consecuencias del acoso. Al año 2010 se constató que la empleada evaluada aun no podía reinsertarse formalmente en el mercado laboral, realizando sólo empleos virtuales, manteniendo sintomatología psicopatológica y compensada psiquiátricamente.

\subsubsection{CASO 6}

1. Fecha de inicio: $23 / 08 / 2006$

2. Fecha de resolución:

3. No Expediente: 37.XXX

4. Nombre: B. G. S. C/ L. C. A.R.T Y OT P/ E. A.

5. Estado: Etapa de sustanciación

6. Resolución: en proceso.

7. Hechos y exordio 
III.- OB.JETO:

A) Que siguiendo expresas instrucciones de mi mandante, y conforme lo autoriza el art. 32 del Código Procesal Laboral, mi parte viene a solicitar a V.E. que previo a correr traslado de la demanda, disponga la MEDIDA CAUTELAR solicitada en la parte final del presente escrito, ordenando a depositar mensualmente a la orden de estos autos, la suma de dinero que V.E. estime prudencial, a fin de solventar los gastos necesarios para que la actora continúe los tratamientos farmacológicos, psicológicos y psiquiátricos con los profesionales que la estaban atendiendo hasta antes de la interrupción de los mismos por falta de recursos económicos, y en subsidio para el supuesto que V.E. considere que no procede contra la A.R.T. la medida cautelar, solicitamos se haga efectiva la misma en contra de su empleador

\section{V.- HECHOS:}

\section{A) Antecedentes}

\section{1-Ingreso a la empresa en plenitud física y mental}

Mi mandante comenzó a trabajar para la demandada como cajera full time de fin de semana en fecha 06/10/01. El horario de trabajo era de sábado a domingo de $9 \mathrm{hs}$ a $18 \mathrm{hs}$.

Al momento del ingreso de la actora se encontraba apta para realizar cualquier tipo de tareas, no presentado ningún tipo de dolencia. Era una persona sana fisica y emocionalmente.

B) Que en el carácter invocado y siguiendo expresas instrucciones de mi mandante vengo a interponer formal demanda ordinaria contra de con domicilio en con domicilio Mendoza, por la suma de PESOS DIEZ Y SIETE MIL OCHENTA CON 81/100 (\$17.080,81), en concepto prestaciones dinerarias de pago mensual por Incapacidad Laboral Transitoria (ILT), y en concepto de Indemnización por Incapacidad Laboral Permanente Parcial derivada de enfermedad profesional conforme la Ley 24.557 ; y contra de con domicilio en calle

de PESOS CUARENTA Y NUEVE MIL OCHOCIENTOS TREINTA Y DOS CON 52/100 $(\$ 49.832,52)$ en concepto de indemnización integral por daños y perjuicios por enfermedad derivada del trabajo (deducidos los importes por los que pueda ser condenada.nongn....), y en concepto de rubros indemnizatorios y remuneratorios que proceden por el despido injustificado de la actora o lo que en mas o en menos resulte de la prueba a rendirse en autos o que estime justo el Tribunal, con mas sus intereses legales y costas del proceso.

\section{desencadenante de sus dolencias.}

2-Trato humillante a la actora por supuesta falla de caja como

restricciones inhumanas impues concurrir a los sanitarios o beber agua, además de malos tratos verbales por parte de los supervisores o jefes de caja que creaban un ambiente laboral tenso y sumamente estresante.

Sin embargo, la actora hasta ese momento a costa de su salud psicofisica había tratado de sobrellevar la situación de estrés en su lugar de trabajo, ya que su sueldo era una ayuda fundamental en el sostén de su familia compuesta por dos hijos menores.

En fecha domingo $\mathbf{2 0}$ de junio del 2004, la actora se presentó a trabajar como lo hacía habitualmente, la habilitaron en la caja $N^{\circ} 12$ a las 11 hs; y le efectuaron un arqueo de caja donde el importe resultante del mismo fue correcto, y por eso la enviaron a almorzar. Dejó el dinero resultante del arqueo en la caja $\mathrm{N}^{\circ} 17$. Cuando la actora regresó de su almuerzo cobró a un solo cliente con tarjeta crédito, y luego de eso le efectuaron un nuevo cambio a la caja $N^{\circ} 18$, ya que tenían que estar habilitadas las cajas de atrás de la línea (cajas pares). En ese momento, el supervisor Adrián Agrícola le ordenó concurrir a una reunión de todo el personal que se desarrolló en otro sector del Hipermercado, perdiendo mi mandante totalmente de su vista la caja. Antes de retirarse de la caja que estaba atendiendo para concurrir a la reunión del personal, pide a la supervisora le retire el cambio con el que contaba hasta el momento, a lo que ésta responde que no iba a hacerlo porque la actora tenía mucho cambio y después lo iba a necesitar. Al finalizar la mencionada reunión, cerca de las 14:40hs aproximadamente, le ordenaron a mi mandante limpiar las cajas (con gamuza y blem). Luego de cumplir con dicha tarea, a eso de las $16 \mathrm{hs}$ la habilitan nuevamente en la caja asignada con anterioridad, es decir la caja $N^{\circ} 18$ y al abrir la actora la caja registradora para dar vuelto a un cliente nota que no tiene ningún billete de $\$ 10, \$ 20, \$ 50, \$ 100$, los cuales ella solía colocarlos a todos en el mismo lugar. Este hecho le extrañó, pero como tenía que continuar atendiendo a los clientes en la fila, esperó al momento del arqueo de caja para hablar con el supervisor del tema. Al realizarse el cierre de caja, la jefa de turno, Sra. Raquel Luque, le suministra el reporte que indicaba que existía un faltante de $\$ 449$. Mi mandante desesperada y sorprendida procedió a revisar los parciales (los parciales son el dinero en billetes de $\$ 20, \$ 50$ y $\$ 100$ que ingresan) e inclusive la bolsa de residuos y la gabeta pero no pudo e. Inmediatamente, la jefa de turno llevó a la actora a una habitación, en la que usualmente las cajeras realizan la entrega del dinero, y se quedó a solas con ella. 

de caja. Mi mandante muy angustiada y al borde de las lágrimas respondió que no sabía, que no comprendía que había ocurrido puesto que hasta el momento anterior a concurrir a la reunión de personal estaba todo el dinero. Les explicó que le había llamado la atención el faltante de billetes al reincorporarse a la caja. Entonces la Jefa de Turno revisó el rollo de auditoría para comprobar si existía una sobreventa. Luego que de informarle a la actora que no existía sobreventa alguna, la jefa de turno le ordenó a la la..... que se retirase a su casa, que no podía hacer nada y la amenazó diciéndole que podía llegar a perder su puesto de trabajo por este hecho. La actora le respondió que no se retiraría del lugar hasta que se averiguase que había sucedido con el faltante ya que hasta ese día su desempeño como cajera habia sido impecable. Prueba de este buen desempeño era su legajo, que no presentaba ningún tipo de sanción disciplinaria ni antecedentes de faltantes de caja en tres años de trabaịo.

La actora le solicitó entonces al Jefe de Seguridad ver los videos de las filmaciones registradas por las cámaras de seguridad del Hipermercado ese día. El jefe de seguridad se negó al requerimiento de la actora sin mayores explicaciones y junto a la Jefa de Turno insistieron en que la actora se retirase del lugar. Tiempo después la actora se enteró que cuando sucedian este tipo de situaciones se les permitía a los empleados ver las filmaciones una vez cerrado el local. Mi mandante insistió en que evaluasen las irregularidades mencionadas, en razón de que hasta ese momento las cajas se podían abrir sin llave, sin ser necesario una clave personal, bastando un golpe para abrirlas, por lo cual cualquiera podría haber sustraido el dinero mientras la actora se encontraba en reunión de personal. La Jefa de Turno expresó que ya las habian arreglado y que ella había quedado a cargo de la línea de caja durante la mentada reunión y que no había visto nada.

La actora desesperada por la falsa acusación, le solicitó a la Jefa de Turno que le separase en el reporte, las ventas en efectivo de aquellas realizadas con tarjeta de crédito, para poder evaluar cuánto dinero en efectivo existía en la caja antes de retirarse a la reunión. Luego de acceder de muy malas ganas y después de 40 minutos, le respondió a mi mandante que de ahi tampoco surgía la justificación del faltante. Entonces le preguntó a la qué monto de dinero le figuraba en el reporte, y ella le expresó que $\$ 500$. Entonces la actora le replicó a su jefa que si faltaban $\$ 449$ y en el reporte de caja figuraban $\$ 500$ quería decir que el dinero se encontraba en la caja cuando ella se retiró a la reunión. La

le respondió que el reporte presentado por la actora del dinero no tenia validez, porque lo único que contaba era la presencia física del dinero. A las 20:30hs. aproximadamente llamó al personal femenino de seguridad para que revisase a la actora, que la sometieron a una revisión vejatoria y humillante haciéndole levantarse la remera, bajarse el pantalón, sacarse las medias y los botines. La actora después se retiró a su casa en un estado de nervios y angustia que le impidió amamantar a su bebé.

3- Ejercicio abusivo del poder disciplinario de la empresa. Imposición de suspensión. Persecusión psicológica y discrimanción de la actora por parte del Jefe de cajas.

Al día siguiente del faltante de caja, es decir el día lunes, la actora llamó por teléfono al personal a cargo de las cámaras de video del quienes le prometieron que le harían ver el video y le señalaron si no le había parecido extraña la actitud de la Jefa de Turno de no querer esclarecer el hecho, y que ellos sospechaban de las personas a cargo del control de las cajas dado que habian ciertas irregularidades, aunque no tenían pruebas porque las cámaras funcionan en forma rotativa, al no ser que la empresa dispusiera la focalización de las mismas en un objetivo.

semana mi mandante recibió una llamada telefónica del

Jefe de Cajas, comunicándole que se encontraba suspendida durante todo el fin de semana siguiente. La actora vivió con gran angustia, llanto, estado de insomnio el transcurso de la mencionada semana. Cabe señalar que a medida que el tiempo transcurría y el acoso moral a mi mandante se tornaba más evidente, la actora sufria de malestar estomacal, vómitos, falta de concentración, estados de angustia, ansiedad, subiendo ocho kilos de peso en un corto período tiempo. 
El día 26 de junio de 2004, la actora se presentó a trabajar en su horario habitual, muy angustiada por la situación, deprimida y con dificultades para expresarse ya que el solo hecho de revivir en aquel espacio físico la situación traumática e injusta a la que había sido sometida por la empresa, la bloqueaba y atemorizaba, pero ella necesitaba el trabajo. En ese momento la vio el quien en forma violenta la separó del grupo de empleados y le reprochó el haber concurrido a trabajar no obstante que telefónicamente se le comunicara la suspensión. La actora le respondió que no había recibido telegrama alguno comunicandole la suspensión y que por eso concurrió a la empresa. El_le insistió que no podía quedarse en la empresa. Asimismo, el Gerente, que estaba al tanto de todo lo sucedido se dispuso a hablar con la quien le expresó en tono terminante: que no podía ver el video del día en que se produjo el faltante (injustamente atribuído a la actora), y que dicho faltante lo tenía que pagar la actora porque figuraba en el reporte de su legajo, que la suspendian y no la despedian teniendo en cuenta su intachable legajo. La actora en esa oportunidad aprovechó para denunciar ante el Gerente situaciones sumamente irregulares que se estaban sucediendo en la empresa desde hacia un tiempo, tales como: 1) que a raíz del déficit que tenía el supermercado por faltantes de cajas se habia implementado un sistema de premios para aquellos cajeros que no registraran faltante alguno, 2) reuniones y charlas con los jefes de caja debido a este problema, 3) que los jefes de caja andaban todo el tiempo con sus billeteras personales no obstante que solo tenía permitido circular durante su horario de trabajo con riñoneras, 4) que dichos jefes tenian acceso directo a la caja fuerte para proveer de cambio a los cajeros y que dos meses antes de que se produjera el faltante atribuído a la actora, habian desaparecido $\$ 500$ de la caja fuerte a la cual sólo tenian acceso los supervisores y jefes de caja. También le manifestó acerca de las condiciones inhumanas a las que estaban sometidas las cajeras que no podian ir al baño o tomar agua, estándoles solo permitido hacerlo durante el horario de almuerzo o a la salida, así como que la mayor parte del tiempo debian trabajar de pie y los malos tratos dispensados por los superiores jerárquicos.

Ese mismo día 26/06/04, cuando la actora regresa a su casa a media mañana, dado que no le permitieron trabajar, recibió la $\mathrm{CD}$ de suspensión que había sido enviada por la empleadora con fecha 25 de junio (CD N ${ }^{\circ} 000775978$ ), la cual en forma extemporánea decía lo siguiente: "Por déficit de caja de \$449,74 día 20/06/04 se le suspende días 26 y 27/06/04". Cabe resaltar, que también con fecha 25/06/04 de junio mi mandante había enviado a la empresa telegrama N\$397375656 AR de fecha que decía: "Ante suspensión verbal efectuada por el intímole en veinticuatro horas ratifique o rectifique la misma. Atento a no ajustarse la situación planteada a derecho, hasta tanto se aclare mi situación laboral notificándoseme por medio fehaciente lo solicitado, concurriré a la empresa en horario habitual a cumplir mis tareas normales. Queda Ud. debidamente notificado". La empleadora hizo efectiva la suspensión los días Sábado 26 y domingo 27 de junio de 2004. Al respecto, si bien la actora impugnó dichas suspensiones en tiempo y forma, no continuó controvirtiendo la sanción por su gran cansancio moral y el temor de perder su trabajo.

El fin de semana siguiente a aquel en que se hizo efectiva la suspensión, la actora se presentó a trabajar con muchísima dificultad por la gran carga de angustia que le implicaba concurrir a A lo que se sumó que el Jefe de Caja,

\footnotetext{
le dificultó la reincorporación a la actora dispensándole un trato agresivo y amenazante en referencia a lo ocurrido y realizándole advertencias para el futuro. (jefe de caja), trataba en forma humillante a las cajeras que no gozaban de su simpatía, las intimidaba continuamente, desconocía los procedimientos que debían seguirse ante una determinada situación de error de un empleado, ejercía su poder en forma abusiva con un total desprecio de la dignidad de sus subordinados y con la anuencia de la empresa. Además dispensaba a la actora un trato discriminatorio con relación a otros subordinados que gozaban de su beneplácito, absteniéndose de colaborar con mi mandante cada vez que ella lo solicitaba, debido que él era el responsable de proporcionar cambio, o bien autorizar alguna liquidación en ausencia de los supervisores asignados. El Sr. Ermácora tenía una mala disposición hacia mi mandante. En numerosas ocasiones la actora encendió la luz de la caja avisando que necesitaba cambio o ayuda, pero éste a pesar que la veía no enviaba a ningún empleado, ni concurría a auxiliarla. Hubo ocasiones en que la actora tenía en la gabeta de la caja $\$ 1000$, y encendía la luz para que retiraran dicha suma por el riesgo que importaba tenerla allí y omitía auxiliarla hasta que algún cliente le señalaba que la cajera necesitaba ayuda. Por otra parte, le generalmente no respetaba el horario de almuerzo de la actora y recién la autorizaba a concurrir cuando el comedor había cerrado.
} 
En ocasiones asignaban a mi mandante a las Cajas para el pago de materiales de construcción, que se encuentran alejadas de la línea de cajas, existiendo una distancia que dificulta a las cajeras avisar si necesitan algo. Las cajas para pago de material de construcción normalmente requieren mucho cambio porque la mayoría de los clientes pagan con billetes grandes y además hay muchas ventas de material en liquidación que requieren sí o sí para su venta la autorización del Supervisor o del mismo Jefe de caja. El constantemente a la actora cuando era asignada a ese puesto diciéndole que molestaba mucho al pedir constantemente cambio o solicitar la autorización de ventas, siendo que el sistema implementado por la empresa funcionaba de esa manera y el Jefe de caja lo sabía. De esta forma Ermácora creaba un clima de temor y amenaza constante respecto a la Sra. quien $\underline{\text { si cumplía con las reglas de autorización de ventas establecidas por la empresa provocaba }}$ malestar y enojo en su superior, pero si no lo hacía podía ser suspendida 0 aplicársele una sanción disciplinaria por no respetar el procedimiento impuesto a las cajeras del sector. Como V.E. podrá apreciar esto representa un mensaje perverso y contradictorio para un empleado que está sujeto a la amenaza de castigo de cualquier forma, aún cumpliendo con las órdenes impartidas, ya que quien ejerce el acoso moral sobre otro trabajador (como el sabe que estas situaciones terminan por desestabilizar emocionalmente al sujeto objeto de persecución y le crean una inseguridad que entorpece sus tareas diarias.

Otro hecho que prueba el trato discriminatorio del Jefe de caja hacia mi mandante sucedió en agosto del 2004, cuando la actora le solicitó al Sr. el cambio de la fecha de sus vacaciones para tomárselas en el mes de enero (habitualmente las tomaba en Octubre). Para ello, invocó lo establecido por el art.75 del CCT No130/75 que dispone: "El personal que tenga hijos en la escuela primaria, tendrá preferencia con relación al resto, para que el otorgamiento de las vacaciones tenga lugar durante la época de receso de las clases, sin perjuicio de cumplir las disposiciones legales vigentes ”.

respondió sin más que no se las podian cambiar, para luego agregar con tono irónico y de burla que para qué quería tomarse vacaciones la actora, que aprovechase para descansar durante la semana, ya que trabajaba el fin de semana. Y además, puso como ejemplo a otro empleado llamado_que trabajaba de lunes a viernes, diciéndole a la actora que él sí se merecía tener vacaciones, en cambio la actora no. En vistas de la respuesta infundada y arbitraria de actora pidió hablar con la Gerencia de Recursos Humanos, se entrevistó con la quién le expresó que todo dependia del

que si él no quería efectuar el cambio de la vacaciones ellos no podian hacer nada. insistió con mostrándole el volante del Centro de Empleados de Comercio en el que figuraba el artículo del CCT $\mathrm{N}^{\circ} 130 / 75$ que otorga el derecho a trabajadores con hijos en edad escolar a gozar de las vacaciones en el mes de enero, y el Jefe de caja le tiró el volante en la cara delante de otros empleados y luego le dijo que lo pensaría. Cuando mi mandante insistió con el tema, le dijo en forma violenta: "que quién se creía ella para hacer este tipo de planteos, que a él no le importaba lo que decía la ley". Asimismo por haber concurrido a la Gerencia de Recursos Humanos diciéndole que las decisiones las tomaba él y que sólo con él debía hablar cualquier tema. Como la conversación se tornó muy tensa, mi mandante pidió hablar con el Gerente. Estando en reunión con el gerente, el Sr. desmintió todos sus dichos frente a éste. Cuando salieron de la reunión comenzó a burlarse y agredir a la actora diciéndole que ella no estaba bien, insinuándole que estaba loca. Ese día, mi mandante se retiró de su lugar de trabajo en un estado de angustia y nervios. Cada día que pasaba, se tornaba más dificil concurrir a trabajar sabiendo que tenía que enfrentar las persecuciones y agresiones de sin que la Gerencia de Resurses Humanne ni al rarente de Easy Supermercado tomaran cartas en el asunto para proteger sus derechos y evitar los abusos del Jefe de caja.

Cabe señalar que la acusación de la jefa de caja,

D, en fecha 20/06/04, respecto a un supuesto faltante de caja del que responsabilizó a la actora, era totalmente infundada y que jamás se realizó sumario 0 investigación alguna destinada a clarificar los hechos que se imputaban a mi mandante.

Los hechos que acabamos de relatar, sumados a la persecución psicológica y maltrato que ejercía sobre la provocaron un grave malestar físico y psiquico en la actora, desencadenándose un cuadro de Depresión Reactiva. Es de destacar que los abusos de Ermácora y otros Jefes de Caja contaban con el conocimiento y anuencia de la Gerencia de Recursos Humanos 
psicológico.

\section{4- Encuadre del caso en la figura de mobbing o acoso}

La situación vivida por mi mandante en su lugar de trabajo se denomina mobbing o acoso psicológico, figura de la que ha comenzado a hablarse en nuesta doctrina a raíz de su inclusión en leyes laborales europeas.

Desde hace unos años, tanto en Europa como en E.E.U.U. se está difundiendo un fenómeno de patología laboral denominado "mobbing". Psicólogos, psiquiatras, médicos laborales, sociólogos y más en general aquellos que se ocupan de estudiar el sistema jerárquico existente en las fábricas y oficinas, sus reflejos sobre la vida de los trabajadores, han individualizado algunas graves y reiteradas distorsiones, capaces de incidir pesadamente sobre la salud individual.

Se trata de un fenómeno conocido como "mobbing". El término proveniente de la lengua inglesa, y del verbo "to mob"(atacar) y de la etología, se refiere al comportamiento de algunos animales, que generalmente acosan minuciosamente a un miembro del grupo para alejarlo. A menudo en la empresas ocurre algo similar, de manera que el trabajador es objeto repetido de abuso por parte de sus superiores, y en particular víctima de prácticas destinadas a aislarlo del ambiente de trabajo y en los casos más graves de repelerlo, prácticas cuyo efecto es atacar gravemente el equilibrio psíquico del trabajador, disminuyendo su capacidad laboral y la confianza en sí mismo y provocándole catástrofe emotiva, depresión y en los peores casos el suicidio(Revista Derecho del Trabajo-2000 B, Jurisprudencia Extranjera, Contrato de Trabajo, Extinción, despido, mobbing, discriminación, Sentencia del Tribunal de Turin, Italia, 16/11/1999-Erriquez, Giacomina c. Eergom Materie Plastiche s.p.a., pag.2013).

Por otra parte, la estrategia de persecución del mobbing puede provenir de sujetos diversos. El mobber (o sujeto activo del mobbing) puede ser tanto uno o más colegas del trabajador que pretenden excluirlo por resultarles incómodo(v.g. por su alto nivel de eficiencia), como, desde luego la misma empresa, en cuyo caso el fenómeno es conocido como bossing o mobbing vertical. En estos casos la presión psicológica de la empresa está acompañada por los side mobbers (colegas, superiores, gerentes de recursos humanos, etc ) que aún no participando directamente del acoso, por razones de posicionamiento dentro de las preferencias jerárquicas, excluyen o evitan todo tipo de solidaridad con la víctima.

Como es de esperarse, el mobbing desemboca generalmente en una renuncia a su empleo o despido indirecto del trabajador, no sin antes haber sufrido, seguramente, patologias psíquicas y psicosomáticas.

El "mobbing" aparece muchas veces en forma directa y en otras oportunidades lo hace a través de una estrategia de hostigamiento sutil. A manera de ejemplo mencionaremos:

1) El aislamiento físico del trabajador; 2) El hostigamiento y la falta de comunicación; 3) La propagación de conceptos peyorativos; 4) La asignación de tareas humillantes o vergonzantes; 5)Tratar de darle al trabajador tareas de muy dificil realización; 6) Retar al trabajador en público, agraviarlo o menoscabar su imagen; 7)Cambiarle constantemente y en forma arbitraria las modalidades de trabajo; 8) Hacerlo trabajar en condiciones antiergonómicas, sabiendo que ello constituye un daño para el trabajador; 9)Acusar y culpar injustamente al trabajador por hechos que le son ajenos; 10) Utilizar técnicas para sabotear las tareas del trabajador; 11) Molestar e interrumpir los trabajos que intenta realizar el trabajador; 12) Insultar y ridiculizar al trabajador;13) intentar agredir fisicamente al trabajador; 14) Impedir que el trabajador utilice los sanitarios para sus necesidades fisiológicas.

Estas caracteristicas enunciadas del mobbing se dan en este caso, y no han sido padecidas sólo por mi mandante sino también por otros empleados que han presentado parte de enfermos a debido a los reiterados abusos de autoridad por parte del Sr.Sebastián Ermácora y otros empleados jerárquicos.

5-Consecuencias del mobbing reflejadas en el estado físico y psíquico de la actora. Primera manifestación invalidante. 
La actora necesitaba su empleo por lo que a pesar de su estado de angustia, siguió esforzándose y obligándose a concurrir habitualmente a su lugar de trabajo. Sin embargo su deterioro psíquico y físico comenzó a manifestarse mediante ataques de pánico, insomnio y crisis de llanto.

En fecha 22/11/04, concurrió al Centro Asistencia Médica del Centro de Empleados de Comercio de Maipú, donde el Dr. Armando Marquez le diagnosticó "crisis de pánico" y prescribió siete dias de reposo (se adjunta certificado médico). El certificado médico de referencia fue entregado en original por el padre de la actora a la empresa, pero la empleadora de la se negó a firmar una copia de recepción del mismo.

En fecha 03/12/04, el Dr. Julio Herrera atendió a la actora y expidió certificado diagnosticando un cuadro de Reacción depresiva angustiosa, indicando reposo por 15 días (se acompaña certificado).

En fecha 17/12/04 el Dr. Julio Herrera, volvió a indicar que debido al cuadro depresivo angustioso, la actora no se encontraba en condiciones de continuar sus actividades laborales ni realizar trámites al respecto, indicando reposo relativo por 30 días a partir del 18 de diciembre del 2004.

Es de destacar que ambos certificados médicos psiquiátricos expedidos por el Dr. Julio Herrera fueron entregados por la actora a su empleadora sin que ésta accediese a firmar las fotocopias para dejar constancia de su recepción.

\section{A) snteceaentes.}

Mi mandante comenzó a trabajar para la demandada como cajera full time de fin de semana en fecha 06/10/01. El horario de trabajo era de sábado a domingo de 9 hs a $18 \mathrm{hs}$.

Conforme lo relatado en esta demanda, la actora ingresó a trabajar para la demandada en condiciones aptas para realizar para realizar cualquier tipo de tareas, no presentado ningún tipo de dolencia. Mi mandante era persona sana física y emocionalmente. Ya realizamos el relato de los hechos que originaron la enfermedad profesional que padece la actora y que fuera denunciada ante su empleador.

A modo de resumen, ya que todas las misivas que intercambió la actora con la demandada han sido transcriptas en el capitulo referente a los HECHOS -apartado 6de esta demanda, tenemos que en fecha 17/12/04 la actora recibió Carta Documento $\left(\mathrm{CDN}^{\circ} 000786644 \mathrm{AR}\right)$ enviada por donde la intimaban a presentarse a su lugar de trabajo en base al informe del médico de la empresa de fecha 11/12/04, bajo apercibimiento de considerarla incursa en abandono de trabajo.

Ante ello la actora envió a su empleadora el telegrama ( $N^{\circ} 62393140$ ) de fecha 20/12/04, mediante el cuál rechazó el emplazamiento efectuado por considerarlo improcedente, toda vez que mi mandante había presentado en fecha 17/12/04 certificado médico psiquiátrico ordenando reposo relativo por 30 días más a partir del 18 de ese mismo mes y año. En dicho telegrama la actora denunció su enfermedad como profesional originada en el acoso moral y situaciones traumáticas vivenciadas en su lugar de trabajo. Asimismo emplazó a su empleadora a denunciar en 72 horas ante la ART la enfermedad referida, realizando reserva de accionar legalmente conforme a las disposiciones de la Ley 23.592 por trato discriminatorio y reclamar el daño moral que le fuera ocasionado por las conductas configurantes del mobbing.

No obstante lo expresado, la empleadora envió a la actora Carta Documento (CD N000787401) de fecha 22 de diciembre de 2004 mediante la cuál la despedía invocando abandono de trabajo. En dicha CD la empleadora negó los hechos configurantes del acoso moral, sin perjuicio de lo cual se comprometió a denunciar ente la ART la enfermedad de la actora.

En fecha $24 / 12 / 04$, la envió telegrama a SA (CD N000833313 AR), ratificando los términos de su telegrama anterior, y rechazando la causal de despido invocada por su empleadora (abandono de trabajo), dado que la actora había acompañado oportunamente certificado médico que justificaba sus inasistencias y había denunciado su enfermedad profesional. Asimismo, solicitó a su empleadora que, ante la disidencia entre el dictamen de su médico y el de la empresa, fijara una Junta Médica en la Subsecretaria de Trabajo, quedando a disposición de efecto.

8. Monto reclamado: $49.832,29$

9. Diagnóstico inicial, herramientas utilizadas, grado de
incapacidad (de parte): 


\subsection{Fecha primer informe: 28.06 .2004}

9.2. Herramientas utilizadas: Mini Mental (evaluación de funciones cognitivas), Inventario de Beck (evaluación depresión), PRIME - MD (Psicopatológico), MIPS (personalidad), Bender (neurológico), H.T.P (Rasgos generales - proyectivo), MBI (estrés laboral), RAIVEN (inteligencia) y entrevistas.

9.3. Diagnostico: La Sra. G. B. según los criterios del DSM IV presenta un Trastorno Adaptativo con ansiedad y estado de ánimo depresivo (309.24). Como característica esencial la paciente ha desarrollado síntomas emocionales y comportamentales en respuesta a un factor estresante psicosocial identificable; la presión laboral sufrida por parte de su jefe al ser acusada de robo, situación que termina agravándose al confirmar esta postura su empresa con la decisión de despedirla.

9.4. Grado de incapacidad: Reacción vivencial anormal grado III (30 \%) por presentar en su cuadro manifestaciones psíquicas y somáticas lo que requiere un tratamiento más intensivo psicológico y psiquiátrico.

\subsection{Diagnóstico psicológico y grado de incapacidad (peritado) \\ 9.6. Fecha informe: 08/09/2009}

\subsection{Pruebas utilizadas}

\section{Entrevista}

Test de Weschler- Belleuve

Tecnicas Graficas

Test de Roschach

\subsection{Diagnóstico y grado de incapacidad}

Los síntomas descriptos configuran el diagnóstico, según el DMS IV, como Episodio Depresivo Mayor de Características Moderadas.

Del material trabajado se puede inferir que se ha producido una modificación en los patrones de conducta habituales de la entrevistada principalmente en lo que hace a su modalidad laboral, participación y actividad social, y el tipo de movilidad con la que se maneja.

El grado de incapacidad psicológica, según los Baremos Ley vigentes en la actualidad, en el Resumen de Incapacidad Reacción Vivencial Anormal Neurótica- RVAN con manifestaciór depresiva es equivalente al $20 \%$.

\section{Reevaluación actual resultado:}




\begin{tabular}{|c|c|c|c|c|c|c|}
\hline Somatizaciones & 36 & total de & 48 & 3,00 & T75 & SOM \\
\hline Obsesiones y compulsiones & 28 & total de & 40 & 2,80 & T63 & OBS \\
\hline Sensitividad interpersonal & 16 & total de & 36 & 1,78 & T63 & S.I. \\
\hline Depresión & 37 & total de & 52 & 2,85 & T63 & DEP \\
\hline Ansiedad & 27 & total de & 40 & 2,70 & T63 & ANS \\
\hline Hostilidad & 15 & total de & 28 & 2,14 & T63 & HOS \\
\hline Ansiedad fóbica & 12 & total de & 24 & 2,00 & T63 & FOB \\
\hline Ideación paranoide & 9 & total de & 24 & 1,50 & T50 & PAR \\
\hline Psicoticismo & 11 & total de & 40 & 1,10 & T63 & PSIC \\
\hline Items adicionales & 22 & total de & 28 & 3,14 & & \\
\hline INDICE DE SEVERIDAD GLOBAL (IGS) & 2,37 & T63 & & & & \\
\hline INDICE DE MALESTAR SINTOMATICO POSITIVO (IMSP) & 2,48 & T50 & & & & \\
\hline TOTAL DE SINTOMAS POSITIVOS (STP) & 86 & T75 & & Impresión & Negativa & \\
\hline ITEMS ADICIONALES & \multicolumn{5}{|c|}{\begin{tabular}{l|l|l} 
Puntaje & Significativo \\
\end{tabular}} & \\
\hline 5: Falta de interes en las relaciones sexuales & & \begin{tabular}{l|l}
2 & \\
\end{tabular} & & NO & & \\
\hline 19: Poco apetito & & 3 & & SI & & \\
\hline 44: Problemas para dormir & & 4 & & SI & & \\
\hline 59: Pensamientos acerca de la muerte o el morirse & & 2 & & NO & & \\
\hline 60: Comer en exceso & & 4 & & SI & & \\
\hline 64: Despertarse muy temprano. & & 4 & & SI & & \\
\hline 66: Sueño intranquilo. & & 4 & & SI & & \\
\hline 89: Sentimientos de culpa. & & 1 & & NO & & \\
\hline ITEMS CRITICOS & & intaje & Sign & nificativo & & \\
\hline 15: Pensar en quitarme la vida & & 2 & & NO & & \\
\hline 16. Escuchar voces que otras personas no oyen & & 2 & & NO & & \\
\hline 54. Perder las esperanzas en el futuro & & 3 & & SI & & \\
\hline
\end{tabular}

11. Conclusión del caso: En este caso aún no se expide la cámara laboral interviniente aunque las pericias dispuestas por la misma, es coincidente con la valoración que dio inicio a la demanda. Es notorio el desgaste que sufre la ex empleada y sobre todo a pesar de estar en tratamiento presenta un profundo malestar somático y sintomatología psicopatológica verificada en varios indicadores como puede verse en los puntajes obtenidos en el punto anterior.

\subsubsection{CASO 7}

1. Fecha de inicio: $05 / 07 / 2007$

2. Fecha de resolución: -

3. No Expediente: 17.XXX

4. Nombre: D. E. V. C/ L. C. A R T Y Ots

5. Estado: Sustentación de pruebas.

6. Resolución: -

\section{Hechos y exordio}

III.- OBJETO:

Que en el carácter invocado y siguiendo expresas instrucciones de mi mandante vengo a interponer formal demanda ordinaria contra de con domicilio en con domicilio en calle Cindad, Mendoza, por la suma de de PESOS CUARENTA MIL TRESCIENTOS NUEVE (\$40.309), en concepto de indemnización por Incapacidad Parcial Permanente Definitiva derivada de enfermedad profesional conforme la Ley 24.557 , o lo que en mas o en menos resulte de la prueba a rendirse en autos o que estime justo el S.R.L con domicilios intereses legales y costas del proceso; y contra de

PESOS SESENTA Y Dorrego, Guaymallen, Mendoza, por la suma de PESOS SESENTA Y OCHO MIL CUATROCIENTOS NOVENTA Y SEIS (\$68.496) en ción integral por daños $\mathrm{y}$ perjuicios por enfermedad derivada del trabajo (ya deducidos los importes por los que pueda ser condenas despido injustificado de la actor concepto de rubros indemnizatorios y remuneratorios que proceden por el autos o que estime justo el Tribunal con mas en mas o en menos resulte de la prueba a rendirse en 
en el sector donde funcionab

empresa en fecha 5 de mayo de 2001. La función que realizaba como promotora consistía en repartir folletos y limpiar anteojos promocionando un liquido para anteojos. A su ingreso la actora fue contratada para trabajar 24 horas semanales, con un sueldo de $\$ 366$ y en la categoría de Administrativa A4, trabajando de lunes a domingo, en el horario $17 \mathrm{hs}$ a $21 \mathrm{hs}$, con un franco intermedio los días miércoles. En el mes de agosto del 2001 la actora quedó embarazada de su primera hija. En el mes de noviembre del 2001, mi mandante comenzó a trabajar como cajera de la óptica del Supermercado, cambio que se reflejó en la categoría con la que aparecía en su bono de sueldo pasando de ADM A4 a Cajera A4, sin embargo siguió cobrando el mismo sueldo. Luego pasó a revestir la Categoría de Cajera B4 que fue la que mantuvo hasta la extinción de la relación laboral.

La empresa comenzó a cambiarle a la actora continuamente sus horarios, llegando a salir a veces de su trabajo a las $23 \mathrm{hs}$. Luego el

cerró. Mi mandante en ese momento estaba cursando un embarazo de cinco meses y no obstante ello el Departamento de Recursos Humanos decidió enviar a mi mandante a desempeñar funciones en la línea de caja.

Al momento del ingreso de la actora se encontraba apta para realizar cualquier tipo de tareas, no presentado ningún tipo de dolencia. Era una persona sana fisica y emocionalmente. Cabe señalar que a la actora se le efectuó un preocupacional psicofísico a través de la empresa Asismec.

\section{2-Modalidad del trabajo de cajera. Origen del burn out}

L te vivenció desde el inicio de su relación laboral restricciones inhumanas impuestas por la empresa a las cajeras tales como la imposibilidad de concurrir a los sanitarios o beber agua. Para ilustrar a V.E. acerca del estrés al que estuvo sometida mi mandante paso a detallar las exigencias y modalidad del trabajo que desempeñaba: 1) Saludar cordialmente al cliente, 2) Pasar rápido los productos, embolsarlos, y venderles algún producto en promoción, 3) Preguntar al cliente lugar proveniencia para ingresarlo por zona a una base de datos, 4) Mirar el carro para que el cliente no se lleve ningún producto sin pasarlo por la caja, revisar los bolsos, solicitarles que levanten los abrigos del carro, revisar que las cajas de productos estén bien cerradas, memorizar los códigos de fruta y verdura que son más de 50,5 ) Si el cliente desea factura y paga con tarjeta pasarla por el "posnet" de lo contrario el sistema de la caja no emite el comprobante de la tarjeta, 6) Si el cliente paga con tickets canasta o ticket envase debe ser registrado como pago en efectivo porque si no se corta la factura; además tenia que controlar que dichos tickets no se encuentren vencidos o que no sean de restaurante, 7) Tener la precaución de no pasar en forma simultánea una tarjeta de débito y una de crédito porque sino no sale el comprobante de la de débito (indicación que no se le dio a mi mandante en su entrenamiento como cajera), controlar el peso de la carne y de cualquier otro producto pesado y envasado por la empresa, todo esto en pocos minutos porque deben alcanzar un objetivo de venta de productos por minuto. El entrenamiento que recibió mi mandante para empezar a desempeñar esta tarea fue solo de 2 horas observando a otra cajera.

El descanso que tenía la actora era sólo de 18 minutos en el que debía comer, ir al baño (ya que durante la atención al público lo tenía prohibido), pero antes de descanso debía dejar un reporte de la caja asignada indicando hora, número de operador, número di caja y productividad que debia ser siempre mayor a un numero de productos estipulados por la empresa (por eso las cajeras deben embolsar rápido). Esta operación de reporte y hora es realizada nuevamente por la cajera al reincorporarse de su descanso para que la empresa pueda verificar po sistema que sólo se tomó 18 minutos. Si la empresa verificaba que la cajera se tomaba más de $1 \xi$ minutos la sancionaba.

Cuando mi mandante fue asignada a la línea de cajas no le dieror ningún instructivo sobre procedimientos, simplemente le dijeron que le preguntara a sus compañeras lo que normalmente no era posible.

2.1-Horarios inapropiados para una mujer en estado de gravidez que ponían en peligro sus seguridad personal.

En ese momento el supervisor era el

encargados de caja los

Al finalizar la primera jornada labora como cajera mi mandante les preguntó a los encargados cuál sería su horario de trabajo y éstos le dijeron que como era empleada de $24 \mathrm{hs}$ iba a tener que concurrir de jueves a domingo en el horario de $18 \mathrm{hs}$ a $24 \mathrm{hs}$. La actora solicitó que por favor se le diera el horario de mañana atento a su avanzado estado de gravidez y le dijeron que no podía ser. 
2.2- Tareas inadecuadas para el estado de gravidez de la actora. No respeto del periodo de descanso por parte de la empresa.

embarazo, su encargado el $\mathrm{S}$

A pesar qu por entonces ya tenía seis meses de devoluciones: que consisten en recoger la mercadería ordenaba realizar, al finalizar el arqueo de caja, las góndolas correspondientes. rollos, perchas, a a mandaban a limpiar las cajas, debiendo sacar la basura: rollos, perchas, alarmas, limpiar las cintas donde se cobra y pasar plumero, todas operaciones implicaban qu

se tuviese que agachar con dificultad por su avanzado embarazo.

porque en el turno noche A esto se sumaba que la actora rara vez podía tomarse el descanso, una bebida para evitar la interrupción clientes, entonces directamente le traían a la caja un alfajor y cion de las operaciones que estaban en curso

Asimismo, en esa época habían 44 cajas habilitadas y sólo servían 20 sillas, por lo cual en muchos momentos mi mandante tuvo que estar atendiendo la caja parada, no obstante su avanzado estado de gravidez.

descuentos en el sueldo de la actora.

2.3- Faltantes de caja, arqueos y notificaciones extemporáneas,

El monto previsto para fallo de caja era de $\$ 30$. Sin embargo y como quedará acreditado mediante la pericia contable, la empresa nunca utilizaba la imputación del faltante al item fallo de caja y efectuaba en forma directa el descuento del salario de la actora.

En marzo del 2002 la actora tuvo su primer faltante de caja de $\$ 43$ que le fue descontado de su sueldo. Los faltantes nunca se los notificaban luego de los arqueos de caja si no varios días después y no le otorgaban ningún derecho a revisar dichos reportes o quedarse con algún comprobante de los mismos para su propio control. El encargado de caja siempre la convencía que habia cobrado mal y aún con desconfianza mi mandante terminaba firmando el reporte del faltante.

En abril del 2002 , se le imputó a la actora otro faltante por $\$ 53,93$ alegando la empresa que había recibido la un falso Lecop. Ella se defendió expresando que siempre pasaba los billetes por la luz ultra violeta, sin embargo el encargado le replicó que las falsificaciones de billetes cada vez eran mejores.

2.4- Consideraciones legales respecto a la improcedencia de los descuentos efectuados a la actora por faltantes de caja y respecto a las sanciones disciplinarias que le fueran aplicadas.

Cabe señalar que el art. 87 de L.C.T. expresa que el trabajador es responsable ante el empleador de los daños que cause a los intereses de éste, por dolo o culpa grave en el ejercicio de sus funciones, es decir que el trabajador no responde por daños no culposos que pudiera originar la prestación de servicios, ya que cumple con las obligaciones a su cargo adoptando las actitudes exigidas por la naturaleza de las prestaciones encomendadas, compitiendo al empleador asumir el riesgo propio de su actividad lucrativa. Precisamente los fallos de caja son casos de daños no culposos por parte del cajero ya que forman parte del riesgo de sus funciones y exigencias de rapidez que impone la empleadora, y por esa misma razón la empresa prevé el item de fallo de caja en el bono de sueldo de las cajeras. Por ello, el fallo de caja nunca puede dar lugar a una sanción disciplinaria que además no tiene ningún respaldo normativo ni en la LCT ni en el CCT de empleados de comercio, por lo que representa un ejercicio abusivo de dicho poder disciplinario.

Se viola asimismo el derecho de defensa del trabajador, ante falsas imputaciones de faltantes por parte de la empleadora, al no tener acceso a las filmaciones del hipermercado, al no realizarse en tiempo y forma los arqueos de caja, ni permitírsele a la cajera, en este caso a la actora, verificar si el arqueo ha sido correctamente realizado y los comprobantes del mismo.

3- Reincorporación a la empresa luego de la licencia por maternidad. Cambio continúo de horarios. Nuevos faltantes de caja.

Mi mandante se reincorporó a la empresa a fines de julio del 2002, después de haber gozado de la licencia por maternidad. Le asignaron el horario de $9 \mathrm{hs}$. a $16 \mathrm{hs}$. tres dias a la semana. Luego le cambiaron el horario y los dias, estableciendo que debía concurrir de jueves a domingo de $10 \mathrm{hs}$ a $15 \mathrm{hs}$. Cabe señalar, que cuando mi mandante se reincorporó le respetaron un mes y medio el horario diumo y luego comenzaron las presiones para pasarla al turno noche. 
En el mes de agosto del 2002 tuvo otro faltante de \$6,47. Luego de esto la empresa le comunicó que le cambiaba nuevamente el horario de trabajo que sería de $18 \mathrm{hs}$. a 24hs. La actora habló con el encargado de caja quien le dijo que no podía modificar ese horario porque ya estaba cargado en sistema y tenian siempre que rotar. Luego la Sra. habló con la trabajar en ese horario porque su esposo también te (es policía) y algunas noches tendría que salir del Supermercado e ir a buscar a su hija de 4 meses a la casa de sus padres que viven en el peligroso y luego conducir con el bebé hasta su casa que se encuentra en el h, que tambien es muy peligroso e inseguro. La encargada en cuestión gestionó el cambio de horario de $9 \mathrm{hs}$ a $17 \mathrm{hs}$, pero éste duró solo una semana, debiendo la actora volver a desempeñarse en el turno noche. Finalmente la que le gestionó el cambio de horario.

$\$ 7,15$.

En octubre del 2002, la actora tuvo un nuevo faltante de caja de

\section{4- Ejercicio abusivo del poder disciplinario de la empresa. Imposición de suspensión. Imputaciones de faltantes en forma extemporánea e imposibilidad de la actora de efectuar el control de los mismos.}

En noviembre del 2002, la encargac suspende a mi mandante por un día, alegando a que la actora no le había preguntado a los clientes de su caja de qué zona provenían (las cajeras son controladas por un intercomunicador mediante el cuál escuchan todo lo que hablan). Le hicieron firmar la suspensión sin dejarle una copia de la misma.

Por otra parte, el encargado de caja

traía los informes de faltantes de caja muchos dias después de que se habían producido, y en el momento en que mi mandante estaba atendiendo al público, por eso cuando cl importe era pequeño mi mandante lo firmaba y continuaba atendiendo. Pero en diciembre del 2002, el faltante fue de $\$ 59,93$ por lo que mi mandante solicitó controlarlo después de terminar con sus tareas, además la actora solicitó ver el rollo testigo que queda en la empresa, pero le dijo que primero tendría que firmar la constancia del faltante. El encargado nunca accedió a mostrarle el rollo testigo pese a que la actora ya había firmado el comprobante del faltante.

La modalidad de la empresa era entregar apercibimientos, suspensiones y constancias de faltantes de caja, mientras la actora estaba atendiendo ya que de ese modo no tenía posibilidad de controlarlos, leerlos y defenderse. Nunca le dejaban una copia de lo que firmaba.

En mayo del 2003 la actora tuvo un faltante $\$ 10,12$; en septiembre otro de $\$ 18,71$ y en octubre del mismo año otro por $\$ 31,21$.

4-1- Suspensión aplicada a la actora por falta de acatamiento a un procedimiento no informado por la empresa.

En el mes de noviembre del 2003 i le aplicó a mi mandante una suspensión por un dia, atento a que la actora había pasado simultáneamente una tarjeta de crédito y otra de débito. La actora nunca había recibido instrucciones de la empresa que esas operaciones no se podian realizar así, de hecho la actora lo había efectuado en otras oportunidades sin tener ningún problema. Pero ese día el comprobante de la tarjeta débito no salió (si salió el comprobante de la tarjeta de crédito), el débito se registró dos veces seguidas, y el encargado de caja se enojó con la actora. La le explicó que nadie le había dicho que no se podía hacer esa operación, que nunca antes habia tenido problemas al efectuar las mismas y que sus compañeras decían que si se podia efectuar así. De hecho el encargado le preguntó a otra cajera si podía realizar la operación como lo había hecho y ésta respondió que sí, lo cual indignó más a a quien le dijo a mi mandante que entonces tendría que aprender en base a sus errores si no estaba informada. luego preguntó a sus compañeras si sabian de esa modalidad de procedimiento y el $90 \%$ no lo sabía. Como la sanción disciplinaria se la aplicaron por error el día de franco, procedieron a hacer salir a la actora una hora antes durante los días jueves y viernes para hacer efectiva dicha sanción y efectuarle el correspondiente descuento en sus haberes.

Al poco tiempo, se organizó una reunión con todas las cajeras del supermercado, y la empresa les informó que como existían muchas diferencias o faltantes de cajas, aquellas cajeras que tuvieran faltantes de $\$ 100,0$ dos o tres faltantes al mes serían pasibles de una
suspensión. 
4-2- Asignación discriminatoria de la fecha de las vacaciones.

Los encargados disponian en mes de septiembre las fechas en que las cajeras se tomarian las vacaciones, beneficiando siempre a aquellas que eran amigas o tenían mayor afinidad. Así había cajeras que dos años seguidos habían gozado de sus vacaciones en el mes de enero y febrero, que eran las fechas más codiciadas. A la actora sus vacaciones le habían tocado en abril del 2002, octubre del 2003, y ese año en marzo del 2004. Al marido de la actora ese año le daban las vacaciones en febrero y por eso solicitó cambio de fecha invocando que a dos de las cajeras habían sido privilegiadas en dos años consecutivos con las fechas en enero y febrero, sin embargo a pesar de la evidencia, le negaron cambio de fecha.

En el mes de diciembre del 2003, la actora y otras cajeras mantienen una reunión con abusivo y discriminatorio que en ocasiones recibia de los dos encargados

En diciembre del 2003, mi mandante es informada por

su caja presentaba un faltante de $\$ 100$. La a de firmar el comprobante, le dice que verifiquen porque probablemente ha existido un error, que tal vez ella entregó dos veces el fondo o bien la otra cajera que entró después a ocupar su lugar tuvo un sobrante al realizarse el arqueo de caja. El avo quedó en averiguar estos detalles, y regresó recién en el mes de enero del 2004 diciendo que la actora tenía que firmar el comprobante y la suspensión por el faltante, a lo que mi mandante accedió con impotencia. Sin embargo mi mandante fue hablar con encargado de Cash Office (que era una de las personas que contaban el dinero de las cajas que rendian las cajeras al finalizar su horario). El encargado de Cash Office revisó las cuentas del día del faltante y comprobó que la cajera que ocupó el lugar de la habia registrado un sobrante de $\$ 100$. Entonces la actora habló con el Gerente- solicitándole que no le efectuaran el descuento de los $\$ 100$ y que no le aplicaran la suspensión atento a que en Cash Office había

detectado el error y que no existía faltante alguno. El gerente le respondió que no podia hacer nada respecto de la suspensión pero que trataría que no le descontasen los $\$ 100$.

Lo cierto es que mi mandante nunca podía controlar lo que entregaba al momento de rendir la caja porque siempre le sacaban la gaveta rápidamente y la llevaban a Cash Office.

En el 2004, la actora tuvo nuevos faltantes de caja de $\$ 16,55$ en enero, de $\$ 5,65$ en febrero, de $\$ 19,45$ en marzo, de $\$ 15,01$ en julio, por los que le hicieron firmar comprobantes de faltantes y luego le efectuaron los descuentos en el recibo de sueldo.

\section{infección urinaria.}

\section{3- Nuevo embarazo de la actora. Amenaza de aborto. Licencia e}

En fecha 25 de agosto del 2004, mi mandante que hacía pocos días habia tomado conocimiento que estaba embarazada, en momentos en que se encontraba cumpliendo funciones sufre una descompostura, comprobando en el baño que tenia pérdida de sangre. La actora pide concurrir a la enfermeria, en donde explica que siente fuertes dolores de ovarios y al tener que permanecer parada (no habia sillas para las cajeras) sentía una fuerte presión vaginal. También pone en conocimiento del enfermero "Omar" que en una prueba reciente de evatest le había dado positivo y estaba embarazada. Finalmente autorizaron a la actora a salir antes de su trabajo.

El esposo de la actora, la llevó a la Clínica Diez de Oñate donde la atendió la Dra. Susana Castro Baldovin, quien le indicó una ecografia de urgencia. Dicho estudio dio como resultado un embarazo de seis semanas, un hematoma en la placenta que representaba amenaza de aborto. Como consecuencia de su estado de saludo, el médico le indicó 7 días de reposo laboral, pero al concurrir la actora el dia 26/08/04 a su Obstetra Dr. Roberto Venrurin le amplió la licencia con reposo absoluto por quince días. Asimismo el obstetra le ordenó una serie de estudios médicos cuyos resultados los recibió la actora en fecha 06/09/04 en los cuales se detectó una infección urinaria debido a que la actora en su trabajo debía reprimir sus ganas de ir al baño hasta que llegaran los 18 minutos de descanso. De hecho mi mandante a parte de óvulos debía ingerir grandes cantidades de líquido para combatir la infección, algo que no podría haber hecho en su lugar de trabajo debido a las restricciones que imperaban para las cajeras en este sentido. 
4.4- Falta de protección a las cajeras con relación a la falta de respeto de clientes del hipermercado.

un nuevo Supervisor de caja llamado

Al poco tiempo que mi mandante se reintegró a trabajar, designaron

En enero del 2005 aproximadamente, mi mandante se encontraba atendiendo la caja a un hombre de unos 45 años de edad que estaba con su hijo de unos 20 años, cuando la actora le dice el total que debía pagar, el hombre sonriendo y forma insinuante le dijo:" $L o$ querés todo o te lo doy de a poquito" con una clara connotación sexual provocando la risa del menor que lo acompañaba. La cobra y le dice:"Usted es un maleducado". Entonces el hombre dijo que queria hablar con el encargado y llamaron a wene vino con un hombre de seguridad. Tanto el cliente como la actora le contaron su versión de lo ocurrido pero el encargado decidió congraciarse con el cliente y solicitarle a la actora que le pidiera disculpa. De hecho el Sr. reurgene le pidió disculpas al cliente por el momento que la actora le había hecho pasar. Luego le expresaron a la quen que cuando le dijeran alguna obscenidad lo que debia hacer es ignorarlo porque era la palabra de ella contra la de un cliente. Esta situación de acoso sexual de un cliente provocó gran malestar en la quien ese dia después de este episodio no podia dejar de llorar. Además debemos recordar que mi mandante estaba embarazada.

La actora cuando habló con an solas le preguntó si tenia que esperar a que la tocaran para que la empresa la defendiera frente a las faltas de respeto de un cliente (la actora no presentaba en su legajo ninguna sanción por atender mal a un cliente) y el Supervisor le dijo que le creía, que el hombre en cuestión tenía cara de degenerado pero que tenia directivas de la empresa de proceder como lo había hecho. Luego otra compañera de la actora atendió al mismo cliente quien le dijo." Vos no te vas a enojar si te digo si lo querés todo o de a poquito, porque una companiera tuya armó un escándalo".

\section{5- Presiones para efectuar un nuevo cambio de horarios}

En diciembre del 2004, la actora estaba cursando su quinto mes de embarazo, y de 18hs. a 24hs. La actora directamente se dirigió al nuevo Supervisor (ya que nunca la escuchaban) y le planteó el problema que representaba para ella porque tenía una hija pequeña que dejaba con sus padres, estaba embarazada y su marido tenía horarios rotativos. El Supervisor quedó en solucionar el tema y poco tiempo después la pasó a la caja del sector de electrodomésticos, asignándole un horario de 10hs. a l6hs. o bien de $11 \mathrm{hs}$ a a 7 hhs.

$\$ 9,94$.

El 18 de diciembre, a la actora la notificaron de un nuevo faltante de
embarazada. No respeto de la jornada laboral pactada.
4.6- Condiciones inadecuadas de trabajo para una mujer 
Un día de enero del 2005, mi mandante entró a trabajar a las $8 \mathrm{hs}$ a.m. y la encargada de cajas le pidió que no fuera por el momento : electrodomésticos, que le iba a habilitar una caja en su sector (linea de caja) porque le faltabar cajeras. A las 10 hs de la mañana la actora rindió su caja y la enviaron al sector de fotografia porqu no tenían cajera. Ese día la actora se tenía que retirar a las $14 \mathrm{hs}$., como había mucha gente no se puds tomar su descanso de 18 minutos. Cuando era la hora de retirarse la encargada le dijo que ese dí tendría que trabajar 8 horas (a pesar que no era rógimen que mi mandante tenía acordado con le empresa) porque la cajera de ese sector había faltado. Cabe señalar que la actora tuvo que estar todo e tiempo parada realizando sus tareas a pesar del avanzado estado de su embarazo. Hasta que a las $15 \mathrm{~h}$ incurrido la le dijo que se fuera a su casa y le pidió disculpas por el abuso en el que habí

En fecha 4/02/05 mi mandante fue a ver a su médico obstetra Dr contracciones le daría no había sentido bien, y después de revisarla le dijo que como estaba con contracciones le daría reposo por tres días a partir de esa fecha.

5- Nuevo faltante de Caja. Negativa de la actora a suscribir empresa. Amenaza de parto por la pra Ejercicio abusivo del poder disciplinario por parte de la a empresa.

costumbre en labajar a la empresa como de costumbre, en la caja del sector de electrodomésticos, ese día no hubo muchas ventas. El día 14/02/05 la actora salió de licencia por vacaciones y se reintegró a su trabajo en fecha 03/03/05. Cuando se reintegró, la actora se encontró con la sorpresa que de que se le imputaba un faltante del día 12/02/05 de un monto de $\$ \mathbf{2 4 0}$ correspondiente a la venta de un microondas y por esa razón se la suspendía por dos días. le dijo al Sr. que no era posible que existiera tal faltante, a lo que él le contestó que seguramente le había cobrado mal al cliente y que a lo mejor no le entregó el reció recibió asesoramiento en el CEC de un abogado que le indicó que estaba en su derecho a negarse a masta situación le provocó contracciones y una descompostura a mi mandante que ya cursaba el séptimo mes de embarazo. Al día siguiente $(04 / 03 / 05)$ cuando concurrió a queria verla. contado que no quería firmar que la había hecho llamar porque le habian microondas. El supervisor había había entregado el dinero o bien le habia dicho el total del precio del producto y ella le había firmar, que estaba pagaria en efectivo. La actora, con enorme cansancio moral, dijo que no iba a Recursos Humano dinero. Después el supervisor la condujo a Recursos Humanos donde la volvieron a presionar para que firmara el faltante y la suspensión con el argumento que si no lo hacía lo mismo se la iban a aplicar y quedaría en su legajo constancia que era qua rebelde lo cual no estaba bien visto en la empresa. prosiguió con su postura porque

Ese mismo dia, luego de la situación de enorme tensión y presiones vividas por la actora, ésta concurrió al consultorio de su médico obstetra que le dio tres días de licencia porque se encontraba con amenaza de parto y le aconsejó reposo absoluto.

La actora le envió un telegrama a la empresa en el que denunciaba que en el dia de la fecha no la habian dejado ingresar a su lugar de trabajo a desempeñar sus funciones habituales, que emplazaba en $48 \mathrm{hs}$ a su empleadora a aclarar situación laboral bajo apercibimiento de darse por despedida. La empresa respondió que la actora seguiría cumpliendo funciones y la notificaban de la fecha de inicio de su licencia por maternidad.

\section{6- Reingreso a la empresa luego de la licencia por maternidad.} uego de haber gozado de la licencia pordante se reintegró en julio del 2005, a su lugar de trabajo, $10 \mathrm{hs}$ a $16 \mathrm{hs}$.. La volvieron a asignar a la linernidad, trabajando nuevamente de jueves a domingo de suando estaba entregando el monedero la linea de cajas. Y el segundo día, después de su reintegro, le dice que tiene que firmar el feltas ventas, la empleada del sector Cash Office regado a firmar antes de su licencia firmar el faltante de $\$ 240$ de fecha 12/02/05 que se habia lescontárselo. Luego vino el licencia. El argumento es que necesitaban su firma para poder nandante firmara el comprobante del faltante del mismo sector y siguió insistiendo con que mi llos.

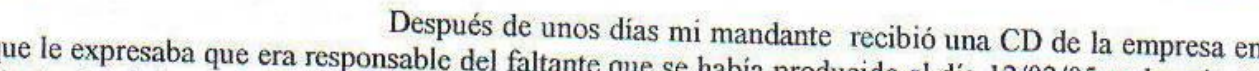
lectrodomésticos y que por lo echazando las imputaciones que le procederian a descontárselo. Mi mandante envió un telegrama res de julio del 2005 le descontaron los $\$ 240$, aultante de caja de referencia. No obstante ello, en el 6.1- Prueba de desempeño. 
En julio del 2005, la actora fue sometida a una prueba de desempeño.

La empleada que la evaluó

le dijo que no alcanzaba el puntaje requerido por la empresa porque solo cumplía con su trabajo y carecía de iniciativa, por ejemplo: porque no iba a buscar a la gente para que fuera a su caja. Sin embargo la actora sabía que si abandonaba la caja, la gente de seguridad del supermercado le iniciaba un procedimiento para sancionarla por dejar la caja sola. Es decir que la empresa transmitía instrucciones y mensajes contradictorios.

También le dijo la evaluadora que la actora no calificaba por no integrarse al grupo y porque no era flexible con sus horarios, lo que dañaba a la empresa y le hacía perder dinero. Integrarse al grupo implicaba acatar todas las órdenes sin defender ningún derecho y tener por encima el ideal de la productividad y la conveniencia de la empresa. En cuanto a la falta de flexibilidad horaria, le resultaba curioso a mi mandante que siempre la hostigaran a ella con ese tema, sabiendo que en el caso de otras empleadas como que vivía 5 cuadras de la empresa, nunca le habían modificado el horario y siempre trabajó en el turno mañana porque era amiga de los dos encargados de caja:

Cabe destacar que cuando se organizaban reuniones de personal, a mi mandante no la enviaban o las organizaban los días que ella tenia franco.

Esta situación volvió a golpear el ánimo de la actora, que se sentía que no importaba cuánto esfuerzo hiciera para realizar lo mejor posible sus tareas, siempre era descalificada.

de presentismo y descuento de faltante de caja.

6.2- Audiencia en la Subsecretaria del Trabajo por falta de pago

En fecha 20/09/05, en el expediente N $8433-D-05$, en la Subsecretaría de Trabajo y Seguridad Social tuvo lugar una audiencia de conciliación entre la actora y

había efectuado una denuncia ante dicho organismo porque no se le había pagado asignación por presentismo, asistencia y puntualidad y por el faltante de caja de fecha $12 / 02 / 05$. La empresa se comprometió a pagar los ítems de presentismo, asistencia y puntualidad pero respecto del faltante de caja consideró que el descuento había sido correcto y se dio por fracasada la audiencia respecto a ese tema. Se acompaña con esta presentación fotocopia del acta de audiencia y de la denuncia que realizó el CEC ante la Subsecretaria.

Después de haber realizado esta denuncia ante la Subsecretaria, la actora sintió que los encargados de caja y la gente de recursos humanos la trataban diferente, comenzaron a correr el rumor que ella era una rebelde y una gremialista con la cuál habia que tener cuidado. Al respecto, lo único que les había pedido la actora a los encargados, era que quería tener copia de todo lo que firmaba inclusive los comprobantes de faltantes de caja.

7.- Nuevos faltantes, cambios horarios. Problemas con el pago de
asignaciones familiares durante su licencia por maternidad.
El día $14 / 09 / 05$ la actora trabajó como de costumbre, al cierre de caja extrajo todo el dinero de la gaveta y lo entregó. Pero al día siguiente cuando llegó a su lugar de trabajo, un ayudante de caja le dijo que cuando abrió la gaveta encontró \$100 y le preguntó si el encargado de caja no le había informado de eso y ella le respondió que no y que le parecia muy raro porque ella verificó antes de irse que la gaveta estuviera vacía. Sin embargo, luego le hicieron firmar un comprobante de un faltante de $\$ 100$ y ella accedió bajo la condición que le dieran una copia.

A mediados de septiembre (en fecha posterior a la audiencia en la Subsecretaria de Trabajo), el encargado le notificó a mi mandante de un nuevo cambio horario, diciéndole que debía pasar a cumplir funciones en el horario de $18 \mathrm{hs}$. a $24 \mathrm{hs}$. La actora le planteó nuevamente su imposibilidad de cumplir ese horario a dado que ahora su situación se veía agravada por el hecho de tener dos bebés a su cargo. La encargada no le dio ninguna solución y le dijo que lo único que podía hacer por ella es dejarla salir a las $22 \mathrm{hs}$ y darle un par de semanas para que reacomodara su situación. Cabe señalar a V.E. que lo más tarde que cierran las guarderias es a las 20hs., y la opción de dejar mi mandante a sus hijas con sus padres en el Barrio , tenía el inconveniente de ir a buscarlas a altas horas de la noche con el riesgo que eso implicaba ante la inseguridad de ese barrio, que es de público conocimiento. La actora habló con Juan Mangione, quien en un principio no le ofreció una solución pero que finalmente accedió a que mi mandante continuara con el horario de mañana.

quedó registrado como tal.

En fecha 27-09-05 la actora tuvo un excedente de caja de $\$ 9,20$ que

Luego, el dia 31/10/05, la actora presentó a la empresa una nota en la que ponía en conocimiento de su empleadora que durante el periodo de licencia por maternidad el ANSES no le habia pagado las asignaciones familiares correspondientes al segundo hijo, atento que la empresa había informado a dicha repartición que le había pagado a la correspondientes a los meses de mayo y junio del 2005, lo cual no era cierto. En Recursos Humanos de la empresa le pidieron que hiciera la nota de referencia para enviarla al ANSES y expresando que le llegaría a la actora una notificación de dicho organismo y que el pago tardaría unos dos meses.

En enero del 2006 la actora concurrió al ANSES para ver como avanzaba su trámite y le dijeron que la empresa no había presentado nada. Entonces, mi mandante le 
preguntó en reiteradas oportunidades a la gente de recursos humanos que había pasado y le dieron mil excusas, no solucionándose nunca el problema, inclusive a la fecha del distracto laboral.

El día 15/01/06, la actora comenzó a sentir molestias que se traducian en dolores de espalda, constantes ganas de ir al baño y fuertes dolores de vejiga. Pidió ir a enfermería, en donde le dieron un calmante, lo cual quedó registrado en el libro de enfermería de la empresa. Como su situación no mejoraba, ese día la dejaron salir. La actora concurrió a la Clínica Santa María y fue atendida por la Dra. Karina Secada, quien le ordenó análisis y estudios, y el Dr Martin le dio dos dias de reposo laboral.

Luego, en fecha 18/01/06 la Sra. Duarte fue atendida por el Dr. Mariano Galbani, quien le diagnosticó una infección urinaria y le dio tres días de licencia a partir de esa fecha.

En febrero del 2006, la actora sufrió una descompostura en su lugar de trabajo, con fuertes dolores de estómago, debido a que el aire acondicionado estaba muy fuerte y ella no llevaba abrigo, y además en la caja que le habían asignado daba un conducto de ventilación que intensificaba el frío. Aunque pidió en varias oportunidades a los encargados

refrigeración, no obtuvo respuestas. Ese día fue atendida en la enfermeria, e incluso debieron inyectarla.

El día 28/02/06, la actora concurrió al médico porque empezó a sentir acidez estomacal. El médico le recetó Milanta, le dijo que no comiera rápido, que tratara de estar tranquila, a lo que ella le respondió que era muy dificil porque en su trabajo tenía que comer e ir al baño en 18 minutos.

El día $16 / 04 / 06$, la actora tuvo un faltante de $\$ 7,49$ y el día $13 / 07 / 06$ tuvo otro faltante por $\$ 7$, por haber recibido un ticket canasta vencido según la gente de Cash Office, aunque ella no tenía ninguna certeza que ese ticket lo hubiera recibido ella y no otra cajera. La actora firmó el faltante, porque se encontraba muy cansada de pedir que le demostraran que esos faltantes eran de ella.

En abril de 2006, solicitó que le imprimieran por sistema las horas que había trabajado de la semana del 20 al 26 de marzo del 2006, y comprobó que su encargado le modificaba los horarios de entrada y salida. Mi mandante por semana tenía que trabajar 24 horas y al efectuar esa modificación que referimos, ella le debía a la empresa 40 minutos cuando en realidad había trabajado 25 horas y cuarenta minutos. La gente de recursos humanos justificó al encargado diciendo que eso era normal y estaba bien que lo hiciera así. Esto era significativo para mi mandante, ya que siempre salia fuera del horario pactado, y sin embargo la empresa no le pagaba las horas que en realidad trabajaba.

La actora también habló con el encargado de Seguridad e Higiene de la empresa, solicitándole que gestionara sillas para las cajeras ya que tenían que permanecer muchas horas paradas. Las sillas se habian ido rompiendo y la empresa no las habia reemplazado, por eso habia 5 sillas que servian para 44 cajeras.

En fecha 10/06/06 concurrió a la Clínica Santa Maria, porque sentía fuertes dolores de cintura, en donde la Dra. Lidia Bordon le diagnóstico lumbalgia y le dio $48 \mathrm{hs}$ de reposo, además de colocarle una inyección para aliviar el malestar.

El mes de mayo del 2006, le tomaron nuevamente la evaluación de desempeño dándole una baja calificación nuevamente, bajo el argumento de su falta de colaboración con la empresa al no ser flexible con su horario de trabajo.

El 17/06/06, cuando la actora entró a trabajar, fue a pedir el monedero de la Caja $N^{\circ} 37$ que se le había sido asignada, y en el momento en que se lo iba a entregar la una compañera llamada pide que se corra. La actora recoge sus cosas para dirigirse a la caja (una operación automatizada en su rutina) y cuando llega a la misma descubre que no tiene el monedero, entonces se dirige a en su rutina) y cuando liega a la encuentra el monedero (que contiene normalmente $\$ 100$ ), la encargada tampoco recuerda si se lo entregó o no. Ante ello, mi mandante pide que le hagan un arqueo de caja antes de empezar a operar, para estar tranquila respecto al dinero que tiene, pero los encargados se niegan y le dicen que no se preocupe, que el monedero ya va a aparecer, que los de Cash Office controlarian al final de la jornada si alguna cajera tenía un sobrante de $\$ 100$. Más tarde el le informaron que informado que el arqueo habia salido bien y que no había faltante, pero al otro día le informaron que tenía que firmar un comprobante por el faltante de $\$ 100$. La actora solicitó ver la filmación de ese día para esclarecer que había ocurrido con el monedero pero la empresa se negó a
hacerlo.

El 23/06/06 el Sr. le pidió a mi mandante que lo acompañara a una oficina para hacerle firmar el comprobante del faltante de $\$ 100$ del día 17/06/06 y una suspensión. El argumento era que supuestamente le habían entregado a la actora el monedero con el dinero y que ella lo había perdido, por lo que tenían que descontárselo. La firmarlo, porque ella en su momento habia solicitado un arqueo y pedido ver la filmación de ese día para comprobar que había pasado con el monedero. Por otra parte la gente de Cash Office no había 
sido puesto al tanto de la situación y el

le había informado ese día que del control realizado con había surgido que no faltaba el dinero. Asimismo alegó la actora que no se le dio intervención al personal de seguridad para que revisara en ese momento las otras cajas para ver si alguien tenía el monedero perdido. Finalmente bajo presiones del Gerente, la actora firmó nada más que la suspensión y en fecha 24/06/06 envió un telegrama impugnando la sanción disciplinaria. La empresa contestó mediante una CD de fecha 27/06/06 ratificando la procedencia de la suspensión y del descuento. El 10/07/06 envió un nuevo telegrama rechazando la CD de la empresa. En el mes de julio, apareció en el bono de sueldo de la actora el descuento de los $\$ 100$. Por lo cual, el día $08 / 08 / 06 \mathrm{mi}$ mandante envió nuevo telegrama emplazando a la empresa al reintegro de los $\$ 100$ descontados.

8-Aparición de los síntomas del burn out, desgaste físico y psicológico de la actora originado por el trabajo.

El día 06/07/06, antes de ir a trabajar se sintió que le faltaba la respiración, que tenía un nudo en el estómago y dolor en el pecho. Concurrió a la Clínica Santa María donde la atendió la Dra. Lidia Bordón y le diagnosticó stress laboral. Asimismo le prescribió unos ansiolíticos y le indicó cuatro días de licencia. Luego la Sra. Duarte se dirigió a la empresa y le entregó el original del certificado al Dr.Marchetti.

El día 14/07/06 la actora volvió a sentirme muy mal, lloraba constantemente y estaba deprimida, entonces concurrió al consultorio de la Dra. Lidia Bordon, quien le dio 3 días de licencia, cuyo certificado original se encuentra en poder de la empresa.

En fecha 21/07/06, estando la actora en su lugar de trabajo comenzó a sentir dolor de estómago y de pecho, le faltaba la respiración y tenía taquicardia. Entonces pidió ir a enfermería y alli comenzó a llorar desconsoladamente.

El día 24/07/06 la actora concurrió al psiquiatra Dr. Marcos Lijteroft y le dijo que la crisis que había sufrido en su lugar de trabajo era un ataque de pánico. Le extendió un certificado con reposo relativo por 15 días.

El 03/08/06 el Lic. Mario Lamagrande le extendió un certificado que expresaba que la actora sufría un episodio depresivo mayor con crisis de angustia que estaba asociado al desgaste psicofisico sufrido en su trabajo.

El 04/08/06 el psiquiatra Lijteroff le dijo que iba a tener que dejar de amamantar para poder medicarla y le extendió nuevo certificado de reposo laboral por otros 15 días.

presentarse para ser examinada ante el

El $14 / 08 / 06$ la actora recibe la notificación de la empresa que debe

El Dr. Lijteroff le extendió un nuevo certificado de licencia psiquiátrica que corria a partir del 19/08/06 pero decidió no medicarla para que pudiera continuar amamantando el bebé.

El día 28/08/06 el médico psiquiatra Gustavo Perez Ravier le extendió un nuevo certificado psiquiátrico de licencia por 20 dias por presentar un cuadro depresivo.

El dia 05/09/06 volvió a concurrir al consultorio psiquiatra Gustavo Perez Ravier quien decidió medicarla y le expresó que le era imposible asistir a la Junta Médica en la Subsecretaría del Trabajo fijada para el día 12/09/06.

El día 12/09/06 mi mandante concurrió sola a la Junta Médica, el médico de la empresa y de la Subsecretaria le pidieron los certificados y luego comenzaron a presionarla diciéndole que no habia trabajo, que cuando uno tenía la suerte de tener uno habia que cuidarlo y que por lo tanto tendría que reintegrarse a cumplir sus tareas habituales. La actora firmó en disconformidad el dictamen de alta médica de la Junta y envió a la empresa en fecha 12/09/06 el telegrama N\$352802703 que decía: “Que en razón de haber firmado en disconformidad el dictamen de la Junta Médica de la Subsecretaria del Trabajo, realizada sin la presencia de mi médico tratante y encontrándose en vigencia el certificado médico por Ud. recepcionado el día 28/08/06 por un lapso de 20 dias, comunicole que mantengo tal licencia ordenada por el Dr.Perez, Ravier
hasta su vencimiento".

En fecha $17 / 09 / 06$ la actora se reintegró a su lugar de trabajo, pero cuando ingresó al sector de las cajas sufrió un ataque de pánico y una crisis nerviosa acompañada de acceso de llanto por lo cual fue derivada a enfermería y quedó asentado alli que mi mandante se retiraba por estar indispuesta.

El día 18/09/06 el marido de la actora se presentó en la sede de la empresa para consignar el certificado psiquiátrico del Dr. Perez Ravier que le extendia la licencia a la actora por no encontrarse en condiciones de reintegrarse. Finalmente en Recursos Humanos accedieron a recibir el certificado. Ese mismo día la actora remitió a su empleadora el telegrama $\mathrm{N}^{\circ} 494082214$ que expresaba:"Ratificando términos de mi telegrama fechado 12/09/06 y que aún en desmedro de mi estado de salud me presenté el día 17/09/06 desencadenadoseme una crisis en el ámbito laboral y dado el nuevo certificado extendido por el Dr. Perez Ravier recepcionado por ustedes y que se me asigna reposo laboral por 15 días comunicoles que en uso de tal licencia determinada por el psiquiatra quedando a su disposición para someterme a cualquier control adicional que requiera la empresa". 
El 29/09/06 la actora concurrió al consultorio del Dr. Perez Ravier quien le extendió por 30 días más la licencia atento a que su estado no presentaba una evolución favorable.

Trabajo.

\section{9- Nueva Junta Médica en el ámbito de la Subsecretaria del}

El día 30/11/06 la empresa solicitó nueva Junta Médica en el ámbito de la Subsecretaria del Trabajo (Expte. N¹1.477-W-05). Mi mandante concurrió acompañada por su médica psiquiatra Silvina Tonel (médica particular ya que el Dr. Perez Ravier de la Obra Social le había expresado que no acompañaba a sus pacientes a Juntas Médicas). El dictamen de la Junta médica resultó en disidencia. A continuación transcribimos lo expresado por la psiquiatra de la actora:"que la paciente presenta un diagnóstico de trastorno adaptativo mixto con ansiedad y estado de ánimo depresivo con fobia especifica de tipo situacional (ámbito laboral) y crisis de angustia (se adjunta informe psicodiagnóstico que avala el diagnóstico anteriormente mencionado) que al momento de ser dada de alta por esta Junta Médica en fecha 12/09/06 la paciente recién comenzaba con tratamiento psicofarmacológico puesto que anteriormente estaba en periodo de lactancia, con lo cual no se dio el debido tiempo a que la medicación comenzara a actuar y de esta forma disminuir la sintomatología. El 25/10/06 fecha en la cual me hago cargo de la paciente efectúo cambio de medicación motivado por los efectos adversos que presento con la anterior. La medicación actual es venlafaxina $75 \mathrm{mg}$. por día, alprazolan $1.5 \mathrm{mg}$ por dia. Actualmente la paciente continúa con tratamiento psiquiátrico y psicológico. Su evolución si bien es favorable, presenta crisis de angustia aisladas, por lo cual aún no puedo determinar que el cuadro desapareció por completo y debe continuar en tratamiento y con reposo laboral ya que las crisis panicosas se desencadenan habitualmente en relación al ámbito laboral" hédico de la empresa ratificó su dictamen de fecha 10/09/06 correspondiente al expte. No8738-W-06.

enfermedad profesional. Despido injustificado de la actora.

10- Intercambio epistolar entre las partes. Denuncia de la le envió a mi mandante la $\mathrm{CDN}^{0} 389584564$ de fecha 05/12/06 que decía: "En atención al resultado de la Junta Médica realizada el día 30/11/2006 que concluyó que Ud. se encuentra en condiciones de retomar tareas, intimamos a Ud. a retomar tareas en el plazo de 48 hs bajo apercibimiento de considerar su actitud como abandono de trabajo"

La actora respondió mediante el telegrama $\mathrm{N}^{\circ} 776922454$ de fecha 09/12/06 que decía: "Rechazo vuestra CDN" 389584564(recibida el 08/12/06) por improcedente y no ajustado a derecho ni a la realidad de los hechos. Asimismo rechazo por improcedente vuestro emplazamiento a reincorporarme a mis tareas habituales ya que el dictamen de la Junta Médica de la Subsecretaria de Trabajo (fecha 30/11/06) fue firmado en disconformidad por mi médica psiquiatra tratante quien considera que debo continuar en reposo laboral ya que mis crisis panicosas se desencadenan en relación al ámbito laboral y fundamentó su disidencia en el psicodiagnostico del Lic. Mario Lamagrande (que pongo a vuestra disposición). Por este medio también pongo en vuestro conocimiento que mi enfermedad de trastorno adaptativo mixto con ansiedad y estado de ánimo depresivo con fobia especifica de tipo situacional (ámbito laboral) es una enfermedad profesional y no inculpable por guardar relación causal con las tareas que desarrollaba para mi empleadora. Y aún en el supuesto que la empresa le pretendiese dar. el tratamiento de enfermedad inculpable a mi dolencia, atento a lo dispuesto por el art. 209 LCT y a mi antighiedad de cinco años y siete meses y a que tengo cargas de familia y al certificado médico psiquiátrico de la Dra. Tonel de fecha 16/11/06 presentado a la empresa, continuaré haciendo uso de mi licencia y preservando mi integridad psicofísica por lo cual mi abstención del débito Laboral se encuentra justificada y no puede ser considerada como abandono de trabajo".

La empresa envió la CD No012185405 de fecha 20/12/06 que decía:"Rechazamos su TCL67230417 y ratificamos nuestra anterior. Negamos la denunciada calidad laboral de la enfermedad que denuncia. Intimamos a Ud. por útima vez y en el perentorio plazo de 48 h. a que retome sus tareas, bajo apercibimiento de considerar el contrato de trabajo resuelto por su exclusiva culpa".

La actora envió en fecha 23/12/06 el telegrama $N^{\circ} 776928182$ que decía: "Rechazo vuestra CD No012185405 de fecha 20/12/06 (recibida el 23/12/06) por improcedente y no ajustada a derecho ni a la realidad de los hechos, reitero en un todo los términos de mi anterior telegramo $N^{\circ} 67230417$ de fecha $09 / 12 / 06$ y en tal sentido los emplazo en 72 horas a denunciar mi enfermedad profesional d pongo nuevamente a vuestra disposición el informe psicodiagnostico del Lic. Mario Lamagrande en el que trasunta la relación de causalidad entre el ámbito laboral en el cual desarrollaba mi actividad y mi enfermedad profesional actual que me imposibilita reintegrarme a mi lugar de
trabajo".

En fecha $05 / 01 / 07$, la empleadora remitió comunicación de despido por supuesto abandono de trabajo, mediante CD N $\mathrm{N}^{\circ} 408528911$ que expresaba lo siguiente: "Rechazamos integramente su TLC 67230417 y ratificamos nuestros anteriores. Ante su injustificada renuencia a retomar sus tareas, conforme fuera resuelto en Juntas Médicas, lo cual pone de manifiesto su abierta voluntad rupturista, consideramos a Ud. incursa en abandono de trabajo v resuelto el contrato por su exclusiva culpa. Liquidación final y certificaciones a su disposición en nlazo legol" 
Es destacarse que a la fecha del despido se encontraba vigente el certificado médico de la Dra.Tonel extendido en fecha 13/12/06 por 30 dias. Por lo cual, la actora contestó mediante telegrama $\mathrm{N}^{\circ} 021667735$ de fecha 12/01/07 manifestado los siguiente: "Por Ia presente rechazo la causal de despido invocada por la empresa por ser falaz y maliciosa toda vez que no ha existido un abandono de trabajo puesto que mi licencia psiquiátrica se encuentra avalada por certificados médicos y el dictamen en disidencia de mi médica psiquiatra en la Junta Médica de fecha 30/11/06 realizada en la Subsecretaria de Trabajo. Asimismo por haber denunciado en anteriores comunicaciones telegráficas que mi enfermedad es de carácter profesional y haber puesto a disposición de la empleadora el informe psicodiagnostico del Licenciado Lamagrande quien determino que padezco un cuadro de neurosis fobica severa con $35 \%$ de incapacidad laboral que me imposibilita desempeñar mis tareas habituales. Por lo expresado considero que he sido despedida sin justa causa y los emplazo en el término de 48hs a abonarme indermización de preaviso, integración mes despido, indemnización por antigiededad, $S A C$ y vacaciones proporcionales. Asimismo, emplazo a la empresa por el mismo término a que haga efectiva la entrega de mi certificado de servicios y remuneraciones (art. 80 LCT), todo bajo apercibimiento de iniciar las correspondientes acciones legales en el fuero laboral y reclamar la indemnización prevista por el art. 2 de la Ley 25.323. Hago reserva de iniciar acciones legales para reclamar la indemnización correspondiente a mi incapacidad laboral".

Luego la actora envió a la empresa telegrama $N^{\circ} 852571610$ de fecha 01/02/07, el cual expresaba: "Por la presente autorizo al

a retirar mi certificación de servicios y remuneraciones y liquidación final, ya que por expresa recomendación de mi psiquiátrica tratante me encuentro imposibilitada de concurrir en forma personal a la sede de la empresa".

En fecha 15/02/06 mi mandante envió a

nuevo telegrama $N^{\circ} 771950405$ que decía: "Atento a que en fecha 09/02/07 mi esposo

concurrió a la sede de retirar la liquidación final, certificado de servicios y remuneraciones, y la Recursos Humanos le expresó que no se encontraba disponible, es que por la presente emplazo a la empresa a que en 48hs haga efectivo el pago de liquidación final y de los rubros indemnizatorios de ley por despido sin justa causa y a la entrega del certificado de servicios bajo apercibimiento de iniciar las correspondientes acciones legales".

\section{1- a) Estrés laboral}

Cuando hablamos de estrés laboral, nos encontramos con que, generalmente, el factor estresante principal es la propia naturaleza del trabajo y que puede, carecer de experiencias positivas, con cúmulo de aspectos laborales negativos, o ser traumático, peligroso o ansiógeno en sí mismo, o producir tensión por una excesiva carga de responsabilidad sobre otras personas (Conf. Abajo Olivares, Francisco, "Mobbing. Acoso psicológico en el ámbito del trabajo", Ed. Lexis Nexis, pág.60).

Téngase en cuenta que el estrés está en el origen de la cuarta parte de las bajas laborales de más de dos semanas de todos los problemas de salud relacionados con el trabajo (Conf. "El estrés provoca la mitad de las bajas laborales en Europa", Diario La Voz del Interior, fecha 29/01/03).

La ausencia de características positivas (tales como posibilidad de autoexpresión, posibilidad de autorrealización y desarrollo de los propios recursos personales y profesionales en el trabajo) y/o la fuerte presencia de negativas(tales como necesidad de demostrar la valia continuamente, presión ambiental estresante, exigencias conflictivas por parte de otras personas, tener que tomar muchas decisiones)- o un desequilibrio importante entre ambas- dará lugar a la presencia de estrés en el trabajo.

Mi mandante en su lugar de trabajo, se vio expuesta a un gran estrés originado por factores de riesgo psico-sociales que la empresa no previno conforme a lo que prescribe el deber de previsión y buena fe contractual. Los factores de riesgo psico-sociales son aquellos aspectos del diseño, organización y gestión del trabajo, así como el contexto social y medioambiental, que pueden causar un daño psicológico, social y físico.

En este sentido es muy interesante, una apreciación que realiza Abajo Olivares quien dice: "Elementos o factores estresantes que no pueden considerarse en si mismos mobbing, si pueden ser utilizados como herramienta de acoso, situándonos en una linea a menudo demasiado delgada como para permitirnos diferenciar claramente una u otra figura" (Conf. Abajo Olivares, Francisco, "Mobbing. Acoso psicológico en el ámbito del trabajo", Ed. Lexis Nexis, pág.
64). supuesto en que ambas figuras se tocan

\section{Consideramos que en el caso puntual de la $\quad$ se dio este}

11-b) Síndrome de burn out.

El síndrome de burn out, que ha sido llamado también de desgaste profesional, quemazón profesional, hace referencia a un mismo fenómeno, cada dia con más presencia en el mundo laboral. Fue descubierto, entre otros, por la psicóloga social Cristina Maslach 
de la Escuela de Palo Alto, California, que estudiaba las respuestas emocionales de aquellos profesionales o empleados en actividades centradas en la ayuda a otras personas.

La definición más conocida es la de Maslach y Jackson que lo caracterizaron como: "Un síndrome de agotamiento emocional, despersonalización, y baja realización personal, que puede ocurrir entre individuos que trabajan con personas". En cuanto a la baja realización personal es la tendencia a evaluar el propio trabajo profesional en forma negativa: los afectados se reprochan no haber alcanzado los objetivos propuestos, con vivencia de insuficiencia personal y baja autoestima profesional (Conf. Abajo Olivares, Francisco, "Mobbing. Acoso psicológico en el ámbito del trabajo", Ed. Lexis Nexis, pág. 65 y siguientes).

En este caso la evaluación negativa del trabajo de la actora era efectuada por su empleadora, creando un sentimiento de culpa y angustia continúa en la Sra. Duarte que es una persona idealista y muy responsable.

En general, el sindrome de burn out se manifiesta en diferentes aspectos y o ámbitos: A) Psicosomáticos: fatiga crónica, frecuentes dolores de cabeza, problemas de sueño, úlceras, y otros desórdenes gastrointestinales, pérdida de peso, dolores musculares, taquicardias, etc; B) Emocionales: distanciamiento afectivo como forma de protección del yo, aburrimiento, sentimientos de vacio, sensación de fracaso, baja autoestima, baja tolerancia a la frustración, incapacidad de concentración, sentimientos depresivos; C)En el ambiente laboral: detrimento de la capacidad de trabajo, detrimento de la calidad de los servicios que se prestan, aumento de interacciones hostiles, comunicaciones deficientes.

Se han podido establecer determinados factores como desencadenantes del síndrome de burn out: a) Sobrecarga de trabajo y ocupación poco estimulante; b) Poca o nula participación en la toma de decisiones, c) Falta de medios para realizar las tareas, d) Excesiva burocracia: no importa el resultado, sólo hacer las cosas de una determinada forma; e)Pérdida de identificación con lo que se realiza; f)Percepción de que no se recibe refuerzo cuando el trabajo se desarrolla eficazmente; sin embargo, si se puede producir castigo por hacerlo mal; g)Baja expectativa de qué hacer para que el trabajo sea tenido en cuenta y valorado (Conf. Abajo Olivares, Francisco, "Mobbing. Acoso psicológico en el ámbito del trabajo", Ed. Lexis Nexis, pág. 67).

elementos antes enunciados que desencadenaron en de posee todos estos la actualidad. Podemos decir que en cuadro psiquiátrico que padece en la actualidad. Podemos decir que es un ámbito en el que abunda la violencia y agresividad tanto de empleados como de jerárquicos y del departamento de recursos humanos. Los procedimientos de control de caja son poco claros, no hay acceso de las cajeras a verificar los faltantes que se les imputan, se le descuentan faltantes de sus sueldos a pesar de lo dispuesto por los arts. 87 y 135 L.C.T. $\mathrm{La}$ actividad es sumamente estresante y con restricciones inhumanas como la de no beber agua, ir al baño y tener sólo 18 minutos de descanso, sumado a que no le proporcionaban una silla para atender la caja. Los horarios de salida nunca se respetan, la empresa siempre tiene razón aunque viole normativa de orden público como es la laboral. No hay un control del ejercicio de la autoridad de los encargados que modifican horarios en forma discriminatoria según su simpatía con la cajera o su enemistad. En la demandada funciona una estructura donde se premia el sometimiento, la tolerancia frente a las injusticias, la productividad ante todo, la descalificación de quien pide que se respeten sus derechos de trabajador. Por eso cuando la comenzó a pedir fotocopias de todo lo que le hacían firmar despertó el descontento de encargados y supervisores quienes acentuaron su
hostigamiento hacia la actora.

La actora, en la actualidad, sufre del síndrome de burn out como consecuencia directa del trabajo de cajera que desempeñaba para demandada.

12 - Consecuencias del mobbing reflejadas en el estado físico y
psico de la actora. Primera manifestación invalidante.

La actora necesitaba su empleo por lo que a pesar de su estado de angustia, siguió esforzándose y obligándose a concurrir habitualmente a su lugar de trabajo. Sin embargo su deterioro psíquico y físico comenzó a manifestarse mediante ataques de pánico, insomnio
y crisis de llanto.

\section{A) - Certificados Médicos} En esta presentación acompañamos los certificados médicos que
acreditan la atención por distintos médicos y psiquiatras de la quien a partir de fecha 06/07/06 comenzó a sufrir los sintomas de un cuadro de estrés laboral que dio lugar a su primera licencia por enfermedad y primera manifestación invalidante.

De lo expuesto en el relato de los hechos. en la transcripción del intercambio telegráfico de las partes, y de la prueba instrumental que acompañamos (con especial referencia a certificados médicos) surge claramente que las dolencias sufridas por la actora fueron consecuencia directa de las tareas realizadas para su empleador. Al respecto es importante señalar que tanto la A.R.T. como su empleadora incumplieron con las obligaciones impuestas por la Ley de Riesgos del Trabajo como por la Ley de Higiene y Seguridad en el Trabajo, dejándola desamparada sin ningún tipo de prestación, trayendo como consecuencia la imposibilidad económica de la actora de solventar los gastos de tratamiento psiquiátrico y medicamento recetados en consecuencia que 
podrian aliviar su malestar psíquico que la limita en el desenvolvimiento de una vida normal para joven de su edad. El mobbing y el burn out dejan secuelas en las víctimas que les impide reinsertarse en el mercado laboral, ya que temen volver a padecer el maltrato sufrido en su último empleo. Por otra parte la forma arbitraria y no ajustada a derecho en que fue despedida mi mandante evidencia que el acoso moral ejercido sobre ella perseguía su renuncia, o desvinculación de la empresa, siendo por ello el despido discriminatorio.

B) Daños sufridas por la actora:

Conforme el informe psicológico expedido por la Lic. Mario Lamagrande (acompañado en autos) de fecha 10/10/06 las dolencias sufridas por la actora son las siguientes: Diagnóstico Clímico: "La paciente presenta un trastorno mixto con ansiedad y estado de ánimo depresivo (309.28), según los criterios propuestos por el DSM-IV, en el Eje I". Luego agrega el citado informe psicológico:"La caracteristica esencial del trastorno adaptativo en la entrevistada es el desarrollo de síntomas emocionales y comportamentales en respuesta a un estresante psicosocial identificable, en el caso de la ${ }_{\text {a }}$, la presión laboral y hostigamiento de carácter crónico. Este subtipo se usa con la paciente pues presenta manifestaciones dominantes donde hay una combinación de ansiedad y depresión".

El Lic. Lamagrande sostiene que la actora presenta una Fobia específica de tipo situacional: ámbito laboral (300.29), según los criterios propuestos por el DSM IV, en el Eje I. Más adelante agrega:"Para experimenta ese temor marcado y persistente cuando se encuentra en presencia de la situación laboral y también cuando anticipa de modo imaginado esa situación. El objeto del miedo en este caso resulta por la propia anticipación del peligro inherente a la situación de hallarse frente a una situación de hostigamiento en el ámbito laboral". Después señala:"El nivel de ansiedad y temor por ende en ella varia en función del grado de proximidad al estímulo fóbico, es decir, las respuestas de miedo observadas en la consulta se van a intensificar a medida que se acerque a su ámbito laboral y disminuye a medida que se aleja de él".

El Lic. Lamagrande considera que es comórbido a la fobia especifica, tipo situacional: su ámbito laboral, crisis de angustia, "panic attack" (300.21), según los criterios propuestos por el DSM IV, en el Eje I. Luego el citado psicólogo le dedica un importante apartado, que es el de "Problemas psicosociales y ambientales", a desarrollar el sindrome de burn out del que sería víctima la actora. En este sentido Lamagrande destaca:"...la paciente fue sometida al hostigamiento laboral de un modo persistente lo que se transformó en un estresor crónico, lo que la llevó a desmejorar. En este caso vemos que el mobbing y el burn out han funcionado al mismo tiempo dando por resultado el cuadro psicopatológico que es la fobia con crisis de angustia".

Recomendación Terapéutica: El Lic. Mario Lamagrande considera que es esencial que la paciente inicie un tratamiento intensivo que lleve a paliar su sintomatología anímica y ansiosa en un primer momento y que la ayude a reconstruir su identidad por los eventos anteriormente descriptos. Esto hace necesario un trabajo psicoterapéutico integrado a un tratamiento psiquiátrico que brinde un soporte farmacológico para evitar las recaídas y mejorar la calidad de vida de la misma. El proceso de trabajo puede variar entre un año a tres dado la comorbilidad del cuadro, las sesiones tienen un costo aproximado de $\$ 50$ y $\$ 100$ por sesión.

Incapacidad: El Lic. Lamagrande señala que al momento de la entrevista no se presentaron otros trastornos psicopatológicos. El citado psicólogo concluye que según el código de tablas de incapacidades laborales del Dr. Castex la paciente presenta: Neurosis fóbica severa $(35 \%)$ por presentar en su cuadro manifestaciones psiquicas y somáticas graves asociadas a una fobia especifica y crisis de angustia que requieren de un tratamiento integrado psicológico y psiquiátrico.

Por lo tanto, de lo expuesto y del informe psicodiágnostico citado, surge claramente que las dolencias sufridas por la actora son consecuencia directa del trabajo, por lo que corresponde condenar a la ART al pago de las prestaciones dispuestas por la LRT, y al empleador, como deudor del deber de seguridad a su personal (art.75 LCT) por la reparación integral por los daños y perjuicios por enfermedad ocasionada como consecuencia del trabajo, y en aplicación de lo dispuesto por el art. 1113 del Código Civil, de la que resulta que el principal es responsable en forma inexcusable de los daños causados por sus dependientes a terceros y además como derivado de un ejercicio abusivo del derecho dirección, organización de la empresa, y facultades disciplinarias.

8. Monto reclamado: $\$ 108.805$

\section{Diagnóstico inicial, herramientas utilizadas, grado de incapacidad (de parte):}

\subsection{Fecha primer informe: $10 / 10 / 2006$}


9.2. Herramientas utilizadas: Entrevistas, H.T.P. (prueba proyectiva: funciones yoicas y mecanismos de defensa), M.B.I (Test para la evaluación del Síndrome de Burnout), L.I.P.T (Inventario de Acoso Laboral de Leymann), PRIME - MD (Evaluación de las funciones psicopatológicas), MIPS (Evaluación validada para la República Argentina de la personalidad), BENDER (evaluación psiconeurológica) y BETA II-R (Test de inteligencia).

\subsection{Diagnostico:}

La paciente E. D. presenta un trastorno mixto con ansiedad y estado de

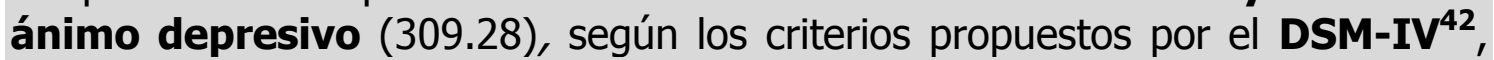
en el Eje I:

La característica esencial del trastorno adaptativo en la entrevistada es el desarrollo de síntomas emocionales y comportamentales en respuesta a un estresante psicosocial identificable, en el caso de la Sra. E. D., la presión laboral y hostigamiento de carácter crónico. Este subtipo se usa con la paciente pues presenta manifestaciones dominantes donde hay una combinación de ansiedad y depresión.

Criterio A: Los síntomas han estado presentes durante los 3 meses siguientes al inicio de la situación estresante.

Criterio B: La expresión clínica de la reacción consiste en un acusado malestar y sobre todo en un deterioro significativo de la actividad social y laboral de la entrevistada.

Criterio C: El trastorno no cumple con los criterios para otro trastorno específico del Eje I (por ejemplo un trastorno por ansiedad o del estado de ánimo) y no es simplemente una exacerbación de un trastorno preexistente del Eje I o del Eje II. Sin embargo, puede diagnosticarse un trastorno adaptativo en presencia de otro trastorno del Eje I o del Eje II si este último no explica el conjunto de síntomas que han aparecido en respuesta al estresante. Por eso aparece como comórbido una Fobia Especifica: tipo situacional con crisis de angustia.

Criterio D: El diagnóstico de trastorno adaptativo en la paciente no representa una reacción de duelo.

Criterio E: El trastorno adaptativo podría resolverse dentro de los 6 meses según los criterios internacionales que siguen a la desaparición de la situación estresante (o de sus consecuencias). Sin embargo, en la paciente los síntomas han persistido por un período más prolongado de tiempo (más de 6 meses) y aparece en respuesta a un estresante con repercusiones importantes y continuos en el caso de la paciente las dificultades económicas y emocionales a partir de la situación laboral.

Cito textual a la paciente: "Cuando comencé a trabajar para Wall-Mart en el 2001 yo me encontraba en el sector de la Óptica Visión Center [...] en agosto quede embarazada de mi primer hija, la óptica cerró y lo último que me dijo mi encargado fue: 'ojala que no te manden a línea de cajas' y cursando un embarazo de 5 meses recursos humanos decidieron

42 Fuente citada: Manual diagnóstico y estadístico de los trastornos mentales. 
pasarme a línea de cajas. [...] le pedía al jefe del sector, que me cambiara de horario por mi estado, le conté que mi marido tenia horarios rotativos y algunas noches no podía venir a buscarme, me tenia que ir sola en la noche y tenia miedo que pudiera pasarme algo y que no pudiera hacer mucho por mi estado, pero él dijo: 'ya voy a ver cómo hacemos', los días pasaron y nunca dio una respuesta a mi pedido, yo no quería presionarlo por que sentía que al ser nueva en su sector ellos me estaban haciendo pagar el derecho de piso [...] Pasaron los días, y el encargado de cajas, me mandaba a hacer devoluciones después que terminábamos de rendir las cajas (es recoger la mercadería que deja la gente en las cajas, ponerlas en carros separarlas por sector y dejarlas en las góndolas) me mandaban a limpiar las cajas (es sacar la basura que dejan las cajeras por ejemplo: rollos, perchas, alarmas, limpiar la cinta donde se cobra, agacharse a sacar las bolsas de basura y pasar un plumero para sacar la tierra de las cajas. Mi papá tuvo que empezar a quedarse en mi casa para poder llevarme porque me dolía la panza y traerme cuando mi esposo no podía, además rara ves nos daban el descanso, porque en la noche había mucha gente y no podíamos irnos de la caja, también me paso que al principio era lenta para atender tenía como 6 meses de embarazo me mandaron al descanso como a las 22 hs [...] en la noche casi nunca me daban el descanso y nos traían a la caja un alfajor con una gaseosa para no darnos el descanso, o sea que atendíamos a la gente y cuando hacia una tarjeta en el momento en que se estaba imprimiendo aprovecha a comer algo, o si no tenía que esperar cuando íbamos a rendir la caja.

Otras compañeras más cercanas al encargado durante dos años seguidos habían obtenido vacaciones en Enero y Febrero. Las vacaciones que a mi me habían tocado eran en Abril del 2002, Octubre del 2003 y en Marzo del 2004 y cuando pedí cambiar las vacaciones porque a mi esposo se la habían dado en Febrero, ella dijo que las fechas ya estaban asignadas, yo le dije entonces por que habían chicas que le habían tocado las vacaciones otra vez en la temporada de Enero y Febrero cuando ya el año pasado le habían tocado en esas fechas, ella dijo que no podía ser ya que siempre hacen rotar para que todos puedan tener esas fechas, me sentía mal ya que siempre me negaban todo, además me mentían como si nada, todo por que obviamente no le caía bien o no era como los demás falsos, que hacían todo para caerles bien, a ellos".

La paciente E. D. presenta un Fobia específica ${ }^{43}$. Tipo situacional: Ámbito laboral. (300.29), según los criterios propuestos por el DSM-IV ${ }^{\mathbf{4}}$, en el Eje I:

Criterio A. La característica esencial de la fobia específica en la paciente es un miedo intenso y persistente al ámbito laboral (que está configurado por las personas que allí trabajan y el espacio de trabajo).

"La Fobia es un miedo persistente, excesivo, irracional y desproporcionado a determinados objetos o situaciones, que se acompaña, con una marcada tendencia a evitarlos. Genera gran malestar o sufrimiento $y$ produce

43 antes fobia simple

44 Fuente citada: Manual diagnóstico y estadístico de los trastornos mentales. 
restricciones importantes en la vida cotidiana, ya sea en las relaciones interpersonales, laborales o sociales, necesita ser tratada". (Cia A.,1999)

Cito textual a la paciente: "Me da miedo ir a mí trabajo, es como que nadie me cree, me descompongo; siento mareos, malestar en el estomago tantos que siento que me estoy retorciendo por eso le pido a mí esposo que lleve los certificados.".

Criterio B. La exposición al estímulo fóbico, que es el ámbito laboral y sus compañeros, en la paciente provocaba una respuesta inmediata de ansiedad.

"Quien padece una fobia específica sabe que, alejándose o evitando la situación, el hecho o el animal generadores de su ansiedad y su temor, no sufrirá experiencias desagradables. Si el enfrentamiento es inevitable, una vez que escape de la situación sentirá un alivio intenso... por un proceso de condicionamiento aversivo, cada vez que tenga que enfrentar el estímulo temido y se aleje de él, comprobará que siente un alivio considerable y tenderá a evitarlo cada vez más, retrayéndose y limitando progresivamente su vida". (Cia A.,1999)

Cito textual a la paciente: "... yo estaba en la caja atendiendo a un hombre de 45 años con su hijo que tenía como 20 años y cuando le digo el total era de $\$ 100$ pesos él me dice, lo queres todo o te lo doy de apoco, cuando lo escucho me quede sin palabras solo le dije el total de la cuenta y él me dice, entonces te lo doy todo, yo no le iba a decir nada pero cuando veo que con el hijo comienzan a reírse en mi cara, yo le cobro y le digo usted es un maleducado que se cree que no me di cuenta de las obscenidades que me dijo, él me miro y dijo, vos a mi no me vas a tratar asíllama ya a tu encargado yo le dije no hace falta porque yo lo voy a llamar. Vino el encargado con un chico de seguridad y me pregunto que necesitaba yo le dije el señor me está diciendo obscenidades y le conté lo que me había dicho, yo le dije a su hijo vos escuchaste lo que me dijo, y él dijo no la verdad que no estaba atento, el hombre le decía que yo le había gritado y faltado el respeto además él solo había venido a comprar tranquilo y yo le había hablado de esa manera, entonces mi encargado le dice que me disculpara por el momento que le había hecho pasar, y cuando se fueron me dice el chico de seguridad en estos casos vos tenes que quedar callada e ignorarlo porque es tu palabra contra la de él, además para que a él lo saquen de la empresa, tendría que haber escuchado uno de seguridad lo cual eso era muy difícil que pasara, yo le dije tengo que esperar que me toque para que me crean, después se fue $y$ yo no podía contener las lagrimas, tenía un nudo en la garganta, y de lejos veía a mi encargado que me decía no te hagas problemas está todo bien. Cuando me dieron el descanso en el baño me larque a llorar, sin que nadie me viera y cuando estábamos rindiendo le comente a mis compañera lo que me había pasado, estaban todas indignada por como había actuado la empresa, ese día apenas vino mi marido me larqué a llorar por lo que me había pasado, me sentía como si me hubieran tocado era horrible la situación y estuve como dos días así, Ilorando cada ves que me acordaba, $y$ el momento en que $m i$ encargado le pedía disculpa no se me podía quitar de la mente". 
Criterio C. En la paciente en muchas ocasiones su temor como a la situación adquirió la forma de una crisis de angustia situacional que fue reconocida por la paciente como un temor excesivo e irracional.

El estresor es el ámbito laboral, lugar donde la paciente fue sistemáticamente hostigada. El proceso conocido como mobbing facilito en la paciente desarrollar un malestar significativo en su salud.

Criterio D. En la mayoría de las ocasiones el estímulo fóbico fue evitado por la entrevistada.

Criterio E. El comportamiento de evitación, miedo y ansiedad de anticipación en relación al estímulo fóbico ha interferido significativamente con las actividades cotidianas de la Sra. E. D., sobre todo en sus relaciones laborales y sociales, además de provocar un malestar evidente en el humor de la entrevistada.

Criterio G. La ansiedad, crisis de angustia y evitación fóbica no responden a la presencia de otro trastorno mental (p. ej., trastorno obsesivo-compulsivo, trastorno por estrés postraumático, trastorno de ansiedad por separación, fobia social, trastorno de angustia con agorafobia o agorafobia sin historia de trastorno de angustia).

Para la Sra. E. D. al experimentar ese temor marcado y persistente cuando se encuentra en presencia la situación laboral y también cuando anticipa de modo imaginado esa situación. El objeto del miedo en este caso resulta por la propia anticipación del peligro inherente a la situación de hallarse frente una situación de hostigamiento en el ámbito laboral. En el trasfondo de este cuadro hay una creencia irracional, por ella identificada, que es la posibilidad de perder el control y angustiarse al exponerse al objeto temido. El nivel de ansiedad y temor por ende en ella varia en función del grado de proximidad al estímulo fóbico, es decir, las respuestas de miedo observadas en la consulta se van intensificar a medida que se acerque a su ámbito laboral y disminuye a medida que se aleja de él.

Las crisis de angustia con sintomatología completa aparecen en respuesta al estímulo fóbico, especialmente cuando la persona se ve obligada a permanecer en esa situación y cree que la huida es imposible. La paciente reconoce que este trastorno es excesivo e irracional.

Aparece como comórbido a la fobia especifica. Tipo situacional: su Ámbito laboral, Crisis de angustia, 'panic attack' (300.21), según los criterios propuestos por el $\mathbf{D S M}-\mathbf{I V}^{\mathbf{4 5}}$, en el Eje I:

El pánico, desde el punto de vista psiquiátrico y psicológico, actualmente es considerado como una vivencia de miedo o terror intenso, con sensación de descontrol, desmayo o muerte inminente, que forma parte del cotejo de síntomas de una crisis o ataque de pánico [...] Su etimología griega nos recuerda al Dios Pan, un niño solitario, triste y taciturno, que solía esconderse en una caverna. Si algún extraño se acercaba a perturbarlo, lanzaba un grito espantoso que

45 Fuente citada: Manual diagnóstico y estadístico de los trastornos mentales. 
atemorizaba y hacía huir al intruso, con un miedo intenso al que se llamó luego "pánico". (Cia A.,1999).

La característica principal de las crisis de angustia en el paciente fue la aparición aislada y temporal de miedo y malestar de carácter intenso, que se acompaña de síntomas somáticos y cognoscitivos. La crisis se iniciaron de forma brusca y alcanzaron su máxima expresión con rapidez (en 10 minutos 0 menos), acompañándose a menudo de una sensación de malestar y en el caso de la paciente de buscar un lugar seguro a fin de manejar sus síntomas.

El primer episodio fue realizando sus actividades laborales. Los síntomas somáticos y cognoscitivos estuvieron constituidos por palpitaciones, sudoración, temblores, sensación de ahogo, malestar torácico, náuseas y molestias abdominales, inestabilidad (aturdimiento), imposibilidad de controlarse por el dolor, parestesias y escalofríos. Esto la llevo a solicitar ayuda por el miedo intenso a que algo le sucediese.

Cito Textual a la paciente: "comencé a descomponerme y empecé a sentir un dolor en el estomago que me llegaba a doblar de apoco yo trataba de respirar por que sentía un nudo en él estomago, y escalofríos".

Sus crisis de angustia son relacionadas con una situación determinada, las cuales tienen simplemente más probabilidades de aparecer al exponerse el paciente a ciertos estímulos como es su ámbito de trabajo y sobre todo el ámbito laboral.

Grado de incapacidad: Neurosis fóbica severa: (35 \%) por presentar en su cuadro manifestaciones psíquicas y somáticas graves asociadas a una fobia específica y crisis de angustia que requieren de un tratamiento integrado psicológico y psiquiátrico.

\subsection{Diagnóstico psiquiátrico y grado de incapacidad (peritado)}

\subsection{Fecha informe: 12/08/2009}

\subsection{Pruebas utilizadas}

Se le realızaron entrevistas clínico-psiquiátricas, se solicitó su autobiografia y se le suministraron los test psicológicos de Bender y H.T.P.

\subsection{Diagnóstico}

De lo expresado y del estudio minucioso del expediente se concluye que ia presenta un cuadro compatible con una Fobia especifica de tipo situacional, ya que cumple con los eriterios diagnósticos del D.S.M.IV Manual Diagnóstico y Estadístico de los Trastornos Mentales "La característica esencial de la fobia especifica es un miedo intenso y persistente hobjetos o situaciones claramente discernibles y circunscritos. La exposición alestímulo fóbico provoca casi invariablemente una respuesta inmediata de insiedad. Esta respuesta puede adquirir la forma de una crisis de angustia situacional o mas o menos relacionada con una situación determinada. En la mayoría de las ocasiones el estimulo fóbico es evitado, si bien a veces puede oxperimentarse, aunque con sumo terror.

El individuo experimenta un temor marcado, persistente y excesivo o

irracional cuando se encuentra en presencia de objetos o situaciones shecificas 0 bien cuando anticipa su aparición." 


\subsection{Grado de incapacidad}

Punto b): La patología que presenta la actora según Baremo de Castex y Silva cademia Nacional de Ciencias de Buenos Aires, Neurosis fóbica leve le confiere una Incapacidad del 10\%. Para Baremo de la Dirección de Reconocimientos Médicos de la Provincia de Buenos Aires, Neurosis fóbica ieve, Incapacidad: $10 \%$ a $30 \%$

\section{Reevaluación actual}

\begin{tabular}{|c|c|c|c|c|c|c|}
\hline Somatizaciones & 18 & total de & 48 & 1,50 & T50 & SOM \\
\hline Obsesiones y compulsiones & 34 & total de & 40 & 3,40 & T63 & OBS \\
\hline Sensitividad interpersonal & 18 & total de & 36 & 2,00 & T63 & S.I. \\
\hline Depresión & 32 & total de & 52 & 2,46 & T63 & DEP \\
\hline Ansiedad & 22 & total de & 40 & 2,20 & T63 & ANS \\
\hline Hostilidad & 19 & total de & 28 & 2,71 & T63 & HOS \\
\hline Ansiedad fóbica & 7 & total de & 24 & 1,17 & T63 & FOB \\
\hline Ideación paranoide & 14 & total de & 24 & 2,33 & T63 & PAR \\
\hline Psicoticismo & 18 & total de & 40 & 1,80 & T63 & PSIC \\
\hline Items adicionales & 12 & total de & 28 & 1,71 & & \\
\hline INDICE DE SEVERIDAD GLOBAL (IGS) & \#\# & \multicolumn{2}{|c|}{ T63 } & \multirow{3}{*}{\multicolumn{2}{|c|}{ Impresión Negativa }} & \\
\hline INDICE DE MALESTAR SINTOMATICO POSITIVO (IMSP) & \#\# & \multicolumn{2}{|l|}{ T50 } & & & \\
\hline TOTAL DE SINTOMAS POSITIVOS (STP) & 79 & \multicolumn{2}{|l|}{ T75 } & & & \\
\hline \multirow[t]{2}{*}{ Cuestionario completo } & \multicolumn{2}{|c|}{ Completo } & & & & \\
\hline & & & & & & \\
\hline ITEMS ADICIONALES & \multicolumn{2}{|c|}{ Puntaje } & \multicolumn{2}{|c|}{ Significativo } & & \\
\hline 5: Falta de interes en las relaciones sexuales & & 3 & \multicolumn{2}{|c|}{ SI } & & \\
\hline 19: Poco apetito & & 3 & \multicolumn{2}{|r|}{ SI } & & \\
\hline 44: Problemas para dormir & & 3 & \multicolumn{2}{|r|}{ SI } & & \\
\hline 59: Pensamientos acerca de la muerte o el morirse & & 1 & \multicolumn{2}{|r|}{ NO } & & \\
\hline 60: Comer en exceso & & $\mathbf{0}$ & \multicolumn{2}{|r|}{ NO } & & \\
\hline 64: Despertarse muy temprano. & & $\mathbf{0}$ & \multirow{2}{*}{\multicolumn{2}{|c|}{ NO }} & & \\
\hline 66: Sueño intranquilo. & & 4 & \multirow{2}{*}{\multicolumn{2}{|c|}{$\begin{array}{l}\text { SI } \\
\text { NO }\end{array}$}} & & \\
\hline 89: Sentimientos de culpa. & & 1 & & & & \\
\hline ITEMS CRITICOS & & untaje & \multicolumn{2}{|c|}{\begin{tabular}{|c|} 
NO \\
Significativo
\end{tabular}} & & \\
\hline 15: Pensar en quitarme la vida & & $\mathbf{0}$ & \multicolumn{2}{|c|}{ NO } & & \\
\hline 16. Escuchar voces que otras personas no oyen & & $\mathbf{0}$ & \multicolumn{2}{|r|}{ NO } & & \\
\hline 54. Perder las esperanzas en el futuro & & 2 & \multicolumn{2}{|r|}{ NO } & & \\
\hline
\end{tabular}

11. Conclusión del caso: Aún no se expide la cámara laboral interviniente aunque las pericias dispuestas por la misma, se desprende una valoración coincidente con la que se reclamó el inicio de la demanda. La ex empleada presenta malestar psicopatológico importante en la reevaluación todos los puntajes se mantienen por encima de la media, lo que es coincidente con una cronificación del malestar y no logra aun reinsertarse laboralmente. 


\subsubsection{CASO 8}

1. Fecha de inicio: 09/06/2009

2. Fecha de resolución: -

3. No Expediente: 21.XXX

4. Nombre: V. C. N. C/ A. A. R. T. S. A. Y Ots

5. Estado: Sustentación de pruebas

6. Resolución: -

7. Hechos y exordio

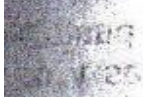
III. EXORDIO:
Que cumpliendo expresas instrucciones de mis mandantes, vengo por este acto a iniciar demanda ordinaria por daños y perjuicios derivados de enfermedad profesional $y / 0$ enfermedad accidente contra las siguientes personas:

calle

a) Ciudad de Mendoza;

Menos reclamos a ART según caso "OLAVARRIA GUZMAN" de la SCJMZA y "AQUINO ISACIO C/ CARGO" de la CSJN

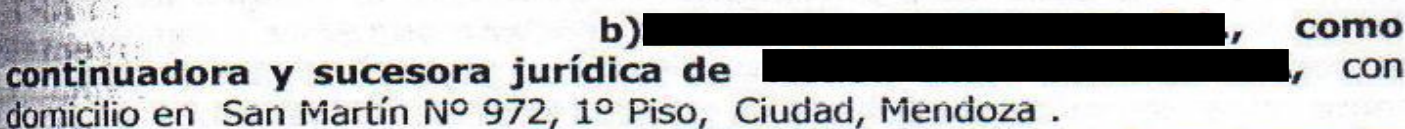
domicilio en San Martín No $972,1^{\circ}$ Piso, Ciudad, Miendoza .

A se le reclaman las prestaciones dinerarias de la Ley de Riesgos del Trabajo, por la suma de \$ 23.877,04 (Pesos veintitrés mil ochocientos setenta y siete con cuatro centavos), en concepto de indemnización por minusvalia que padece la actora a consecuencia de enfermedad psiquiátrica contraída con motivo y en ocasión del trabajo y que debe considerarse "Enfermedad-accidente" de trabajo, A los importes adeudados deberá adicionársele los intereses estipulados específicamente por las Resoluciones SRT No 104/96 y 414/99 (tasa activa mensual del B.N.A.) desde el devengamiento de cada una de las prestaciones, hasta la fecha del efectivo pago.

reclama la suma de $\$ \mathbf{4 8 . 9 0 1}$ (Pesos cuarenta y ocho mil novecientos uno) por su responsabilidad civil (extrasistémica) a fin que le sea reconocido a $\mathrm{m}$ parte el derecho a indemnización integral de los daños y perjuicios por li Enfermedad -Accidente que incapacitó a mi representada , en el establecimiento de su propiedad, o lo que en más o en menos resulte di las pruebas a rendirse en autos, sujeto a la consideración y criterio de V.E., a fil de establecer el correcto y equitativo monto de la reparación del daño en form: integral, comprensiva del daño patrimonial emergente, pérdida de ganancii futura (chance) y daño moral; todo ello con más los intereses legales y costa del pleito. 
S.A para fecha $25 / 08 / 2.007$, en la calificación profesional de Vendedora B C.C.T No 130/75, con horario de trabajo de 13 hs a 19 horas, en e establecimiento sito en calle Ciudad, Mendoza, contando en ese entonces con 54 años de edad. Se la encontró APTÁ en é examen pre-ocupacional que se le realizara en dicha oportunidad, desempeñándose ininterrumpidamente en dicho establecimiento desde si: ingreso hasta el distracto de fecha 16/09/2.008.

\section{La Empresa}

telefónica o telemarketing , se dedica al servicio de call center, venta Are encargo de terceros entre ellónica de Argentina S.A, Tesa entre otras, habiendo sido mi representada operadord. vendedora telefónica de esa Empresa .

Comenzó a trabajar en dicha empresa el día 25/08/07, con un período de capacitación de 2 semanas, dictado por la capacitadota durante los cuales le informaron las tareas que iba a realizar, el horario y la remuneración ( pesos 1.700 entre sueldo y productividad), que no habría tiempo límite para poder ir al baño, que no existiria ningún tipo de presión si no se consiguiera el objetivo de 3 (tres) ventas diarias, que no se exigiría más de una hora o una hora diaria de conexión con el cliente, quedando establecido que el tiempo para almorzar sería de 20 minutos.

Que terminado el período de capacitación, la actora se encontró con la desagradable sorpresa de disponer de solamente 10 minutos para poder ir al baño en una jornada laboral de 6 horas, y si excedía ese limite le llamaban la atención con amenazas de aplicación de apercibimientos por tardar unos segundos mas. De igual modo sucedía con el tiempo de almuerzo ya que en los 20 minutos que le otorgaban era imposible comer, ya que todo el personal salía corriendo para almorzar a la misma hora afuera del edificio, el ascensor estaba casi siempre ocupado, teniendo que bajar y subir a las corridas, llegando con taquicardia y muy agitada, sin permitirle descansar ni 1 minuto.

Que de las tres ventas telefónicas diarias que le exigieron en el periodo de capacitación, se la lievaron hasta catorce, y cuando no se alcanzaban, el acoso por parte de los líderes era permanente. Le mencionaban que si faltaba, perjudicaba a todo el equipo y los que quedaban tenían que trabajar recargados "por culpa" del compañero que no había asistido y que perdía la oportunidad de ganarse un franco, creando un clima de enemistad entre los compañeros de trabajo.

Que en una oportunidad su lider

a los gritos, delante de sus compañeros de trabajo, le mencionó que vendiera más, siendo que se atrasaba porque los programas eran muy lentos y las computadoras también, debiendo quedarse a laborar en horario extraordinario por esa situación, sin paga adicional alguna.

Que de las directivas que le daban a diario muchas veces las cambiaban totalmente, teniendo que cambiarle todo al cliente que ya estaba hablando, debiendo mentirle al cliente sobre el producto en cuanto a sus características, provocando así la venta engañosa por un juego de paiabras tramado por su lider En otras oportunidades su lider le exigía mayor producción comparándola con el resto de sus compañeros , recriminándole que no tenía las mismas condiciones que el resto, haciendo relación a su edad, que debía buscar otro trabajo y dejar de perjudicar al grupo. 
Que en cuanto a la remuneración prometida, nunca se cumplió con las expectativas sembradas en la capacitación, ya que en reiteradas oportunidades le preguntaba a su lider, recibiendo como respuesta que del $100 \%$ de las ventas, se caían más de la mitad.

Que todas estas exigencias, le produjeron a mi representada repetidas infecciones urinarias y graves desordenes digestivos, teniendo que estar permanente con atención médica, llevándola a una situación tal que comenzó a padecer un grado de estrés tan grande que tuve que recurrir a tratamiento psiquiátrico y psicológico, causándole cuadros de depresión y ataques de pánico .

Que la presión psicológica y acoso laboral por parte de su líder por la concreción de ventas telefónicas, sumado a las condiciones de medio ambiente de trabajo relatadas era tan grande que producía en su cuerpo alteraciones que nunca había tenido (dolores de cabeza, de oído, prolongadas afonías, insomnio, nerviosismo, diarrea, sudoración).

Que al transcurrir su sexto mes de trabajo para fecha 13/02/2008 debió concurrir a tratamiento psiquiátrico, como consecuencia de los padecimientos psicofísicos que presentaba de agotamiento intelectual y físico, ya que sentía "quemada", extenuada, sin fuerzas n ganas para hacer más nada y totaimente abúlica. $Y$ esto fue el inicio de los padecimientos que comenzaron a afectar a la L, y que con ed conjunto de las restantes conductas acosadoras llevadas a cabo por su empleadora, terminarían con el serio daño psíquico que hoy padece, y que finalmente le impidió retornar a su trabajo por el riesgo de vida que ello significaría, según los profesionales que la trataron y la tratan en la actualidad.

\section{Acoso moral laboral - mobbing}

El mobbing ha sido definido como proceso de maltrato psicológico que atenta contra la personalidad, dignidado la integridad física de un trabajador y que pone en peligro su empleo o degradz el clima laboral" (Conf.María Irigoyen " el acoso moral : el maltrato psicológico en la vida cotidiana "Edit .Paidós.Barcelona.1999).

$$
\text { Generalmente consiste en }
$$

"-aislamiento físico del trabajador, la marginación a través de la hostilidad y la falta de comunicación, la difusión de conceptos peyorativos, la asignación de tareas humiliantes, descalificadoras, o de muy difícil concreción, el menoscabo de la imagen del empleado frente a sus colegas, clientes o superiores, cambios continuos, etc... (M.F.D "Acoso psicológico al trabajador, el nuevo fenómeno del "mobbing" D.T .2000-B-2011) .

Como consecuencia de los hechos

relatados precedentemente, que significaron someter a la actora a grave excesivo stress ó distrés laboral, su vida de relación ya no fue la misma Comenzó a padecer de insomnio, cambios de humor y sentimientos de angustia que los trasladaba a su grupo familiar y repercutían en su relación interpersonal laboral. No obstante lo cual se esforzaba para seguir adelante tratando de cumplir con sus obligaciones de la mejor manera posible.

Las actividades de acoso ya señaladas, que recibía la actora por parte de sus líderes terminaron por hacer eclosión en la salud psicofísica de la actora, lo que además de producirle daños permanentes sicofísicos, sin dudas buscaban que se cansara y se autoexciuyera de la organización. Ante el desequilibrio morai y físico que padecía el actor, debió recurrir a recibir tratamiento médico-psiquiátrico y medicamentoso desde fecha 13/02/2008, con el Dr.Daniel Parente en el Centro PREMED S.A. de Salud Mental . 
1.a.) Señales que identifican la situación de Mobbing : El Doctor Heinz Leyman bautiza al Acoso psicológico o Mobbing , como psicoterrorismo, al tiempo que logra que este viejo problema se visualice, transparente y vuelva accesible de ser comprendido. Le debemos la posibilidad de tomar -como referencia- lo descrito en su cuadro de "Psicología Terrorista", que muestra la consigna o razón de Acosar, como el intento de Asesinar psíquicamente al objetivo o ser humano, mediante un sostenido modus operandi delictual, estratagema tan generalizada en este tiempo ( Extractado de la Obra Moobing. Acoso Moral y psicológico en las relaciones laborales Alejandro Martín Induvio Editora-Marzo 2.006, página 1 ).

El profesional citado acuñó una lista de señales que identifican una situación de mobbing, (obra citada 9 a 11) por lo que de los hechos relatados, podemos sostener que Vanina Rodríguez entre otras pasó por las siguientes: 1.- El Jefe o acosador no permite a la víctima comunicarse .2.-Se le amaza por escrito. 3. Se ignora su presencia, por ejemplo dirigiéndose exclusivamente a terceros (como si no lo vieran o no existiera) .4. No se habla nunca con la víctima 5.- Se le asigna un puesto de trabajo que le aísla de sus compañeros. 6.- Se prohibe a sus compañeros hablar con él. 7.- Se le exige el cumplimiento de metas imposible de alcanzar 8.- Se le asignan tareas muy inferiores a su capacidad o competencia profesionales. 9.- Se le asignan sin césar tareas nuevas.

1.b. Organización perversa :Que en un reciente artículo publicado en el Diario Los Andes, de fecha 20 de Mayo de 2.009, en la sección Estilo y titulado "El estrés que acarrea el call center,

según una investigación" , cuya copia se acompaña, se sostiene que " el sindrome de estrés laboral crónico (burn out) ( que es un tipo de mobbing) , sobre un estudio de 100 jóvenes de ambos sexos, con un promedio de edad de 25 años, que trabajan como agentes de atención telefónica de consultas y redamos de todo tipo y para cualquier empresa local o internacional, Pablo Cólica autor de la investigación, sostiene que el síndrome se produce como consecuencia de trabajar por lo menos, seis horas con un alto grado de exigencia, sobreestimación auditiva y visual, escasas pausas y maltrato psicológico de jefes y supervisores, continuando la investigación mencionando que " los pacientes que llegan a la consulta tienen jaquecas trastornos del sueño y digestivos palpitaciones, falta de aire, debilidad , contracturas musculares,alteraciones cognitivas, pérdidas de concentración y de memoria, entre otras."

propen el presente caso, es la propia organización la que mantiene un esquema de tipo "perverso" (en la definición de Marie-France Irigoyen "El acoso moral .El maltrato psicológico pág.72) , o bien utiliza la figura del mobbing como lo que la Asociación Española contra el Acoso Psicológico en el Trabajo llama una "lenta y silenciosa alternativa al despido". . La autora citada, expresa: "La Empresa en su conjunto se puede convertir en un sistema perverso: cuando el fin justifica los medios y cuando está dispuesta a todo-incluso a destruir a sus empleados-con tal de alcanzar sus objetivos. En este caso, la mentira desencadena el proceso perverso en el mismo nivel de la organización del trabajo, así los dirigentes se mantienen en su posición únicamente gracias a un sistema de defensa destructivo, se niegan a considerar al factor humano, huyen de sus responsabilidades y utilizan la mentira y el miedo para dirigir. En fin, la empresa utiliza a sabiendas los procedimientos perversos de un individuo inn la idea de obtener un rendimiento mavor. 
psiquiátrico:

Sometida a tratamiento psicológico

y psiquiátrico, se le diagnosticó a Cristina Noemi Valiina para fecha 17/08/2.008 y por informe de su psicólogo Licenciado Mario Lamagrande que " Los trastornos presentados por el paciente son según el Manual Internacional de Trastornos Mentales DSM IV, padeciendo trastorno depresivo .Episodio depresivo mayor .Moderado. Crisis de angustia (panik attack), problemas músculo esqueléticas a consecuencia de contracturas, trastornos vasculares HTA, problemas laborales. El referido Profesional manifiesta que : "Según el código de tablas de incapacidades laborales del Dr.Castex el paciente presenta producto del mobbing teniendo en cuenta las pautas para diagnosticar problemas físicos y psicosomáticos de incapacidades producidas por el acoso psicológico (mobbing) según el Dr.Rubinstein " Depresión Moderada (30\%) inducido por acoso laboral, por presentar manifestaciones psíquicas y somáticas severas permanentes asociadas a una reacción adaptativa específica con crisis de angustia que requieren de un tratamiento específico, con crisis de angustia que requieren de un tratamiento integrado psicológico y psiquiátrico. Dentro de la recomendación terapéutica, sostiene "A fin de preservar su condición psíquica se recomienda no volver a su ámbito laboral ."

También se adjunta certificado

médico de PROMED S.A. (Instituto de Salud Mental), suscripto por la Dra.Yanina Falcón de fecha 03/11/2.008 , que dice :" Certifico que la Señora Vallina Cristina Noemí, se encuentra en tratamiento en esta entidad, desde el día 13/02/2008 con el Dr.Parente Daniel y actualmente con quien suscribe .Fue medicada con Anafronil $75 \mathrm{mg}$,Plidan $10 \mathrm{mg} /$ día y Clonozepan $1 \mathrm{mg} /$ día , bajo el diagnóstico de Síndrome depresivo ansioso ".

Atento a lo informado por diagnóstico profesional, la comprobada existencia de graves patologías psiquiátricas que provocan minusvalía laboral y obligan a la paciente a someterse a tratamiento médico-medicamentoso, así como la comprobación de la existencia de MOBBING LABORAL por parte de la empleadora y/o sus dependientes con ia gravedad y concatenación de las acciones despiegadas, la imposibilidad de obtener en lo inmediato y en el marco de la Ley de Riesgos del Trabajo ayuda psiquiátrica y las pertinentes licencias por ILT que la le 24557 prevé para enfermedades-accidente y/o producidas con motivo ó en ocasión del trabajo, se advirtió necesario e indispensable para salvaguardar la vida de la Señora ( la salud ya estaba gravemente deteriorada) el provocar la ruptura de la relación laboral y producir el despido indirecto fundado en justa causa y en los agravios que el accionar descripto provocó por culpa de su empleadora. Así se remitió telegrama No 955685865 en fech $16 / 09 / 2008$, con el siguiente texto: 
Que atento a la sobrecarga de trabajo funciones que como teleoperadora de call center de su propiedad, desde el 25 d Agosto de 2.007 , he sufrido gran presión y stress ó distrés laboral y serios problemas d salud como consecuencia de ello; al disponer solamente de 10 minutos para poder ir a baño en una jornada laboral de 6 horas, bajo pena de llamado de atención y amenaza de sancioncs disciplinarias, mc otorgaban 20 minutos para almorzar sicndo imposible comer en ese tiempo, ya que todo el personal lo hacía a la misma hora, eso implicabo subir y bajar corriendo las escaleras para salir del edificio, ya que era imposible utilizar el ascensor. Todas estas exigencias me produjeron repetidas infecciones urinarias y graves desordenes digestivos, teniendo que estar permanente con atención médica.,La presión psicológica y acoso laboral se acrecentaba día a día, produciendo en mi cuerpo alteraciones que nunca había tenido (dolores de cabeza, de oído, prolongadas afonías, insomnio, nerviosismo, diarrea, sudoración). Sumado a ello se me pretendita hacerme cumplir metas excesivas de productividad en tiempo preestablecido, así de las 3 ventas diarias que mencionaron en las jornadas de capacitación que debia hacer las llevaron hasta 14, llegando a efectuar más de 160 llamadas telefónicas en la jornada de trabajo, en caso que no alcanzaba las metas propuestas, era pasible de malos tratos. , acoso y actitud persecutoria por parte de mi líder Así, de un hora de conexión (telefónica con los clientes), a partir del mes de Diciembre 2.007 sé me exigió que fueran tres horas de conexión, lo que aumentó el estrés que ya padecía Se me decía a su vez, que si faltaba perjudicaba a todo el equipo porque los que quedaban tenían que trabajar recargados "por culpa" del compañero que no habia asistido y que perdíamos la oportunidad de ganarnos un franco, situación esta qué creaba un clima de enemistad entre los compañeros de trabajo. No se me permitla descansar ni un minuto y la comunicación interpersonal con mis compañeros estabé prohibida. Toda esta situación me llevó a un grado de estrés tan grande que tuve que recurrir a tratamiento psiquiátrico y psicológico, causándome daños como depresión y ataques de pánico. Que tales actitudes han provocado distrés laboral y daños a mi salud fisica y psiquica afectando también mi vida de relación, con graves crisis depresivoansiosas que debieron ser tratadas y motivaron sucesivas licencias por enfermedad. Hoy me ha sido diagnosticado " trastorno depresivo mayor . Episodio depresivo mayor recidivante. Fobia específica. Tipo ambiental: ámbito laboral. Crisis de angustia (panil attack)" y dictaminado que me provoca discapacidad laboral ( $30 \%)$, parcial y permanente, nombre DSM-IV trastorno por estrés postraumático crónico manifestaciones síquicas y somáticas graves asociadas a crisis de angustia que requieren de un tratamiento integrado psicológico y psiquiátrico medicamentoso, según certificado en mi poder y expedido por el Licenciado en Psicologia Mario Lamagrande La enfermedad accidente que padezco, fue oportunamente comunicada a Ustedes negando tal carácter y asistencia, por lo que en la convicción que vuestras actitudes me causan grave perjuicio material y moral que configura injuria que por su gravedad no permite la prosecución de la relación laboral, y que además, de continuar pondría en serio riesgo mi salud mentai y hasta mi vida, COMUNICOLES ME DOY POR DESPEDIDA CONFORME LAS CAUSALES INDICADAS Y POR SU EXCLUSIVA CULPA, debiendo considerarse al distracto a los efectos indemnizatorios comprendido. en los arts. 242 y 245 LCT . Atento despido indirecto producido, intímoles 5 días de recibida ia presente me hagan efectivas las sumas de indemnizaciones por despido, por falta de preaviso e integración mes de despido bajo apercibimiento considerar procedente incremento indemnizatorio artículo 2 ley 25323, así como también al pago dé las sumas de ítems de liquidación final. Asimismo, hago expresa reserva de accionar por indemnizaciones de minusvaiía que resuitan a consecuencia del Miobbing laboral de que he sido objeto y que deben atribuirse causal ó concausalmente al trabajo y 
directamente relacionadas con vivencias propias del ámbito laboral y tareas que desempeñara en relación de dependencia par

A su vez solicito me hagan entrega del formulario PS6.2 de Anses, debidamente autenticado, bajo apercibimiento de ley.

La empleadora rechaza este telegrama mediante Carta Documento de fecha 18 de Setiembre de .2008 , negando las razones invocadas para el despido.

Hoy se hace necesaria la interposición de la presente demanda para obtener la reparación integral de los daños por el accidente y enfermedad- accidente, provocada por el cuadro de stress sufrido a causa de la presión psicológica, así como por el acoso y mobbing laboral sufrido en el trabajo y con motivo y en ocasión del mismo, y que ha derivado en la patología psiquiátrica que se diagnosticara y que hoy se trata.

A los efectos de la atribución de responsabilidad deberá tenerse presente que la empleadora, a través de sus dependientes responsables de lo organizacional y directriz de la empresa incurrió en una serie de acciones que trajeron consigo condiciones de trabajo antirreglamentarias con el consiguiente stress ó distrés laboral, así como también se llevó a cabo otras acciones que deben considerarse mobbing laboral, sometiéndola a estrés laboral que desencadenó la gravedad y virulencia con que hoy se presenta la patología psiquiátrica que padece la actora como consecuencia de todo ello.

8. Monto reclamado: $72.778,49$

\section{Diagnóstico inicial, herramientas utilizadas, grado de incapacidad (de parte):}

\subsection{Fecha primer informe 17/08/2008}

9.2. Herramientas utilizadas: Entrevistas, H.T.P. (prueba proyectiva: funciones yoicas y mecanismos de defensa), M.B.I (Test para la evaluación del Síndrome de Burnout), L.I.P.T (Inventario de Acoso Laboral de Leymann), IMPIL (Evaluación psicológica del estrés por inestabilidad laboral), PRIME MD (Evaluación global psicopatológica de trastornos anímicos, ansiosos y miscelanea), DTS ${ }^{\mathbf{4 6}}$ (Escala de Trauma de Davidson), $\mathbf{T Q}^{\mathbf{4 7}}$ (El Cuestionario para Experiencias Traumáticas), $\mathbf{F Q}$ (El cuestionario de miedos es un instrumento de autoevaluación de fobias), HRSD (La Escala de Evaluación para la Depresión de Hamilton fue diseñada para ofrecer una medida de la intensidad o gravedad de la depresión), MIPS (Evaluación validada para la República Argentina de la personalidad), BENDER (evaluación psiconeurológica) y BETA II-R (Test de inteligencia).

46 Escala diseñada para valorar la frecuencia y severidad de los síntomas del trastorno por estrés postraumático en sujetos que han sufrido un evento estresante. Su utilidad reside en la valoración de la gravedad y frecuencia de síntomas de trastorno por estrés postraumático y en la valoración de la respuesta al tratamiento.

47 Diseñado por Davidson y cols. como un instrumento para el cribado de pacientes con trastorno por estrés postraumático. Consta de tres partes claramente diferenciadas: Listado de experiencias traumáticas; Acontecimiento traumático que más preocupa en el momento actual; Listado de síntomas. 


\subsection{Diagnostico:}

La paciente V., C. N. presenta un Trastorno depresivo. Episodio depresivo mayor. Moderado (F3.21), según los criterios propuestos por el $\mathbf{D S M - I V}{ }^{\mathbf{4 8}}$, en el Eje I:

"La depresión se ha definido como una sensación duradera y sostenida de inutilidad, de que el mundo no tiene sentido y el futuro es desesperanzador. Sin embargo, padecer una enfermedad psiquiátrica conocida como depresión es muy distinto de estar generalmente triste o de experimentar cambios de estado de ánimo". (Katon \& Schulberg, 1992)

La característica esencial del trastorno depresivo mayor en la paciente Vallina, Cristina Noemí es el haber padecido uno o más episodios depresivos mayores sin historia de episodios maníacos, mixtos 0 hipomaníacos.

Criterio A: Frecuentemente, el estado de ánimo en un episodio depresivo mayor es descrito por el entrevistado como deprimido, triste, desesperanzado y desanimado un comentario común del paciente a lo largo de la entrevista es: "Se me hace pesado el camino, este año ha sido larguísimo". Con quejas somáticas manifestadas en dolor de cabeza que son jaquecas crónicas, contracturas y dolores inespecíficos. Relacionados a su empleo.

Cito textual a la paciente: "Con respecto a los tiempos de descanso teníamos solo 20 minutos en todo el día para almorzar, solo 10 minutos para ir al baño y tomar agua en 6 horas de trabajo, si nos excedíamos aunque fuera un segundo éramos victimas de recriminación y maltrato por nuestro líder y aparte la empresa nos apercibía, con constantes amenazas de despido; estos tiempos estabas controlados por el sistema en cada PC, tanto del empleado como del líder"

Criterio A2: Todo el tiempo la paciente manifestó la pérdida de interés o la capacidad de disfrutar en cosas que le eran gratas como estar con su familia.

Criterio A3: Durante este episodio depresivo mayor la paciente aumento de peso sin intención.

Criterio A4: La paciente V., C. N. presento trastornos del sueño graves que en la paciente se manifiestan en la incapacidad para mantener el sueño y debieron ser compensados psiquiátricamente.

Criterio A5: El enlentecimiento psicomotor en la paciente al momento de la entrevista fue lo bastante grave como para ser observado y también fue referida esta sensación de retardo motor por la paciente.

Criterio A6: Al momento de la entrevista la paciente presento falta de energía, cansancio y fatiga. Lo que significo un rendimiento menor en todas sus actividades personales.

Criterio A7: Los sentimientos de culpa asociados a este episodio depresivo mayor en la paciente aparecieron en todas las entrevistas psicodiagnósticas en referencia a hacer evaluaciones negativas no realistas del propio valor, preocupaciones y rumiaciones de culpa referidas a pequeños errores pasados sobre todo de los acontecimientos laborales.

48 Fuente citada: Manual diagnóstico y estadístico de los trastornos mentales. 
Cito textual a la paciente: "Se nos daban directivas diarias a seguir que muchas veces a la media hora de estar trabajando nos las cambiaban totalmente, teniendo que en consecuencia cambiarle todo al cliente que ya estábamos hablando y tener que mentirle sobre el producto en características no en precios, provocando así la venta engañosa por un juego de palabras bien tramado por el líder; luego esas ventas eran caídas ya que el cliente no recibía lo dicho o el líder los llamaba a los veinte minutos y les decía que era un técnico y la gente desconfiaba y anulaba la venta, luego de eso nos intimaban o acosaban diciéndonos que hacíamos todo mal y que era culpa nuestra la caída siendo que siempre ,por miedo al despido, todos hacíamos al pie de la letra que se pedía sin atrevernos a cambiar nada"

Criterio A8: La paciente presento su capacidad disminuida para pensar, concentrarse y tomar decisiones. Se hizo un diagnóstico diferencial en este asunto y se encontraron indicares de organicidad.

Criterio A9: La paciente V., C. N. no presento ideas de muerte.

Criterio B: No cumple su sintomatología con los criterios de un episodio mixto.

Criterio C: El grado de incapacidad que se asocio a sus episodios depresivos mayores fue persistente, hubo un malestar clínico significativo (problemas gastrointestinales, vasculares y músculo-esqueléticos), el deterioro social y afectar las respuestas todos sus ámbitos.

Criterio D: Por definición, un episodio depresivo mayor no es debido a los efectos fisiológicos directos de las drogas, a los efectos secundarios de los medicamentos y a la exposición a tóxicos. Asimismo, el episodio no es debido a los efectos fisiológicos directos de ninguna enfermedad médica. Es importante destacar que los episodios no son producto de un trastorno esquizoafectivo y no están superpuestos a una esquizofrenia, un trastorno esquizofreniforme, un trastorno delirante o un trastorno psicótico no especificado.

Al trastorno depresivo mayor aparece como comórbido Crisis de angustia o 'panic attack' (300.21), según los criterios propuestos por el $\mathbf{D S M - I V}{ }^{\mathbf{4 9}}$, en el Eje I:

"El pánico, desde el punto de vista psiquiátrico y psicológico, actualmente es considerado como una vivencia de miedo o terror intenso, con sensación de descontrol, desmayo 0 muerte inminente, que forma parte del cotejo de síntomas de una crisis o ataque de pánico [...] Su etimología griega nos recuerda al Dios Pan, un niño solitario, triste y taciturno, que solía esconderse en una caverna. Si algún extraño se acercaba a perturbarlo, lanzaba un grito espantoso que atemorizaba y hacía huir al intruso, con un miedo intenso al que se llamó luego 'pánico". (Cia A., 1999).

La característica principal de las crisis de angustia en la paciente fue la aparición de miedo y malestar de carácter intenso, que se acompaña de síntomas somáticos y cognoscitivos.

49 Fuente citada: Manual diagnóstico y estadístico de los trastornos mentales. 
"La reacción de estrés se vuelve patológica cuando la situación estresante, que puede ser imprevista, demasiado intensa o, por el contrario, conocida pero reiterada, supera la posibilidad de acondicionamiento del sujeto, que se siente sobrepasado". (Ferrari M., 2000)

La sensación de descontrol representa para la paciente un estado de desprotección que la lleva a aferrarse a aquellas situaciones que puedan dar garantía de estabilidad incluso las insalubres como las utilizadas por su organización.

Cito textual a la paciente: "/e pedí a mi supervisor si podía tomar agua, tenía la boca reseca-mal, me dolían los maxilares, no podía ni estar de pie, recibió una llamada a su celular la atendió y pude ir a la sala de break a tomar agua. El Supervisor vino a la sala de break, él veía que varios compañeros de todo el call venían a ver qué me pasaba, el supervisor se acercó a ver que pasaba porque una compañera de mi equipo me vino a ver, se dio cuenta que yo no estaba bien y le dijo al supervisor por qué no me tomaba la presión, él accedió y la mandó a mi compañera a buscar el estetoscopio. Tenía más de 20 de presión, me dijo que me tomara 1/4 de Plidan y agua, y que me quedara sentada. A la hora vino un compañero de mi equipo y me tomó nuevamente la presión y tenía 19 me dijo él, quizás estaba más alta. En ningún momento me dijeron "llamamos al médico o sea a la emergencia médica de la empresa". Me quedé en la sala de break, se hicieron las 18 horas y fiché mi horario de salida. Previo a esto me dijeron si tenía a alguien que me fuera a buscar, llamé a mi hija, quien me estaba esperando en la esquina. Por supuesto caminé 20 metros con mi hija y entré a un consultorio y me hice atender".

El estrés relacionado con el trabajo se define como "el conjunto de reacciones emocionales, cognitivas, fisiológicas y del comportamiento a ciertos aspectos adversos o nocivos del contenido, la organización o el entorno de trabajo... Es un estado que se caracteriza por altos niveles de excitación y angustia, con la frecuente sensación de no poder hacer frente a la situación" (Quintin O.,1999).

Este trastorno a modo análogo es como la "fiebre" en los cuadros clínicos, esta "fiebre psicológica" muestra los desesperados intentos por ajustar sus condiciones psicofísicas a las demandas ambientales pero tal asunto le resulta imposible.

Las crisis bruscas resultan de la imposibilidad del autocontrol por la acumulación de malestar. Por eso hacen su aparición en un corto instante las crisis que alcanzan su máxima expresión con rapidez (en 10 minutos o menos), acompañándose a menudo de una sensación de malestar extremo como es la opresión en el pecho "una pisada de elefante" y un "nudo en la garganta" que en el caso de la paciente la llevaron en casos extremos a dejar su lugar de trabajo por las repercusiones personales de ser inundado por ese estado angustioso.

"El estrés percibido ${ }^{50}$ es el grado en el cual un individuo percibe y es capaz de soportar las demandas de la vida; Afecto Negativo es el grado a partir del cual el individuo se siente infeliz o ansioso sobre si mismo; Eventos

50 Ídem. 
Estresantes de la vida son las circunstancias capaces de desencadenar estrés en un individuo". (Oakley R., 2003)

El primer episodio fue realizando sus actividades laborales. Los síntomas somáticos y cognoscitivos estuvieron constituidos por palpitaciones, sudoración, temblores, sensación de ahogo, diarrea, vómitos, malestar torácico, náuseas y molestias abdominales, inestabilidad (aturdimiento), imposibilidad de controlarse por el dolor, parestesias y escalofríos. Esto la llevo a solicitar ayuda por el miedo intenso a que algo le sucediese.

Sus crisis de angustia son relacionadas con una situación determinada, las cuales tienen simplemente más probabilidades de aparecer al exponerse la paciente a su ámbito de trabajo.

\subsection{Grado de incapacidad: Depresión. moderada (30 \%) inducido} por acoso laboral. Por presentar manifestaciones psíquicas y somáticas severas permanentes asociadas a una reacción adaptativa específica con crisis de angustia que requieren de un tratamiento integrado psicológico y psiquiátrico.

\subsection{Diagnóstico psiquiátrico y grado de incapacidad (peritado)}

\subsection{Fecha informe:}

\subsection{Pruebas utilizadas}

Que para llevar a cabo el informe pericial procedi a examinar al actor zando como técnica la entrevista semiestructurada sobre factores etiológicos, fenoménicos sicopatológicos preexistentes, aspectos evolutivos a partir de inicio evento mórbido actual, ps previos y posteriores de personalidad, y pesquisando asimismo síntomas psíquicos
jales con abordaje semiológico.

\subsection{Diagnóstico}

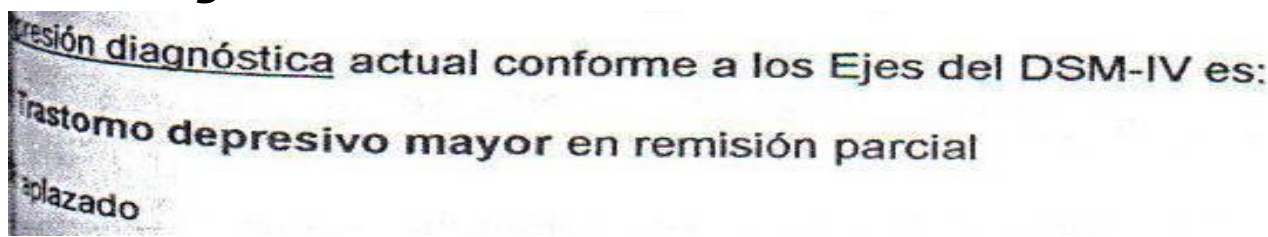

\subsection{Grado de incapacidad}

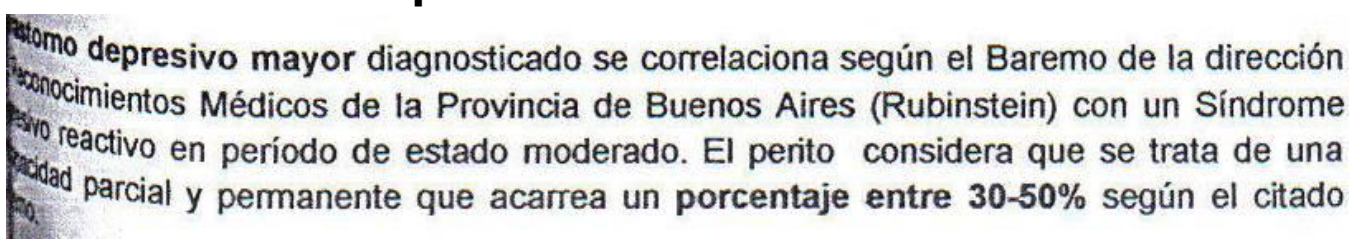

\section{Reevaluación actual resultado:}




\begin{tabular}{|c|c|c|c|c|c|c|}
\hline Somatizaciones & 36 & total de $<$ & 48 & 3,00 & T75 & SOM \\
\hline Obsesiones y compulsiones & 21 & total de & 40 & 2,10 & T63 & OBS \\
\hline Sensitividad interpersonal & 15 & total de 3 & 36 & 1,67 & T50 & S.I. \\
\hline Depresión & 24 & total de 5 & 52 & 1,85 & T50 & DEP \\
\hline Ansiedad & 27 & total de & 40 & 2,70 & T63 & ANS \\
\hline Hostilidad & & total de 2 & 28 & 0,00 & T50 & HOS \\
\hline Ansiedad fóbica & 10 & total de 2 & 24 & 1,67 & T63 & FOB \\
\hline Ideación paranoide & 11 & total de & 24 & 1,83 & T50 & PAR \\
\hline Psicoticismo & 5 & total de & 40 & 0,50 & T50 & PSIC \\
\hline Items adicionales & 7 & total de & 28 & 1,00 & & \\
\hline INDICE DE SEVERIDAD GLOBAL (IGS) & 1,73 & T63 & & & & \\
\hline INDICE DE MALESTAR SINTOMATICO POSITIVO (IMSP) & 2,40 & T50 & & & & \\
\hline TOTAL DE SINTOMAS POSITIVOS (STP) & 65 & T63 & & & & \\
\hline ITEMS ADICIONALES & \multicolumn{5}{|c|}{ Puntaje Significativo } & \\
\hline 5: Falta de interes en las relaciones sexuales & & \begin{tabular}{l|l}
3 & \\
\end{tabular} & & SI & & \\
\hline 19: Poco apetito & & $\mathbf{0}$ & & NO & & \\
\hline 44: Problemas para dormir & & $\mathbf{0}$ & & NO & & \\
\hline 59: Pensamientos acerca de la muerte o el morirse & & $\mathbf{0}$ & & NO & & \\
\hline 60: Comer en exceso & & 4 & & SI & & \\
\hline 64: Despertarse muy temprano. & & $\mathbf{0}$ & & NO & & \\
\hline 66: Sueño intranquilo. & & 2 & & NO & & \\
\hline 89: Sentimientos de culpa. & & 1 & & NO & & \\
\hline ITEMS CRITICOS & & Intaje & Sign & ificativo & & \\
\hline 15: Pensar en quitarme la vida & & $\mathbf{0}$ & & NO & & \\
\hline 16. Escuchar voces que otras personas no oyen & & $\mathbf{0}$ & & NO & & \\
\hline 54. Perder las esperanzas en el futuro & & $\mathbf{0}$ & & NO & & \\
\hline
\end{tabular}

11. Conclusión del caso: En este caso aún no se expide la cámara laboral interviniente aunque las pericias dispuestas por la misma, es coincidente con la valoración que dio inicio a la demanda. Es notorio el desgaste que sufre la ex empleada y sobre todo a pesar de estar en tratamiento presenta un profundo malestar somático y sintomatología psicopatológica verificada en varios indicadores como puede verse en la reevaluación por medio de la escala SDL-90.

\subsection{Anexo reglamentaciones provinciales y proyectos}

\section{de ley en la República Argentina}

\subsubsection{LEGISLATURA DE LA CIUDAD AUTONOMA DE LA CIUDAD DE BUENOS AIRES}

28a SESION 4 DE DICIEMBRE DE 2003

SANCION DE LA LEY CONTRA LA VIOLENCIA LABORAL Nro.1225

Articulo $1^{\circ}$ OBJETO:

La presente Ley tiene por objeto prevenir y sancionar la violencia Laboral de los/las superiores jerárquicos hacia el personal dependiente de cualquier organismo de los instituidos por los títulos Tercero a Séptimo del libro Segundo de la Constitución de la Ciudad Autónoma de Buenos Aires.

Articulo $2^{\circ}$ AMBITO DE APLICACIÓN:

Esta sancionada por esta Ley toda acción ejercida sobre un /una trabajador/ trabajadora dentro de la administración pública que atente contra la dignidad, integridad física, sexual, psicológica o social de aquel/aquella mediante 
amenaza, intimidación, abuso de poder, acoso, acoso sexual, maltrato psíquico o psicológico, social u ofensa ejercida sobre un trabajador/ trabajadora. Articulo $3^{\circ}$ MALTRATO PSÍQUICO Y SOCIAL:

Se entiende por maltrato psíquico y social contra el trabajador/ trabajadora a la hostilidad continua y repetida del/ de la superior jerárquico en forma de insulto, hostigamiento psicológico, desprecio y critica. Se define con carácter enunciativo como maltrato psíquico y social a las siguientes acciones contra el/ la trabajador/ trabajadora.

a) Bloquear constantemente sus iniciativas de interacción, generando aislamiento.

b) Cambiar de oficina, lugar habitual de trabajo, con ánimo de separarlo / la de sus compañeros / compañeras o colaboradores / colaboradoras más cercanas.

c) Prohibir a los empleados / empleadas que hablen con el / ella.

d) Obligarlo /obligarla a ejecutar tareas denigrantes para su dignidad personal.

e) Juzgar de manera ofensiva su desempeño en la organización.

f) Asignarle misiones sin sentido, innecesarias, con la intención de humillar.

g) Encargarle trabajo imposible de realizar.

h) Obstaculizar o imposibilitar la ejecución de una actividad, u ocultar las herramientas necesarias para concretar una tarea atinente a su puesto.

i) Promover su hostigamiento Psicológico.

j) Amenazarlo /amenazarla, repetidamente, con despido infundado.

k) Privarlo /a de información útil para desempeñar su tarea o ejercer sus derechos.

Articulo $4^{\circ}$ MALTRATO FISICO:

Se entiende por maltrato físico a toda conducta del/de la superior jerárquico que directa $o$ indirectamente este dirigida a ocasionar un daño o sufrimiento físico a los/las trabajadores / trabajadoras.

Articulo $5^{\circ}$ ACOSO: 
Se entiende por acoso a la acción persistente y reiterada de incomodar con palabras, gestos, bromas o insultos en razón de su genero, orientación sexual, ideología, edad, nacionalidad u origen étnico, color, religión estado civil, capacidades diferentes, conformación física, preferencias artísticas, culturales, deportivas, situación familiar, social, económica, o cualquier circunstancia que implique distinción, exclusión, restricción o menoscabo.

Articulo $6^{\circ}$ ACOSO SEXUAL:

Se entiende por acoso sexual solicitar por cualquier medio de favores de naturaleza sexual, para si o para un tercero, prevaliéndose de una situación de superioridad, cuando concurriere alguna de las siguientes circunstancias:

a) Cuando se formulare con anuncio expreso o tácito causar un daño a la victima respecto de las expectativas que pueda tener en el ámbito de la relación.

b) Cuando el rechazo o negativa de la victima fuere utilizado como fundamento de la toma de decisiones relativas a dicha persona o a una tercera persona vinculada directamente con ella.

c) Cuando el acoso interfiriere el habitual desempeño del trabajo, estudio, prestaciones o tratamiento, provocando un ambiente intimidatorio, hostil $\mathrm{u}$ ofensivo.

El acoso sexual reviste especial gravedad cuando la victima se encontrare en una situación de particular vulnerabilidad por razón de su edad, estado de salud, u otra condición.

Articulo $7^{\circ}$ SANCIONES:

Las conductas definidas en los artículos terceros al sexto deben ser sancionadas con suspensión de hasta 30 días, cesantía o exoneración, sin prestación de servicios ni percepción de haberes, teniendo en cuenta la gravedad de la falta y los perjuicios causados. Puede aplicarse la suspensión preventiva del/ de la agente.

En el caso de un diputado / diputada la comisión de algunos de los hechos sancionados por esta ley es considerada en conducta grave en el ejercicio de las funciones, en los términos del artículo 79 de la Constitución de la Ciudad Autónoma de Buenos Aires. 
En el caso de los funcionarios comprendidos por el artículo 92 de la Constitución de la Ciudad Autónoma de Buenos Aires, la comisión de alguno de los hechos sancionados por esta ley es considerada causal de mal desempeño a los fines del juicio político.

\section{Articulo $8^{\circ}$ PROCEDIMIENTO APLICABLE:}

La victima debe comunicar al superior jerárquico inmediato la presunta comisión del hecho ilícito sancionado por esta ley, salvo que fuere este quien lo hubiere cometido, en cuyo caso debe informarlo al/ la funcionario / funcionaria superior al/ la denunciado / denunciada. La recepción de la denuncia debe notificarse al área de sumarios correspondiente, a los efectos de instruir la instrucción sumarial pertinente.

Para la aplicación de las sanciones disciplinarias que pudieren corresponder al procedimiento establecido en él articulo 51 y subsiguientes de la ley 471 de Relaciones Laborales en la Administración Pública de la Ciudad Autónoma de buenos Aires.

Cuando existiere un órgano de colegiación o disciplina que regule él ejercito de la profesión del/ de la denunciado / denunciada debe notificársele la denuncia de acoso sexual.

Articulo $9^{\circ}$ SUPERIORES JERÁRQUICOS:

La máxima autoridad jerárquica del área es responsable de las conductas previstas por la presente ley ejercida por el personal a su cargo, si a pesar de conocerlas no tomo las medidas necesarias para impedirlas.

Articulo $10^{\circ}$ APLICACIÓN:

Es responsabilidad prioritaria de cada organismo establecer un procedimiento interno, adecuado y efectivo en cumplimiento de esta ley, facilitar y difundir su conocimiento, y establecer servicios de orientación a la víctima.

Articulo $11^{\circ}$ RESERVA DE IDENTIDAD:

Desde el inicio hasta la finalización del procedimiento sancionatorio, la autoridad interviniente debe adoptar todos los recaudos necesarios que garanticen la confidencialidad, discrecionalidad y el resguardo absoluto de la identidad de todos los involucrados. La reserva de la identidad del damnificado se extiende aun después de concluido el procedimiento. 
Articulo $12^{\circ}$ Comuníquese, etc.

\subsubsection{PROYECTO DE LEY DE LA PROVINCIA DE MENDOZA DE VIOLENCIA LABORAL}

Art. 1: La presente Ley tiene por objeto prevenir, controlar, sancionar y erradicar la violencia laboral.

Art. 2: Se entiende por violencia laboral a toda acción que manifieste abuso de poder, ejercida en el ámbito laboral, por el empleador, por personal jerárquico o un tercero vinculado directa o indirectamente a él, atentando contra su dignidad, integridad física, sexual, psicológica y/o social mediante amenaza, intimidación, iniquidad salarial, acoso, maltrato físico y/o psicológico - social y acoso sexual.

Art. 3: Son responsables por las acciones de violencia ejercidas sobre el trabajador, su empleador, personal jerárquico o un tercero vinculado directa o indirectamente a él o ella.

Art. 4: Desde el momento que el empleador toma conocimiento de la acción violenta está obligado a dar fin a la misma y a reparar el daño laboral, moral y material causado a la víctima, de la misma forma cuando ésta es ejercida por terceros bajo su responsabilidad.

Art. 5: Las personas responsables de ejercer violencia laboral deberán ser sancionadas por el empleador.

Art. 6: Si el empleador no cumpliera con lo expuesto en el Art. 4 y 5 las víctimas podrán accionar ante la autoridad competente.

Art. 7: El empleador deberá indemnizar al damnificado cuando la violencia laboral se hubiere ejercido con su conocimiento y no hubiere tomado las medidas necesarias para dar fin a dicha conducta.

Art. 8: Quienes hayan denunciado ser víctimas de las acciones expuestas e el Art. 2 ó haya comparecido como testigo de las partes, no podrá sufrir perjuicio personal alguno en su trabajo.

Art. 9: Ningún trabajador podrá ser despedido ni sancionado por haber sufrido o haberse negado a sufrir los actos de acoso de su empleador, personal jerárquico o un tercero vinculado directa o indirectamente a él o ella. 